Simulação de membranas viscosas

\author{
Italo Valença Mariotti Tasso
}



SERVIÇO DE PÓS-GRADUAÇÃO DO ICMC-USP

Data de Depósito:

Assinatura:

\title{
Simulação de membranas viscosas
}

\author{
Italo Valença Mariotti Tasso
}

Orientador: Prof. Dr. Gustavo Carlos Buscaglia

Tese apresentada ao Instituto de Ciências Matemáticas e de Computação - ICMC-USP, como parte dos requisitos para obtenção do título de Doutor em Ciências - Ciências de Computação e Matemática Computacional. VERSÃO REVISADA.

USP - São Carlos

Agosto de 2013 
Ficha catalográfica elaborada pela Biblioteca Prof. Achille Bassi e Seção Técnica de Informática, ICMC/USP, com os dados fornecidos pelo(a) autor(a)

Tasso, Italo Valença Mariotti
Simulaço de membranas viscosas / Italo Valença
Mariotti Tasso; orientador Gustavo Carlos
Buscaglia. -- São Carlos, 2013.
150 p.
Tese (Doutorado - Programa de Pós-Graduação em
Ciências de Computação e Matemática Computacional) --
Instituto de Ciências Matemáticas e de Computação,
Universidade de São Paulo, 2013.
1. Mecânica dos Fluidos Computacional. 2.
Membranas Celulares. 3. Viscosidade. I. Buscaglia,
Gustavo Carlos, orient. II. Título.


Computer programming is an art, because it applies accumulated knowledge to the world, because it requires skill and ingenuity, and especially because it produces objects of beauty. A programmer who subconsciously views himself as an artist will enjoy what he does and will do it better. 

A meu pai, Renato, e minha mãe, Teresa. 



\section{Resumo}

A simulação computacional de membranas biológicas, em particular membranas formadas por bicamadas lipídicas, é uma área de grande interesse na atualidade. Enquanto simulações moleculares são bastante populares, a simulação na escala de uma célula inteira requer modelos baseados na mecânica dos meios contínuos. Essas membranas apresentam um comportamento de fluido viscoso incompressível bidimensional. Além disso, as formas de equilíbrio são bem explicadas pela energia de Canham-Helfrich, que depende da curvatura da membrana.

Neste trabalho, um novo método de simulação de membranas viscosas, baseado em elementos finitos, é apresentado. Ele se inspira no conceito de James Clerk Maxwell de "elasticidade fugaz", o qual é usado para adaptar técnicas bem estabelecidas de simulação de membranas elásticas. Trata-se do primeiro método a levar em conta, de maneira rigorosa, o aspecto viscoso da membrana, que é dominante na escala de tamanho de uma célula biológica, além da sua característica de fluido incompressível.

Palavras-chave: membranas viscosas, bicamada lipídica, inextensibilidade, energia de Canham-Helfrich, elementos finitos. 



\section{Abstract}

The computational simulation of biological membranes, in particular of those made of lipid bilayers, is currently an area of great interest. While molecular simulations are quite popular, the simulation on the scale of a whole cell requires models based on continuum mechanics. Those membranes behave like a bidimensional incompressible viscous fluid. Furthermore, the equilibrium shapes are well explained by means of the Canham-Helfrich energy, which depends on the curvature of the membrane.

In this work, a novel finite element based method for the simulation of viscous membranes is presented. It is inspired by James Clerk Maxwell's concept of "fugitive elasticity", which is used to adapt well established simulation techniques for elastic membranes. This is the first method to take into account, in a rigorous fashion, the viscous aspect of the membrane, which is dominant at the length scale of a biological cell, in addition to its characteristics as an incompressible fluid.

Keywords: viscous membranes, lipid bilayer, inextensibility, Canham-Helfrich energy, finite elements. 



\section{Sumário}

1 Introdução 17

2 Membranas Elásticas $\quad 21$

2.1 Variáveis de estado e parâmetros . . . . . . . . . . . . . . . . . . . . . . 21

2.2 Evolução temporal . . . . . . . . . . . . . . . . . . . . . . . 22

2.3 Princípio do trabalho virtual . . . . . . . . . . . . . . . . . . . . . 22

2.4 Cinemática de membranas . . . . . . . . . . . . . . . . . . . . . . 23

2.4.1 Tensor gradiente de deformação . . . . . . . . . . . . . . . . 23

2.4.2 Tensor gradiente de deformação discreto tangente . . . . . . . . . . . . . 24

2.4.3 Formulação de elementos finitos . . . . . . . . . . . . . . . . . . . . 26

2.4 .4 O tensor esquerdo de Cauchy-Green . . . . . . . . . . . . . . . 27

2.4.5 Gradiente discreto tangente de uma função . . . . . . . . . . . . . . . 27

2.5 Modelos de elasticidade . . . . . . . . . . . . . . . . . . . . . . 28

2.5 .1 Molas . . . . . . . . . . . . . . . . . . . 28

2.5 .2 Modelo de Hooke . . . . . . . . . . . . . . . . . . . . . . . . . 29

2.5 .3 Neo-hookeano e Mooney-Rivlin . . . . . . . . . . . . . . . . . . . 29

2.5 .4 Skalak . . . . . . . . . . . . . . . . . . . 29

2.6 Gravidade . . . . . . . . . . . . . . . . . . . . . . . . . . . . . 29

2.7 Arrasto de Stokes . . . . . . . . . . . . . . . . . . . . . . . . . . 30

2.8 Pressão e tensão superficial . . . . . . . . . . . . . . . . . . . 31

2.9 Discretização temporal explícita . . . . . . . . . . . . . . . . . . . . . . 32

2.9 .1 Euler explícito . . . . . . . . . . . . . . . . . . . 32

2.9.2 Euler semi-implícito . . . . . . . . . . . . . . . . . . . . . . . . 32

2.9.3 Adams-Bashforth de dois passos . . . . . . . . . . . . . . . . . . . . . . . . . . . . . . 32

2.9 .4 Runge-Kutta de quarta ordem . . . . . . . . . . . . . . . . . . . . 33

2.9 .5 Runge-Kutta-Fehlberg . . . . . . . . . . . . . . . . . . 33

2.10 Discretização temporal implícita . . . . . . . . . . . . . . . . . . . . . . . . . . . . . . . . . . . . . .

2.10 .1 Euler implícito . . . . . . . . . . . . . . . . . . . . . . . . . . . . . . . . . . . . . . . . . . .

2.10 .2 Crank-Nicolson . . . . . . . . . . . . . . . . . . . . . . . 34

2.10 .3 Euler generalizado . . . . . . . . . . . . . . . . . . . . . . 34

2.10 .4 Sistemas com massa zero . . . . . . . . . . . . . . . . . . . . . 35

2.10 .5 O método de Newton-Raphson . . . . . . . . . . . . . . . . . . . . . . . . . . . . . . . . . . . .

2.11 Conservação de volume e área . . . . . . . . . . . . . . . . . . . . . . . . . . . . . . . .

2.11 .1 Conservação de volume . . . . . . . . . . . . . . . . . . . . . . . . . . . . . . . . . 36

2.11 .2 Conservação global de área . . . . . . . . . . . . . . . . . . . 37

2.11 .3 Conservação local de área . . . . . . . . . . . . . . . . . 38

2.12 Convergência temporal . . . . . . . . . . . . . . . . . . . . . . 39

2.12.1 Runge-Kutta de quarta ordem . . . . . . . . . . . . . . . . . . . . . . 40 . . . . . . . 41

2.12 .2 Euler explícito . . . . . . . . . . . . . . . . . . . . . . . . . . . . 41 
2.12.3 Euler semi-implícito . . . . . . . . . . . . . . . . . . . . . . . 42

2.12.4 Adams-Bashforth de dois passos . . . . . . . . . . . . . . . . . . 43

2.12 .5 Euler implícito . . . . . . . . . . . . . . . . . . . . . . . 43

2.12 .6 Crank-Nicolson . . . . . . . . . . . . . . . . . . . . . . . . . 43

2.13 Passo temporal adaptativo . . . . . . . . . . . . . . . . . . . . . . 43

2.14 Resultados . . . . . . . . . . . . . . . . . . . . . 46

2.14.1 Instabilidade de Plateau-Rayleigh . . . . . . . . . . . . . . . . . . 46

2.14 .2 Termo de estabilização . . . . . . . . . . . . . . . . . . . . . . . . . . . . . . . . . . . . . . . 47

2.14.3 Parametrização de malhas . . . . . . . . . . . . . . . . . . . . . . 47

3 Forças eletromagnéticas $\quad 55$

3.1 Rotações . . . . . . . . . . . . . . . . . . . . . . . 55

3.1 .1 Quatérnions . . . . . . . . . . . . . . . 55

3.1 .2 Quatérnions e rotações . . . . . . . . . . . . . . . . . 56

3.1.3 Equações governantes para rotações . . . . . . . . . . . . . . . . . 56

3.2 Campo elétrico e campo magnético . . . . . . . . . . . . . . . . . . 57

3.3 Lei de Coulomb . . . . . . . . . . . . . . . . . . . . . . . . . . . . . 57

3.4 Dipolos . . . . . . . . . . . . . . . . . . . . . . . . . . . . . 57

3.5 Resultados . . . . . . . . . . . . . . . . . . . . . . . . . . . 58

3.5 .1 Dipolos . . . . . . . . . . . . . . . . . . . . 58

3.5 .2 Acoplamento . . . . . . . . . . . . . . . . . . . . 59

4 Colisão e Atrito $\quad 65$

4.1 Detecção de contato . . . . . . . . . . . . . . . . . . . . 66

4.1 .1 Contato ponto-superfície . . . . . . . . . . . . . . . 66

4.1 .2 Contato aresta-aresta . . . . . . . . . . . . . . . . . . 67

4.1 .3 Restrição ao passo temporal . . . . . . . . . . . . . . . . . . 69

4.1 .4 Eficiência . . . . . . . . . . . . . . . . . . . . . . 69

4.2 Conservação de momento linear e angular . . . . . . . . . . . . . . . . . 70

4.2.1 Colisão ponto-superfície . . . . . . . . . . . . . . . . . . . . . 71

4.2 .2 Colisão aresta-aresta . . . . . . . . . . . . . . . . . . . . 72

4.3 Coeficiente de restituição . . . . . . . . . . . . . . . . . . . . . . . . 73

4.4 Modelo baseado em forças . . . . . . . . . . . . . . . . . . . 74

4.5 Modelo baseado em impulso . . . . . . . . . . . . . . . . . . . . . . . . . 75

4.5.1 Colisão ponto-superfície . . . . . . . . . . . . . . . . . 76

4.5 .2 Colisão aresta-aresta . . . . . . . . . . . . . . . . . 77

4.6 Atrito . . . . . . . . . . . . . . . . . . . . 78

4.6 .1 Atrito fluido . . . . . . . . . . . . . . . . . . . 78

4.6.1.1 Dissipador viscoso . . . . . . . . . . . . . . . . . . 78

4.6 .2 Atrito seco . . . . . . . . . . . . . . . . . . . . . . . . . . . . . . . . . . . . 79

4.6.2.1 Modelo numérico . . . . . . . . . . . . . . . . . 80

4.7 Resultados - modelo baseado em impulso . . . . . . . . . . . . . . . . 81

4.7 .1 Colisão elástica . . . . . . . . . . . . . . . . . . . . . . . 81

4.7.2 Colisão perfeitamente inelástica . . . . . . . . . . . . . . . . . . . 82

4.7.3 Colisão ponto-superfície entre dois triângulos . . . . . . . . . . . . . . . 82

4.7.4 Colisão aresta-aresta entre três triângulos . . . . . . . . . . . . . . . 82

4.7 .5 Colisão entre vários triângulos . . . . . . . . . . . . . . . . . . . . . 82

4.7 .6 Plano inclinado . . . . . . . . . . . . . . . . . . 83

4.8 Resultados - modelo baseado em força . . . . . . . . . . . . . . . 85 
4.8.1 Colisão com objetos fixos . . . . . . . . . . . . . . . . . . 85

4.8 .2 Colisão entre membranas . . . . . . . . . . . . . . . . . 86

4.9 Considerações finais . . . . . . . . . . . . . . . . . . . . . . . 87

5 Curvatura $\quad 93$

5.1 Energia de Canham-Helfrich . . . . . . . . . . . . . . . . 93

5.2 Curvatura . . . . . . . . . . . . . . . . . . . . . . . . . . . . 94

5.3 Vetor normal nos vértices . . . . . . . . . . . . . . . . . . . 95

5.4 Método de Meyer . . . . . . . . . . . . . . . . . . . . . . . 96

5.4.1 Método de Meyer modificado . . . . . . . . . . . . . . . . . . . . 97

5.5 Método de Langer . . . . . . . . . . . . . . . . . . . . . . . . . . . . . . . 98

5.6 Método de Taubin . . . . . . . . . . . . . . . . . . . . . . . . . . . . . . . . 99

5.7 Método de Belkin . . . . . . . . . . . . . . . . . . . . . 100

5.8 Métodos contínuos . . . . . . . . . . . . . . . . . . . . . 100

5.8.1 Método dos mínimos quadrados . . . . . . . . . . . . . . . . . . . . . . . . . . . . . . . . . . . . . . . . . .

5.8 .2 Equações normais . . . . . . . . . . . . . . . . . . . . . . . . . 101

5.8 .3 Decomposição QR . . . . . . . . . . . . . . . . . . . . . 102

5.8 .4 Cálculo da normal e da curvatura média . . . . . . . . . . . . . . 102

5.9 Ajuste de paraboloide . . . . . . . . . . . . . . . . . . . . . . . . . . . . . . . . . . . . . . . . . . . .

5.9.1 Estimativa da normal . . . . . . . . . . . . . . . . . . . . . . 103

5.10 Método de ordem cúbica . . . . . . . . . . . . . . . . . . . . 104

5.11 Enrugamento . . . . . . . . . . . . . . . . . . . . 105

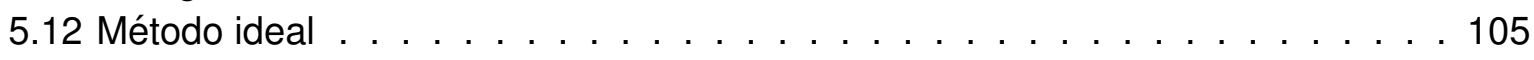

5.13 Resultados . . . . . . . . . . . . . . . . . . . . . . 107

5.13.1 Formas de mínima energia . . . . . . . . . . . . . . . . 107

5.13 .2 Outras formas . . . . . . . . . . . . . . . . . . . 109

5.13.3 Curvatura espontânea . . . . . . . . . . . . . . . . . . . 110

6 Membranas Viscosas $\quad 115$

6.1 Viscosidade superficial . . . . . . . . . . . . . . . . . 115

6.2 Molas e amortecedores . . . . . . . . . . . . . . . . . . 116

6.2.1 Princípio do trabalho virtual . . . . . . . . . . . . . . . . . . 117

6.3 Método para simulação de membranas viscosas . . . . . . . . . . . . . . . 118

6.4 Resultados . . . . . . . . . . . . . . . . . . . . . . . . . . 119

6.4 .1 Cilindro sob tração . . . . . . . . . . . . . . . . . . . . . . . . 119

6.4 .2 Pinçamento de vesícula . . . . . . . . . . . . . . . . . . . 120

6.4.3 Viscosidade versus arrasto . . . . . . . . . . . . . . . . . . 122

7 Conclusão 129

A Desempenho $\quad 131$

A.1 Metodologia . . . . . . . . . . . . . . . . . . . . . . 131

A.2 Compiladores e OpenMP . . . . . . . . . . . . . . . . . . . . 131

A.3 Solucionadores de sistemas lineares . . . . . . . . . . . . . . . . . . . . . 132

A.3.1 Matrizes esparsas . . . . . . . . . . . . . . . . . . . . . . . . . . 133

A.3.2 Preenchimento . . . . . . . . . . . . . . . . . . . . . . . . 133

A.3.3 Desempenho . . . . . . . . . . . . . . . . . . . . . . 135

A.4 Intel MKL e PARDISO . . . . . . . . . . . . . . . . . . . . . . . . 135

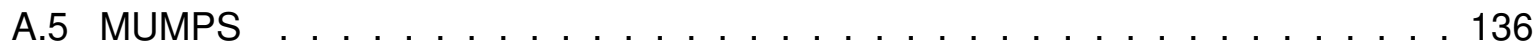




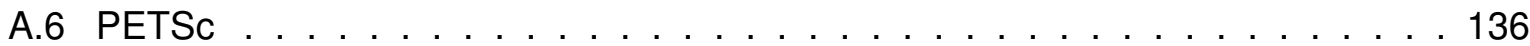

A.7 HSL . . . . . . . . . . . . . . . . . . . . . . . . 137

A.8 SuperLU . . . . . . . . . . . . . . . . . . . . . . . . . 137

A.9 Comparação . . . . . . . . . . . . . . . . . . . . . 138

B Remalhamento 139

B.1 Pinçamento de vesícula . . . . . . . . . . . . . . . . . . . . . . . . . . . . 139

B.2 Atrelamento . . . . . . . . . . . . . . . . . . . . . 141

$\begin{array}{ll}\text { Referências Bibliográficas } & 143\end{array}$ 
Wise men speak because they have something to say; fools because they have to say something.

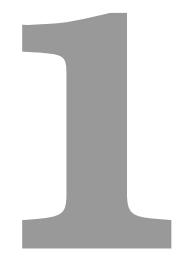

Introdução

A modelagem e simulação de membranas elásticas têm inúmeras aplicações. É uma área de estudo já bastante consolidada. Membranas biológicas, em particular membranas celulares, apresentam comportamento viscoso, e requerem um tratamento diferente daquele dado a membranas puramente elásticas. A modelagem e simulação de membranas viscosas ainda é uma área pouco explorada.

Membranas celulares são formadas por bicamadas de fosfolipídios anfipáticos. Essas moléculas apresentam a característica de possuir uma região hidrofílica, solúvel em meio aquoso, e outra hidrofóbica, insolúvel em água, mas solúvel em lipídeos ou solventes orgânicos.

Em solução aquosa, a forma mais estável dessas moléculas é a de uma micela. Micelas são glóbulos formados por uma única camada de moléculas, como pode ser visto na figura 1.1. Essa forma é atingida porque permite que apenas a parte hidrofílica fique em contato com o meio aquoso. O tamanho de micelas varia entre $1 \mathrm{~nm}$ e $100 \mathrm{~nm}$.

Outra configuração que permite que apenas a parte hidrofílica fique em contato com o meio aquoso é a de um lipossoma. Lipossomas são camadas duplas de moléculas, como também pode ser visto na figura 1.1. Lipossomas pequenos têm dezenas de nanômetros de diâmetro. Os grandes podem chegar a alguns micrômetros.

Membranas celulares têm a mesma característica de dupla camada dos lipossomas. As moléculas possuem grande mobilidade tangencial, enquanto a taxa de transferência entre camadas é baixa. Simulações moleculares melhoraram muito o entendimento desses sistemas, em particular do comportamento tangencial (Saiz et al., 2002; Shkulipa et al., 2005; Den Otter \& Shkulipa, 2007; Noguchi, 2009). Além do comportamento viscoso, o citoesqueleto dá a célula características de elasticidade.

Entretanto, simulações na escala de uma célula inteira durante tempos significativos do ponto de vista biológico requerem modelos mecânicos contínuos. O melhor modelo é aquele de um fluido bidimensional em uma superfície curva deformável imersa em três dimensões.

O comportamento reológico das bicamadas lipídicas é predominantemente de um fluido viscoso newtoniano incompressível, i.e. a área da membrana é constante (Seifert, 1997; Lipowsky, 1991; Mader et al., 2006). A viscosidade superficial varia entre 5 e $13 \times 10^{-9}$ 

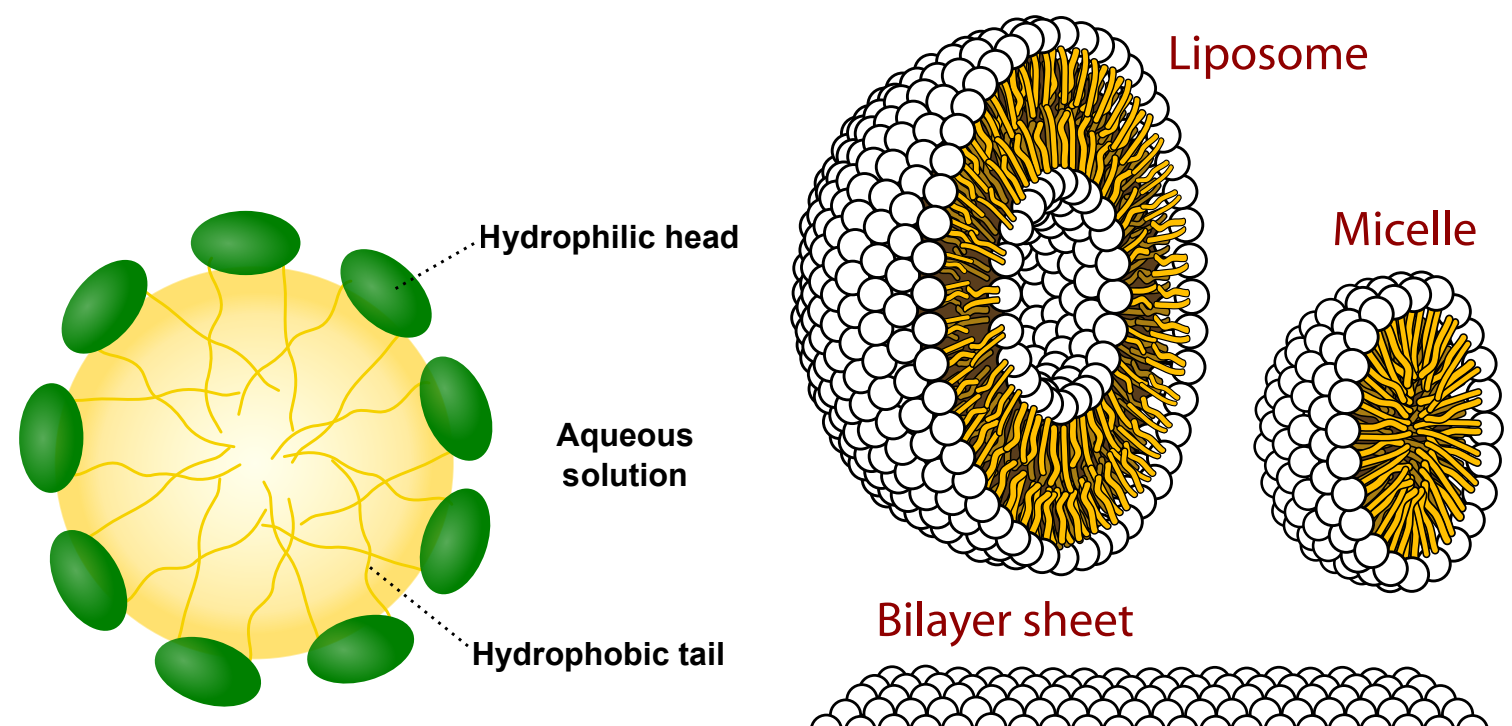

Bilayer sheet

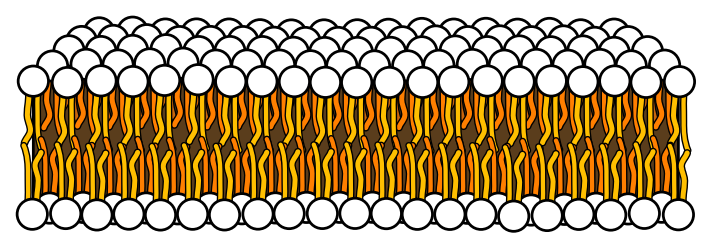

Figura 1.1: Estruturas de fosfolipídios em solução aquosa. Imagem retirada de (Wikipedia, 2013d).

Pa s m (Waugh, 1982a,b), podendo chegar a $2 \times 10^{-6}$ Pa s m. Efeitos viscoelásticos não são significativos (Harland et al., 2010, 2011).

Neste trabalho, um método para a simulação por elementos finitos de membranas viscosas é proposto. Ele é baseado em métodos variacionais bem estabelecidos na área de mecânica dos sólidos, onde as equações discretas são obtidas por meio de perturbações nas energias apropriadas.

O capítulo 2 faz uma breve revisão do tratamento por elementos finitos de membranas elásticas. Essa é a base do método para membranas viscosas. Mais detalhes podem ser vistos em (Holzapfel et al., 1996) e aplicações biológicas em (Ramanujan \& Pozrikidis, 1998; Lac \& Barthès-Biesel, 2005; Sui et al., 2010; Li \& Sarkar, 2008; Le et al., 2009).

O capítulo 3 explora membranas eletricamente carregadas, ou magnetizadas. A expansão multipolar é usada para aproximar as forças eletromagnéticas.

O capítulo 4 trata do problema de colisões entre membranas, inclusive colisão de uma membrana com ela mesma. Dois modelos são apresentados, um baseado em forças e o outro em impulsos.

O capítulo 5 discute técnicas de estimativa de curvatura em malhas triangulares. Isso é necessário porque a energia de Canham-Helfrich (Canham, 1970; Helfrich, 1973; Evans, 1974), que depende diretamente da curvatura, é usada como força motriz para as simulações. Essa energia produz formas de repouso condizentes com as observadas experimentalmente.

O capítulo 6 mostra que, em um limite apropriado, o operador elástico tende ao operador viscoso. A condição de incompressibilidade é adicionada para reproduzir o comportamento de fluido bidimensional. Isso introduz um campo de multiplicadores de Lagrange que desempenha o papel de uma tensão superficial heterogênea. Um termo 
de estabilização proporcional ao Laplaciano desse campo é usado para permitir o uso dos mesmos interpoladores para todos os campos.

As conclusões do trabalho são apresentadas no capítulo 7. O apêndice A traz alguns testes de desempenho do código implementado. $O$ apêndice $B$ contém resultados preliminares do acoplamento de um código remalhador com o código simulador de membranas. 

If you have a difficult task, give it to a lazy person. They will find an easier way to do it.

Hlade's Law

\section{2}

Membranas Elásticas

A análise em elementos finitos de membranas é algo bem conhecido. Por exemplo, (Bonet et al., 2000) apresenta um método para estruturas de membranas fechadas que contenham fluido, como o ar. O artigo (Holzapfel et al., 1996) mostra uma formulação geral de membranas finas incompressíveis e investiga o comportamento de tecidos biológicos moles.

Neste capítulo, duas formulações lagrangianas de elementos finitos, uma explícita e outra implícita no tempo, são propostas para a simulação de membranas elásticas. Elas servirão de base para extensões feitas em capítulos posteriores. A formulação explícita é baseada em métodos de Runge-Kutta de alta ordem, enquanto a implícita usa o método iterativo de Newton-Raphson com discretização temporal feita pelo método de Euler.

\subsection{Variáveis de estado e parâmetros}

A representação lagrangiana da membrana é dada por uma malha de triângulos. O vetor de estado $\mathbf{Y}$, na sua forma mais simples, é composto pelas variáveis de estado posição $\mathbf{x}_{i}$ e velocidade $\mathbf{v}_{i}$ de cada vértice $i$ de triângulo, de um total de $N$ vértices:

$$
\mathbf{Y}=\left(\begin{array}{c}
\mathbf{Y}_{1} \\
\mathbf{Y}_{2} \\
\vdots \\
\mathbf{Y}_{N}
\end{array}\right)
$$

onde

$$
\mathbf{Y}_{i}=\left(\begin{array}{c}
\mathbf{x}_{i} \\
\mathbf{v}_{i}
\end{array}\right)
$$

Outras variáveis de estado serão adicionadas à medida que o método for estendido. São elas: orientação, velocidade angular, pressão global, tensão superficial global, tensão superficial local e os "multiplicadores de Lagrange para massa zero". Cada uma será discutida adiante.

Visto que há muitos parâmetros, eles não serão todos enumerados aqui. Cada um será discutido na seção apropriada. Há parâmetros físicos, como a massa, e parâmetros 
da simulação, como o passo no tempo. Parâmetros diferem de variáveis de estado na medida em que variáveis de estado evoluem a partir de estados anteriores, enquanto parâmetros geralmente não mudam ou mudam independentemente do estado do sistema.

O estado do sistema é definido pelo conjunto de variáveis de estado, isto é, pelo vetor de estado. Conhecendo-se o estado em um tempo $t_{0}$, é possível determinar univocamente o estado no tempo $t>t_{0}$, se os parâmetros são conhecidos no intervalo $\left[t_{0}, t\right]$.

Cada vértice da malha é tratado como uma partícula, que pode ter massa. Uma maneira de calcular esta massa é prescrever uma massa total à membrana, a partir da qual a densidade superficial pode ser obtida. Alternativamente, a densidade pode ser fixada diretamente. Cada triângulo passaria a ter uma massa associada e cada vértice receberia um terço da massa dos triângulos aos quais pertence.

$\mathrm{Na}$ formulação implícita, é possível simplesmente ignorar a massa da partícula e tomá-la como sendo zero. Isto tem um grande impacto na boa postura do problema, o qual precisa ser tratado seja pela adição de uma força de arrasto semelhante à viscosa ou pelo uso de "multiplicadores de Lagrange para massa zero", que serão discutidos mais adiante.

\subsection{Evolução temporal}

As leis da mecânica clássica são usadas na simulação. A velocidade $\mathbf{v}_{i}$ da partícula $i$ é a derivada da sua posição $\mathbf{x}_{i}$ com respeito ao tempo $t$ ou

$$
\mathbf{v}_{i}=\frac{\mathrm{d} \mathbf{x}_{i}}{\mathrm{~d} t}
$$

A segunda lei de Newton diz que a força resultante $\mathbf{F}_{i}$ sobre uma partícula é a taxa de variação do seu momento linear $\mathbf{p}_{i}=m_{i} \mathbf{v}_{i}$ :

$$
\mathbf{F}_{i}=\frac{\mathrm{d} \mathbf{p}_{i}}{\mathrm{~d} t}=\frac{\mathrm{d}\left(m_{i} \mathbf{v}_{i}\right)}{\mathrm{d} t}
$$

Em geral, a força resultante sobre uma partícula pode depender das posições e velocidades de todas as partículas do sistema, i.e. a força depende do vetor de estado. Ela também depende dos parâmetros, mas estes são constantes, se não durante toda a simulação, pelo menos durante um passo de tempo. Outras variáveis do sistema, como pressão ou tensão superficial, podem também influenciar essa força. Admitindo que a massa das partículas é constante, ou que pelo menos não mude durante um passo de tempo,

$$
\frac{\mathrm{d}}{\mathrm{d} t} \mathbf{Y}_{i}=\frac{\mathrm{d}}{\mathrm{d} t}\left(\begin{array}{c}
\mathbf{x}_{i} \\
\mathbf{v}_{i}
\end{array}\right)=\left(\begin{array}{c}
\mathbf{v}_{i} \\
\frac{1}{m_{i}} \mathbf{F}_{i}(\mathbf{Y}, t)
\end{array}\right)=\mathscr{F}_{i}(\mathbf{Y}, t),
$$

e, considerando todas as partículas do sistema,

$$
\frac{\mathrm{d}}{\mathrm{d} t} \mathbf{Y}=\mathscr{F}(\mathbf{Y}, t)
$$

\subsection{Princípio do trabalho virtual}

As forças que compõem a força resultante $\mathbf{F}_{i}(\mathbf{Y}, t)$ sobre a partícula $i$ na equação 2.5 podem não ter uma expressão analítica simples. Às vezes, somente a energia do sistema $E(\mathbf{Y}, t)$ é conhecida, e a força precisa ser calculada a partir dela. Para fazer isso, o princípio 
do trabalho virtual é empregado. Seja $\mathbf{Y}^{+}$igual ao vetor de estado do sistema $\mathbf{Y}$, mas com a partícula $i$ deslocada de $+h$ na direção $x . \mathbf{Y}^{-}$é o análogo para um deslocamento negativo $-h$. Usando uma aproximação de diferenças centradas de segunda ordem, a força sobre a partícula $i$ na direção $x$ é

$$
\left[\mathbf{F}_{i}(\mathbf{Y}, t)\right]_{x} \approx-\frac{E\left(\mathbf{Y}^{+}, t\right)-E\left(\mathbf{Y}^{-}, t\right)}{2 h},
$$

e, usando diferenças centradas de quarta ordem,

$$
\left[\mathbf{F}_{i}(\mathbf{Y}, t)\right]_{x} \approx-\frac{-E\left(\mathbf{Y}^{++}, t\right)+8 E\left(\mathbf{Y}^{+}, t\right)-8 E\left(\mathbf{Y}^{-}, t\right)+E\left(\mathbf{Y}^{--}, t\right)}{12 h},
$$

onde $\mathbf{Y}^{++}$e $\mathbf{Y}^{--}$representam deslocamentos de $+2 h$ e $-2 h$. As forças nas outras direções são calculadas de forma similar.

A aproximação de quarta ordem é utilizada para forças viscosas. A aproximação de segunda ordem é usada para tensão superficial, curvatura e forças elásticas, exceto para o modelo simples de molas, onde a força é calculada diretamente. O cálculo também é feito diretamente para forças gravitacionais, de arrasto, colisão e atrito. A pressão interna pode ser calculada tanto diretamente quanto a partir da energia.

$O$ valor de $h$ é calibrado manualmente. Inicialmente, para os esquemas explícitos no tempo, um valor de $10^{-6}$ era usado para uma membrana de raio unitário com 1280 elementos. Com a introdução dos esquemas implícitos, valores maiores se fizeram necessários para garantir a convergência do método de Newton-Rhapson. O Jacobiano também é calculado por diferenças finitas, i.e. são feitas diferenças finitas de diferenças finitas, o que provoca um acúmulo de erros de arredondamento. Para compensar o valor maior de $h$, a fórmula de quarta ordem é usada para o cálculo da viscosidade.

Para os casos simulados nesse trabalho, foi definido um comprimento característico da malha como sendo a raiz quadrada da área média dos triângulos. $O$ valor de $h$ é esse comprimento característico multiplicado por um fator, em geral $10^{-2}$ ou $10^{-3}$.

Uma exposição mais elaborada sobre o princípio do trabalho virtual, com aplicações em tensão superficial e capilaridade, pode ser encontrada em (Buscaglia \& Ausas, 2011).

\subsection{Cinemática de membranas}

Quando deformados, materiais elásticos tendem a retornar à sua forma original visto que ela tem a menor energia de deformação. A função densidade de energia de deformação é em geral calculada em termos das invariantes do tensor de deformação esquerdo de Cauchy-Green $\underline{\underline{B}}$, definido como

$$
\underline{\underline{B}}=\underline{\underline{F}} \underline{\underline{F}}^{T},
$$

onde $\underline{\underline{F}}$ é o tensor gradiente de deformação.

\subsubsection{Tensor gradiente de deformação}

Seja $\mathbf{X}$ a posição de uma partícula de um corpo deformável na configuração de referência, i.e. não deformada. A posição $\mathbf{x}$ desta mesma partícula em uma configuração deformada no tempo $t$ é dada pela função de mapeamento $\chi$

$$
\mathbf{x}=\chi(\mathbf{X}, t)
$$


Seja, também, $d \mathbf{X}$ um vetor infinitesimal que conecta a partícula na posição $\mathbf{X}$ a uma partícula vizinha que está na posição $\mathbf{X}+d \mathbf{X}$, ambas na configuração de referência. Supondo que a função de mapeamento $\chi$ seja contínua e diferenciável, na configuração deformada, esta partícula vizinha se moverá para

$$
\mathbf{x}+d \mathbf{x}=\chi(\mathbf{X}+d \mathbf{X}, t)
$$

onde $d \mathbf{x}$ é um vetor infinitesimal na configuração deformada. Uma expansão em série de Taylor em torno do ponto $\mathbf{X}$, desprezando termos de alta ordem, é

$$
\chi(\mathbf{X}+d \mathbf{X}, t) \approx \chi(\mathbf{X}, t)+\nabla \chi(\mathbf{X}, t) d \mathbf{X}
$$

A partir de 2.10, 2.11 e 2.12,

$$
d \mathbf{x}=\nabla \chi(\mathbf{X}, t) d \mathbf{X}
$$

O gradiente da função de mapeamento $\chi$ é o tensor gradiente de deformação $\underline{\underline{F}}$ :

$$
\underline{\underline{F}} \equiv \nabla \chi(\mathbf{X}, t)
$$

então,

$$
d \mathbf{x}=\underline{\underline{F}} d \mathbf{X}
$$

\subsubsection{Tensor gradiente de deformação discreto tangente}

Ao se trabalhar com membranas bidimensionais imersas em três dimensões, deve-se tomar um cuidado especial no cálculo do gradiente de deformação, visto que não existem derivadas na direção normal à membrana. No caso discreto, dadas as posições dos nós de um elemento nas configurações de referência e deformada, o objetivo é calcular o tensor gradiente de deformação tangente, que transforma um vetor infinitesimal no elemento da configuração de referência para a deformada.

Para fazer os cálculos, é conveniente definir uma parametrização que mapeia os pontos de um triângulo unitário $\hat{T}$ em $2 \mathrm{D}$ para o espaço $3 \mathrm{D} \mathbb{R}^{3}$. O triângulo unitário é definido como

$$
\hat{T}=\left\{\left(\xi_{1}, \xi_{2}\right) \in \mathbb{R}^{2} \quad \mid 0<\xi_{1}<1 \quad ; \quad 0<\xi_{2}<1-\xi_{1}\right\} .
$$

A função de mapeamento $\psi: \hat{T} \rightarrow \mathbb{R}^{3}$ leva um ponto $\xi=\left(\xi_{1}, \xi_{2}\right)$ do triângulo unitário para a configuração de referência e $\phi: \hat{T} \rightarrow \mathbb{R}^{3}$ leva o mesmo ponto para a configuração deformada, de modo que, omitindo a dependência temporal,

$$
\begin{aligned}
\mathbf{X} & =\psi(\xi), \\
\mathbf{X} & =\phi(\xi), \\
\chi(\mathbf{X}) & =\phi\left(\psi^{-1}(\mathbf{X})\right) .
\end{aligned}
$$

Seja $d \xi=\left(d \xi_{1}, d \xi_{2}\right)$ um vetor infinitesimal no triângulo unitário $\hat{T}$. Desprezando os termos de alta ordem, uma expansão em série de Taylor em torno de $\xi$ produz, para a 
configuração de referência,

$$
\begin{aligned}
\psi(\xi+d \xi) & =\psi(\xi)+\nabla \psi(\xi) d \xi \\
& =\psi(\xi)+\left(\begin{array}{ll}
\frac{\partial \psi_{1}}{\partial \xi_{1}} & \frac{\partial \psi_{1}}{\partial \xi_{2}} \\
\frac{\partial \psi_{2}}{\partial \xi_{1}} & \frac{\partial \psi_{2}}{\partial \xi_{2}} \\
\frac{\partial \psi_{3}}{\partial \xi_{1}} & \frac{\partial \psi_{3}}{\partial \xi_{2}}
\end{array}\right)\left(\begin{array}{l}
d \xi_{1} \\
d \xi_{2}
\end{array}\right), \\
& =\psi(\xi)+\left(\begin{array}{l}
\frac{\partial \psi_{1}}{\partial \xi_{1}} d \xi_{1}+\frac{\partial \psi_{1}}{\partial \xi_{2}} d \xi_{2} \\
\frac{\partial \psi_{2}}{\partial \xi_{1}} d \xi_{1}+\frac{\partial \psi_{2}}{\partial \xi_{2}} d \xi_{2} \\
\frac{\partial \psi_{3}}{\partial \xi_{1}} d \xi_{1}+\frac{\partial \psi_{3}}{\partial \xi_{2}} d \xi_{2}
\end{array}\right), \\
& =\mathbf{X}+d \mathbf{X} .
\end{aligned}
$$

Aqui, $d \mathbf{X}$ é tangente ao elemento na configuração de referência no ponto $\mathbf{X}$. É importante notar que se o elemento não for plano, $\mathbf{X}+d \mathbf{X}$ não estará sobre a superfície. Fica, então, subentendida a projeção desse ponto sobre o elemento. $O$ conjunto de todos os vetores tangentes $d \mathbf{X}$ pode ser obtido a partir do conjunto de todos os $d \xi$. Logo, os vetores

$$
\begin{aligned}
& \mathbf{G}^{(1)}=\left(\frac{\partial \psi_{1}}{\partial \xi_{1}}, \frac{\partial \psi_{2}}{\partial \xi_{1}}, \frac{\partial \psi_{3}}{\partial \xi_{1}}\right) \\
& \mathbf{G}^{(2)}=\left(\frac{\partial \psi_{1}}{\partial \xi_{2}}, \frac{\partial \psi_{2}}{\partial \xi_{2}}, \frac{\partial \psi_{3}}{\partial \xi_{2}}\right)
\end{aligned}
$$

formam uma base para o plano tangente. Uma base ortonormal $\left(\mathbf{V}^{(1)}, \mathbf{V}^{(2)}\right)$ para o plano tangente seria

$$
\begin{aligned}
\mathbf{N} & =\frac{\mathbf{G}^{(1)} \times \mathbf{G}^{(2)}}{\left|\mathbf{G}^{(1)} \times \mathbf{G}^{(2)}\right|} \\
\mathbf{V}^{(1)} & =\frac{\mathbf{G}^{(1)}}{\left|\mathbf{G}^{(1)}\right|} \\
\mathbf{V}^{(2)} & =\mathbf{N} \times \mathbf{V}^{(1)}
\end{aligned}
$$

onde $\mathbf{N}$ é a normal do elemento no ponto $\mathbf{X}$. Nesta base, o vetor $d \mathbf{X}$ se torna

$$
d \mathbf{X}=\left(d \mathbf{X} \cdot \mathbf{V}^{(1)}\right) \mathbf{V}^{(1)}+\left(d \mathbf{X} \cdot \mathbf{V}^{(2)}\right) \mathbf{V}^{(2)}
$$

Usando 2.20,

$$
\begin{aligned}
& d \mathbf{X} \cdot \mathbf{G}^{(1)}=\left|\mathbf{G}^{(1)}\right|^{2} d \xi_{1}+\mathbf{G}^{(1)} \cdot \mathbf{G}^{(2)} d \xi_{2}, \\
& d \mathbf{X} \cdot \mathbf{G}^{(2)}=\mathbf{G}^{(1)} \cdot \mathbf{G}^{(2)} d \xi_{1}+\left|\mathbf{G}^{(2)}\right|^{2} d \xi_{2} .
\end{aligned}
$$

Então,

$$
\begin{aligned}
& d \mathbf{X} \cdot \mathbf{V}^{(1)}=\left|\mathbf{G}^{(1)}\right| d \xi_{1}+\frac{\mathbf{G}^{(1)} \cdot \mathbf{G}^{(2)}}{\left|\mathbf{G}^{(1)}\right|} d \xi_{2}, \\
& d \mathbf{X} \cdot \mathbf{V}^{(2)}=\frac{\left|\mathbf{G}^{(1)} \times \mathbf{G}^{(2)}\right|}{\left|\mathbf{G}^{(1)}\right|} d \xi_{2} .
\end{aligned}
$$


A matriz $\underline{\underline{F}}^{(\psi)}$ é definida como

$$
\underline{\underline{F}}^{(\psi)}=\left(\begin{array}{cc}
\left|\mathbf{G}^{(1)}\right| & \frac{\mathbf{G}^{(1)} \cdot \mathbf{G}^{(2)}}{\left|\mathbf{G}^{(1)}\right|} \\
0 & \frac{\left|\mathbf{G}^{(1)} \times \mathbf{G}^{(2)}\right|}{\left|\mathbf{G}^{(1)}\right|}
\end{array}\right),
$$

de forma que

$$
d \mathbf{X}=\underline{F}^{(\psi)} d \xi .
$$

Todo esse processo pode ser repetido para a configuração deformada, o que produz

$$
\underline{F}^{(\phi)}=\left(\begin{array}{cc}
\left|\mathbf{g}^{(1)}\right| & \frac{\mathbf{g}^{(1)} \cdot \mathbf{g}^{(2)}}{\left\langle\mathbf{g}^{(1)}\right|} \\
0 & \frac{\left|\mathbf{g}^{(1)} \times \mathbf{g}^{(2)}\right|}{\left|\mathbf{g}^{(1)}\right|}
\end{array}\right),
$$

e

$$
d \mathbf{x}=\underline{F}^{(\phi)} d \xi
$$

Combinando 2.32 e 2.34,

$$
d \mathbf{x}=\underline{\underline{F}}^{(\phi)}\left(\underline{\underline{F}}^{(\psi)}\right)^{-1} d \mathbf{X}
$$

que é o mesmo que a equação 2.15 para um gradiente de deformação

$$
\underline{\underline{F}}=\underline{\underline{F}}^{(\phi)}\left(\underline{\underline{F}}^{(\psi)}\right)^{-1}
$$

\subsubsection{Formulação de elementos finitos}

O único passo restante é calcular as derivadas $\frac{\partial \psi}{\partial \xi}$, para a configuração de referência, e $\frac{\partial \phi}{\partial \xi}$, para a configuração deformada. Sejam $M^{1}(\xi), M^{2}(\xi), \ldots, M^{m}(\xi)$ as funções de base definidas no elemento mestre. Os nós do elemento mestre serão referenciados como $\eta^{(1)}, \eta^{(2)}, \ldots, \eta^{(m)}$, tal que $M^{i}\left(\eta^{(j)}\right)=\delta_{i j}$.

Se $\mathbf{X}^{(1)}, \mathbf{X}^{(2)}, \ldots, \mathbf{X}^{(m)}$ são as posições dos nós do elemento na configuração de referência e $\mathbf{x}^{(1)}, \mathbf{x}^{(2)}, \ldots, \mathbf{x}^{(m)}$ as posições dos mesmos nós na configuração deformada, então

$$
\begin{aligned}
& \psi(\xi)=\sum_{i=1}^{m} \mathbf{X}^{(i)} M^{(i)}(\xi), \\
& \phi(\xi)=\sum_{i=1}^{m} \mathbf{x}^{(i)} M^{(i)}(\xi),
\end{aligned}
$$

e

$$
\begin{aligned}
\frac{\partial \psi_{j}}{\partial \xi_{k}}(\xi) & =\sum_{i=1}^{m} x_{j}^{(i)} \frac{\partial M^{(i)}}{\partial \xi_{k}}(\xi), \\
\frac{\partial \phi_{j}}{\partial \xi_{k}}(\xi) & =\sum_{i=1}^{m} x_{j}^{(i)} \frac{\partial M^{(i)}}{\partial \xi_{k}}(\xi) .
\end{aligned}
$$

Neste trabalho, o elemento mestre é $\hat{T}$, definido em 2.16 , e elementos $\mathbb{P}_{1}$ são usados:

$$
\begin{aligned}
& M^{1}\left(\xi_{1}, \xi_{2}\right)=1-\xi_{1}-\xi_{2}, \\
& M^{2}\left(\xi_{1}, \xi_{2}\right)=\xi_{1}, \\
& M^{3}\left(\xi_{1}, \xi_{2}\right)=\xi_{2},
\end{aligned}
$$


com

$$
\begin{aligned}
& \eta^{(1)}=(0,0), \\
& \eta^{(2)}=(1,0), \\
& \eta^{(3)}=(0,1) .
\end{aligned}
$$

As bases para o plano tangente resumem-se a

$$
\begin{aligned}
& \mathbf{G}^{(1)}=\mathbf{X}^{(2)}-\mathbf{X}^{(1)}, \\
& \mathbf{G}^{(2)}=\mathbf{X}^{(3)}-\mathbf{X}^{(1)},
\end{aligned}
$$

e

$$
\begin{aligned}
& \mathbf{g}^{(1)}=\mathbf{x}^{(2)}-\mathbf{x}^{(1)}, \\
& \mathbf{g}^{(2)}=\mathbf{x}^{(3)}-\mathbf{x}^{(1)} .
\end{aligned}
$$

\subsubsection{O tensor esquerdo de Cauchy-Green}

O tensor gradiente de deformação depende não apenas da deformação em si, mas também de rotações rígidas do objeto. Visto que rotações rígidas não afetam a energia de deformação, ao invés de se usar o tensor gradiente de deformação, o tensor esquerdo de Cauchy-Green é usado para calcular essa energia. Isso se justifica pelo teorema da decomposição polar, que aplicado ao tensor gradiente de deformação o decompõe de forma única em

$$
\underline{\underline{F}}=\underline{\underline{V}} \underline{\underline{R}}
$$

onde $\underline{\underline{R}}$ é um tensor de rotação e $\underline{\underline{V}}$ é simétrico positivo definido e não é influenciado por rotações rígidas. Visto que $\underline{\underline{R}}$ é ortogonal,

$$
\begin{aligned}
\underline{\underline{B}} & =\underline{\underline{F}} \underline{\underline{F}}^{T} \\
& =\underline{\underline{V}} \underline{\underline{R}} \underline{\underline{R}}^{T} \underline{\underline{V}}^{T} \\
& =\underline{\underline{V}} \underline{\underline{V}}^{T},
\end{aligned}
$$

e portanto o tensor esquerdo de Cauchy-Green não depende de rotações rígidas.

\subsubsection{Gradiente discreto tangente de uma função}

O ferramental desenvolvido até aqui serve também para calcular o gradiente de uma função qualquer sobre a membrana. Seja $\lambda(\mathbf{x})$ uma função escalar definida sobre a membrana na configuração deformada. Seja também $\hat{\lambda}(\xi)$ uma função escalar definida sobre o triângulo unitário $\hat{T}$ de forma que $\hat{\lambda}(\xi)=\lambda(\phi(\xi))$. O gradiente de $\hat{\lambda}$, calculado no triângulo unitário $\hat{T}$, é

$$
\nabla \hat{\lambda}=\left(\begin{array}{l}
\frac{\partial \hat{\lambda}}{\partial \xi_{1}} \\
\frac{\partial \hat{\lambda}}{\partial \xi_{2}}
\end{array}\right)
$$



deformada

Usando a regra da cadeia, podemos calcular o gradiente na configuração

$$
\begin{gathered}
\nabla \hat{\lambda}=\left(\begin{array}{c}
\frac{\partial \lambda}{\partial x_{1}} \frac{\partial \phi_{1}}{\partial \xi_{1}}+\frac{\partial \lambda}{\partial x_{2}} \frac{\partial \phi_{2}}{\partial \xi_{1}}+\frac{\partial \lambda}{\partial x_{3}} \frac{\partial \phi_{3}}{\partial \xi_{1}} \\
\frac{\partial \lambda}{\partial x_{1}} \frac{\partial \phi_{1}}{\partial \xi_{2}}+\frac{\partial \lambda}{\partial x_{2}} \frac{\partial \phi_{2}}{\partial \xi_{2}}+\frac{\partial \lambda}{\partial x_{3}} \frac{\partial \phi_{3}}{\partial \xi_{2}}
\end{array}\right) \\
\nabla \hat{\lambda}=\left(\begin{array}{lll}
\frac{\partial \phi_{1}}{\partial \xi_{1}} & \frac{\partial \phi_{2}}{\partial \xi_{1}} & \frac{\partial \phi_{3}}{\partial \xi_{1}} \\
\frac{\partial \phi_{1}}{\partial \xi_{2}} & \frac{\partial \phi_{2}}{\partial \xi_{2}} & \frac{\partial \phi_{3}}{\partial \xi_{2}}
\end{array}\right)\left(\begin{array}{l}
\frac{\partial \lambda}{\partial x_{1}} \\
\frac{\partial \lambda}{\partial x_{2}} \\
\frac{\partial \lambda}{\partial x_{3}}
\end{array}\right) \\
\nabla \hat{\lambda}=\left(\underline{\underline{F}}^{(\phi)}\right)^{T} \nabla \lambda \\
\nabla \lambda=\left(\left(\underline{\underline{F}}^{(\phi)}\right)^{T}\right)^{-1} \nabla \hat{\lambda} .
\end{gathered}
$$

A forma de calcular $\underline{\underline{F}}^{(\phi)}$ com elementos finitos já foi discutida. $O$ cálculo de $\nabla \hat{\lambda}$ é análogo. No caso discreto, os valores de $\lambda$ são amostrados nos vértices da malha. Se $\lambda^{(i)}$ for o valor de $\lambda$ no vértice $i$ do elemento, então

$$
\hat{\lambda}(\xi)=\sum_{i=1}^{m} \lambda^{(i)} M^{(i)}(\xi)
$$

e

$$
\frac{\partial \hat{\lambda}}{\partial \xi_{k}}(\xi)=\sum_{i=1}^{m} \lambda^{(i)} \frac{\partial M^{(i)}}{\partial \xi_{k}}(\xi)
$$

Usando elementos $\mathbb{P}_{1}$ sobre o triângulo,

$$
\nabla \hat{\lambda}=\left(\begin{array}{l}
\lambda^{(2)}-\lambda^{(1)} \\
\lambda^{(3)}-\lambda^{(1)}
\end{array}\right)
$$

\subsection{Modelos de elasticidade}

Em geral, nos modelos de elasticidade, a função de densidade de energia de deformação é expressa em termos dos autovalores do tensor esquerdo de CauchyGreen, $\Lambda_{1}^{2}$ e $\Lambda_{2}^{2}$, e de propriedades materiais, como os parâmetros de Lamé, módulo de compressibilidade, módulo de Young, razão de Poisson, e módulo de cisalhamento. Essas propriedades relacionam a deformação que o material sofre quando sujeito a forças.

O módulo de compressibilidade $K$ de uma substância mede a sua resistência à compressão uniforme. É definido como a razão entre o aumento infinitesimal de pressão e o decréscimo relativo de volume.

O módulo de Young, ou módulo de elasticidade, é uma medida da rigidez de um material elástico. É definido como a razão entre a tensão e a deformação uniaxiais, dentro da faixa de tensão na qual a lei de Hooke, i.e. elasticidade linear, é válida. Está relacionada com a constante $k$ de uma mola. 
O segundo parâmetro de Lamé $\mu$, também conhecido como módulo de cisalhamento ou módulo de rigidez, é definido como a razão entre a tensão de cisalhamento e a deformação de cisalhamento.

O primeiro parâmetro de Lamé $\lambda$ está relacionado ao módulo de compressibilidade e ao módulo de cisalhamento por $K=\lambda+\frac{2}{3} \mu$. Sua finalidade é simplificar as fórmulas da lei de Hooke.

Quando um material é comprimido (ou estendido) em uma direção, ele tende a se dilatar (ou a se contrair) na direção perpendicular. Esse fenômeno é chamado de efeito de Poisson, e a razão de Poisson entre a compressão (ou extensão) relativa e a dilatação (ou contração) relativa.

A constante da mola tem unidades de força por comprimento, no SI newton por metro $(\mathrm{N} / \mathrm{m})$. Os outros parâmetros materiais têm unidades de pressão, no SI pascal $(\mathrm{Pa})$, exceto a razão de Poisson que é adimensional.

\subsubsection{Molas}

O modelo mais simples de elasticidade é conectar os vértices dos triângulos com molas lineares, as quais obedecem à lei de Hooke. A partícula $i$ é submetida à força

$$
\mathbf{F}_{i}=-\sum_{j \in N(i)} k_{i j}\left(\left|\mathbf{x}_{j}-\mathbf{X}_{i}\right|-\left|\mathbf{x}_{j}-\mathbf{x}_{i}\right|\right) \frac{\mathbf{x}_{j}-\mathbf{x}_{i}}{\left|\mathbf{x}_{j}-\mathbf{x}_{i}\right|},
$$

onde $k_{i j}$ é a constante da mola conectando os nós $i$ e $j$. A soma é feita sobre os $N(i)$ vizinhos de $i$. Aqui, $\mathbf{X}$ representa a posição da partícula na configuração de referência e $\mathbf{X}$ na configuração deformada.

\subsubsection{Modelo de Hooke}

O modelo de Hooke é uma extensão da elasticidade linear de molas para duas dimensões. Em um material isotrópico, a densidade de energia de um triângulo deformado é

$$
E=\frac{\lambda}{8}\left(\Lambda_{1}^{2}+\Lambda_{2}^{2}-2\right)^{2}+\frac{\mu}{4}\left[\left(\Lambda_{1}^{2}-1\right)^{2}+\left(\Lambda_{2}^{2}-1\right)^{2}\right]
$$

É importante notar que essa densidade é energia por unidade de área na configuração de referência. Logo, a energia total de um triângulo é a sua densidade multiplicada pela área na configuração de referência.

\subsubsection{Neo-hookeano e Mooney-Rivlin}

Mooney-Rivlin é um modelo não linear para grandes deformações,

$$
E=\alpha\left[\frac{\mu}{2}\left(l_{1}-3\right)\right]+(1-\alpha)\left[\frac{\mu}{2}\left(l_{2}-3\right)\right],
$$

com

$$
\begin{aligned}
& l_{1}=\Lambda_{1}^{2}+\Lambda_{2}^{2}+\frac{1}{\Lambda_{1}^{2} \Lambda_{2}^{2}}, \\
& l_{2}=\Lambda_{1}^{2} \Lambda_{2}^{2}+\frac{1}{\Lambda_{1}^{2}}+\frac{1}{\Lambda_{2}^{2}},
\end{aligned}
$$

onde $\alpha$ está entre zero e um. Tomar $\alpha=1$ produz o modelo neo-hookeano. 


\subsubsection{Skalak}

Um modelo para o comportamento elástico da membrana de hemácias foi proposto por (Skalak et al., 1973),

$$
E=\frac{\mu}{2}\left(\frac{l_{1}^{2}}{2}+I_{1}-I_{2}\right)+\frac{K}{4} l_{2}^{2}
$$

com

$$
\begin{aligned}
& l_{1}=\Lambda_{1}^{2}+\Lambda_{2}^{2}-2, \\
& l_{2}=\Lambda_{1}^{2} \Lambda_{2}^{2}-1 .
\end{aligned}
$$

\subsection{Gravidade}

A partícula $i$, com massa $m_{i}$, recebe uma força

$$
\mathbf{F}_{i}=m_{i} \mathbf{g}
$$

quando um campo de aceleração constante g é aplicado a ela. Assim é como a membrana em si responde à gravidade. Também é possível aproximar o comportamento da gravidade agindo sobre um fluido de densidade $\rho$ contido em uma membrana fechada. A energia potencial seria

$$
E=-\int \mathbf{g} \cdot \mathbf{r} \rho d V
$$

onde $r$ é o vetor posição e a integral é feita sobre todo o volume $V$ englobado pela membrana.

Uma maneira de calcular a integral 2.72 para uma malha de triângulos é escolher um ponto fixo no espaço, e.g. a origem do sistema de coordenadas, e conectar todos os vértices a ele. Cada triângulo se tornaria um tetraedro. A energia potencial gravitacional toma a forma

$$
E=-\sum_{j} \mathbf{g} \cdot \mathbf{R}_{j} \rho V_{j}
$$

onde $\mathbf{R}_{j}$ é a posição do centro de massa e $V_{j}$ o volume do tetraedro $j$.

Se o volume englobado pela malha tiver uma forma convexa e o ponto fixo estiver dentro dele, os tetraedros formarão uma partição do volume, e a quadratura da equação 2.73 estará correta. Por outro lado, se a forma não for convexa ou se o ponto fixo estiver fora do volume, alguns tetraedros poderão, parcial ou totalmente, ficar fora do volume ou se sobrepor. Os tetraedros não serão mais uma partição do volume, e a quadratura da equação 2.73 estará incorreta.

Para contornar essa questão, um volume com sinal é usado. Sejam $\mathbf{x}_{a}, \mathbf{x}_{b}$ e $\mathbf{x}_{c}$ as posições dos vértices do triângulo $j$ e $\mathbf{x}_{0}$ o ponto fixo. Os vértices estão ordenados de forma que a normal exterior não normalizada é

$$
\mathbf{n}=\left(\mathbf{x}_{b}-\mathbf{x}_{a}\right) \times\left(\mathbf{x}_{c}-\mathbf{x}_{a}\right)
$$

O volume com sinal do tetraedro é

$$
V_{j}=-\frac{1}{6}\left(\mathbf{x}_{0}-\mathbf{x}_{a}\right) \cdot \mathbf{n}
$$


ou, admitindo que $\mathbf{x}_{0}$ seja a origem,

$$
V_{j}=\frac{1}{6} \mathbf{x}_{a} \cdot \mathbf{x}_{b} \times \mathbf{x}_{c}
$$

Quando o ponto fixo está do lado "errado" do triângulo, i.e. do lado que a normal exterior aponta, o volume com sinal fica negativo. Isso pode acontecer para regiões côncavas ou para um ponto fixo exterior à membrana. Esses volumes negativos compensam os volumes positivos que se sobrepõe ou estão fora da membrana, e a quadratura fica correta.

É importante lembrar que a inércia do fluido interior não é levada em consideração. Portanto, situações em que essa inércia é importante, como uma membrana cheia de fluido em queda livre, não serão simuladas corretamente.

\subsection{Arrasto de Stokes}

Em geral, para considerar o efeito do fluido adjacente, é necessário resolver as equações de Navier-Stokes em três dimensões acopladas a 2.6. Se a inércia do fluido for desconsiderada, a formulação de elementos de contorno baseada nas soluções fundamentais das equações de Stokes tem ganhado muita popularidade (Ramanujan \& Pozrikidis, 1998; Lac \& Barthès-Biesel, 2005; Sui et al., 2010; Li \& Sarkar, 2008; Veerapaneni et al., 2011). A sua vantagem é que todos os cálculos são feitos na interface, sem a necessidade de uma malha volumétrica. Neste trabalho, uma versão simplificada dessa abordagem é usada para simular o efeito do fluido adjacente.

Uma partícula $i$ movendo-se através de um fluido estacionário a velocidades relativamente baixas onde não há turbulência, i.e. número de Reynolds baixo, é submetida a uma força $\mathbf{F}_{i}$ que é aproximadamente proporcional à sua velocidade $\mathbf{v}_{i}$, mas em sentido oposto,

$$
\mathbf{F}_{i}=-b \mathbf{v}_{i},
$$

onde $b$ é uma constante de proporcionalidade que depende das propriedades do fluido, como a viscosidade e a densidade, e da forma do objeto. O fluido em si também pode estar se movendo, e uma equação mais geral seria

$$
\mathbf{F}_{i}=-b\left[\mathbf{v}_{i}-\mathbf{U}\left(\mathbf{x}_{i}\right)\right]
$$

onde $\mathbf{U}\left(\mathbf{x}_{i}\right)$ é a velocidade do fluido na posição da partícula $\mathbf{x}_{i}$.

\subsection{Pressão e tensão superficial}

Uma membrana fechada cheia de fluido será submetida a forças normais à sua superfície se a pressão interna for diferente da externa. Se $p$ for a diferença entre as pressões interna e externa, a força $\mathbf{F}_{j}$ sobre o triângulo $j$ será

$$
\mathbf{F}_{j}=p A_{j} \mathbf{n}_{j}
$$

onde $A_{j}$ é a área e $\mathbf{n}_{j}$ a normal exterior do triângulo. Esta força é aplicada sobre o baricentro do triângulo, de forma que não gere rotações. Portanto, cada vértice recebe um terço da força total. 
virtual e a energia

O efeito da pressão também pode ser simulado usando o princípio do trabalho

$$
E=-\int p d V
$$

onde a integral é calculada sobre o volume $V$ englobado pela membrana. A quadratura é calculada de forma similar ao que foi feito na seção 2.6,

$$
E=-\sum_{j} p V_{j}
$$

onde $V_{j}$ é o volume com sinal do tetraedro construído a partir do triângulo $j$. A soma é feita sobre todos os elementos $j$.

De forma análoga à pressão, pode-se definir uma energia relacionada à tensão superficial $\lambda$,

$$
E=\int \lambda d A
$$

onde a integral é feita sobre toda a área $A$ da membrana. A quadratura correspondente é

$$
E=\sum_{j} \lambda A_{j}
$$

onde $A_{j}$ é a área do triângulo $j$ e a soma é feita sobre todos os elementos $j$.

\subsection{Discretização temporal explícita}

\subsubsection{Euler explícito}

O método de Euler explícito é provavelmente a maneira mais simples de se discretizar a evolução temporal de um sistema. A discretização da equação 2.6 leva a

$$
\mathbf{Y}^{n+1}=\mathbf{Y}^{n}+\Delta t \mathscr{F}\left(\mathbf{Y}^{n}, t^{n}\right)
$$

com

$$
t^{n+1}=t^{n}+\Delta t
$$

onde $\Delta t$ é o passo temporal (possivelmente variável) e o sobrescrito $n$ indica o ciclo da simulação. Neste sentido, $t^{n}$ é o tempo de simulação no ciclo $n$ e $\mathbf{Y}^{n}$ é o vetor de estado neste mesmo ciclo. Expandindo usando 2.5,

$$
\begin{aligned}
& \mathbf{x}_{i}^{n+1}=\mathbf{x}_{i}^{n}+\Delta t \mathbf{v}_{i}^{n}, \\
& \mathbf{v}_{i}^{n+1}=\mathbf{v}_{i}^{n}+\Delta t \frac{1}{m_{i}} \mathbf{F}_{i}^{n} .
\end{aligned}
$$

\subsubsection{Euler semi-implícito}

Também conhecido como método Euler simplético, Euler semiexplícito, EulerCromer ou Newton-Stormer-Verlet. Sua formulação é

$$
\begin{aligned}
& \mathbf{x}_{i}^{n+1}=\mathbf{x}_{i}^{n}+\Delta t \mathbf{v}_{i}^{n+1} \\
& \mathbf{v}_{i}^{n+1}=\mathbf{v}_{i}^{n}+\Delta t \frac{1}{m_{i}} \mathbf{F}_{i}^{n} .
\end{aligned}
$$

A equação das posições é implícita enquanto a das velocidades é explícita. As novas velocidades $\mathbf{v}_{i}^{n+1}$ são calculadas primeiro e a partir delas são calculadas as novas posições $\mathbf{x}_{i}^{n+1}$. 


\subsubsection{Adams-Bashforth de dois passos}

O método de Euler é um método de um passo pois usa apenas informação do tempo $t^{n}$ para estimar o estado do sistema no tempo $t^{n+1}$. O método de Adams-Bashforth de dois passos usa também informação do tempo $t^{n-1}$ para melhorar a aproximação. Ele é dado por

$$
\mathbf{Y}^{n+1}=\mathbf{Y}^{n}+\frac{3}{2} \Delta t \mathscr{F}\left(\mathbf{Y}^{n}, t^{n}\right)-\frac{1}{2} \Delta t \mathscr{F}\left(\mathbf{Y}^{n-1}, t^{n-1}\right)
$$

ou, expandindo usando 2.5 ,

$$
\begin{aligned}
& \mathbf{x}_{i}^{n+1}=\mathbf{x}_{i}^{n}+\frac{3}{2} \Delta t \mathbf{v}_{i}^{n}-\frac{1}{2} \Delta t \mathbf{v}_{i}^{n-1} \\
& \mathbf{v}_{i}^{n+1}=\mathbf{v}_{i}^{n}+\frac{3}{2} \Delta t \frac{1}{m_{i}} \mathbf{F}_{i}^{n}-\frac{1}{2} \Delta t \frac{1}{m_{i}} \mathbf{F}_{i}^{n-1} .
\end{aligned}
$$

A vantagem do método de Adams-Bashforth é que ele é de segunda ordem e não requer muito processamento adicional. Os valores calculados para $\mathscr{F}$ podem ser armazenados e reutilizados, fazendo com que $\mathscr{F}$ seja avaliada apenas uma vez por ciclo, o mesmo custo do método de Euler explícito. A desvantagem é o consumo adicional de memória.

Visto que, em geral, os problemas simulados possuem apenas um estado inicial, o método de Adams-Bashforth não pose ser usado para o primeiro ciclo de simulação. Neste trabalho, usa-se o método de Runge-Kutta de quarta ordem para o primeiro ciclo.

\subsubsection{Runge-Kutta de quarta ordem}

Enquanto o método de Adams-Bashforth usa passos anteriores para melhorar a ordem, o método de Runge-Kutta usa passos intermediários entre os estados no tempo $t^{n}$ e $t^{n+1}$. Quando aplicado à equação 2.6, esse comumente utilizado membro da família de métodos de Runge-Kutta produz

$$
\mathbf{Y}^{n+1}=\mathbf{Y}^{n}+\frac{1}{6}\left(\mathbf{K}_{1}+2 \mathbf{K}_{2}+2 \mathbf{K}_{3}+\mathbf{K}_{4}\right)
$$

com

$$
\begin{aligned}
& \mathbf{K}_{1}=\Delta t \mathscr{F}\left(t^{n}, \mathbf{Y}^{n}\right) \\
& \mathbf{K}_{2}=\Delta t \mathscr{F}\left(t^{n}+\frac{1}{2} \Delta t, \mathbf{Y}_{n}+\frac{1}{2} \mathbf{K}_{1}\right) \\
& \mathbf{K}_{3}=\Delta t \mathscr{F}\left(t^{n}+\frac{1}{2} \Delta t, \mathbf{Y}_{n}+\frac{1}{2} \mathbf{K}_{2}\right), \\
& \mathbf{K}_{4}=\Delta t \mathscr{F}\left(t^{n}+\Delta t, \mathbf{Y}_{n}+\mathbf{K}_{3}\right) .
\end{aligned}
$$

O método é de quarta ordem, mas o custo é quatro vezes maior do que o do método de Euler explícito.

\subsubsection{Runge-Kutta-Fehlberg}

O método Runge-Kutta-Fehlberg é um método de Runge-Kutta adaptativo. Ao invés de impor um passo temporal, uma tolerância de controle de erro é usada para calcular o passo temporal.

A ideia por trás do método é comparar uma solução de Runge-Kutta de quarta ordem com outra de quinta ordem. A diferença entre as duas soluções pode ser usada como uma estimativa do erro de discretização. Se o erro estiver muito grande, o passo temporal será reduzido e a solução recalculada. Se o erro estiver dentro da tolerância, a solução será 
aceita. Se o erro for muito pequeno, a solução também será aceita, mas o próximo passo temporal será aumentado.

Para reduzir o custo computacional, os métodos de quarta e quinta ordem são escolhidos de forma a reutilizar a maioria dos vetores intermediários $\mathbf{K}$. Os vetores intermediários compartilhados são

$$
\begin{aligned}
& \mathbf{K}_{1}=\Delta t \mathscr{F}\left(t^{n}, \mathbf{Y}^{n}\right), \\
& \mathbf{K}_{2}=\Delta t \mathscr{F}\left(t^{n}+\frac{1}{4} \Delta t, \mathbf{Y}_{n}+\frac{1}{4} \mathbf{K}_{1}\right), \\
& \mathbf{K}_{3}=\Delta t \mathscr{F}\left(t^{n}+\frac{3}{8} \Delta t, \mathbf{Y}_{n}+\frac{3}{32} \mathbf{K}_{1}+\frac{9}{32} \mathbf{K}_{2}\right), \\
& \mathbf{K}_{4}=\Delta t \mathscr{F}\left(t^{n}+\frac{12}{13} \Delta t, \mathbf{Y}_{n}+\frac{1932}{2197} \mathbf{K}_{1}-\frac{7200}{2197} \mathbf{K}_{2}+\frac{7296}{2197} \mathbf{K}_{3}\right), \\
& \mathbf{K}_{5}=\Delta t \mathscr{F}\left(t^{n}+\Delta t, \mathbf{Y}_{n}+\frac{439}{216} \mathbf{K}_{1}-8 \mathbf{K}_{2}+\frac{3680}{513} \mathbf{K}_{3}-\frac{845}{4104} \mathbf{K}_{4}\right), \\
& \mathbf{K}_{6}=\Delta t \mathscr{F}\left(t^{n}+\frac{1}{2} \Delta t, \mathbf{Y}_{n}-\frac{8}{27} \mathbf{K}_{1}+2 \mathbf{K}_{2}-\frac{3544}{2565} \mathbf{K}_{3}+\frac{1859}{4104} \mathbf{K}_{4}-\frac{11}{40} \mathbf{K}_{5}\right) .
\end{aligned}
$$

A solução de quarta ordem é

$$
\mathbf{Y}^{n+1}=\mathbf{Y}^{n}+\frac{25}{216} \mathbf{K}_{1}+\frac{1408}{2565} \mathbf{K}_{3}+\frac{2197}{4104} \mathbf{K}_{4}-\frac{1}{5} \mathbf{K}_{5}
$$

e a de quinta ordem é

$$
\mathbf{Z}^{n+1}=\mathbf{Y}^{n}+\frac{16}{135} \mathbf{K}_{1}+\frac{6656}{12825} \mathbf{K}_{3}+\frac{28561}{56430} \mathbf{K}_{4}-\frac{9}{50} \mathbf{K}_{5}+\frac{2}{55} \mathbf{K}_{6}
$$

O erro $\varepsilon$, i.e. a diferença entre as duas soluções, é calculado usando a norma do máximo ou norma $\mathbf{L}^{\infty}$ :

$$
\varepsilon=\left|\mathbf{Z}^{n+1}-\mathbf{Y}^{n+1}\right| \mathbf{L}^{\infty}
$$

O erro máximo tolerado é prescrito. Se o erro calculado for maior, o passo temporal é dividido por 1,1 e a solução recalculada. Se o erro for menor do que um décimo do erro máximo, o próximo passo temporal será multiplicado por 1,1.

\subsection{Discretização temporal implícita}

\subsubsection{Euler implícito}

O método implícito de Euler de primeira ordem aplicado à equação 2.6 produz

$$
\mathbf{Y}^{n+1}=\mathbf{Y}^{n}+\Delta t \mathscr{F}\left(\mathbf{Y}^{n+1}, t^{n+1}\right)
$$

ou, expandindo usando 2.5 ,

$$
\begin{aligned}
& \mathbf{x}_{i}^{n+1}=\mathbf{x}_{i}^{n}+\Delta t \mathbf{v}_{i}^{n+1}, \\
& \mathbf{v}_{i}^{n+1}=\mathbf{v}_{i}^{n}+\Delta t \frac{1}{m_{i}} \mathbf{F}_{i}^{n+1},
\end{aligned}
$$

onde $\mathbf{F}_{i}^{n+1}=\mathbf{F}_{i}\left(\mathbf{Y}^{n+1}, t^{n+1}\right)$. Este é um sistema de equações não lineares, visto que um $\mathbf{F}_{i}^{n+1}$ pode ser uma função não linear de $\mathbf{x}_{j}^{n+1}$ ou $\mathbf{v}_{j}^{n+1}$, para algum $j$. A sua solução será calculada pelo método de Newton-Raphson. Para isso, é conveniente definir o resíduo $\mathbf{R}\left(\mathbf{Y}^{n+1}, \mathbf{Y}^{n}\right)$ como

$$
\mathbf{R}\left(\mathbf{Y}^{n+1}, \mathbf{Y}^{n}\right) \equiv \mathbf{Y}^{n+1}-\mathbf{Y}^{n}-\Delta t \mathscr{F}\left(\mathbf{Y}^{n+1}, t^{n+1}\right)
$$


ou

e resolver a equação

$$
\mathbf{R}\left(\mathbf{Y}^{n+1}, \mathbf{Y}^{n}\right) \equiv\left(\begin{array}{c}
\mathbf{x}_{1}^{n+1}-\mathbf{x}_{1}^{n}-\Delta t \mathbf{v}_{1}^{n+1} \\
\mathbf{x}_{2}^{n+1}-\mathbf{x}_{2}^{n}-\Delta t \mathbf{v}_{2}^{n+1} \\
\vdots \\
\mathbf{x}_{N}^{n+1}-\mathbf{x}_{N}^{n}-\Delta t \mathbf{v}_{N}^{n+1} \\
m_{1}\left(\mathbf{v}_{1}^{n+1}-\mathbf{v}_{1}^{n}\right)-\Delta t \mathbf{F}_{1}^{n+1} \\
m_{2}\left(\mathbf{v}_{2}^{n+1}-\mathbf{v}_{2}^{n}\right)-\Delta t \mathbf{F}_{2}^{n+1} \\
\vdots \\
m_{N}\left(\mathbf{v}_{N}^{n+1}-\mathbf{v}_{N}^{n}\right)-\Delta t \mathbf{F}_{N}^{n+1}
\end{array}\right)
$$

\subsubsection{Crank-Nicolson}

$$
\mathbf{R}\left(\mathbf{Y}^{n+1}, \mathbf{Y}^{n}\right)=\mathbf{0}
$$

O método de Crank-Nicolson é um método implícito de segunda ordem no tempo. Sua formulação, quando aplicado à equação 2.6, é

$$
\mathbf{R}\left(\mathbf{Y}^{n+1}, \mathbf{Y}^{n}\right) \equiv \mathbf{Y}^{n+1}-\mathbf{Y}^{n}-\Delta t \frac{\mathscr{F}\left(\mathbf{Y}^{n+1}, t^{n+1}\right)+\mathscr{F}\left(\mathbf{Y}^{n}, t^{n}\right)}{2}
$$

\subsubsection{Euler generalizado}

O método de Euler generalizado é dado por

$$
\mathbf{R}\left(\mathbf{Y}^{n+1}, \mathbf{Y}^{n}\right) \equiv \mathbf{Y}^{n+1}-\mathbf{Y}^{n}-\Delta t\left[\theta \mathscr{F}\left(\mathbf{Y}^{n+1}, t^{n+1}\right)+(1-\theta) \mathscr{F}\left(\mathbf{Y}^{n}, t^{n}\right)\right]
$$

onde $\theta$ varia entre 0 e 1 . Tomando $\theta=0,5$ temos o método de Crank-Nicolson. $\theta=1$ equivale a Euler implícito. Se $\theta$ for zero, o método deixa de ser implícito e corresponde ao método de Euler explícito.

\subsubsection{Sistemas com massa zero}

Ao contrário da formulação explícita, a formulação implícita permite que a massa das partículas seja feita zero na equação 2.99. Isso efetivamente remove a inércia do sistema. O próximo estado do sistema não depende mais das velocidades ou momentos do estado anterior. O problema passa a ser encontrar um estado onde a resultante das forças $\mathbf{F}_{i}^{n+1}$ é zero, i.e., as forças atuando sobre cada partícula estão em equilíbrio.

Um sistema com massa zero pode ser um problema mal posto. Por exemplo, se todas as forças dependem apenas das posições relativas das partículas, dada uma possível solução, qualquer translação ou rotação rígida também é solução.

Uma maneira de contornar essa má postura seria introduzir uma força dependente da velocidade, como a força de arrasto discutida na seção 2.7. Outra maneira seria impor vínculos ao sistema usando multiplicadores de Lagrange para eliminar as rotações e translações espúrias e limitar o número de possíveis soluções.

Visto que existem seis graus de liberdade, três translacionais e três rotacionais, seis "multiplicadores de Lagrange para massa zero" $\lambda_{k}$ são necessários para cada malha conexa. Se a malha for desconexa, cada submalha conexa terá seis multiplicadores. Eles se tornarão novas variáveis de estado e serão adicionados ao vetor de estado Y. Cada multiplicador está relacionado a uma nova equação que será adicionada ao sistema não linear, equação 2.99. 
Sejam $\mathbf{X}_{a}, \mathbf{X}_{b}$ e $\mathbf{X}_{c}$ as posições de três pontos não colineares da malha no tempo $t=0$ e $\mathbf{x}_{a}, \mathbf{x}_{b}$ e $\mathbf{x}_{c}$ os mesmos pontos no tempo $t=t^{n+1}$, o tempo do novo estado que está sendo calculado. Uma base ortonormal $\mathbf{B}_{1}, \mathbf{B}_{2}$ e $\mathbf{B}_{3}$ do espaço pode ser definida como

$$
\begin{aligned}
& \mathbf{B}_{1}=\frac{\mathbf{X}_{b}-\mathbf{X}_{a}}{\left|\mathbf{X}_{b}-\mathbf{X}_{a}\right|}, \\
& \mathbf{B}_{3}=\mathbf{B}_{1} \times \frac{\mathbf{X}_{c}-\mathbf{X}_{a}}{\left|\mathbf{X}_{c}-\mathbf{X}_{a}\right|}, \\
& \mathbf{B}_{2}=\mathbf{B}_{3} \times \mathbf{B}_{1} .
\end{aligned}
$$

O conjunto de equações a ser adicionado ao sistema 2.99 é

$$
\begin{aligned}
& R_{\lambda_{1}} \equiv\left(\mathbf{x}_{a}-\mathbf{X}_{a}\right)_{x} \quad=0, \\
& R_{\lambda_{2}} \equiv\left(\mathbf{x}_{a}-\mathbf{X}_{a}\right)_{y} \quad=0, \\
& R_{\lambda_{3}} \equiv\left(\mathbf{x}_{a}-\mathbf{X}_{a}\right)_{z}=0, \\
& R_{\lambda_{4}} \equiv\left(\mathbf{x}_{b}-\mathbf{X}_{a}\right) \cdot \mathbf{B}_{3}=0, \\
& R_{\lambda_{5}} \equiv\left(\mathbf{x}_{c}-\mathbf{X}_{a}\right) \cdot \mathbf{B}_{3}=0, \\
& R_{\lambda_{6}} \equiv\left(\mathbf{x}_{b}-\mathbf{X}_{a}\right) \cdot \mathbf{B}_{2}=0,
\end{aligned}
$$

onde os $R_{\lambda_{k}}$ são os novos componentes do resíduo. Além disso, à energia total do sistema, o termo

$$
E_{z m / m}=\sum_{k=1}^{6} \lambda_{k} R_{\lambda_{k}}
$$

precisa ser adicionado. Novamente, se a malha for desconexa, três pontos devem ser escolhidos em cada submalha conexa e o procedimento repetido.

\subsubsection{O método de Newton-Raphson}

O sistema de equações não lineares 2.99 pode ser resolvido por meio do método iterativo de Newton-Raphson

$$
\underline{\underline{\mathbf{J}}}\left[\mathbf{Y}^{k+1}-\mathbf{Y}^{k}\right]=\mathbf{R}\left(\mathbf{Y}^{k}, \mathbf{Y}^{n}\right)
$$

onde $\underline{\underline{\mathbf{J}}}$ é a matriz jacobiana

$$
\underline{\underline{\mathbf{J}}}=\left[\begin{array}{ccc}
\frac{\partial R_{1}}{\partial q_{1}} & \frac{\partial R_{1}}{\partial q_{2}} & \ldots \\
\frac{\partial R_{2}}{\partial q_{1}} & \frac{\partial R_{2}}{\partial q_{2}} & \ldots \\
\vdots & \vdots & \ddots
\end{array}\right],
$$

e os $q_{i}$ representam as variáveis de estado do vetor $\mathbf{Y}^{k}$. A equação 2.106 é um sistema linear que pode ser resolvido por métodos convencionais.

Dado um valor tentativo inicial $\mathbf{Y}^{k}$ para a equação $\mathbf{R}\left(\mathbf{Y}^{k}, \mathbf{Y}^{n}\right)=\mathbf{0}$, uma iteração do método produz $\mathbf{Y}^{k+1}$, que em geral está mais próximo da solução procurada $\mathbf{Y}^{n+1}$. O processo é repetido até que o resíduo $\left|\mathbf{R}\left(\mathbf{Y}^{k+1}, \mathbf{Y}^{n}\right)\right|$ ou a variação da solução tentativa $\left|\mathbf{Y}^{k+1}-\mathbf{Y}^{k}\right|$ seja suficientemente próxima de 0 . A norma do máximo é usada aqui.

O jacobiano é calculado a cada iteração para $\mathbf{R}\left(\mathbf{Y}^{k}, \mathbf{Y}^{n}\right)$ usando diferenças finitas centrais. Seja $\mathbf{Y}^{+}$o vetor de estado $\mathbf{Y}^{k}$, mas com a variável de estado $q_{j}$ incrementada de $+h$. $\mathbf{Y}^{-}$é o análogo para um decremento $-h$. Então,

$$
\frac{\partial R_{i}}{\partial q_{j}}=\frac{R_{i}\left(\mathbf{Y}^{+}, \mathbf{Y}^{n}\right)-R_{i}\left(\mathbf{Y}^{-}, \mathbf{Y}^{n}\right)}{2 h}
$$


Para problemas bem postos, o método converge em poucas iterações. A matriz jacobiana se torna singular para problemas mal postos e o método falha em chegar a uma solução. Até mesmo para problemas bem postos, uma escolha ruim para o passo temporal ou para o incremento $h$ das diferenças finitas, no cálculo tanto do jacobiano quanto das forças, pode fazer com que o método não convirja.

\subsection{Conservação de volume e área}

Espera-se que uma membrana fechada cheia de fluido incompressível conserve o seu volume. No caso de membranas lipídicas, espera-se também que a área da membrana não mude, visto que elas são sabidamente inextensíveis. Até agora, a maioria dos métodos encontrados na literatura impõe essa condição globalmente (Feng \& Klug, 2006; Ma \& Klug, 2008; Dziuk, 2008; Bonito et al., 2010). Em outras palavras, a área total da membrana é constante, mas não necessariamente cada parte da superfície conserva sua área inicial. Isso seria conservação de área local. Recentemente, (Veerapaneni et al., 2011) usou uma formulação espectral e (Boedec et al., 2011) usou uma formulação de elementos de contorno não estruturados para impor conservação de área local.

\subsubsection{Conservação de volume}

Uma maneira de impor a conservação de volume é ajustar a pressão interna para compensar as mudanças de volume. Para tal, toma-se a pressão como sendo

$$
p=-\alpha\left(V-V_{0}\right)
$$

onde $V$ é o volume atual da membrana, $V_{0}$ o volume inicial, ou prescrito, e $\alpha$ uma constante de proporcionalidade. Essa técnica é chamada de penalização. Ela pode ser usada tanto na formulação explícita quanto na implícita.

Quanto maior for a constante $\alpha$, melhor será a conservação de volume, no sentido em que a oscilação de volume terá uma amplitude menor. No entanto, um valor muito grande para $\alpha$ pode impor restrições ao passo de tempo. Para contornar isso, uma abordagem implícita pode ser usada, onde o objetivo é achar o valor preciso de $p$ que conserva o volume. Seja $V(p)$ o volume da membrana após um ciclo de simulação com pressão interna $p, 0$ objetivo é achar o valor de $p$ que é solução da equação

$$
V(p)-V_{0}=0
$$

Na formulação explícita, usa-se o método regula falsi para encontrar a solução da equação 2.110. Um ciclo de simulação é feito para cada valor tentativo de $p$ e o volume resultante é calculado. Já na formulação implícita, a pressão deixa de ser um parâmetro e se torna uma nova variável de estado. A conservação de volume é um vínculo e a pressão é o multiplicador de Lagrange correspondente. A equação de vínculo

$$
-\left(V-V_{0}\right)=0
$$

é adicionada como uma componente do resíduo, equação 2.99. Além disso, a energia

$$
E_{p}=-p\left(V-V_{0}\right)
$$

é adicionada à energia total do sistema. O termo $V_{0}$ pode ser desconsiderado nessa última equação por ser constante. 


\subsubsection{Conservação global de área}

Conservação global de área significa conservar a área total de uma membrana. Isso é feito de maneira análoga à conservação de volume, substituindo a pressão pela tensão superficial. Então, usando a técnica de penalização, ajustamos a tensão superficial $\gamma$ como sendo

$$
\gamma=\alpha\left(A-A_{0}\right)
$$

onde $A$ e $A_{0}$ são as áreas atual e inicial (ou prescrita) e $\alpha$ é uma constante de proporcionalidade. A conservação será melhor quanto maior for $\alpha$, mas valores grandes podem restringir o passo temporal.

Para conservar a área de forma implícita, a equação

$$
A(\gamma)-A_{0}=0
$$

é resolvida da mesma forma que a análoga da conservação de volume. Na formulação explícita, para cada valor tentativo da tensão superficial $\gamma$, um ciclo de simulação é feito e a área da membrana $A(\gamma)$ é calculada. O método regula falsi é usado para encontrar o valor preciso de $\gamma$ que seja solução da equação 2.114 .

É possível também conservar área e volume simultaneamente. Para tal, é necessário resolver o sistema de equações formado pelas equações 2.110 e 2.114. O método de Newton-Raphson é usado.

$\mathrm{Na}$ formulação implícita, a conservação de área é um vínculo e o multiplicador de Lagrange correspondente, a tensão superficial, passa a ser uma variável de estado. A equação de vínculo

$$
A-A_{0}=0
$$

é adicionada como uma componente do resíduo, equação 2.99. À energia total adiciona-se

$$
E_{\gamma}=\gamma\left(A-A_{0}\right)
$$

Por ser constante, $A_{0}$ pode ser desconsiderado nessa última equação.

\subsubsection{Conservação local de área}

Conservação local de área significa que qualquer parte da membrana conserva a sua área, e não apenas a membrana como um todo. Conservação local implica em conservação global, mas o contrário não é válido, pois um triângulo pode aumentar de área e ser compensado pelo decréscimo de área de outro.

Uma maneira de impor conservação local de área na membrana é tomar o módulo de compressibilidade como sendo muito grande na lei constitutiva do material. Isso é semelhante à técnica de penalização. Variações de área causam aumento na energia elástica e quanto maior for o módulo de compressibilidade, maior será o aumento de energia. Assim como na penalização, a conservação é melhor quanto maior for o módulo de compressibilidade, mas valores muito grandes podem produzir restrições ao passo temporal.

Outra maneira é usar uma tensão superficial local, cujo valor não é o mesmo em todos os pontos da membrana. Isso faz com que a tensão superficial seja um campo de multiplicadores de Lagrange distribuídos na superfície da membrana. Por questões de estabilidade, no problema discreto, essa tensão superficial deve ser amostrada nos vértices da malha, e não no centro dos triângulos. A tensão superficial do triângulo é a média simples 
das tensões de seus vértices. A energia associada à tensão superficial local é dada pela equação

$$
E_{\gamma}=\sum_{j} \sum_{n \in N_{j}} \frac{\gamma_{n}}{3}\left(A_{j}-A_{j}^{0}\right)
$$

onde $A_{j}$ é a área atual e $A_{j}^{0}$ a área de referência do triângulo $j$ e $\gamma_{n}$ é a tensão superficial no vértice $n$ do triângulo $j$. A soma em $j$ é feita sobre todos os triângulos da malha, e a soma em $n$ é feita sobre os três vértices do triângulo $j$. O conjunto de vértices do triângulo $j$ é $N_{j}$.

A energia também pode ser expressa como

$$
E_{\gamma}=\sum_{i} \sum_{m \in M_{i}} \frac{\gamma_{i}}{3}\left(A_{m}-A_{m}^{0}\right)
$$

onde $A_{m}$ é a área atual e $A_{m}^{0}$ a área de referência do triângulo $m$ e $\gamma_{i}$ é a tensão superficial no vértice $i$. A soma em $i$ é feita sobre todos os vértices da malha e $M_{i}$ é o conjunto de triângulos adjacentes ao vértice $i$.

Ao resíduo, equação 2.99, deve-se adicionar as equações do vínculo de conservação de área local. Cada vértice da malha possui uma nova variável de estado, a tensão superficial local. Então, uma equação de conservação de área é necessária para cada vértice $i$. A área associada a cada vértice é um terço da área de cada triângulo adjacente. Logo, a equação do vínculo de conservação de área do vértice $i$ é

$$
\sum_{m \in M_{i}} \frac{1}{3}\left(A_{m}-A_{m}^{0}\right)=0
$$

A inextensibilidade de uma membrana é análoga à incompressibilidade de um fluido bidimensional. Experiências anteriores com métodos de elementos finitos para equações de Navier-Stokes (Hughes et al., 1986; Codina, 2001; Buscaglia et al., 2000; Codina et al., 2001) mostram que a discretização com elementos finitos de mesmo grau para a posição, velocidade e pressão, ou, neste caso, a tensão superficial, causam o aparecimento de oscilações espúrias. Para evitar o aparecimento de oscilações na tensão superficial local, é necessário adicionar o termo de estabilização

$$
\frac{\partial}{\partial \gamma_{i}} \int \tau|\nabla \gamma|^{2} \mathrm{~d} A
$$

à equação de vínculo correspondente à tensão superficial $\gamma_{i}$ do vértice $i$. A integral é feita sobre toda a área $A$ da membrana. $\nabla \gamma$ é o gradiente da tensão superficial local sobre a membrana. $\tau$ é um parâmetro de estabilização. Se for muito pequeno ou zero, oscilações não físicas aparecerão na solução. Um valor muito grande faz com que a tensão superficial seja constante em toda a membrana. No triângulo $m$, ele é tomado como

$$
\tau_{m}=c_{\tau} \frac{A_{m}^{0}}{\mu}
$$

onde $c_{\tau}$ é um parâmetro ajustável e $\mu$ é a viscosidade da membrana.

A forma discreta da equação 2.120 envolve o cálculo do gradiente da tensão superficial $\gamma$ em um triângulo. Como $\gamma$ é conhecida nos vértices do triângulo, o procedimento descrito na seção 2.4.5 pode ser usado para calcular o gradiente.

A quadratura da integral em 2.120 só precisa ser avaliada nos triângulos adjacentes ao vértice $i$, pois os gradientes nos triângulos não adjacentes não dependem de 
$\gamma_{i}$ e por isso têm derivada nula com relação a $\gamma_{i}$. A equação estabilizada do vínculo passa a ser

$$
\sum_{m \in M_{i}} \frac{1}{3}\left(A_{m}-A_{m}^{0}\right)-\frac{\partial}{\partial \gamma_{i}} \sum_{m \in M_{i}} \tau_{m}\left|\nabla \gamma_{m}\right|^{2} A_{m}=0,
$$

onde $\nabla \gamma_{m}$ significa o gradiente de $\gamma$ no triângulo $m$ e a derivada em relação a $\gamma_{i}$ é feita por diferenças finitas centrais.

\subsection{Convergência temporal}

Como forma de testar a implementação dos esquemas de evolução temporal, foi feito um teste de convergência. O caso simulado é o de uma membrana com formato de esferoide oblato, inicialmente com raios 1 por 0,25 por 1. Essa forma inicial foi obtida a partir de uma membrana esférica de raio 1 onde a coordenada $y$ da posição de todos os vértices foi multiplicada por 0,25. A forma inicial pode ser vista na figura 2.1, à esquerda.
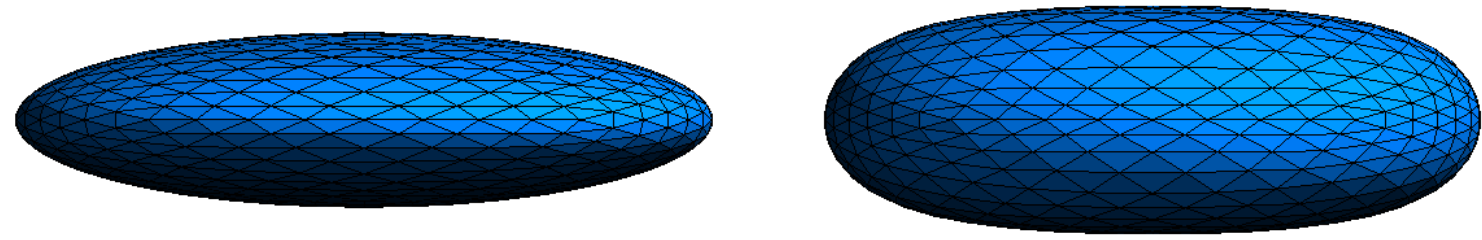

Figura 2.1: Formas inicial (esquerda) e final (direita) do caso teste de convergência dos esquemas de evolução temporal. A membrana oscila até o estado final, onde as forças elásticas e de curvatura estão em equilíbrio.

A membrana é elástica e segue o modelo neo-hookeano, com módulo de cisalhamento igual a 1. A forma de referência é a forma inicial. A massa total da membrana tem valor 1 .

Foi usada a energia de Canham-Helfrich, que será discutida em detalhes na seção 5.1 , com rigidez de dobramento $10^{-3}$. O cálculo de curvatura segue o esquema modificado de Meyer, discutido na seção 5.4.1.

A membrana oscila até que as forças elásticas e de curvatura se equilibrem. Um arrasto com valor 1 foi usado para dissipar energia e levar a um estado estacionário. A forma final pode ser vista na figura 2.1, à direita.

A mesma simulação é feita com os diversos esquemas e diferentes passos temporais. O erro no cálculo das posições e velocidades de todos os vértices é medido. Como não se conhece a solução analítica para este problema, a solução obtida pelo método 
de Runge-Kutta de quarta ordem com passo temporal de $10^{-6}$ foi adotada como referência para o cálculo dos erros.

Os valores foram amostrados em intervalos iguais entre o tempo inicial 0 e o final 10, num total de 1000 amostras. Para os casos onde o passo temporal era grande e não era possível tomar 1000 amostras, o número máximo permitido de amostras foi tomado. Três normas foram utilizadas para o cálculo dos erros. A norma $L^{1}$ normalizada corresponde à média aritmética simples

$$
|\mathbf{x}-\mathbf{y}|_{L^{1}}=\frac{1}{N}\left[\left|x_{1}-y_{1}\right|+\left|x_{2}-y_{2}\right|+\ldots+\left|x_{N}-y_{N}\right|\right] .
$$

A norma $L^{2}$ normalizada corresponde à média quadrática (root mean square ou RMS)

$$
|\mathbf{x}-\mathbf{y}|_{L^{2}}=\sqrt{\frac{1}{N}\left[\left(x_{1}-y_{1}\right)^{2}+\left(x_{2}-y_{2}\right)^{2}+\ldots+\left(x_{N}-y_{N}\right)^{2}\right]} .
$$

A norma $L^{\infty}$ é o valor máximo.

$$
|\mathbf{x}-\mathbf{y}|_{L^{\infty}}=\max \left(\left|x_{1}-y_{1}\right|,\left|x_{2}-y_{2}\right|, \ldots,\left|x_{N}-y_{N}\right|\right) .
$$

Nas fórmulas acima, $x_{i}$ representa uma componente da posição ou velocidade de uma partícula em uma amostra da simulação. $y_{i}$ é o valor esperado para $x_{i}$. A soma é feita sobre todas as componentes de todas as partículas em todas as amostras. Portanto, $N$ é três vezes o número de partículas multiplicado pelo número de amostras.

\subsubsection{Runge-Kutta de quarta ordem}

O método de Runge-Kutta de quarta ordem tem uma convergência muito rápida,

\begin{tabular}{|c|c|c|c|c|c|c|}
\hline \multicolumn{7}{|c|}{ Runge-Kutta de quarta ordem } \\
\hline \multicolumn{7}{|c|}{ Posição } \\
\hline & \multicolumn{3}{|c|}{ erro } & \multicolumn{3}{|c|}{ ordem } \\
\hline$\Delta t$ & $L^{1}$ & $L^{2}$ & $L^{\infty}$ & $L^{1}$ & $L^{2}$ & $L^{\infty}$ \\
\hline $1,00 \cdot 10^{-2}$ & $8,20 \cdot 10^{-5}$ & $1,64 \cdot 10^{-4}$ & $2,11 \cdot 10^{-3}$ & & & \\
\hline $1,00 \cdot 10^{-3}$ & $3,48 \cdot 10^{-8}$ & $1,01 \cdot 10^{-7}$ & $2,06 \cdot 10^{-6}$ & 3,37 & 3,21 & 3,01 \\
\hline $7,50 \cdot 10^{-4}$ & $1,07 \cdot 10^{-8}$ & $3,14 \cdot 10^{-8}$ & $6,32 \cdot 10^{-7}$ & 4,09 & 4,08 & 4,10 \\
\hline $5,00 \cdot 10^{-4}$ & $2,17 \cdot 10^{-9}$ & $6,36 \cdot 10^{-9}$ & $1,28 \cdot 10^{-7}$ & 3,94 & 3,94 & 3,94 \\
\hline $2,50 \cdot 10^{-4}$ & $1,35 \cdot 10^{-10}$ & $3,97 \cdot 10^{-10}$ & $8,00 \cdot 10^{-9}$ & 4,00 & 4,00 & 4,00 \\
\hline $1,00 \cdot 10^{-4}$ & $4,10 \cdot 10^{-12}$ & $1,01 \cdot 10^{-11}$ & $2,05 \cdot 10^{-10}$ & 3,82 & 4,00 & 4,00 \\
\hline $1,00 \cdot 10^{-5}$ & $1,27 \cdot 10^{-12}$ & $2,14 \cdot 10^{-12}$ & $3,92 \cdot 10^{-11}$ & 0,51 & 0,67 & 0,72 \\
\hline
\end{tabular}
como pode ser visto nas tabelas 2.1 e 2.2. Os valores medidos estão de acordo com o esperado valor 4 para a ordem de convergência.

Tabela 2.1: Erros e ordem de convergência da posição para o método de Runge-Kutta de quarta ordem.

\subsubsection{Euler explícito}

O método de Euler explícito mostrou convergência linear, como pode ser visto nas tabelas 2.3 e 2.4 . 


\begin{tabular}{c|c|c|c|c|c|c}
\hline \multicolumn{7}{c}{ Runge-Kutta de quarta ordem } \\
\hline \multicolumn{7}{c}{ Velocidade } \\
\hline$\Delta t$ & $L^{1}$ & $L^{2}$ & $L^{\infty}$ & $L^{1}$ & $L^{2}$ & $L^{\infty}$ \\
\hline $1,00 \cdot 10^{-2}$ & $6,48 \cdot 10^{-3}$ & $2,33 \cdot 10^{-2}$ & $5,65 \cdot 10^{-1}$ & & & \\
$1,00 \cdot 10^{-3}$ & $7,01 \cdot 10^{-6}$ & $2,22 \cdot 10^{-5}$ & $4,60 \cdot 10^{-4}$ & 2,97 & 3,02 & 3,09 \\
$7,50 \cdot 10^{-4}$ & $2,17 \cdot 10^{-6}$ & $6,88 \cdot 10^{-6}$ & $1,42 \cdot 10^{-4}$ & 4,08 & 4,08 & 4,08 \\
$5,00 \cdot 10^{-4}$ & $4,39 \cdot 10^{-7}$ & $1,39 \cdot 10^{-6}$ & $2,88 \cdot 10^{-5}$ & 3,94 & 3,94 & 3,94 \\
$2,50 \cdot 10^{-4}$ & $2,74 \cdot 10^{-8}$ & $8,72 \cdot 10^{-8}$ & $1,81 \cdot 10^{-6}$ & 4,00 & 4,00 & 3,99 \\
$1,00 \cdot 10^{-4}$ & $6,87 \cdot 10^{-10}$ & $2,18 \cdot 10^{-9}$ & $4,61 \cdot 10^{-8}$ & 4,02 & 4,02 & 4,00 \\
$1,00 \cdot 10^{-5}$ & $5,53 \cdot 10^{-11}$ & $9,73 \cdot 10^{-11}$ & $1,52 \cdot 10^{-9}$ & 1,09 & 1,35 & 1,48 \\
\hline
\end{tabular}

Tabela 2.2: Erros e ordem de convergência da velocidade para o método de Runge-Kutta de quarta ordem.

\begin{tabular}{c|c|c|c|c|c|c}
\hline \multicolumn{7}{c}{ Euler explícito } \\
\hline \multicolumn{5}{c}{ Posição } \\
\hline \multicolumn{1}{c}{ erro } & $L^{2}$ & $L^{\infty}$ & $L^{1}$ & $L^{2}$ & $L^{\infty}$ \\
\hline $1,00 \cdot 10^{-5}$ & $6,77 \cdot 10^{-6}$ & $1,23 \cdot 10^{-5}$ & $1,88 \cdot 10^{-4}$ & & & \\
$1,00 \cdot 10^{-6}$ & $5,54 \cdot 10^{-7}$ & $9,75 \cdot 10^{-7}$ & $1,64 \cdot 10^{-5}$ & 1,09 & 1,10 & 1,06 \\
$7,50 \cdot 10^{-7}$ & $4,13 \cdot 10^{-7}$ & $7,28 \cdot 10^{-7}$ & $1,22 \cdot 10^{-5}$ & 1,01 & 1,02 & 1,01 \\
$5,00 \cdot 10^{-7}$ & $2,75 \cdot 10^{-7}$ & $4,83 \cdot 10^{-7}$ & $8,13 \cdot 10^{-6}$ & 1,01 & 1,01 & 1,01 \\
$2,50 \cdot 10^{-7}$ & $1,37 \cdot 10^{-7}$ & $2,41 \cdot 10^{-7}$ & $4,05 \cdot 10^{-6}$ & 1,01 & 1,01 & 1,01 \\
$1,00 \cdot 10^{-7}$ & $5,46 \cdot 10^{-8}$ & $9,60 \cdot 10^{-8}$ & $1,62 \cdot 10^{-6}$ & 1,00 & 1,00 & 1,00 \\
\hline
\end{tabular}

Tabela 2.3: Erros e ordem de convergência da posição para o método de Euler explícito.

\begin{tabular}{c|c|c|c|c|c|c}
\hline \multicolumn{7}{c}{ Euler explícito } \\
\hline \multicolumn{7}{c}{ Velocidade } \\
\hline$\Delta t$ & $L^{1}$ & $L^{2}$ & $L^{\infty}$ & $L^{1}$ & $L^{2}$ & $L^{\infty}$ \\
\hline $1,00 \cdot 10^{-5}$ & $9,03 \cdot 10^{-4}$ & $2,13 \cdot 10^{-3}$ & $3,47 \cdot 10^{-2}$ & & & \\
$1,00 \cdot 10^{-6}$ & $6,45 \cdot 10^{-5}$ & $1,50 \cdot 10^{-4}$ & $2,98 \cdot 10^{-3}$ & 1,15 & 1,15 & 1,07 \\
$7,50 \cdot 10^{-7}$ & $4,81 \cdot 10^{-5}$ & $1,11 \cdot 10^{-4}$ & $2,23 \cdot 10^{-3}$ & 1,02 & 1,03 & 1,01 \\
$5,00 \cdot 10^{-7}$ & $3,18 \cdot 10^{-5}$ & $7,37 \cdot 10^{-5}$ & $1,48 \cdot 10^{-3}$ & 1,02 & 1,02 & 1,01 \\
$2,50 \cdot 10^{-7}$ & $1,58 \cdot 10^{-5}$ & $3,66 \cdot 10^{-5}$ & $7,38 \cdot 10^{-4}$ & 1,01 & 1,01 & 1,01 \\
$1,00 \cdot 10^{-7}$ & $6,29 \cdot 10^{-6}$ & $1,46 \cdot 10^{-5}$ & $2,95 \cdot 10^{-4}$ & 1,00 & 1,00 & 1,00 \\
\hline
\end{tabular}

Tabela 2.4: Erros e ordem de convergência da velocidade para o método de Euler explícito.

\subsubsection{Euler semi-implícito}

O método de Euler semi-implícito tem a mesma ordem de convergência que o método de Euler explícito, como pode ser visto nas tabelas 2.5 e 2.6. No entanto, ele se mostrou mais estável, permitindo um passo temporal bem maior, e o erro é cerca de dez vezes menor. 


\begin{tabular}{c|c|c|c|c|c|c}
\hline \multicolumn{7}{c}{ Euler semi-implícito } \\
\hline \multicolumn{7}{c}{ Posição } \\
\hline$\Delta t$ & $L^{1}$ & $L^{2}$ & $L^{\infty}$ & $L^{1}$ & $L^{2}$ & $L^{\infty}$ \\
\hline $1,00 \cdot 10^{-3}$ & $1,59 \cdot 10^{-5}$ & $2,85 \cdot 10^{-5}$ & $6,65 \cdot 10^{-4}$ & & & \\
$1,00 \cdot 10^{-4}$ & $1,27 \cdot 10^{-6}$ & $2,37 \cdot 10^{-6}$ & $6,61 \cdot 10^{-5}$ & 1,10 & 1,08 & 1,00 \\
$5,00 \cdot 10^{-5}$ & $6,26 \cdot 10^{-7}$ & $1,18 \cdot 10^{-6}$ & $3,30 \cdot 10^{-5}$ & 1,02 & 1,01 & 1,00 \\
$1,00 \cdot 10^{-5}$ & $1,24 \cdot 10^{-7}$ & $2,34 \cdot 10^{-7}$ & $6,60 \cdot 10^{-6}$ & 1,01 & 1,00 & 1,00 \\
$5,00 \cdot 10^{-6}$ & $6,19 \cdot 10^{-8}$ & $1,17 \cdot 10^{-7}$ & $3,30 \cdot 10^{-6}$ & 1,00 & 1,00 & 1,00 \\
$1,00 \cdot 10^{-6}$ & $1,24 \cdot 10^{-8}$ & $2,33 \cdot 10^{-8}$ & $6,60 \cdot 10^{-7}$ & 1,00 & 1,00 & 1,00 \\
\hline
\end{tabular}

Tabela 2.5: Erros e ordem de convergência da posição para o método de Euler semi-implícito.

\begin{tabular}{c|c|c|c|c|c|c}
\hline \multicolumn{7}{c}{ Euler semi-implícito } \\
\hline \multicolumn{7}{c}{ Velocidade } \\
\hline$\Delta t$ & $L^{1}$ & $L^{2}$ & $L^{\infty}$ & $L^{1}$ & $L^{2}$ & $L^{\infty}$ \\
\hline $1,00 \cdot 10^{-3}$ & $1,01 \cdot 10^{-3}$ & $2,55 \cdot 10^{-3}$ & $5,78 \cdot 10^{-2}$ & & & \\
$1,00 \cdot 10^{-4}$ & $3,52 \cdot 10^{-5}$ & $6,80 \cdot 10^{-5}$ & $1,25 \cdot 10^{-3}$ & 1,46 & 1,57 & 1,66 \\
$5,00 \cdot 10^{-5}$ & $1,56 \cdot 10^{-5}$ & $2,88 \cdot 10^{-5}$ & $5,00 \cdot 10^{-4}$ & 1,17 & 1,24 & 1,33 \\
$1,00 \cdot 10^{-5}$ & $2,82 \cdot 10^{-6}$ & $4,98 \cdot 10^{-6}$ & $8,22 \cdot 10^{-5}$ & 1,06 & 1,09 & 1,12 \\
$5,00 \cdot 10^{-6}$ & $1,39 \cdot 10^{-6}$ & $2,44 \cdot 10^{-6}$ & $4,00 \cdot 10^{-5}$ & 1,02 & 1,03 & 1,04 \\
$1,00 \cdot 10^{-6}$ & $2,75 \cdot 10^{-7}$ & $4,81 \cdot 10^{-7}$ & $7,82 \cdot 10^{-6}$ & 1,01 & 1,01 & 1,01 \\
\hline
\end{tabular}

Tabela 2.6: Erros e ordem de convergência da velocidade para o método de Euler semi-implícito.

\subsubsection{Adams-Bashforth de dois passos}

O método de Adams-Bashforth de dois passos tem o mesmo custo de processamento do método de Euler explícito e semi-implícito. No entanto, sua ordem de convergência é quadrática, o que o torna bastante interessante. O cálculo dos erros está nas tabelas 2.7 e 2.8 .

\begin{tabular}{c|l|l|l|l|l|l}
\hline \multicolumn{7}{c}{ Adams-Bashforth de dois passos } \\
\hline \multicolumn{5}{c}{ Posição } \\
\hline \multicolumn{7}{c|}{ erro } \\
\hline$\Delta t$ & $L^{1}$ & $L^{2}$ & $L^{\infty}$ & $L^{1}$ & $L^{2}$ & $L^{\infty}$ \\
\hline $1,00 \cdot 10^{-3}$ & $6,09 \cdot 10^{-4}$ & $1,39 \cdot 10^{-3}$ & $2,55 \cdot 10^{-2}$ & & & \\
$1,00 \cdot 10^{-4}$ & $5,24 \cdot 10^{-7}$ & $1,22 \cdot 10^{-6}$ & $2,44 \cdot 10^{-5}$ & 3,06 & 3,06 & 3,02 \\
$1,00 \cdot 10^{-5}$ & $5,25 \cdot 10^{-9}$ & $1,22 \cdot 10^{-8}$ & $2,44 \cdot 10^{-7}$ & 2,00 & 2,00 & 2,00 \\
$1,00 \cdot 10^{-6}$ & $5,25 \cdot 10^{-11}$ & $1,22 \cdot 10^{-10}$ & $2,44 \cdot 10^{-9}$ & 2,00 & 2,00 & 2,00 \\
\hline
\end{tabular}

Tabela 2.7: Erros e ordem de convergência da posição para o método de Adams-Bashforth de dois passos.

\subsubsection{Euler implícito}

O método implícito de Euler é o mais estável. Ele aceita um passo temporal com valor 10 , que corresponde ao tempo total da simulação. No entanto, ele tem convergência 


\begin{tabular}{c|c|c|c|c|c|c}
\hline \multicolumn{7}{c}{ Adams-Bashforth de dois passos } \\
\hline \multicolumn{7}{c}{ Velocidade } \\
\hline \multicolumn{1}{c}{ erro } & $L^{\infty}$ & $L^{1}$ & $L^{2}$ & $L^{\infty}$ \\
\hline$\Delta t$ & $L^{1}$ & $L^{2}$ & \multicolumn{3}{c}{ ordem } \\
\hline $1,00 \cdot 10^{-3}$ & $3,80 \cdot 10^{-2}$ & $1,19 \cdot 10^{-1}$ & $2,84 \cdot 10^{0}$ & & & \\
$1,00 \cdot 10^{-4}$ & $8,72 \cdot 10^{-5}$ & $2,39 \cdot 10^{-4}$ & $5,12 \cdot 10^{-3}$ & 2,64 & 2,70 & 2,74 \\
$1,00 \cdot 10^{-5}$ & $8,73 \cdot 10^{-7}$ & $2,39 \cdot 10^{-6}$ & $5,11 \cdot 10^{-5}$ & 2,00 & 2,00 & 2,00 \\
$1,00 \cdot 10^{-6}$ & $8,73 \cdot 10^{-9}$ & $2,39 \cdot 10^{-8}$ & $5,11 \cdot 10^{-7}$ & 2,00 & 2,00 & 2,00 \\
\hline
\end{tabular}

Tabela 2.8: Erros e ordem de convergência da velocidade para o método de Adams-Bashforth de dois passos.

lenta, como pode ser visto nas tabelas 2.9 e 2.10. A figura 2.2 mostra a trajetória de um dos pontos da malha para os diversos passos temporais. O método suaviza a solução quando 0 passo de tempo é muito grande.

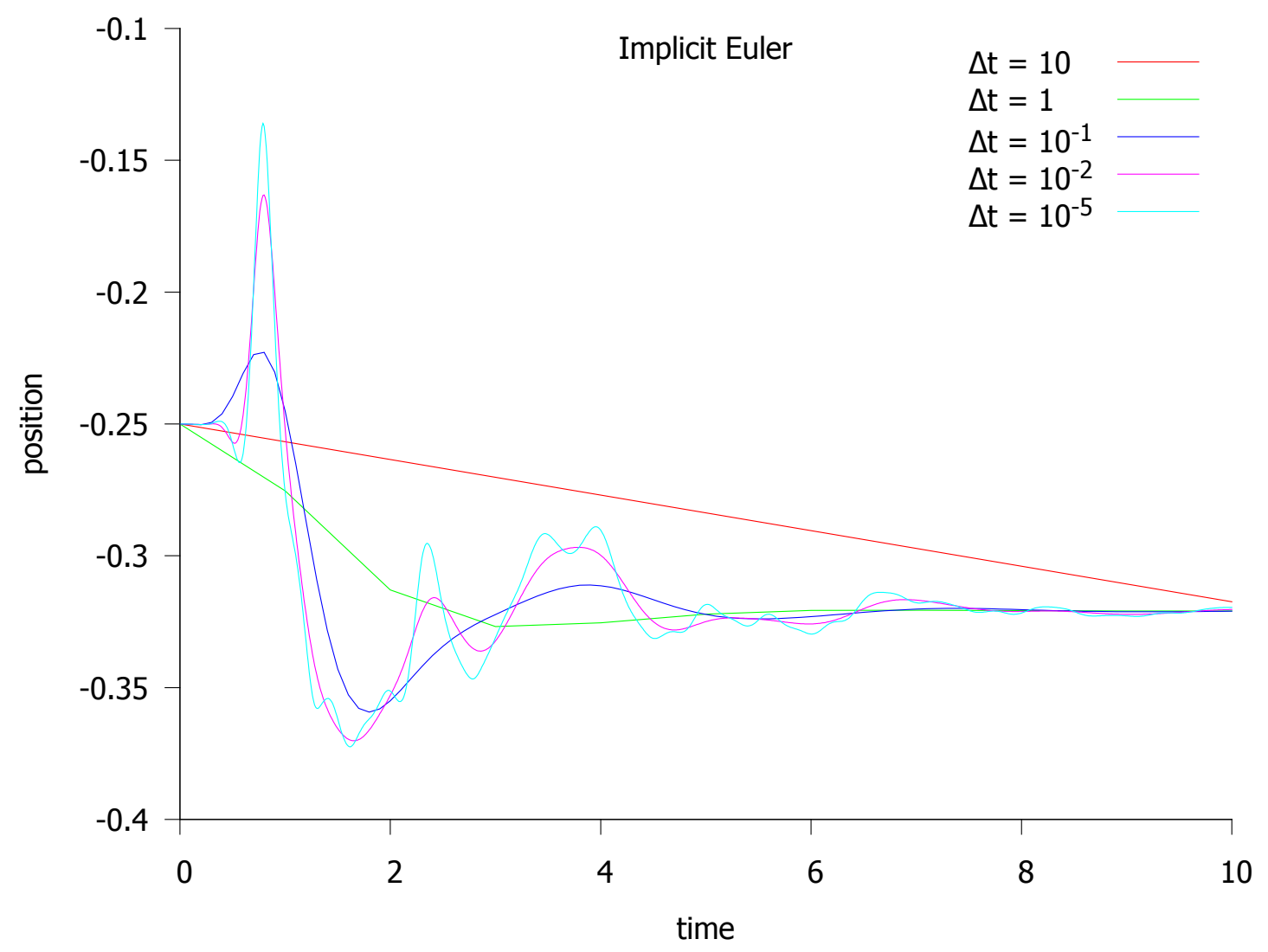

Figura 2.2: Trajetória de um dos pontos da malha para os diversos passos temporais com o método de Euler implícito. A solução de referência coincide com a curva para $\Delta t=10^{-5}$ e por isso foi omitida.

\subsubsection{Crank-Nicolson}

O método de Crank-Nicolson possui convergência quadrática, como pode ser visto nas tabelas 2.11 e 2.12. No entanto, para passos temporais grandes, ele produz oscilações espúrias, mostradas na figura 2.3. 


\begin{tabular}{|c|c|c|c|c|c|c|}
\hline \multicolumn{7}{|c|}{ Euler implícito } \\
\hline \multicolumn{7}{|c|}{ Posição } \\
\hline & \multicolumn{3}{|c|}{ erro } & \multicolumn{3}{|c|}{ ordem } \\
\hline$\Delta t$ & $L^{1}$ & $L^{2}$ & $L^{\infty}$ & $L^{1}$ & $L^{2}$ & $L^{\infty}$ \\
\hline $1,00 \cdot 10^{1}$ & $2,07 \cdot 10^{-4}$ & $4,98 \cdot 10^{-4}$ & $2,58 \cdot 10^{-3}$ & & & \\
\hline $1,00 \cdot 10^{0}$ & $1,61 \cdot 10^{-3}$ & $4,13 \cdot 10^{-3}$ & $3,89 \cdot 10^{-2}$ & $-0,89$ & $-0,92$ & $-1,18$ \\
\hline $1,00 \cdot 10^{-1}$ & $1,11 \cdot 10^{-3}$ & $2,51 \cdot 10^{-3}$ & $8,58 \cdot 10^{-2}$ & 0,16 & 0,22 & $-0,34$ \\
\hline $1,00 \cdot 10^{-2}$ & $4,80 \cdot 10^{-4}$ & $9,73 \cdot 10^{-4}$ & $2,74 \cdot 10^{-2}$ & 0,36 & 0,41 & 0,50 \\
\hline $1,00 \cdot 10^{-3}$ & $1,41 \cdot 10^{-4}$ & $2,53 \cdot 10^{-4}$ & $4,48 \cdot 10^{-3}$ & 0,53 & 0,58 & 0,79 \\
\hline $1,00 \cdot 10^{-4}$ & $3,12 \cdot 10^{-5}$ & $5,24 \cdot 10^{-5}$ & $8,31 \cdot 10^{-4}$ & 0,66 & 0,68 & 0,73 \\
\hline $1,00 \cdot 10^{-5}$ & $4,80 \cdot 10^{-6}$ & $8,32 \cdot 10^{-6}$ & $1,41 \cdot 10^{-4}$ & 0,81 & 0,80 & 0,77 \\
\hline
\end{tabular}

Tabela 2.9: Erros e ordem de convergência da posição para o método de Euler implícito.

\begin{tabular}{c|c|c|c|c|c|c}
\hline \multicolumn{7}{c}{ Euler implícito } \\
\hline \multicolumn{7}{c|}{ Velocidade } \\
\hline \multicolumn{1}{c|}{$L^{1}$} & $L^{1}$ & $L^{2}$ & $L^{\infty}$ & \multicolumn{1}{c}{$L^{1}$} & $L^{2}$ & $L^{\infty}$ \\
\hline $1,00 \cdot 10^{1}$ & $1,25 \cdot 10^{-3}$ & $2,65 \cdot 10^{-3}$ & $9,67 \cdot 10^{-3}$ & & & \\
$1,00 \cdot 10^{0}$ & $9,12 \cdot 10^{-3}$ & $2,33 \cdot 10^{-2}$ & $4,69 \cdot 10^{-1}$ & $-0,86$ & $-0,94$ & $-1,69$ \\
$1,00 \cdot 10^{-1}$ & $1,09 \cdot 10^{-2}$ & $2,37 \cdot 10^{-2}$ & $8,78 \cdot 10^{-1}$ & $-0,08$ & $-0,01$ & $-0,27$ \\
$1,00 \cdot 10^{-2}$ & $8,99 \cdot 10^{-3}$ & $1,79 \cdot 10^{-2}$ & $4,69 \cdot 10^{-1}$ & 0,08 & 0,12 & 0,27 \\
$1,00 \cdot 10^{-3}$ & $5,56 \cdot 10^{-3}$ & $1,08 \cdot 10^{-2}$ & $2,51 \cdot 10^{-1}$ & 0,21 & 0,22 & 0,27 \\
$1,00 \cdot 10^{-4}$ & $2,27 \cdot 10^{-3}$ & $4,80 \cdot 10^{-3}$ & $1,14 \cdot 10^{-1}$ & 0,39 & 0,35 & 0,34 \\
$1,00 \cdot 10^{-5}$ & $5,01 \cdot 10^{-4}$ & $1,15 \cdot 10^{-3}$ & $2,55 \cdot 10^{-2}$ & 0,66 & 0,62 & 0,65 \\
\hline
\end{tabular}

Tabela 2.10: Erros e ordem de convergência da velocidade para o método de Euler implícito.

\begin{tabular}{|c|c|c|c|c|c|c|}
\hline \multicolumn{7}{|c|}{ Crank-Nicolson } \\
\hline \multicolumn{7}{|c|}{ Posição } \\
\hline & \multicolumn{3}{|c|}{ erro } & \multicolumn{3}{|c|}{ ordem } \\
\hline$\Delta t$ & $L^{1}$ & $L^{2}$ & $L^{\infty}$ & $L^{1}$ & $L^{2}$ & $L^{\infty}$ \\
\hline $1,00 \cdot 10^{0}$ & $4,34 \cdot 10^{-3}$ & $7,92 \cdot 10^{-3}$ & $6,96 \cdot 10^{-2}$ & & & \\
\hline $1,00 \cdot 10^{-1}$ & $9,65 \cdot 10^{-4}$ & $1,70 \cdot 10^{-3}$ & $6,62 \cdot 10^{-2}$ & 0,65 & 0,67 & 0,02 \\
\hline $1,00 \cdot 10^{-2}$ & $1,42 \cdot 10^{-4}$ & $2,49 \cdot 10^{-4}$ & $4,03 \cdot 10^{-3}$ & 0,83 & 0,83 & 1,22 \\
\hline $5,00 \cdot 10^{-3}$ & $6,82 \cdot 10^{-5}$ & $1,26 \cdot 10^{-4}$ & $2,50 \cdot 10^{-3}$ & 1,06 & 0,98 & 0,69 \\
\hline $1,00 \cdot 10^{-3}$ & $8,77 \cdot 10^{-6}$ & $2,02 \cdot 10^{-5}$ & $4,64 \cdot 10^{-4}$ & 1,27 & 1,14 & 1,05 \\
\hline $5,00 \cdot 10^{-4}$ & $2,58 \cdot 10^{-6}$ & $5,97 \cdot 10^{-6}$ & $1,22 \cdot 10^{-4}$ & 1,77 & 1,76 & 1,92 \\
\hline $1,00 \cdot 10^{-4}$ & $1,05 \cdot 10^{-7}$ & $2,43 \cdot 10^{-7}$ & $4,89 \cdot 10^{-6}$ & 1,99 & 1,99 & 2,00 \\
\hline
\end{tabular}

Tabela 2.11: Erros e ordem de convergência da posição para o método de Crank-Nicolson.

\subsection{Passo temporal adaptativo}

O mesmo caso simulado na seção 2.12 foi usado para testar o método de RungeKutta-Fehlberg 45. O tempo total de simulação foi aumentado para 100. Três tolerâncias, $10^{-4}, 10^{-5}$ e $10^{-6}$ foram usadas. Os resultados podem ser vistos na figura 2.4. Nos três casos, o passo de tempo aumenta à medida que a simulação chega ao estado estacionário. Há um limite superior para o passo temporal, o qual independe da tolerância prescrita. 


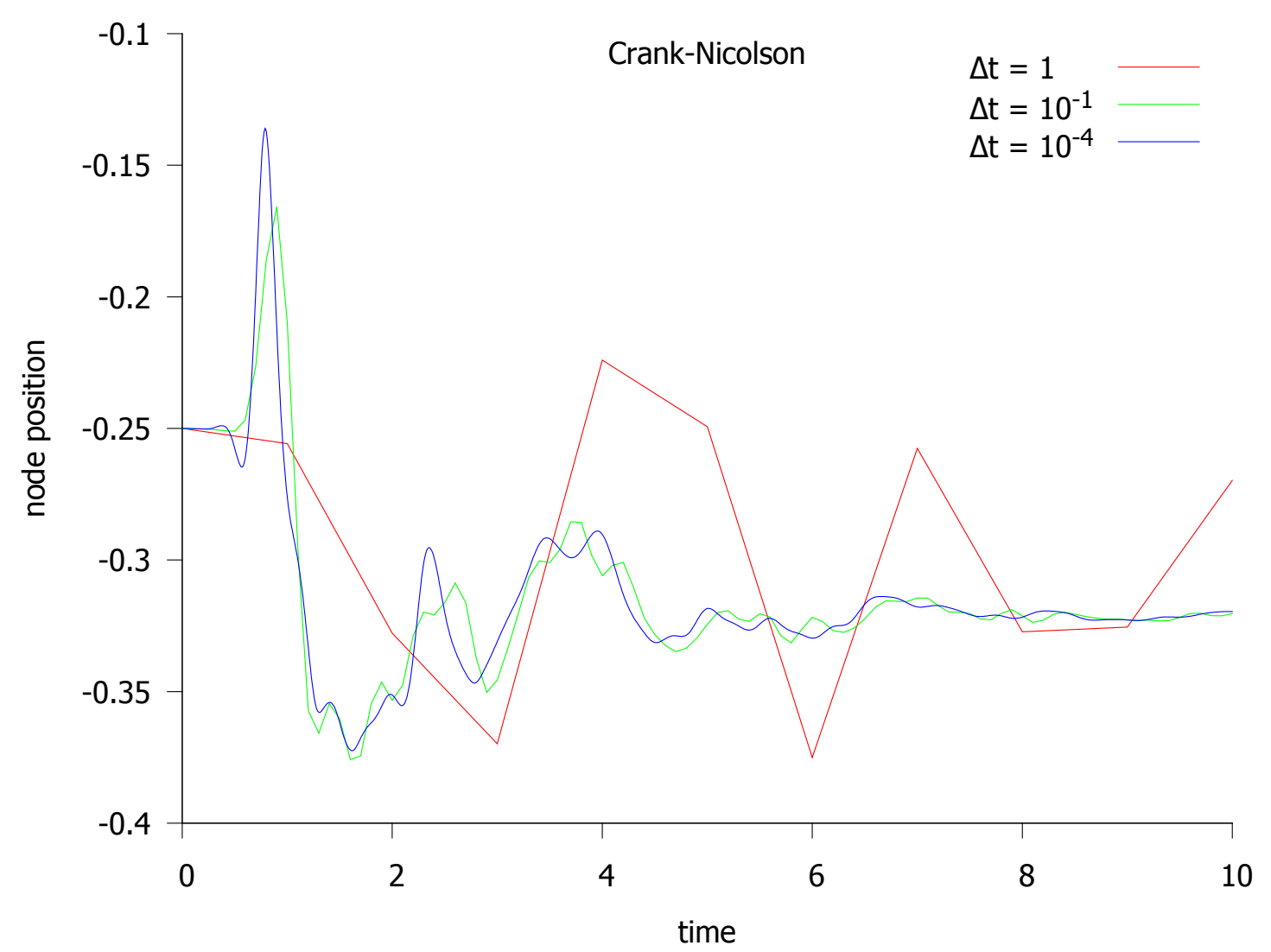

Figura 2.3: Trajetória de um dos pontos da malha para os diversos passos temporais com o método de Crank-Nicolson. A solução de referência coincide com a curva para $\Delta t=10^{-4}$ e por isso foi omitida.

\begin{tabular}{|c|c|c|c|c|c|c|}
\hline \multicolumn{7}{|c|}{ Crank-Nicolson } \\
\hline \multicolumn{7}{|c|}{ Velocidade } \\
\hline & \multicolumn{3}{|c|}{ erro } & \multicolumn{3}{|c|}{ ordem } \\
\hline$\Delta t$ & $L^{1}$ & $L^{2}$ & $L^{\infty}$ & $L^{1}$ & $L^{2}$ & $L^{\infty}$ \\
\hline $1,00 \cdot 10^{0}$ & $5,43 \cdot 10^{-2}$ & $8,09 \cdot 10^{-2}$ & $4,78 \cdot 10^{-1}$ & & & \\
\hline $1,00 \cdot 10^{-1}$ & $3,14 \cdot 10^{-2}$ & $4,73 \cdot 10^{-2}$ & $8,29 \cdot 10^{-1}$ & 0,24 & 0,23 & $-0,24$ \\
\hline $1,00 \cdot 10^{-2}$ & $8,55 \cdot 10^{-3}$ & $1,70 \cdot 10^{-2}$ & $4,27 \cdot 10^{-1}$ & 0,57 & 0,44 & 0,29 \\
\hline $5,00 \cdot 10^{-3}$ & $5,52 \cdot 10^{-3}$ & $1,22 \cdot 10^{-2}$ & $2,72 \cdot 10^{-1}$ & 0,63 & 0,48 & 0,65 \\
\hline $1,00 \cdot 10^{-3}$ & $1,32 \cdot 10^{-3}$ & $3,74 \cdot 10^{-3}$ & $9,08 \cdot 10^{-2}$ & 0,89 & 0,74 & 0,68 \\
\hline $5,00 \cdot 10^{-4}$ & $4,25 \cdot 10^{-4}$ & $1,17 \cdot 10^{-3}$ & $2,48 \cdot 10^{-2}$ & 1,64 & 1,68 & 1,87 \\
\hline $1,00 \cdot 10^{-4}$ & $1,74 \cdot 10^{-5}$ & $4,77 \cdot 10^{-5}$ & $1,02 \cdot 10^{-3}$ & 1,98 & 1,99 & 1,98 \\
\hline
\end{tabular}

Tabela 2.12: Erros e ordem de convergência da velocidade para o método de Crank-Nicolson.

Para simular uma situação onde não há estado estacionário, o arrasto foi removido. Isso faz com que a membrana oscile indefinidamente. O resultado pode ser visto na figura 2.5. O passo temporal varia pouco durante a simulação e o erro fica limitado.

É importante lembrar que o erro mostrado nas figuras 2.4 e 2.5 é a diferença entre os métodos de quarta e quinta ordem, dado pela equação 2.95. O erro em relação ao método de Runge-Kutta de quarta ordem com passo temporal $10^{-6}$ pode ser visto nas tabelas 2.13 , $2.14,2.15$ e 2.16 . 


\begin{tabular}{c|c|c|c|}
\hline \multicolumn{4}{c}{ Runge-Kutta-Fehlberg 45 } \\
\hline & \multicolumn{3}{c}{ Estacionário - Posição } \\
\hline tol & $L^{1}$ & $L^{2}$ & $L^{\infty}$ \\
\hline $1,00 \cdot 10^{-4}$ & $1,07 \cdot 10^{-5}$ & $1,77 \cdot 10^{-5}$ & $3,47 \cdot 10^{-4}$ \\
$1,00 \cdot 10^{-5}$ & $9,88 \cdot 10^{-6}$ & $1,66 \cdot 10^{-5}$ & $3,48 \cdot 10^{-4}$ \\
$1,00 \cdot 10^{-6}$ & $9,86 \cdot 10^{-6}$ & $1,66 \cdot 10^{-5}$ & $3,48 \cdot 10^{-4}$ \\
\hline
\end{tabular}

Tabela 2.13: Erros da posição para o método de Runge-Kutta-Fehlberg 45, caso estacionário.

\begin{tabular}{c|c|c|c}
\hline \multicolumn{4}{c}{ Runge-Kutta-Fehlberg 45 } \\
\hline \multicolumn{3}{c}{ Estacionário - Velocidade } \\
\hline & \multicolumn{3}{c}{ erro } \\
\hline tol & $L^{1}$ & $L^{2}$ & $L^{\infty}$ \\
\hline $1,00 \cdot 10^{-4}$ & $6,90 \cdot 10^{-4}$ & $1,68 \cdot 10^{-3}$ & $4,16 \cdot 10^{-2}$ \\
$1,00 \cdot 10^{-5}$ & $4,36 \cdot 10^{-4}$ & $7,56 \cdot 10^{-4}$ & $1,23 \cdot 10^{-2}$ \\
$1,00 \cdot 10^{-6}$ & $4,28 \cdot 10^{-4}$ & $7,49 \cdot 10^{-4}$ & $1,23 \cdot 10^{-2}$ \\
\hline
\end{tabular}

Tabela 2.14: Erros da velocidade para o método de Runge-Kutta-Fehlberg 45, caso estacionário.

\begin{tabular}{c|c|c|c}
\hline \multicolumn{4}{c}{ Runge-Kutta-Fehlberg 45 } \\
\hline \multicolumn{3}{c}{ Transiente - Posição } \\
\hline & \multicolumn{3}{c}{ erro } \\
\hline tol & $L^{1}$ & $L^{2}$ & $L^{\infty}$ \\
\hline $1,00 \cdot 10^{-4}$ & $1,38 \cdot 10^{-4}$ & $2,20 \cdot 10^{-4}$ & $2,95 \cdot 10^{-3}$ \\
$1,00 \cdot 10^{-5}$ & $1,38 \cdot 10^{-4}$ & $2,20 \cdot 10^{-4}$ & $2,94 \cdot 10^{-3}$ \\
$1,00 \cdot 10^{-6}$ & $1,38 \cdot 10^{-4}$ & $2,20 \cdot 10^{-4}$ & $2,94 \cdot 10^{-3}$ \\
\hline
\end{tabular}

Tabela 2.15: Erros da posição para o método de Runge-Kutta-Fehlberg 45, caso transiente.

\begin{tabular}{c|c|c|c|}
\hline \multicolumn{4}{c}{ Runge-Kutta-Fehlberg 45 } \\
\hline \multicolumn{4}{c}{ Transiente - Velocidade } \\
\hline tol & $L^{1}$ & $L^{2}$ & $L^{\infty}$ \\
\hline $1,00 \cdot 10^{-4}$ & $6,41 \cdot 10^{-3}$ & $1,09 \cdot 10^{-2}$ & $1,55 \cdot 10^{-1}$ \\
$1,00 \cdot 10^{-5}$ & $6,33 \cdot 10^{-3}$ & $1,06 \cdot 10^{-2}$ & $1,49 \cdot 10^{-1}$ \\
$1,00 \cdot 10^{-6}$ & $6,33 \cdot 10^{-3}$ & $1,06 \cdot 10^{-2}$ & $1,49 \cdot 10^{-1}$ \\
\hline
\end{tabular}

Tabela 2.16: Erros da velocidade para o método de Runge-Kutta-Fehlberg 45, caso transiente.

\subsection{Resultados}

\subsubsection{Instabilidade de Plateau-Rayleigh}

Uma coluna de líquido se parte em gotas devido à ação da tensão superficial. Isso foi observado por Félix Savart (Savart, 1833) e Joseph Plateau (Plateau, 1873) e demonstrado por Lord Rayleigh (Rayleigh, 1878).

A tensão superficial busca uma forma com a menor área possível, o que torna a forma esférica a de menor energia. Por isso, uma membrana fluida cilíndrica é instável e se parte em gotas, como pode ser visto na figura 2.6. Nessa simulação, o volume englobado pela 
membrana é mantido constante. Além disso, atuam sobre a membrana a tensão superficial e arrasto. Do tempo $t=0$ até $t=7,5$, a membrana é estrangulada em pontos específicos visando induzir a transição.

\subsubsection{Termo de estabilização}

A figura 2.7 mostra a influência do termo de estabilização, equação 2.122, no comportamento da tensão superficial quando o vínculo de conservação local de área é usado. Nota-se que sem a estabilização $\left(c_{\tau}=0\right)$ há oscilações espúrias de alta frequência. Os valores se alternam com a resolução da malha. $O$ aumento do fator $c_{\tau}$ suaviza a tensão superficial. Para valores muito altos de $c_{\tau}$, a tensão superficial é praticamente constante.

É de se esperar que a tensão superficial fique constante no estado estacionário para este problema. Além da tensão superficial (seção 2.11.3), há pressão (seção 2.11.1), energia de Canham-Helfrich (seção 5.1), força viscosa superficial (seção 6.1) e arrasto de Stokes (seção 2.7) sobre a membrana. A pressão e a energia de Canham-Helfrich atuam apenas na direção normal. A força viscosa e o arrasto são nulos no estado estacionário. Portanto, para que haja equilíbrio de forças na direção tangencial, não deve haver gradiente na tensão superficial.

\subsubsection{Parametrização de malhas}

Várias aplicações em geração de malhas requerem que se construa uma parametrização em $\mathbb{R}^{2}$ de uma malha superficial imersa em três dimensões. Uma técnica bastante popular consiste em tratar a malha como uma membrana elástica (Floater, 1997). A cada aresta é associada uma mola elástica, cujo comprimento de referência é zero. A borda da malha é fixada nos extremos do domínio da parametrização desejada. O sistema de molas tende a evoluir para um estado estacionário, e esse estado é uma possível parametrização da malha.

Cada escolha das constantes elásticas das molas produz uma parametrização diferente. Em geral, a equação do estado estacionário é resolvida diretamente. Mas aqui, uma simulação transiente é feita com o intuito de verificar o código implementado. Todas as constantes das molas são iguais, o que corresponde à parametrização uniforme. Uma força de arrasto foi adicionada para dissipar a energia elástica.

A figura 2.8 mostra o estado inicial, ou seja, a malha tridimensional que se deseja parametrizar, e o estado final, a parametrização. A figura 2.9 mostra alguns quadros da simulação feita. 

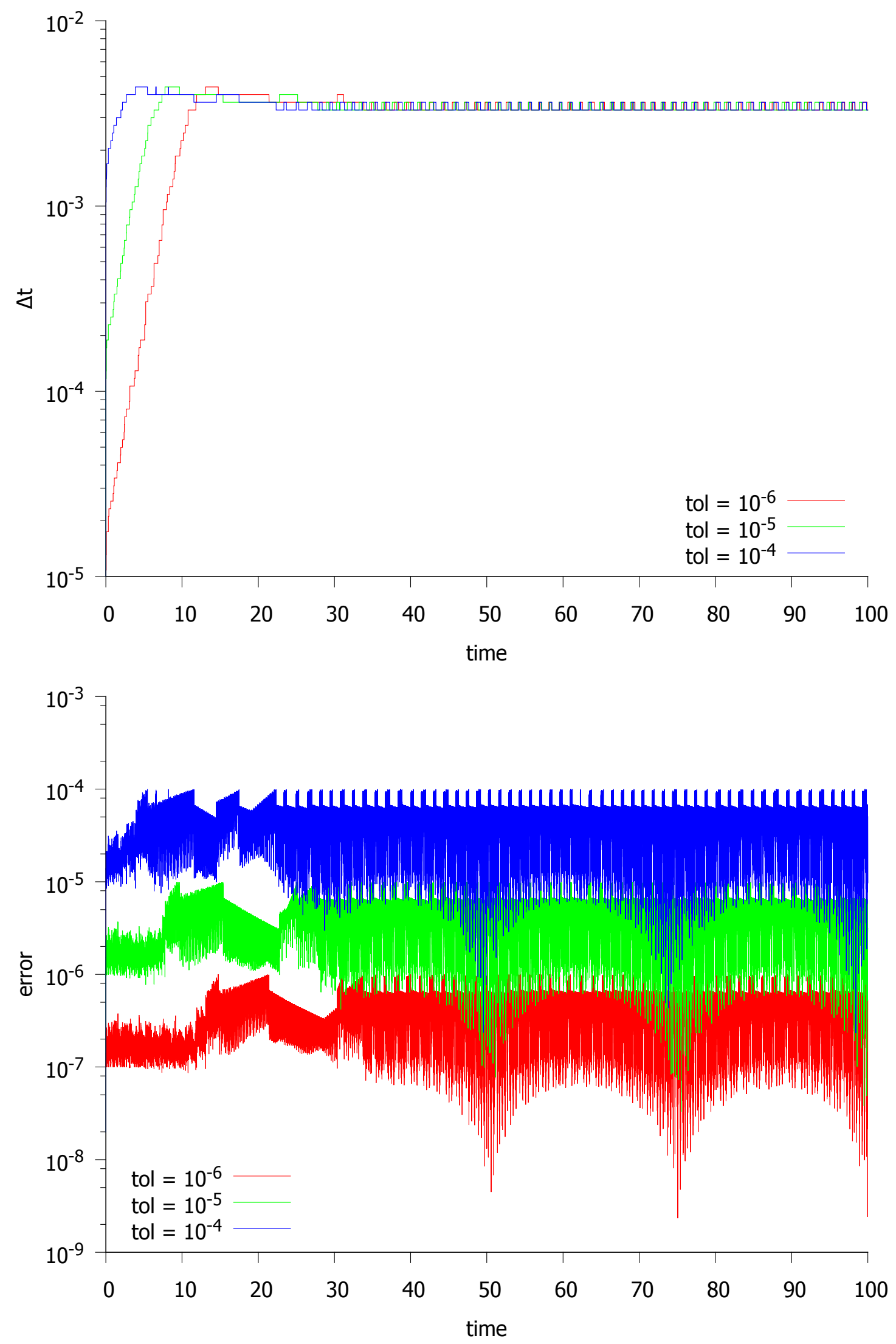

Figura 2.4: Passo temporal e erro do método de Runge-Kutta-Fehlberg 45, caso estacionário. O passo temporal aumenta à medida que a simulação se aproxima do estado estacionário. 

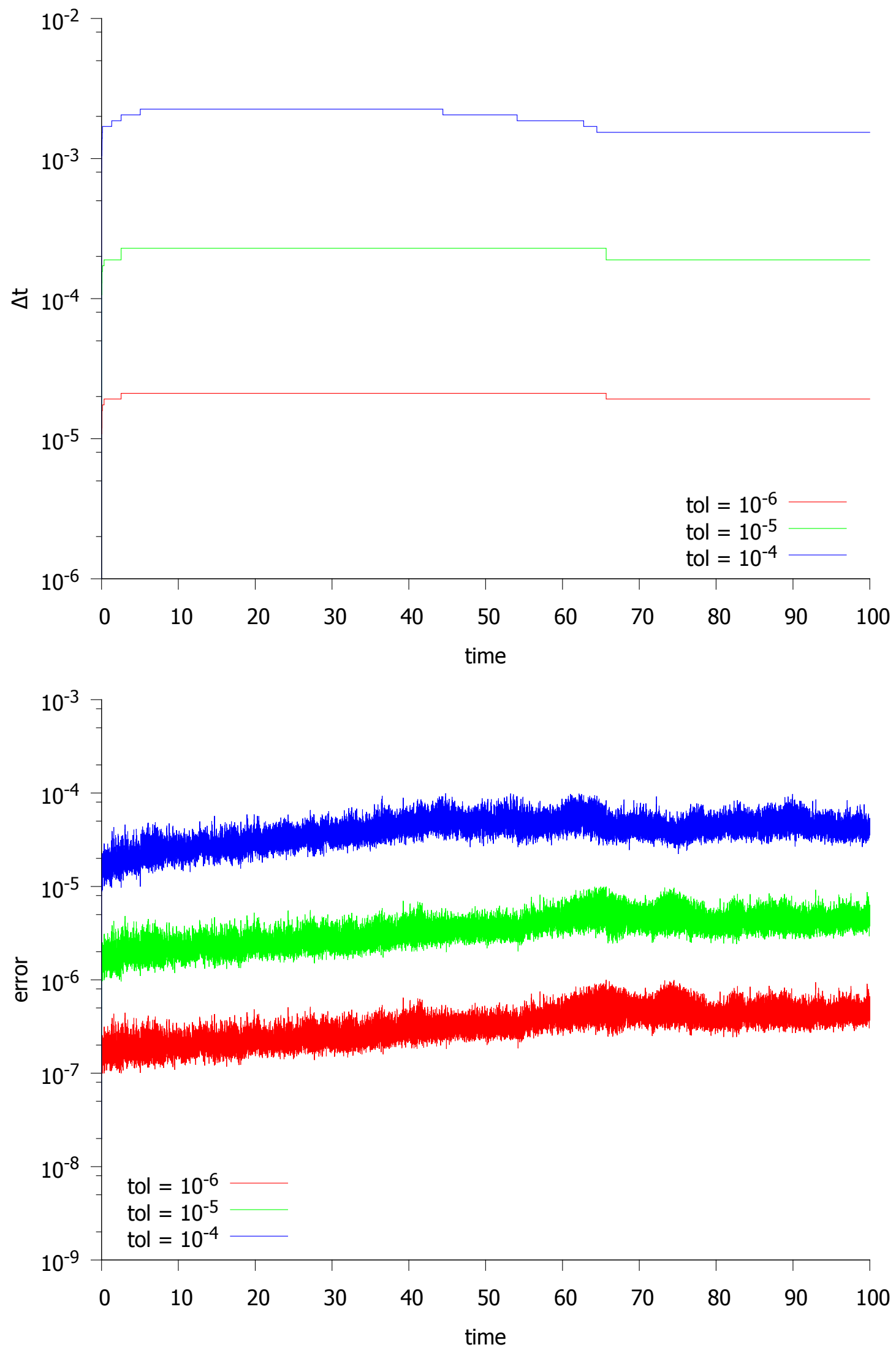

Figura 2.5: Passo temporal e erro do método de Runge-Kutta-Fehlberg 45, caso transiente. Neste caso não há estado estacionário, então o passo temporal varia pouco. 


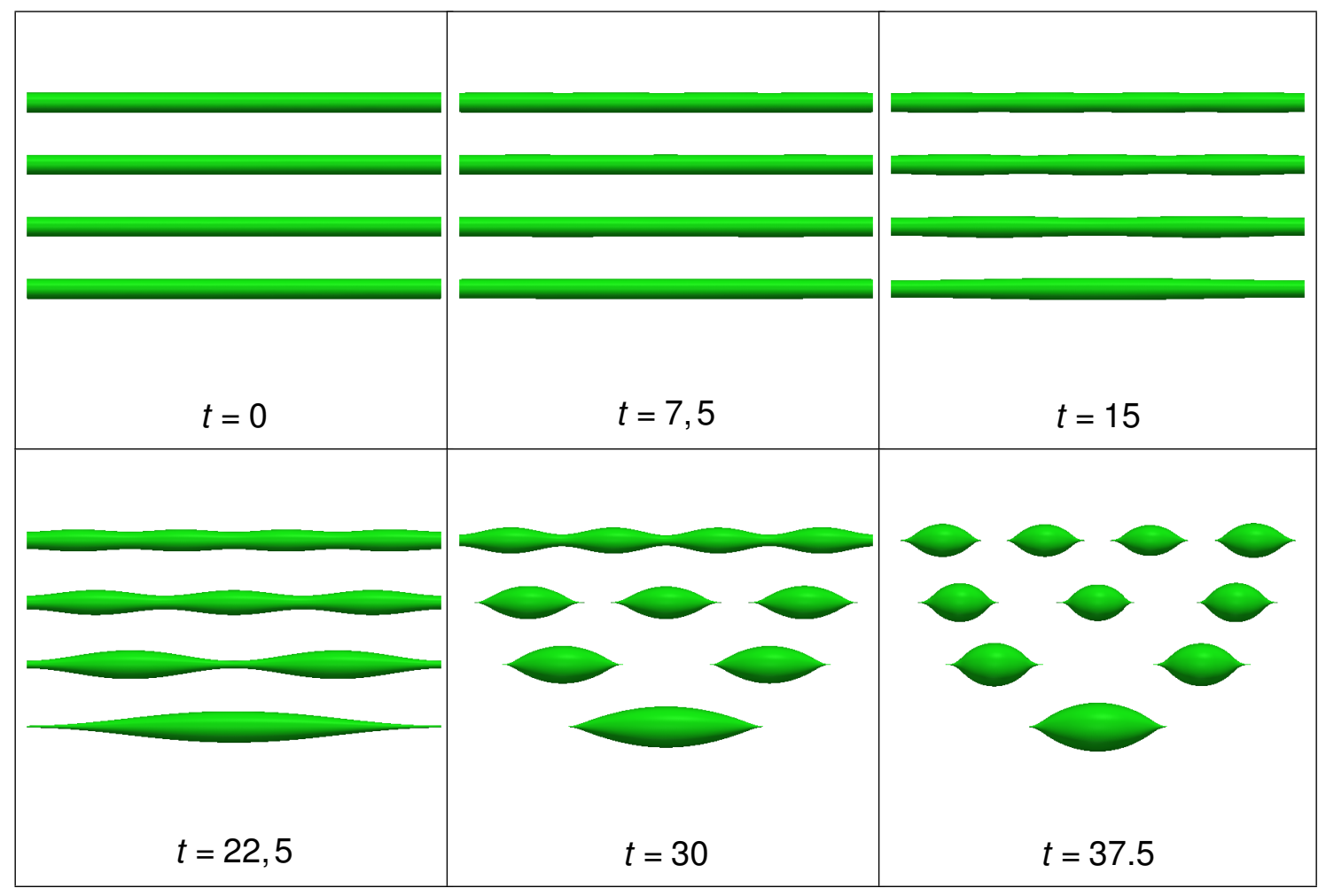

Figura 2.6: Instabilidade de Plateau-Rayleigh. Uma membrana fluida cilíndrica é instável quando sob ação da tensão superficial. Na simulação acima, uma força estrangula o cilindro em pontos específicos desde o tempo $t=0$ até $t=7,5$, o que induz a transição. 


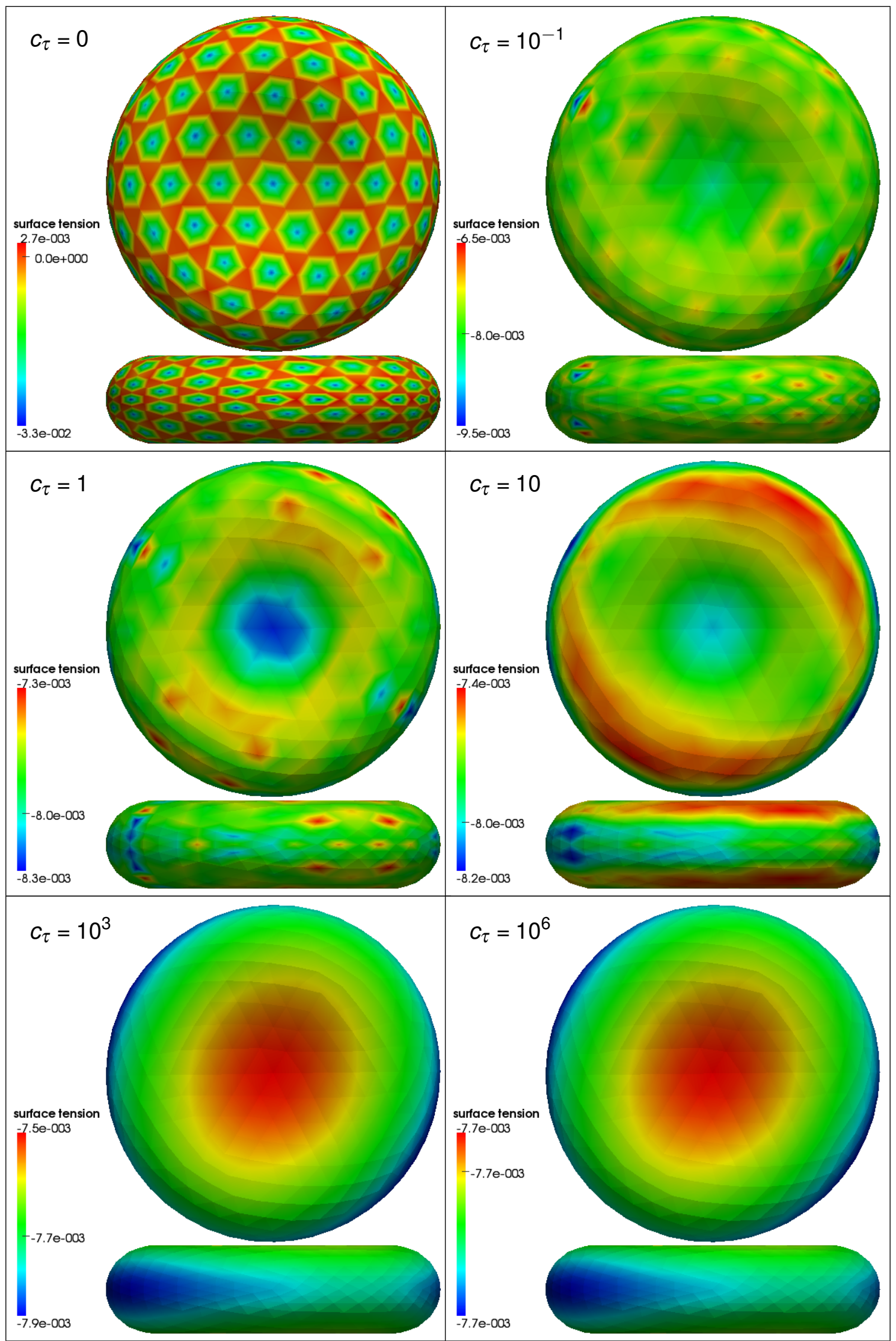

Figura 2.7: Influência do termo de estabilização, equação 2.122, no comportamento da tensão superficial para o vínculo de conservação local de área. Sem a estabilização $\left(c_{\tau}=0\right)$, a tensão superficial apresenta um comportamento oscilatório de alta frequência. Quando maior o peso do termo de estabilização, mais suave se torna a tensão superficial. Com $c_{\tau}=10^{6}$, a tensão superficial é praticamente constante sobre a membrana, como é esperado para o estado estacionário. 


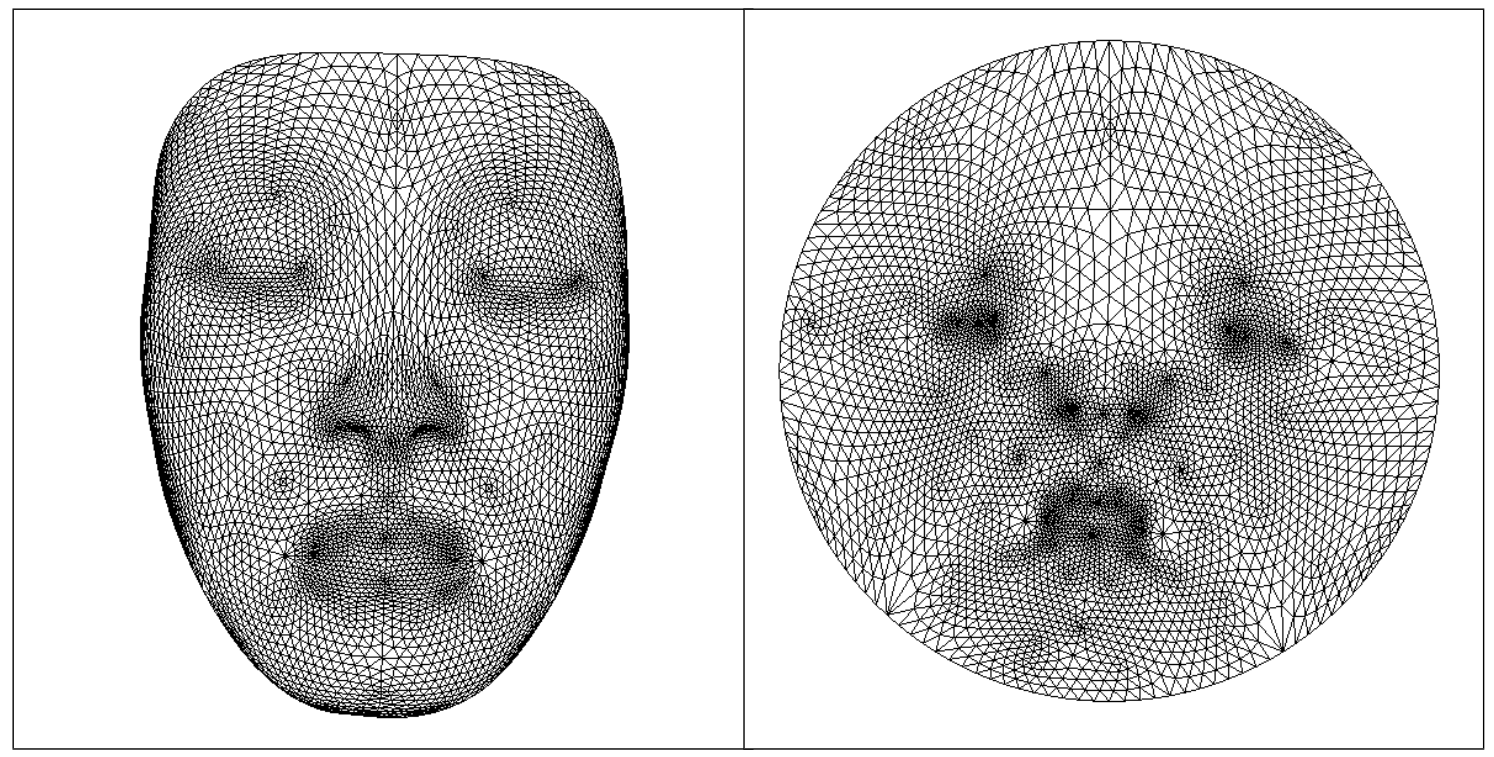

Figura 2.8: Parametrização uniforme. À esquerda, a malha tridimensional e a direita a sua parametrização bidimensional. 


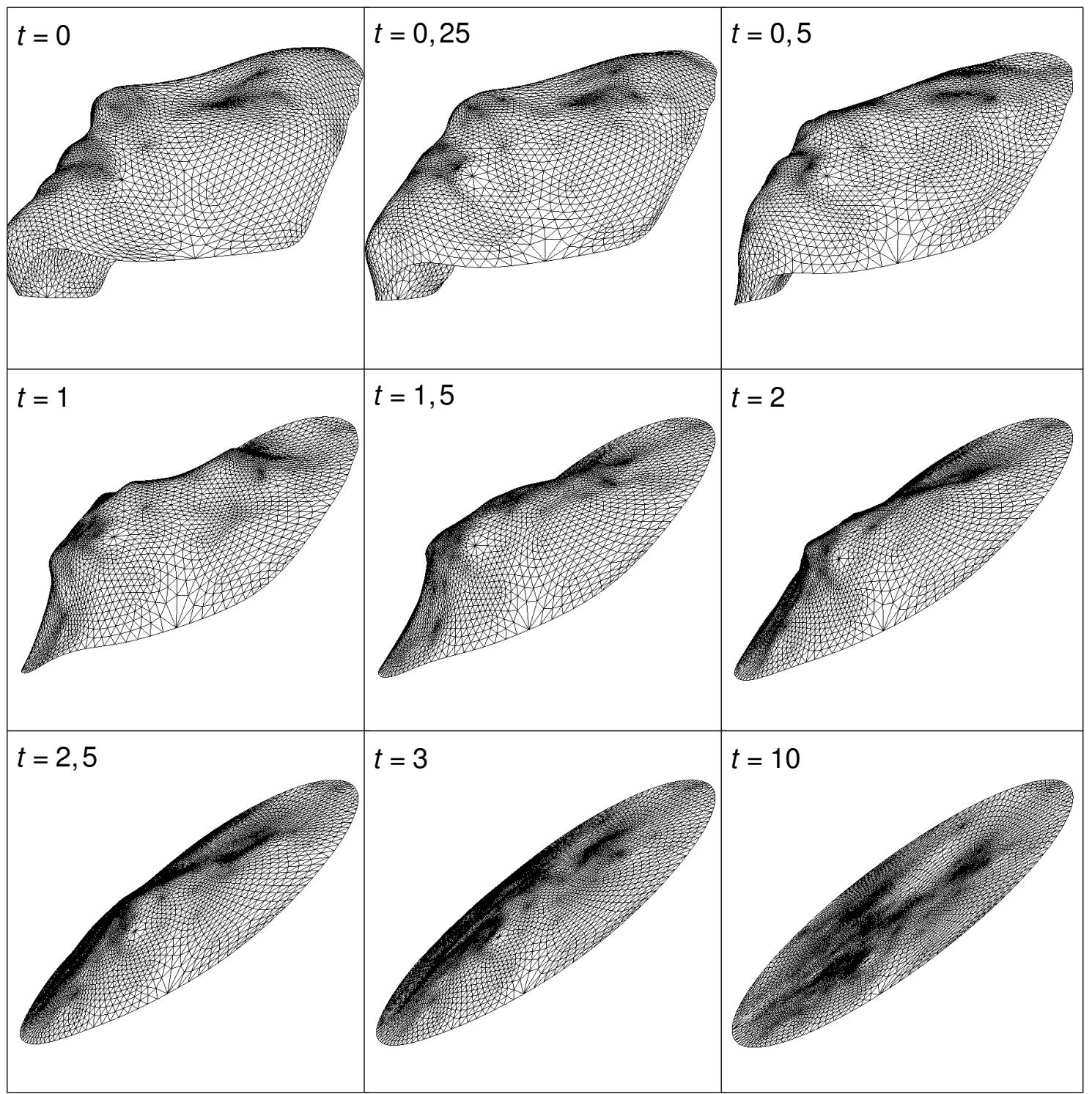

Figura 2.9: Evolução temporal. Se cada aresta da malha for associada a uma mola elástica, o estado de equilíbrio corresponde a uma possível parametrização da malha. O tempo de simulação está indicado em cada quadro. 
Mathematicians may flatter themselves that they possess new ideas which mere human language is as yet unable to express.

James Clerk Maxwell

\section{3 \\ Forças eletromagnéticas}

Uma membrana que possua um excesso, ou falta, de cargas elétricas distribuídas em sua superfície está eletrizada. Nesses casos, é importante considerar o efeito de forças eletromagnéticas. Usando o conceito de expansão multipolar, essa distribuição de cargas pode ser aproximada por um conjunto de cargas e dipolos pontuais situados nas partículas, i.e., nos nós da malha. Dipolos magnéticos também podem ser associados às partículas caso a membrana esteja magnetizada.

\subsection{Rotações}

Em alguns casos, como na interação entre dipolos elétricos e magnéticos, é necessário associar às partículas características rotacionais, como orientação, velocidade angular e momento de inércia. As leis da mecânica clássica para rotações são análogas àquelas aplicadas a translações. Existe uma correspondência direta entre grandezas translacionais e rotacionais:

\begin{tabular}{c|c}
\hline translação & rotação \\
\hline posição $\mathbf{x}$ & orientação $\mathbf{q}$ \\
velocidade $\mathbf{v}$ & velocidade angular $\omega$ \\
momento linear $\mathbf{p}$ & momento angular $\mathbf{L}$ \\
força $\mathbf{F}$ & torque $\tau$ \\
massa $m$ & momento de inércia $/$ \\
\hline
\end{tabular}

\subsubsection{Quatérnions}

Em geral, para representar a orientação de uma partícula em simulações numéricas, quatérnions são usados, por questões de eficiência e estabilidade. Quatérnions são uma extensão dos números complexos. Um quatérnion q possui uma parte real, $a$, e três partes imaginárias, $b, c$ e $d$ :

$$
\mathbf{q}=a+b \mathbf{i}+c \mathbf{j}+d \mathbf{k}
$$

onde i, j e k são as unidades imaginárias. 
A soma e subtração de quatérnions são feitas componente a componente:

$$
(a+b \mathbf{i}+c \mathbf{j}+d \mathbf{k}) \pm(e+f \mathbf{i}+g \mathbf{j}+h \mathbf{k})=(a \pm e)+(b \pm f) \mathbf{i}+(c \pm g) \mathbf{j}+(d \pm h) \mathbf{k}
$$

O produto entre as unidades imaginárias segue a regra

$$
\mathbf{i}^{2}=\mathbf{j}^{2}=\mathbf{k}^{2}=\mathbf{i j k}=-1,
$$

a qual, junto com a propriedade distributiva da multiplicação, leva ao produto entre quatérnions:

$$
\begin{aligned}
(a+b \mathbf{i}+c \mathbf{j}+d \mathbf{k})(e+f \mathbf{i}+g \mathbf{j}+h \mathbf{k})= & (a e-b f-c g-d h)+ \\
& (a f+b e+c h-d g) \mathbf{i}+ \\
& (a g+c e+d f-b h) \mathbf{j}+ \\
& (a h+d e+b g-c f) \mathbf{k} .
\end{aligned}
$$

A soma e produto de quatérnions com escalares é feita considerando-se o escalar como um quatérnion de parte imaginária nula. Para vetores, considera-se a parte real nula e cada componente do vetor como uma componente imaginária do quatérnion.

O conjugado complexo de um quatérnion é

$$
\mathbf{q}^{*}=a-b \mathbf{i}-c \mathbf{j}-d \mathbf{k} \text {. }
$$

A norma é dada por

$$
|\mathbf{q}|=\sqrt{\mathbf{q} \mathbf{q}^{*}}=\sqrt{\mathbf{q}^{*} \mathbf{q}}=\sqrt{a^{2}+b^{2}+c^{2}+d^{2}}
$$

e o inverso é

$$
\mathbf{q}^{-1}=\frac{\mathbf{q}^{*}}{\mid \mathbf{q}^{2}}
$$

\subsubsection{Quatérnions e rotações}

Quatérnions podem ser usados para representar rotações. Seja û um vetor unitário. A rotação de um ângulo $\alpha$ em torno de û é dada pelo quatérnion

$$
\begin{aligned}
\mathbf{q} & =\cos (\alpha / 2)+\hat{\mathbf{u}} \sin (\alpha / 2) \\
& =\cos (\alpha / 2)+u_{x} \sin (\alpha / 2) \mathbf{i}+u_{y} \sin (\alpha / 2) \mathbf{j}+u_{z} \sin (\alpha / 2) \mathbf{k} .
\end{aligned}
$$

A rotação de um vetor $\mathbf{v}$ usando um quatérnion é feita por meio do produto de

Hamilton

$$
\mathbf{v}^{\prime}=\mathbf{q v q}^{*}
$$

onde $\mathbf{v}^{\prime}$ é o vetor após a rotação.

É importante notar que o quatérnion que representa a rotação é unitário, ou seja, tem módulo igual a um. Portanto, apesar de ter quatro componentes, ele possui apenas três graus de liberdade.

\subsubsection{Equações governantes para rotações}

A velocidade angular $\omega_{i}$ é a taxa de variação temporal da orientação da partícula $i$, representada pelo quatérnion de rotação $\mathbf{q}_{i}$. Ela obedece à equação

$$
\frac{\mathrm{d}}{\mathrm{d} t} \mathbf{q}_{i}=\frac{1}{2} \omega_{i} \mathbf{q}_{i}
$$


O momento angular $\mathbf{L}_{i}=l_{i} \omega_{i}$ segue a segunda lei de Newton para rotações

$$
\tau_{i}=\frac{\mathrm{d} \mathbf{L}_{i}}{\mathrm{~d} t}=\frac{\mathrm{d}\left(l_{i} \omega_{i}\right)}{\mathrm{d} t}
$$

onde $\tau_{i}$ é o torque aplicado à partícula $i$ e $l_{i}$ o momento de inércia.

No caso mais geral, o momento de inércia é dado por um tensor simétrico, visto que um objeto de formato arbitrário pode responder de forma distinta a torques em diferentes direções. Para uma esfera, devido à sua simetria, o momento de inércia é igual para qualquer direção, e pode ser representado por um escalar. Admite-se, então, que as partículas têm simetria esférica.

Finalmente, com a inclusão das equações de rotação, a evolução temporal do vetor de estados, que antes era dada pela equação 2.5, passará a ser

$$
\frac{\mathrm{d}}{\mathrm{d} t} \mathbf{Y}_{i}=\frac{\mathrm{d}}{\mathrm{d} t}\left(\begin{array}{c}
\mathbf{x}_{i} \\
\mathbf{v}_{i} \\
\mathbf{q}_{i} \\
\omega_{i}
\end{array}\right)=\left(\begin{array}{c}
\mathbf{v}_{i} \\
\frac{1}{m_{i}} \mathbf{F}_{i}(\mathbf{Y}, t) \\
\frac{1}{2} \omega_{i} \mathbf{q}_{i} \\
\frac{1}{l_{i}} \tau_{i}(\mathbf{Y}, t)
\end{array}\right)=\mathscr{F}_{i}(\mathbf{Y}, t) .
$$

\subsection{Campo elétrico e campo magnético}

Se a partícula $i$ possuir uma carga elétrica $q_{i}$, ela receberá uma força elétrica

$$
\mathbf{F}_{i}=q_{i} \mathbf{E}\left(\mathbf{x}_{i}\right),
$$

onde $\mathbf{E}$ é o campo elétrico e $\mathbf{x}_{i}$ é a posição atual da partícula.

Em um campo magnético $\mathbf{B}$, a partícula está sujeita à força

$$
\mathbf{F}_{i}=q_{i} \mathbf{v}_{i} \times \mathbf{B}\left(\mathbf{x}_{i}\right),
$$

onde $\mathbf{v}_{i}$ é a velocidade da partícula.

\subsection{Lei de Coulomb}

Uma carga $q_{i}$ produz o campo elétrico

$$
\mathbf{E}_{i}(\mathbf{x})=\frac{q_{i}}{4 \pi \varepsilon} \frac{\mathbf{x}-\mathbf{x}_{i}}{\left|\mathbf{x}-\mathbf{x}_{i}\right|^{3}}
$$

onde $\varepsilon$ é a permissividade elétrica do meio.

\subsection{Dipolos}

Ao contrário da carga elétrica, que é uma grandeza escalar, o momento de dipolo elétrico é um vetor. Duas cargas elétricas próximas, com cargas $+q$ e $-q$, produzem 0 momento de dipolo

$$
\mathbf{p}=q \mathbf{d}
$$

onde d é o vetor que aponta da carga negativa para a positiva. O dipolo pontual é uma idealização onde a carga é infinita mas a separação é infinitesimal, produzindo um momento 
finito. Os campos elétricos, vindos da lei de Coulomb, produzidos pelas cargas se cancelam, e o dipolo $p_{i}$ associado à partícula $i$ gera o campo elétrico

$$
\mathbf{E}_{i}(\mathbf{x})=\frac{1}{4 \pi \varepsilon}\left[\frac{3\left[\mathbf{p}_{i} \cdot\left(\mathbf{x}-\mathbf{x}_{i}\right)\right]\left(\mathbf{x}-\mathbf{x}_{i}\right)}{\left|\mathbf{x}-\mathbf{x}_{i}\right|^{5}}-\frac{\mathbf{p}_{i}}{\left|\mathbf{x}-\mathbf{x}_{i}\right|^{3}}\right]
$$

O análogo magnético é o dipolo magnético pontual, que possui momento magnético $\mathbf{m}$. O campo magnético produzido tem uma expressão similar

$$
\mathbf{B}_{i}(\mathbf{x})=\frac{\mu}{4 \pi}\left[\frac{3\left[\mathbf{m}_{i} \cdot\left(\mathbf{x}-\mathbf{x}_{i}\right)\right]\left(\mathbf{x}-\mathbf{x}_{i}\right)}{\left|\mathbf{x}-\mathbf{x}_{i}\right|^{5}}-\frac{\mathbf{m}_{i}}{\left|\mathbf{x}-\mathbf{x}_{i}\right|^{3}}\right]
$$

onde $\mu$ é a permeabilidade magnética do meio.

Se a partícula $i$, com um momento de dipolo $\mathbf{p}_{i}$, estiver imersa em um campo elétrico E, ela estará sujeita a um torque

$$
\tau_{i}=\mathbf{p}_{i} \times \mathbf{E}\left(\mathbf{x}_{i}\right),
$$

onde $\mathbf{x}_{i}$ é a posição da partícula. Analogamente, para um momento de dipolo magnético $\mathbf{m}_{i}$ e um campo magnético $\mathbf{B}$, o torque será

$$
\tau_{i}=\mathbf{m}_{i} \times \mathbf{B}\left(\mathbf{x}_{i}\right)
$$

\subsection{Resultados}

\subsubsection{Dipolos}

Para testar o comportamento dos dipolos elétricos, uma malha plana retangular com $30 \times 30$ nós foi usada. Os dipolos, que estão nos nós da malha, podem interagir entre si, produzindo torque uns nos outros. Os dipolos giram e finalmente atingem um estado estacionário, pois há um arrasto rotacional que dissipa energia. Esse arrasto é o análogo rotacional do arrasto de Stokes, discutido na seção 2.7 .

A figura 3.1 mostra o caso onde a malha tem dimensões $1 \times 0,25$. Cada quadro representa um tempo da simulação. A parte de cima do quadro mostra uma visão na direção normal ao plano. A parte de baixo mostra uma visão tangencial. Nota-se que a maioria dos dipolos se alinha com os vizinhos mais próximos, pois essa é uma situação de equilíbrio estável, formando linhas verticais. Há também alguns casos de inversão no alinhamento, onde parte dos dipolos está alinhada para cima e a outra para baixo em uma mesma linha. Esse equilíbrio é, no entanto, instável.

A figura 3.2 mostra o caso de uma malha quadrada. Como os dipolos estão equidistantes dos vizinhos nas duas direções, não há alinhamento, pois não há direção preferencial.

Na figura 3.3, um campo elétrico externo é aplicado entre os tempos $t=200 \mathrm{e}$ $t=300$. Os dipolos se alinham ao campo, como esperado. No entanto, quando o campo é desligado, o alinhamento se perde. Essa perda de alinhamento pode ser causada por efeitos de borda.

Nas figuras 3.4 e 3.5, os dipolos são dispostos em uma membrana fechada que muda de forma. Os dipolos interagem entre si ao mesmo tempo em que se movem junto com a membrana. Na figura 3.5, um campo elétrico externo é aplicado entre os tempos $t=2 \mathrm{e}$ $t=3$. Em ambos os casos, os dipolos tendem a se alinhar com os vizinhos mais próximos. 


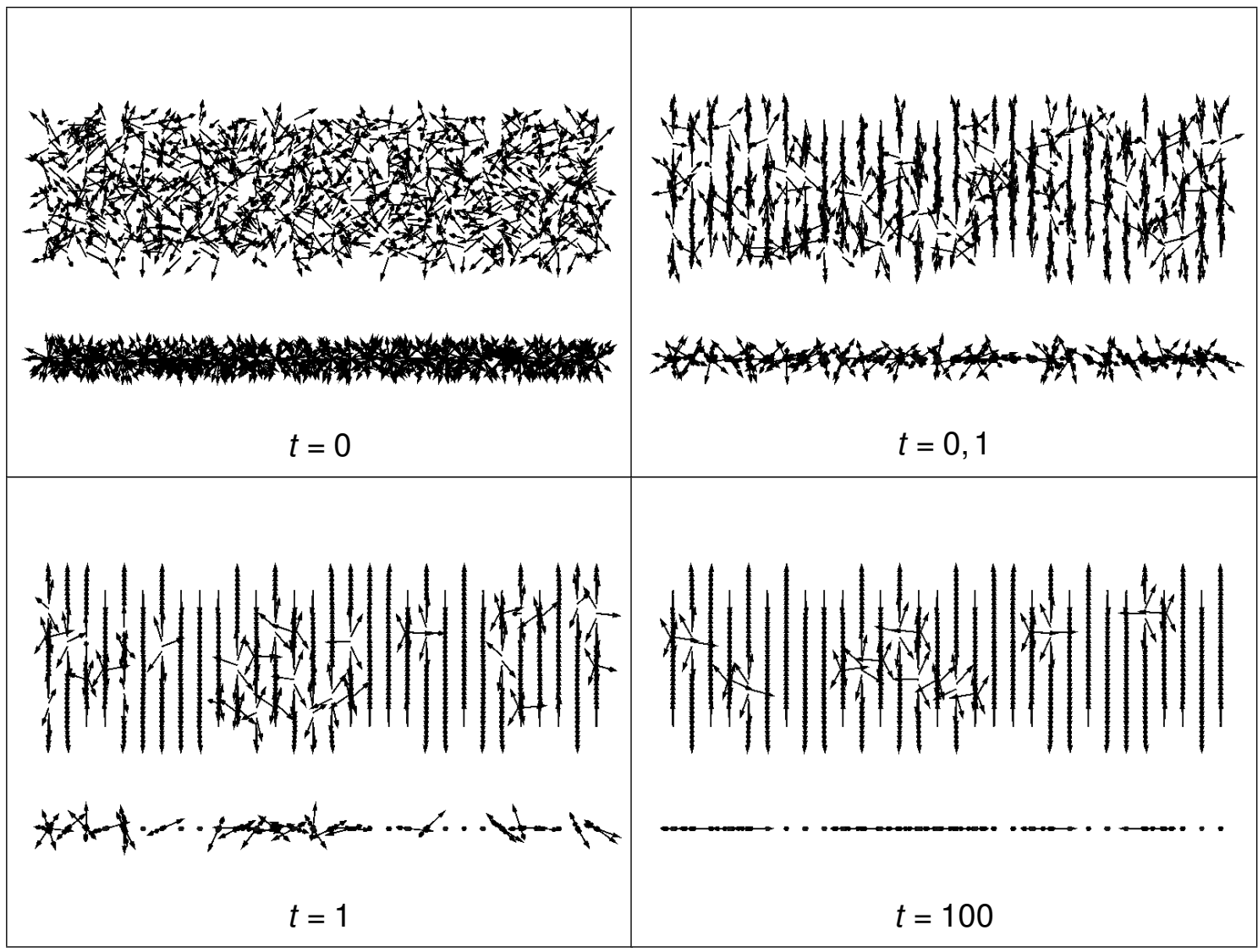

Figura 3.1: Interação entre dipolos dispostos em uma malha plana retangular. Os dipolos interagem entre si, produzindo torque uns nos outros, até que um estado estacionário é atingido. Cada quadro representa um tempo da simulação. Em cada quadro, na parte de cima, tem-se uma visão normal ao plano e, na parte de baixo, a visão é tangente. Os dipolos tendem a se alinhar com os vizinhos mais próximos, pois essa é uma situação de equilíbrio estável. Há casos de inversões (instáveis) nesse alinhamento.

\subsubsection{Acoplamento}

Nos exemplos anteriores, a forma da membrana influenciava o comportamento dos dipolos, pois os dipolos estão fixos nos nós da malha e se movem com ela. No entanto, os dipolos não afetavam a forma da membrana. Uma maneira de gerar um acoplamento entre a orientação dos dipolos e a forma da membrana é usar uma energia do tipo

$$
E=\alpha|\mathbf{d} \times \mathbf{n}|
$$

onde $\mathbf{d}$ é a orientação do dipolo e $\mathbf{n}$ é a normal da superfície no ponto onde está localizado o dipolo. Ambos os vetores são normalizados. A constante $\alpha$ regula a intensidade do acoplamento. O princípio do trabalho virtual, seção 2.3, é utilizado para calcular as forças que atuam sobre a membrana a partir dessa energia. O comportamento esperado é que a superfície da membrana fique perpendicular aos dipolos. Nessa configuração, as normais e os dipolos estariam paralelos, produzindo um estado de baixa energia.

A figura 3.6 mostra uma simulação envolvendo esse tipo de acoplamento. A membrana é elástica e possui rigidez de dobramento (energia de Canham-Helfrich), mas não há restrição de área ou volume. No início, os dipolos estão orientados aleatoriamente. A membrana muda de forma brevemente enquanto os dipolos se acomodam. No tempo $t=2000$, um campo elétrico constante é ligado, o que faz com que os dipolos se orientem na mesma direção. O acoplamento deforma a membrana, que adquire uma configuração 


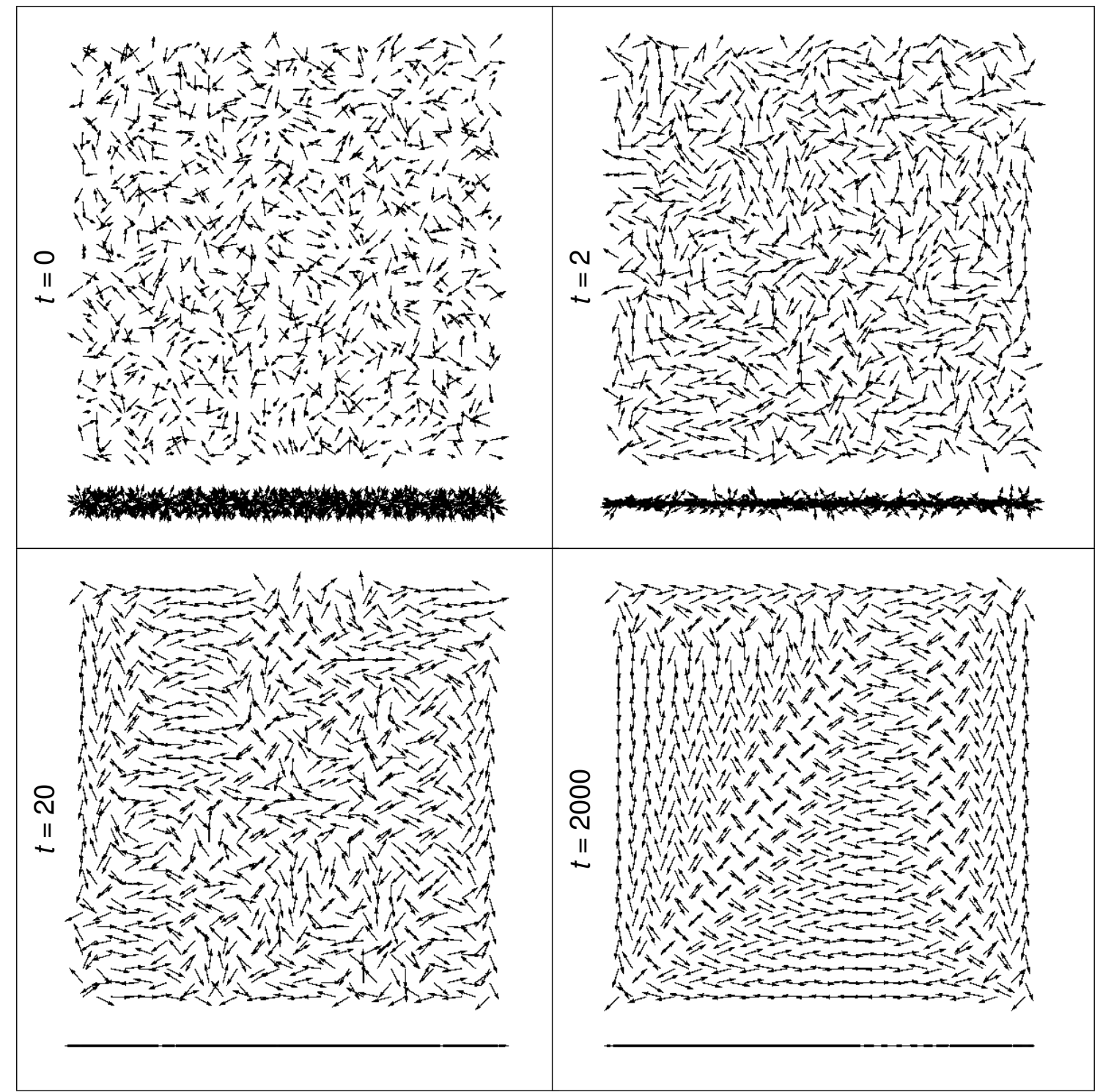

Figura 3.2: Quando dispostos em uma malha quadrada, não há alinhamento, pois não há direção preferencial. Os dipolos estão equidistantes de seus vizinhos nas duas direções.

achatada. No tempo $t=4000$ o campo é desligado. A membrana passa por várias formas transientes até chegar a um estado de equilíbrio. 


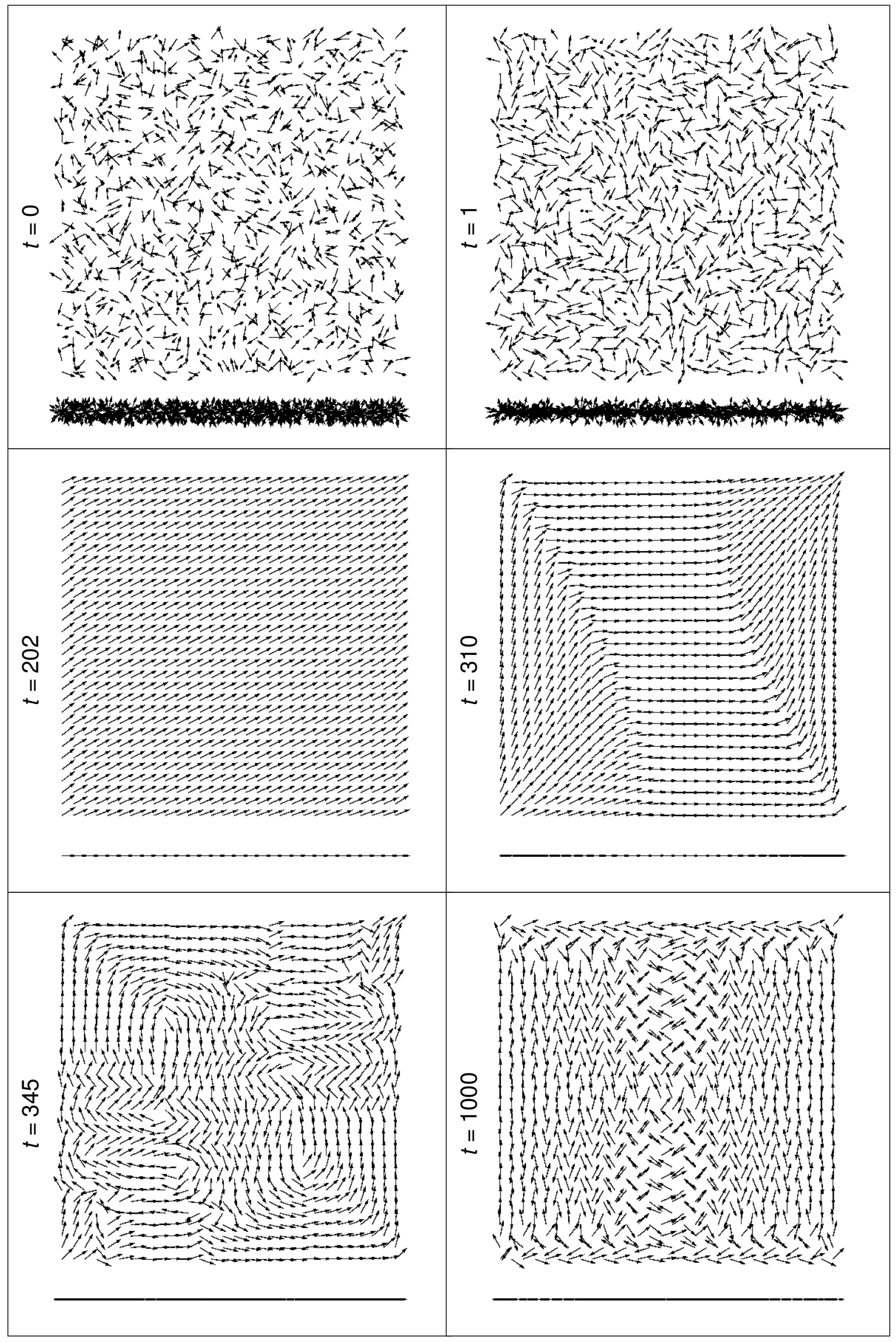

Figura 3.3: Na presença de um campo elétrico externo, os dipolos se alinham na direção do campo. Esse alinhamento se perde quando o campo desaparece. 


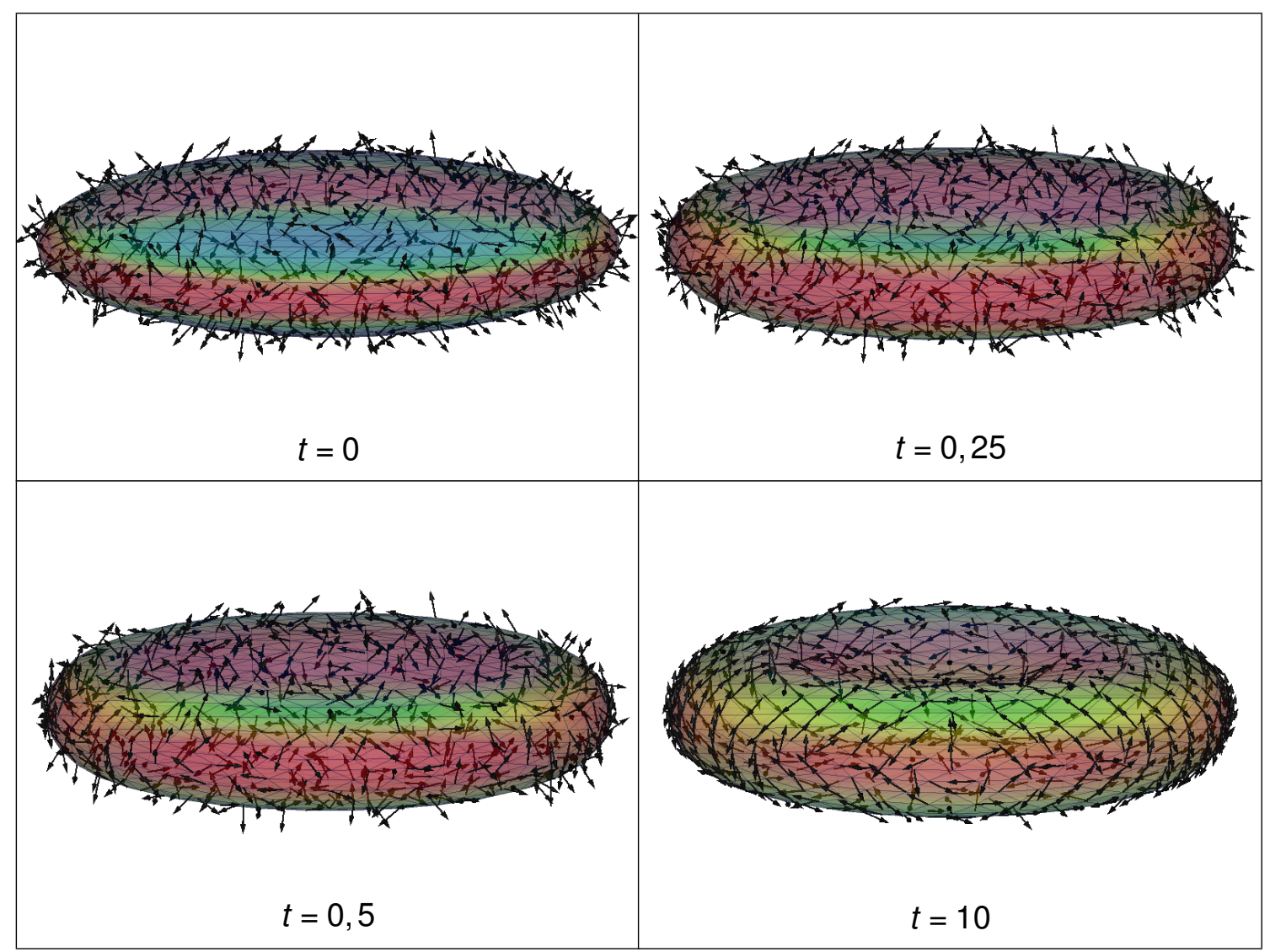

Figura 3.4: Dipolos dispostos sobre uma membrana fechada que muda de forma. Os dipolos interagem entre si ao mesmo tempo em que se movem junto com a membrana. As cores representam a curvatura média da membrana. No estado estacionário, há algum alinhamento dos dipolos com seus vizinhos mais próximos. 


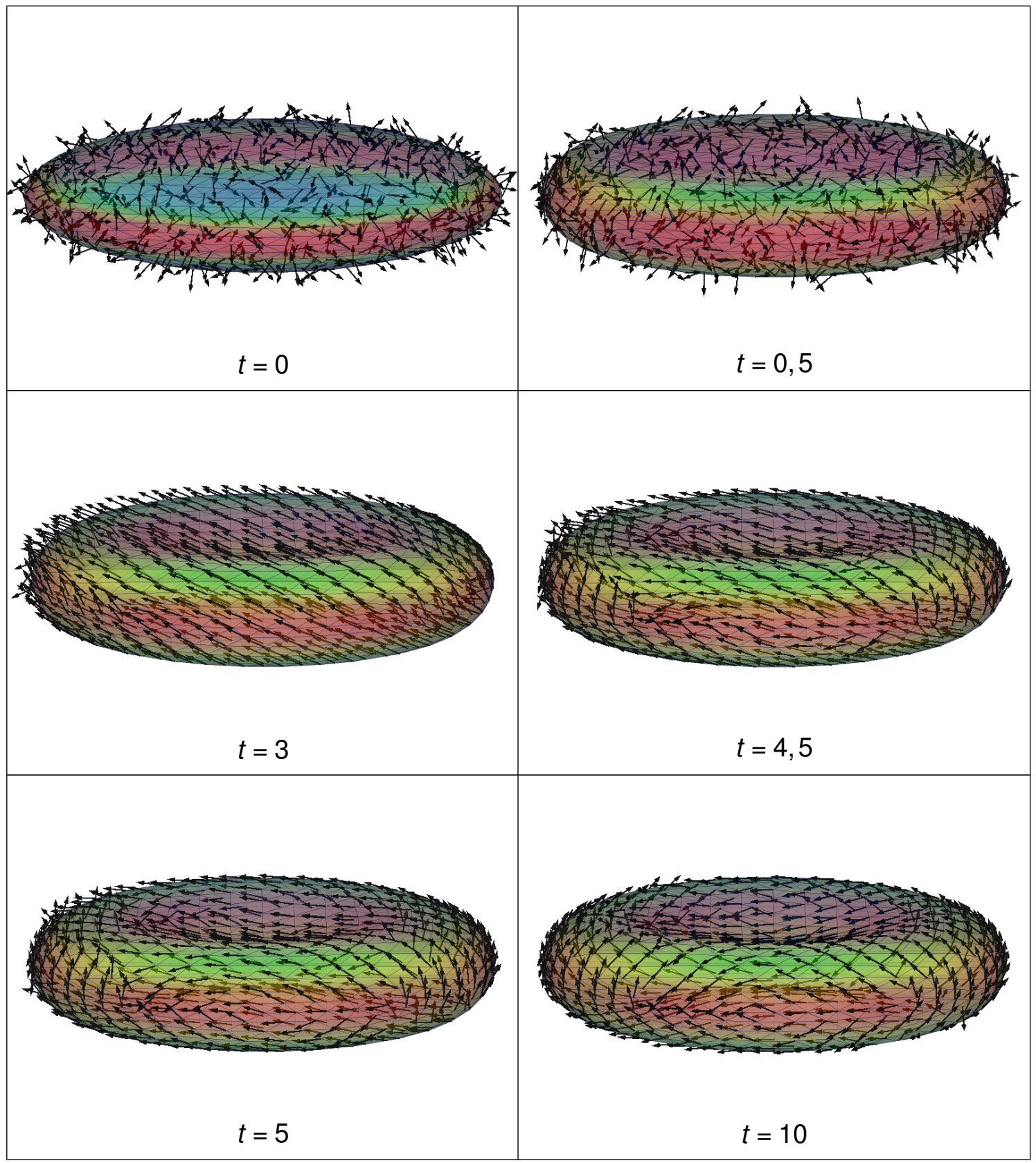

Figura 3.5: Também no caso de dipolos em uma membrana, há alinhamento quando um campo elétrico externo é aplicado. Sem o campo elétrico, os dipolos tendem a se alinhar com os vizinhos mais próximos. 


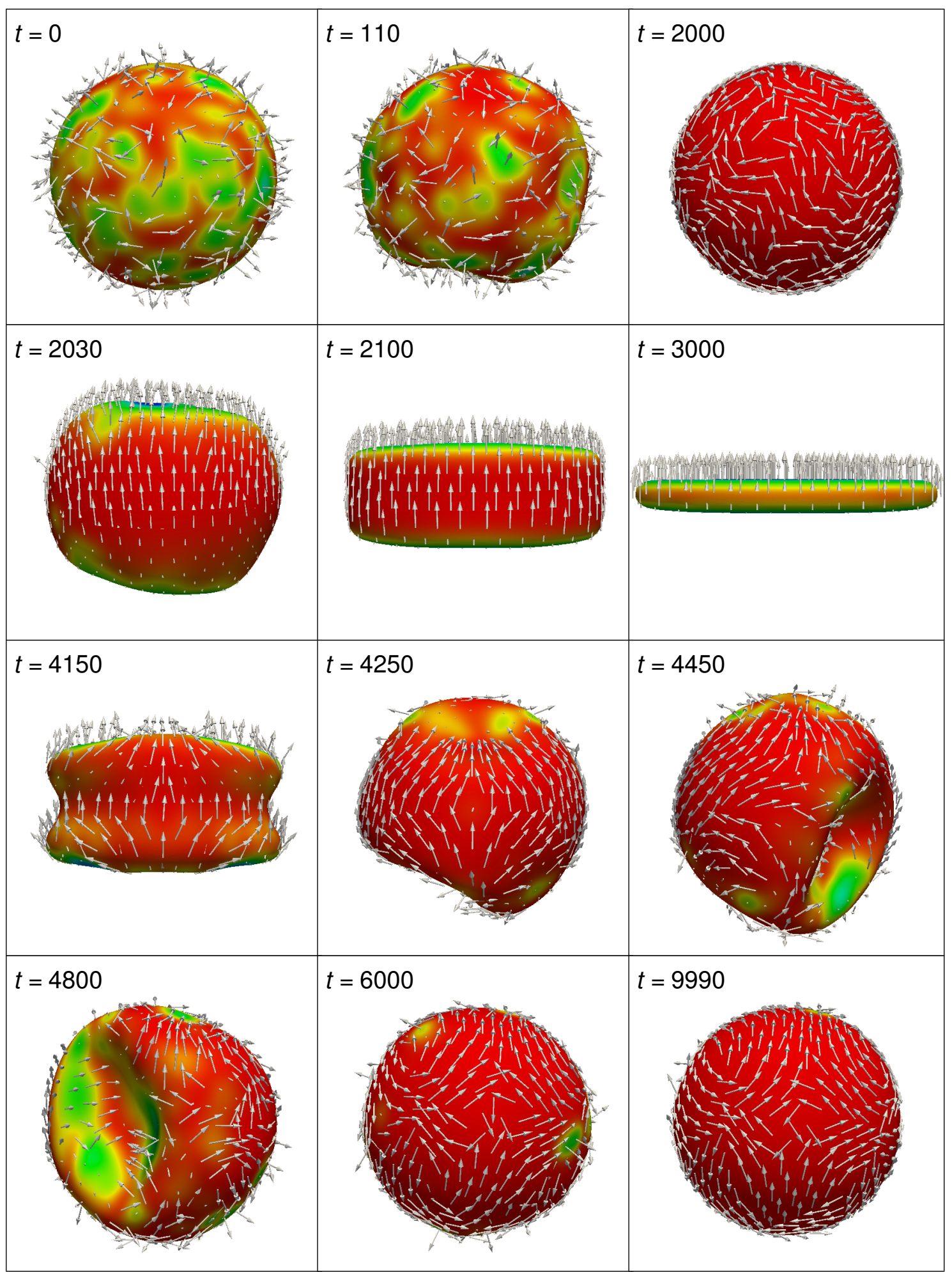

Figura 3.6: Acoplamento entre a orientação dos dipolos e a forma da membrana, dada pela equação 3.21. A energia de acoplamento é mínima quando o dipolo está na mesma direção que a normal no vértice, e máxima quando são perpendiculares. A cor vermelha indica uma energia alta, verde média e azul baixa. As setas são a orientação dos dipolos. O tempo está indicado em cada quadro. Os dipolos estão orientados aleatoriamente em $t=0$. Em $t=2000$ um campo elétrico é ligado, o que faz com que todos os dipolos se orientem na mesma direção. Isso afeta drasticamente a forma da membrana. Em $t=4000$ o campo é desligado e a membrana retorna à forma de repouso. 
To every action there is always opposed an equal reaction.

Isaac Newton

\section{4 \\ Colisão e Atrito}

Colisão é um evento no qual dois ou mais corpos em movimento exercem mutuamente forças impulsivas por um breve período. Se não houver forças externas, tanto o momento linear quanto o angular serão conservados. Se não houver perda de energia cinética, a colisão é dita elástica. Uma colisão inelástica ou plástica é aquela na qual alguma energia cinética é convertida em outra forma de energia, e.g. calor. Uma colisão perfeitamente inelástica ou perfeitamente plástica é um caso limite no qual dois corpos se aderem depois do impacto. O coeficiente de restituição, um valor que em geral varia entre zero e um, quantifica o grau de elasticidade ou inelasticidade de uma colisão. Uma colisão elástica possui coeficiente de restituição um e uma colisão perfeitamente inelástica possui coeficiente zero.

Superfícies sólidas em contato que estejam em movimento relativo podem exercer mutuamente forças de atrito. Essas forças convertem energia cinética principalmente em calor, diminuindo a velocidade relativa entre os objetos em contato.

Em geral, quando objetos estão em contato, tanto forças de colisão quanto de atrito são trocadas. Para simplificar o acoplamento desses dois conceitos, forças de colisão são usualmente consideradas normais e as de atrito tangenciais à superfície no ponto de contato. Mais especificamente, forças de atrito estão na mesma direção da componente tangencial da velocidade relativa entre os objetos em contato.

Tratamento analítico clássico de colisão e atrito pode ser encontrado na maioria dos livros introdutórios de Física, como (Landau \& Lifshitz, 1976) e (Halliday et al., 2011). Abordagens computacionais usualmente seguem as ideias básicas propostas por (Moore \& Wilhelms, 1988), onde forças elásticas são usadas em contatos estacionários e impulsos de colisão são usados para tratar impactos de alta velocidade. Em (Bridson et al., 2002, 2003), os autores usam tanto forças elásticas quanto impulsos de colisão combinados com o conceito de "zonas de impacto rígidas", originalmente proposto por (Provot, 1997). Baseado nos mesmos conceitos, em (Selle et al., 2009), um algoritmo mais eficiente baseado em histórico é apresentado. Eficiência em detecção de colisões é discutida em detalhes por (Ericson, 2005).

Neste capítulo, dois modelos, um baseado em forças e o outro em impulsos, são apresentados para a simulação numérica de colisões e atrito em membranas. 


\subsection{Detecção de contato}

Primeiramente, é importante definir alguns conceitos usados para descrever os modelos apresentados aqui. Dois objetos são considerados em contato se suas superfícies estão suficientemente próximas para trocar forças. Se há contato, o ponto, da superfície de um dos objetos, mais próximo da superfície do outro objeto é chamado ponto de contato. Como dito anteriormente, forças de colisão são normais à superfície no ponto de contato e forças de atrito são tangenciais.

O problema discreto envolve determinar se triângulos estão em contato e, se estiverem, a quais forças estão submetidos. Dois triângulos podem se intersectar de duas maneiras: ponto-superfície ou aresta-aresta, como visto na figura 4.1. Um contato pontosuperfície acontece quando um vértice de um triângulo atravessa o interior de outro. Um contato aresta-aresta ocorre quando as arestas de dois triângulos se cruzam.

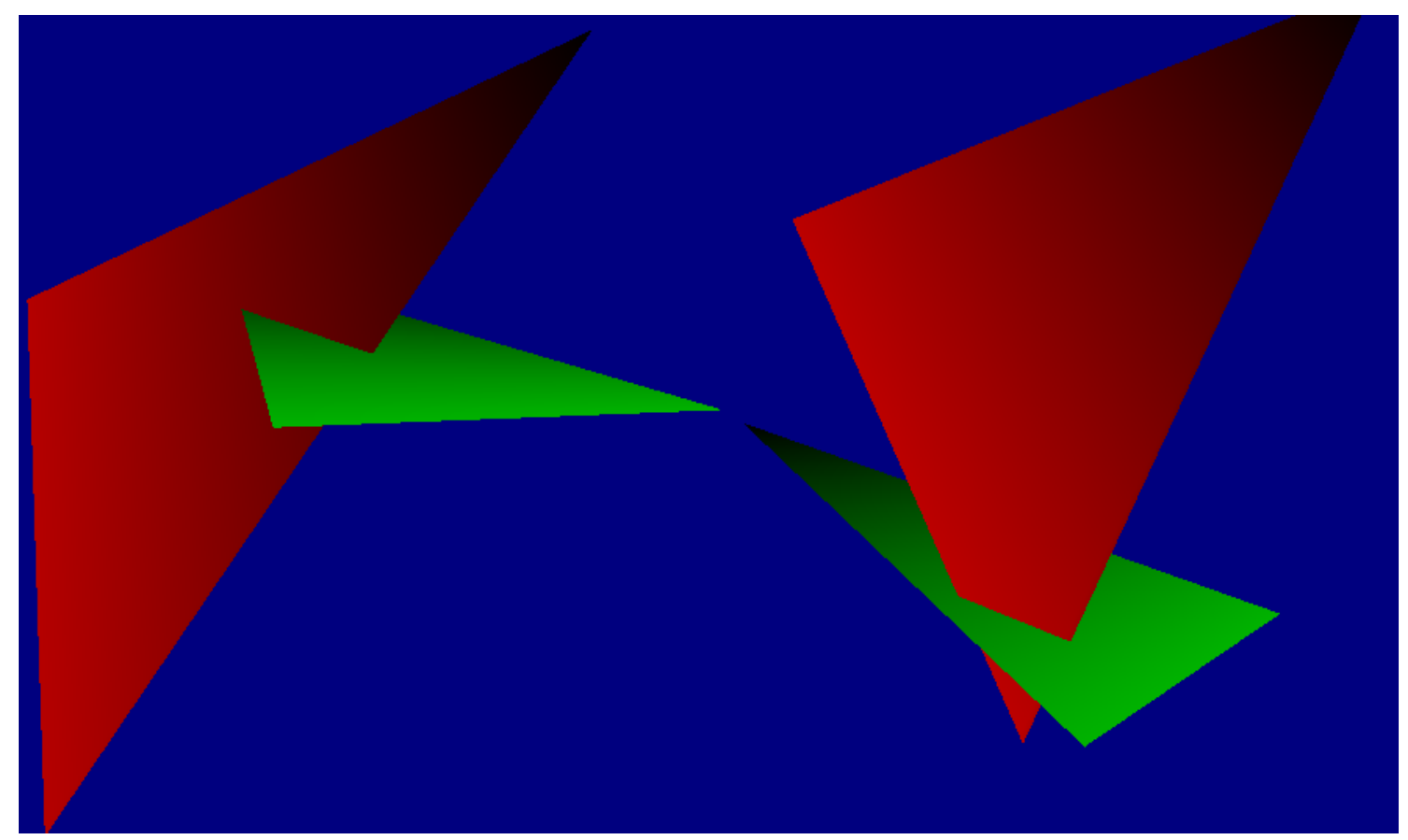

Figura 4.1: Possíveis casos para contato entre triângulos. Na esquerda, contato aresta-aresta ocorre quando as arestas dos triângulos se cruzam. Na direita, contato ponto-superfície se dá quando o vértice de um triângulo atravessa o interior de outro. Imagem retirada de (CMSoft, 2013).

\subsubsection{Contato ponto-superfície}

Para determinar se um ponto está em contato com a superfície de um triângulo, primeiro a distância entre o ponto e o plano do triângulo é calculada. Se este valor for maior do que uma quantidade prescrita, a espessura do triângulo, não haverá contato. Caso contrário, o ponto será projetado sobre o plano do triângulo. Haverá contato se a projeção estiver dentro do triângulo.

Sejam $\mathbf{r}_{1}, \mathbf{r}_{2}$ e $\mathbf{r}_{3}$ os vértices de um triângulo. Qualquer ponto $\mathbf{r}$ localizado no plano do triângulo pode ser escrito como uma combinação linear desses três vértices, i.e.

$$
\mathbf{r}=\lambda_{1} \mathbf{r}_{1}+\lambda_{2} \mathbf{r}_{2}+\lambda_{3} \mathbf{r}_{3}
$$


onde $\lambda_{1}, \lambda_{2}$ e $\lambda_{3}$ são as coordenadas baricêntricas do ponto $\mathbf{r}$. Elas estão sujeitas à restrição

$$
\lambda_{1}+\lambda_{2}+\lambda_{3}=1
$$

Além disso, se todas as três coordenadas estiverem entre zero e um, o ponto estará dentro do triângulo. Isso pode ser usado em um algoritmo de detecção de contato, como descrito abaixo.

Primeiramente, para calcular as coordenadas baricêntricas, os vértices do triângulo e o ponto precisam estar em um sistema de coordenadas apropriado. A primeira direção desse sistema é escolhida de forma que coincida com uma das arestas do triângulo. A terceira direção é a normal do triângulo e a segunda é perpendicular às outras duas. Os sentidos devem respeitar a regra da mão direita.

Nesse sistema de coordenadas, o triângulo está sobre o plano x-y. A terceira componente da posição do ponto é a distância até o plano do triângulo. Se o valor absoluto desta componente for menor do que a espessura prescrita, poderá haver contato. Essa é a primeira condição necessária para haver contato. Além disso, o sinal dessa componente indica de que lado do triângulo o ponto está.

Desprezando a terceira componente da posição do ponto, o vetor restante é a projeção do ponto sobre o plano do triângulo, i.e. o ponto de contato. Visto que as terceiras componentes dos vértices são nulas, elas também podem ser desprezadas, e as seguintes fórmulas são usadas para calcular as coordenadas baricêntricas:

$$
\begin{gathered}
\mathbf{T}=\left(\begin{array}{ll}
x_{1}-x_{3} & x_{2}-x_{3} \\
y_{1}-y_{3} & y_{2}-y_{3}
\end{array}\right), \\
\left(\begin{array}{l}
\lambda_{1} \\
\lambda_{2}
\end{array}\right)=\mathbf{T}^{-1}\left(\mathbf{r}-\mathbf{r}_{3}\right),
\end{gathered}
$$

onde $\left(x_{i}, y_{i}\right)$ são as componentes do vértice $\mathbf{r}_{i}$. A equação 4.2 é usada para obter a terceira coordenada baricêntrica.

Se todas as coordenadas baricêntricas estiverem entre zero e um, o ponto de contato estará dentro do triângulo. Pode ser desejável capturar situações onde o ponto está um pouco fora do triângulo, em particular quando não é feita a detecção de contato aresta-aresta. Para isso, o intervalo das coordenadas baricêntricas é aumentado de $[0,1]$ para $[-\delta, 1+\delta]$, onde $\delta$ é a espessura da membrana dividida pela raiz quadrada da área do triângulo, um comprimento característico do triângulo. Essa é a segunda condição necessária. Se ambas forem atendidas, haverá contato.

\subsubsection{Contato aresta-aresta}

A detecção de contato aresta-aresta se resume ao problema de encontrar a distância mínima entre dois segmentos de reta em três dimensões. Para tal, o algoritmo descrito em (Ericson, 2005) é usado. Dois segmentos de reta, $\mathscr{L}_{1}$ e $\mathscr{L}_{2}$, podem ser parametrizados como

$$
\begin{array}{ll}
\mathscr{L}_{1}(s)=(1-s) \mathbf{p}_{1}+s \mathbf{q}_{1}, & 0 \leq s \leq 1, \\
\mathscr{L}_{2}(t)=(1-t) \mathbf{p}_{2}+t \mathbf{q}_{2}, & 0 \leq t \leq 1 .
\end{array}
$$

Onde $\mathbf{p}$ e q são os extremos dos respectivos segmentos. A distância entre um ponto do segmento $\mathscr{L}_{1}$ e outro do segmento $\mathscr{L}_{2}$ é

$$
\mathbf{d}(s, t)=\mathscr{L}_{1}(s)-\mathscr{L}_{2}(t)
$$


Quer-se encontrar os valores de s e $t$ que minimizam $|\mathbf{d}(s, t)|$. Se $S$ e $T$ forem os valores que minimizam $|\mathbf{d}(s, t)|$, então $\mathscr{L}_{1}(S)$ e $\mathscr{L}_{2}(T)$ são os pontos de contato e $|\mathbf{d}(S, T)|$ é a distância entre os segmentos.

O ponto de contato pode estar no interior do segmento ou em uma de suas extremidades. Existem quatro possíveis casos, vistos na figura 4.2. O algoritmo testa cada um desses casos.

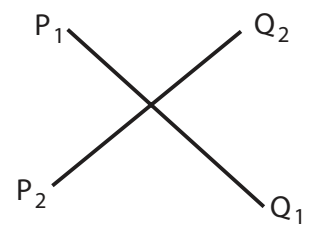

(a)

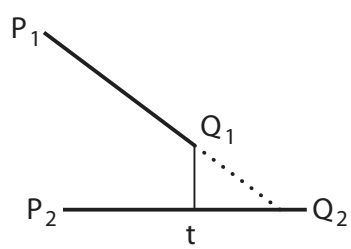

(b)

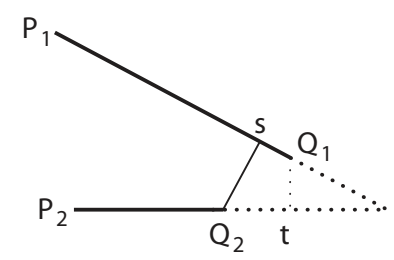

(c)

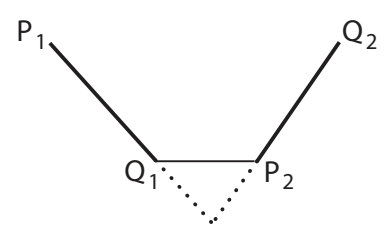

(d)

Figura 4.2: Pontos de contato entre dois segmentos de reta. (a) no interior de ambos os segmentos. (b) e (c) no interior de um segmento e no extremo do outro. (d) no extremo de ambos os segmentos. Imagem retirada de (Ericson, 2005).

Primeiro, calcula-se a distância entre as retas que contêm os segmentos. Isso é feito ao se resolver o sistema

$$
\begin{aligned}
& \mathbf{d}(s, t) \cdot\left(\mathbf{q}_{1}-\mathbf{p}_{1}\right)=0, \\
& \mathbf{d}(s, t) \cdot\left(\mathbf{q}_{2}-\mathbf{p}_{2}\right)=0,
\end{aligned}
$$

pois o menor vetor que liga duas retas é perpendicular a ambas. A solução é

$$
\begin{aligned}
& s=(b f-c e) /\left(a e-b^{2}\right), \\
& t=(a f-b c) /\left(a e-b^{2}\right),
\end{aligned}
$$

com

$$
\begin{aligned}
& a=\left(\mathbf{q}_{1}-\mathbf{p}_{1}\right) \cdot\left(\mathbf{q}_{1}-\mathbf{p}_{1}\right), \\
& b=\left(\mathbf{q}_{1}-\mathbf{p}_{1}\right) \cdot\left(\mathbf{q}_{2}-\mathbf{p}_{2}\right), \\
& c=\left(\mathbf{q}_{1}-\mathbf{p}_{1}\right) \cdot\left(\mathbf{p}_{1}-\mathbf{p}_{2}\right), \\
& e=\left(\mathbf{q}_{2}-\mathbf{p}_{2}\right) \cdot\left(\mathbf{q}_{2}-\mathbf{p}_{2}\right), \\
& f=\left(\mathbf{q}_{2}-\mathbf{p}_{2}\right) \cdot\left(\mathbf{p}_{1}-\mathbf{p}_{2}\right) .
\end{aligned}
$$

Se $s$ e $t$ estiverem no intervalo $[0,1]$, trata-se do caso (a), e esses valores são os pontos de contato. Se $s$ ou $t$ estiver fora do intervalo, então o ponto de contato está no extremo de pelo menos um dos segmentos. É necessário testar os demais casos. Para tal, fixa-se um ponto de contato em um dos extremos de um segmento e mede-se a distância dele até o outro segmento.

Se o ponto $s$ estiver fixo no segmento $\mathscr{L}_{1}$, o menor vetor entre esse ponto e a reta que contém $\mathscr{L}_{2}$ é perpendicular a essa reta, ou seja,

$$
\mathbf{d}(s, t) \cdot\left(\mathbf{q}_{2}-\mathbf{p}_{2}\right)=0
$$

que resulta em

$$
t=(b s+f) / e .
$$

Se $t$ estiver no intervalo $[0,1]$, trata-se do caso (b). 
Analogamente, se o ponto $t$ estiver fixo no segmento $\mathscr{L}_{2}$, o menor vetor entre esse ponto e a reta que contém $\mathscr{L}_{1}$ é perpendicular a essa reta, ou seja,

$$
\mathbf{d}(s, t) \cdot\left(\mathbf{q}_{1}-\mathbf{p}_{1}\right)=0,
$$

que resulta em

$$
s=(b t-c) / a .
$$

Se $s$ estiver no intervalo $[0,1]$, trata-se do caso (c).

Por fim, se os testes acima falharem, tem-se o caso (d), onde ambos os pontos devem ser fixados nos extremos. O algoritmo completo é

- Calcula-se $s=(b f-c e) /\left(a e-b^{2}\right)$. Se estiver fora do intervalo [0,1], s é truncado para esse intervalo. Ou seja, se $s<0$ então $s=0$. Se $s>1$ então $s=1$.

- Calcula-se $t=(b s+f) / e$. Se $t$ estiver dentro do intervalo [0,1], então a solução foi encontrada.

- Se $t$ estiver fora do intervalo $[0,1]$, ele é truncado para esse intervalo. Calcula-se $s=(b t-c) / a$, truncando o valor caso esteja fora do intervalo.

Em (Ericson, 2005), o autor também testa os casos degenerados onde o segmento é muito pequeno e tende a um ponto. Para isso, basta fixar $s$ ou $t$ em zero caso o respectivo segmento seja muito pequeno.

\subsubsection{Restrição ao passo temporal}

Se o passo temporal $\Delta t$ da simulação for muito grande, um ponto poderá atravessar um triângulo em um único ciclo de simulação e o algoritmo de detecção de contato falhará. Para evitar isso, a condição CFL deve ser imposta. Se um triângulo tiver espessura $h$, como descrito na figura 4.3, então

$$
C=\frac{\left|\mathbf{u}_{r e l}\right| \Delta t}{h} \leq 1
$$

onde $\mathbf{u}_{r e l}$ é a velocidade relativa entre o ponto e o triângulo e $C$ é o número de Courant. Essa condição deve ser satisfeita para todas as possíveis combinações de pontos e triângulos. É suficiente escolher

$$
\Delta t=\frac{1}{4} \frac{h}{u_{\max }}
$$

onde $u_{\max }$ é o máximo valor absoluto dentre as componentes das velocidades de todos os pontos da malha.

Essa escolha também garante que uma aresta não atravessará outra em um único passo de tempo, visto que a velocidade dos pontos interiores da aresta é sempre menor ou igual à velocidade do extremo mais rápido.

\subsubsection{Eficiência}

Quando se trata de superfícies deformáveis, qualquer ponto pode colidir com qualquer triângulo, exceto aqueles dos quais ele é vértice. Um algoritmo ingênuo que testa todas as possíveis combinações de pontos e triângulos teria complexidade $O\left(n^{2}\right)$ no tempo, 


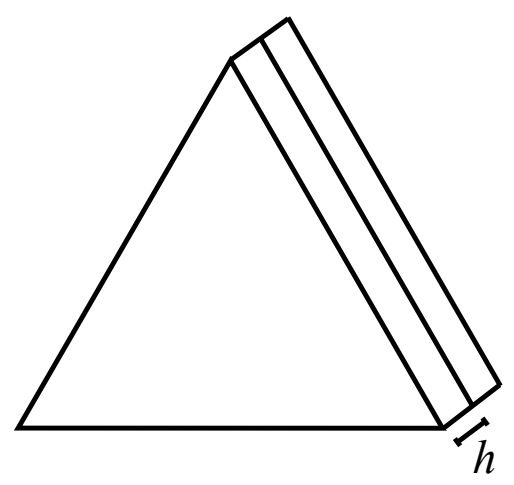

Figura 4.3: $O$ passo temporal $\Delta t$ deve ser pequeno o suficiente para evitar que um ponto atravesse a espessura do triângulo $h$ em um único ciclo de simulação. $O$ contato pode ocorrer em ambos os lados do triângulo. Por isso, a espessura $h$ é considerada em ambos os lados.

que é impraticável, visto que simulações geralmente envolvem milhares ou até milhões de triângulos e testes de colisão são caros.

Para melhorar a eficiência, caixas delimitadoras alinhadas aos eixos são usadas neste trabalho. Cada triângulo é envolvido pelo menor hexaedro cujos lados são perpendiculares (alinhados) aos eixos cartesianos. Isso é facilmente feito ao se calcular os valores mínimos e máximos de cada coordenada das posições dos vértices. Antes de testar se um ponto está em contato com um triângulo, um teste mais simples é feito para checar se o ponto está dentro da caixa.

Uma grade uniforme também é usada. O espaço é dividido em células uniformes. Uma primeira varredura determina a qual célula da grade cada ponto pertence. Em seguida, a caixa delimitadora determina quais células da grade são englobadas pelo triângulo. Testes de contato são feitos apenas entre pontos e triângulos que ocupem a mesma célula da grade. O tamanho ideal da célula é determinado experimentalmente para cada simulação.

No caso de contatos aresta-aresta, cada aresta é envolvida por uma caixa delimitadora, levando em conta a espessura prescrita. A grade uniforme também é usada e o teste de contato só é feito entre arestas que ocupem uma mesma célula da grade.

Mais detalhes sobre essas e outras técnicas estão em (Ericson, 2005).

\subsection{Conservação de momento linear e angular}

Newton usou sua terceira lei para demonstrar a lei de conservação de momento, mas conservação de momento é hoje considerada uma lei mais fundamental. A lei de conservação de momento linear diz que em um sistema fechado, i.e. sem forças externas, o momento linear total é conservado. Analogamente, na ausência de torque externo, o momento angular é conservado.

Em mecânica clássica, o momento linear $\mathbf{p}$ de uma partícula é uma quantidade vetorial dada por

$$
\mathbf{p}=m \mathbf{v},
$$

onde $m$ é a massa da partícula e $\mathbf{v}$ sua velocidade. $O$ momento angular $\mathbf{L}$ com respeito à origem do sistema de coordenadas é

$$
\mathbf{L}=\mathbf{r} \times \mathbf{p}
$$

onde $\mathbf{r}$ é a posição da partícula. 
Colisão e atrito são forças internas trocadas entre corpos de um sistema. Portanto, o momento total antes e depois de uma colisão deve se conservar.

\subsubsection{Colisão ponto-superfície}

Quando se trata da colisão entre um ponto e um triângulo, a variação de momento dos vértices do triângulo deve compensar a variação de momento do ponto.

Sejam $\mathbf{p}_{p}, m_{p}, \mathbf{v}_{p}, \mathbf{L}_{p}$ e $\mathbf{r}_{p}$ as quantidades físicas do ponto e $\mathbf{p}_{i}, m_{i}, \mathbf{v}_{i}, \mathbf{L}_{i}$ e $\mathbf{r}_{i}$ as quantidades físicas do vértice $i$ do triângulo. A lei de conservação de momento diz que

$$
\begin{aligned}
& \mathbf{p}_{p}+\sum_{i} \mathbf{p}_{i}=\mathbf{p}_{p}^{*}+\sum_{i} \mathbf{p}_{i}^{*}, \\
& \mathbf{L}_{p}+\sum_{i} \mathbf{L}_{i}=\mathbf{L}_{p}^{*}+\sum_{i} \mathbf{L}_{i}^{*},
\end{aligned}
$$

onde as quantidades com asterisco são tomadas antes da colisão e as sem asterisco depois da colisão. O somatório é sobre os três vértices do triângulo. Essas equações podem ser reescritas em termos da variação de momento, ou seja, da diferença entre o momento depois e antes da colisão

$$
\begin{aligned}
& \Delta \mathbf{p}_{p}=-\sum_{i} \Delta \mathbf{p}_{i}, \\
& \Delta \mathbf{L}_{p}=-\sum_{i} \Delta \mathbf{L}_{i} .
\end{aligned}
$$

A variação de momento linear $\Delta \mathbf{p}=\mathbf{p}-\mathbf{p}^{*}$ é chamada impulso I. Admitindo que as partículas não se movem durante a colisão,

$$
\begin{gathered}
\mathbf{I}_{p}=-\sum_{i} \mathbf{I}_{i}, \\
\mathbf{r}_{p} \times \mathbf{I}_{p}=-\sum_{i} \mathbf{r}_{i} \times \mathbf{I}_{i},
\end{gathered}
$$

e usando o fato que uma força constante $\mathbf{F}$ atuando durante um tempo $\Delta t$ produz o impulso $\mathbf{I}=\mathbf{F} \Delta t$ :

$$
\begin{gathered}
\mathbf{F}_{p}=-\sum_{i} \mathbf{F}_{i}, \\
\mathbf{r}_{p} \times \mathbf{F}_{p}=-\sum_{i} \mathbf{r}_{i} \times \mathbf{F}_{i} .
\end{gathered}
$$

De acordo com a terceira lei de Newton, as forças mútuas de ação e reação entre dois corpos são iguais em módulo, de sinal oposto e mesma direção. Então, admitindo que durante a colisão o ponto troca forças com os vértices do triângulo mas estes não trocam forças entre si,

$$
\begin{aligned}
\mathbf{I}_{i} & =-\alpha_{i} \mathbf{I}_{p}, \\
\mathbf{F}_{i} & =-\alpha_{i} \mathbf{F}_{p},
\end{aligned}
$$

onde $\alpha_{i}$ é um escalar não negativo. Substituindo a equação 4.26 em 4.22 e 4.23 (ou a equação 4.27 em 4.24 e 4.25):

$$
\begin{gathered}
\sum_{i} \alpha_{i}=1 \\
\sum_{i} \alpha_{i} \mathbf{r}_{i}=\mathbf{r}_{p}
\end{gathered}
$$


Esta é a definição das coordenadas baricêntricas do ponto de contato no triângulo. Então, a força (ou impulso) de reação que cada vértice do triângulo recebe do ponto é a força (ou impulso) aplicada ao ponto pelo triângulo com sinal oposto e ponderada pela coordenada baricêntrica correspondente ao vértice.

É importante notar que na discussão acima é admitido que o ponto colisor está sobre o triângulo. Isso não é verdade no problema discreto, onde o triângulo possui uma espessura prescrita, e o ponto está distante do plano do triângulo por no máximo esse valor. Isso não afeta a conservação de momento linear, pois ela não depende da posição do ponto. A conservação de momento angular também não é comprometida. Isso é devido ao fato de que a diferença entre a posição do ponto e a sua projeção é normal ao triângulo, e portanto paralela à força (ou impulso). O produto vetorial entre a força (ou impulso) e essa diferença é nulo.

\subsubsection{Colisão aresta-aresta}

Sejam dois segmentos de reta, um que vai do ponto $p_{1}$ ao ponto $q_{1}$ e outro que vai do ponto $p_{2}$ ao ponto $q_{2}$, como descrito na seção 4.1.2. Conservação do momento linear significa que o impulso I recebido pelas partículas deve se anular, ou seja,

$$
\mathbf{I}_{p_{1}}+\mathbf{I}_{q_{1}}+\mathbf{I}_{p_{2}}+\mathbf{I}_{q_{2}}=0
$$

Conservação de momento angular é equivalente a

$$
\mathbf{r}_{p_{1}} \times \mathbf{I}_{p_{1}}+\mathbf{r}_{q_{1}} \times \mathbf{I}_{q_{1}}+\mathbf{r}_{p_{2}} \times \mathbf{I}_{p_{2}}+\mathbf{r}_{q_{2}} \times \mathbf{I}_{q_{2}}=0
$$

onde $\mathbf{r}$ denota a posição dos extremos dos segmentos. Ou seja, o momento dos impulsos sobre as partículas deve se anular.

Se os segmentos de reta estiverem parametrizados, como descrito na seção 4.1.2, e $s$ e $t$ indicarem o ponto de contato, então haverá conservação de momento linear e angular quando cada extremo da aresta receber o impulso de colisão

$$
\begin{aligned}
& \mathbf{I}_{p_{1}}=(1-s) \mathbf{I}, \\
& \mathbf{I}_{q_{1}}=s \mathbf{I}, \\
& \mathbf{I}_{p_{2}}=-(1-t) \mathbf{I}, \\
& \mathbf{I}_{q_{2}}=-t \mathbf{I},
\end{aligned}
$$

onde I é o impulso de colisão trocado entre os segmentos.

Substituindo 4.32 em 4.30,

$$
(1-s) \mathbf{I}+s \mathbf{I}-(1-t) \mathbf{I}-t \mathbf{I}=0
$$

que é uma tautologia. Substituindo 4.32 em 4.31,

$$
\begin{gathered}
(1-s) \mathbf{r}_{p_{1}} \times \mathbf{I}+s \mathbf{r}_{q_{1}} \times \mathbf{I}-(1-t) \mathbf{r}_{p_{2}} \times \mathbf{I}-t \mathbf{r}_{q_{2}} \times \mathbf{I}=0 \\
\left(\left[(1-s) \mathbf{r}_{p_{1}}+s \mathbf{r}_{q_{1}}\right]-\left[(1-t) \mathbf{r}_{p_{2}}+t \mathbf{r}_{q_{2}}\right]\right) \times \mathbf{I}=0, \\
\mathbf{d}(s, t) \times \mathbf{I}=0,
\end{gathered}
$$

que também é verdade visto que o impulso de colisão I está na mesma direção do vetor distância entre os segmentos $\mathbf{d}(s, t)$. 


\subsection{Coeficiente de restituição}

Quando dois corpos com velocidades $v_{a}$ e $v_{b}$ colidem, o coeficiente de restituição é definido como

$$
C_{R}=-\frac{v_{b}-v_{a}}{v_{b}^{*}-v_{a}^{*}}
$$

onde, mais uma vez, as velocidades com asterisco são tomadas antes e as sem asterisco depois do impacto. Essas velocidades são medidas na direção da colisão, i.e. normal à superfície no ponto de contato.

O coeficiente de restituição está relacionado com a conservação de energia. Um valor de um significa que a energia cinética é conservada, ou seja, colisão elástica. Zero significa que toda a energia cinética, no referencial do centro de momento, foi convertida em outra forma de energia, ou seja, colisão perfeitamente inelástica. Valores entre zero e um indicam uma colisão inelástica.

Valores negativos e acima de um são possíveis, embora incomuns. Um objeto passando através de outro, de forma que suas velocidades relativas não mudem de sinal, resultaria em um coeficiente negativo. Essa pode ser considerada uma colisão parcial, visto que o momento não foi completamente trocado.

Se, por exemplo, uma explosão acontecer no momento da colisão, a energia cinética total aumentará e o coeficiente de restituição será maior do que um. Um coeficiente acima de um também é possível no caso de colisões oblíquas entre superfícies deformáveis, como uma bola de tênis e uma quadra de saibro, figura 4.4. É importante notar que esses casos não violam de forma alguma o princípio da conservação de energia. É apenas uma questão de conversão de energia. Em uma explosão, energia química é convertida em cinética. $\mathrm{E}$ a quadra de saibro pode exercer uma força sobre a bola que não é perpendicular a ela, convertendo uma parte da energia cinética tangencial em energia cinética normal.

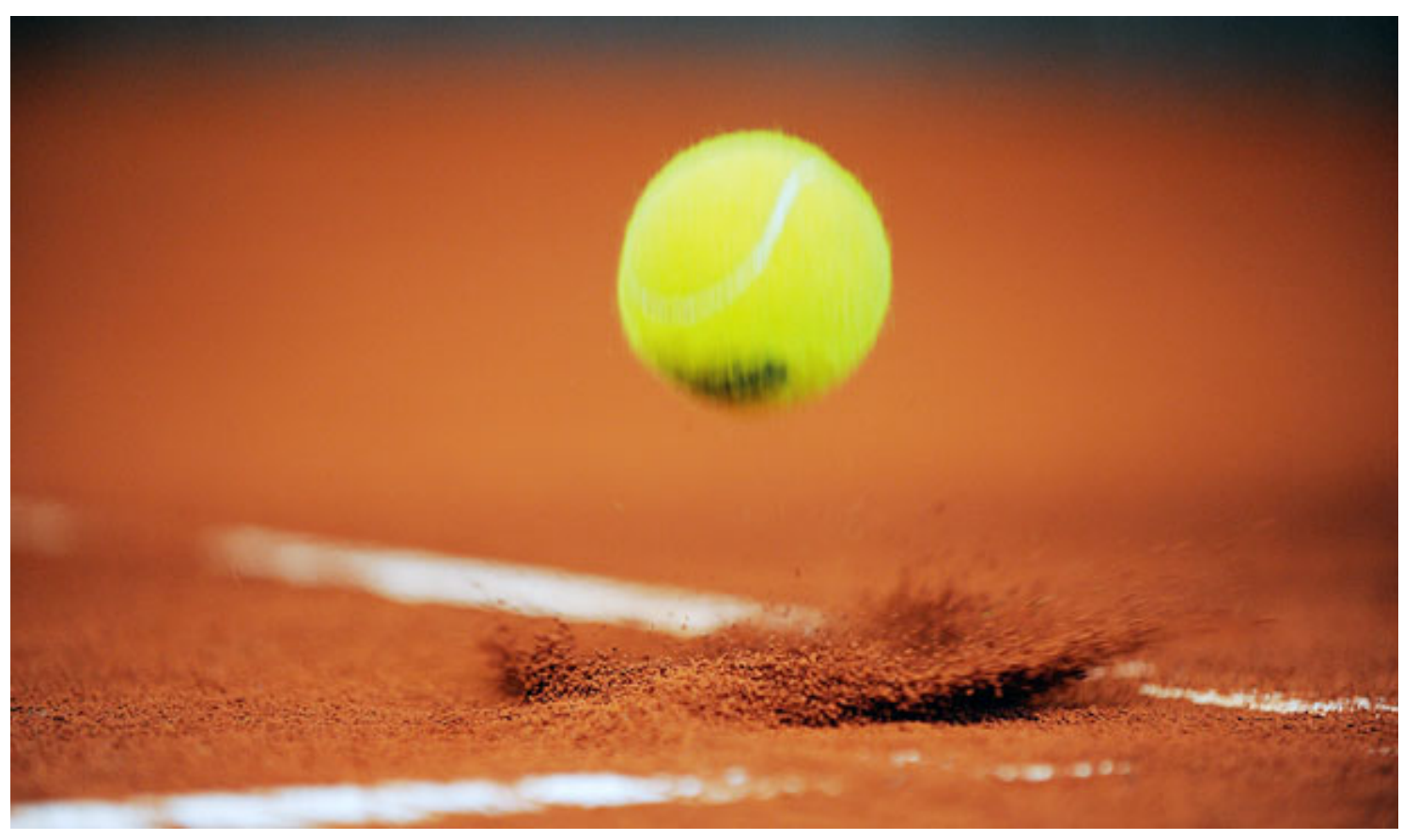

Figura 4.4: Uma bola de tênis que atinge uma quadra de saibro pode exibir um coeficiente de restituição maior do que um. Isso se dá devido ao fato de que a quadra de saibro é uma superfície deformável, e a sua normal pode mudar durante a colisão. Imagem retirada de (Tumblr, 2013). 


\subsection{Modelo baseado em forças}

O modelo baseado em forças para colisão é inspirado no problema clássico da colisão bloco-mola, como visto na figura 4.5. Um bloco se move em direção a outro, ao qual uma mola elástica está conectada. A mola é comprimida e, se a constante da mola $k$ for suficientemente grande, os blocos se repelirão.

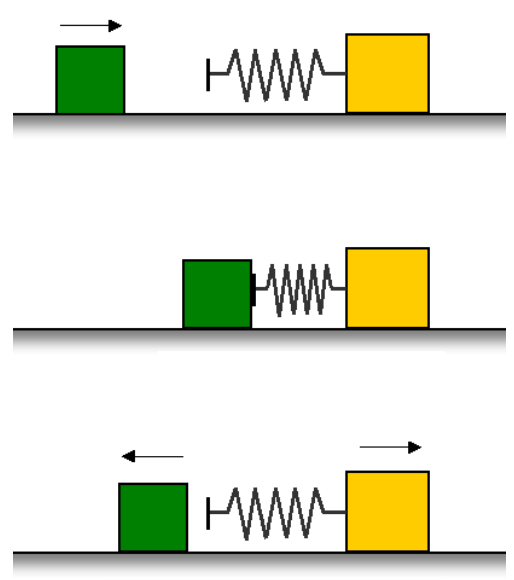

Figura 4.5: No problema clássico da colisão bloco-mola, uma mola elástica entre dois blocos que colidem garante uma perfeita colisão elástica. Forças externas como o atrito são desprezadas. O objetivo é determinar as velocidades depois da colisão dadas as velocidades iniciais. A solução é obtida ao se impor conservação de momento e energia entre os estados anterior e posterior à colisão. Também é possível saber a compressão máxima da mola, que é aquela que produz uma energia elástica igual à energia cinética total, no referencial do centro de momento. Imagem adaptada de (Real World Physics Problems, 2013).

A conservação de energia impõe que a energia total, elástica mais cinética, antes da colisão deve ser igual à energia total no momento da máxima compressão da mola. Antes da colisão, a mola não está comprimida, logo a energia elástica é zero. No momento de máxima compressão, no referencial do centro de momento, os blocos estão parados, e a energia cinética é zero. Então,

$$
\frac{m_{1} v_{1}^{2}}{2}+\frac{m_{2} v_{2}^{2}}{2}=\frac{k x_{\max }^{2}}{2}
$$

onde $m_{1}$ e $m_{2}$ são as massas, $v_{1}$ e $v_{2}$ são as velocidades antes da colisão, $k$ é a constante da mola e $x_{\max }$ é a máxima compressão. Se a mola não comprimida tem comprimento $h$, então

$$
k>\frac{m_{1} v_{1}^{2}+m_{2} v_{2}^{2}}{h^{2}}
$$

Se essa condição não for respeitada, a mola não terá força suficiente para parar os blocos. No problema contínuo, não há limite superior para a constante da mola $k$. Qualquer valor grande o suficiente garantirá uma colisão elástica.

O modelo discreto baseado em forças para colisões é análogo. A espessura do triângulo $h$ é o tamanho da mola não comprimida. Se houver contato entre o ponto e 0 triângulo, como descrito na seção 4.1 , uma força repulsiva $F=k x$, normal à superfície do triângulo, será aplicada ao ponto. Neste caso, $x$ é a compressão, i.e. a diferença entre o tamanho da mola $h$ e a distância do ponto ao triângulo. Para garantir conservação de momento, os vértices do triângulo devem receber a força de reação descrita na seção 4.2. 
Como no caso contínuo, a constante da mola $k$ deve ser grande o suficiente para evitar que o ponto atravesse o triângulo. Infelizmente, no modelo discreto, isso não é suficiente para garantir uma colisão elástica. Uma constante da mola $k$ muito grande leva a uma máxima compressão $x_{\max }$ pequena. Na discretização temporal explícita, descrita na seção 2.9, um ponto pode se mover além desta máxima compressão. Isso produziria um ganho de energia. O ponto será arremessado com velocidade maior do que aquela de aproximação.

Uma constante da mola adaptativa foi considerada para resolver este problema. Sabendo-se a massa, velocidade e distância do ponto ao triângulo, a constante da mola mudaria de forma que a força aplicada mandasse o ponto de volta no sentido oposto com a mesma velocidade. Isso, no entanto, não funciona como esperado devido à própria natureza do esquema de discretização temporal explícito.

Se o contato acontece no tempo $t^{n}$, significa que o ponto já está bastante próximo do triângulo. No próximo passo de tempo $t^{n+1}$, o ponto não deve se aproximar mais ainda, ou ele poderá atravessar o triângulo. No esquema explícito, a posição no tempo $t^{n+1}$ depende da velocidade no tempo $t^{n}$. A velocidade no tempo $t^{n}$ depende da força no tempo $t^{n-1}$. Mas no tempo $t^{n-1}$, o contato ainda não havia ocorrido, e não havia força de colisão. Este atraso entre a aplicação da força e a movimentação do ponto impossibilita uma constante da mola adaptativa.

O modelo baseado em forças também é inapropriado para o esquema de discretização temporal implícita descrito na seção 2.10. A derivada da força de colisão é descontínua, o que prejudica o cálculo da matriz jacobiana, fundamental para o método de Newton-Raphson.

\subsection{Modelo baseado em impulso}

Como discutido na seção 4.4, o atraso entre a aplicação da força de colisão e o movimento do ponto impede que o modelo discreto baseado em forças produza uma colisão elástica. A ideia por trás do modelo baseado em impulso é remover esse atraso. Ao invés de aplicar a força por um período de tempo $\Delta t$, o passo temporal da simulação, a força de colisão seria aplicada instantaneamente. Para tratar de forças instantâneas, o conceito de impulse é muito útil.

Em mecânica clássica, se uma força $\mathbf{F}$ é aplicada do tempo $t_{1}$ até o tempo $t_{2}$, o impulso I é uma quantidade vetorial definida como a integral da força com respeito ao tempo,

$$
\mathbf{I}=\int_{t_{1}}^{t_{2}} \mathbf{F} d t
$$

Da segunda lei de Newton, a força está relacionada ao momento p por

$$
\mathbf{F}=\frac{d \mathbf{p}}{d t}
$$

Logo,

$$
\mathbf{I}=\int_{t_{1}}^{t_{2}} \frac{d \mathbf{p}}{d t} d t=\Delta \mathbf{p}
$$

onde $\Delta \mathrm{p}$ é a variação de momento do tempo $t_{1}$ até $t_{2}$.

No modelo discreto baseado em impulso para colisões, o intervalo de tempo $\delta t$ entre $t_{1}$ e $t_{2}$ é quando a colisão ocorre. Esse intervalo de tempo é infinitesimal, e o impulso é aplicado entre os ciclos da simulação. 
O algoritmo funciona da seguinte forma: dadas as posições $\mathbf{x}_{i}^{n}$ e velocidades $\mathbf{v}_{i}^{n}$ dos pontos $i$ no tempo $t^{n}$, o esquema de evolução temporal $\mathscr{F}$, tanto explícito quanto implícito, produzirá posições e velocidades tentativas $\mathbf{x}_{i}^{*}$ e $\mathbf{v}_{i}^{*}$ no tempo $t^{*}=t^{n}+\Delta t$. Neste estado intermediário, serão feitos testes de contato. Se houver contato entre um ponto e um triângulo, um impulso de colisão será aplicado a eles. Depois que todos os impulsos forem aplicados, as posições e velocidades resultantes serão $\mathbf{x}_{i}^{n+1}$ e $\mathbf{v}_{i}^{n+1}$ no tempo $t^{n+1}=t^{*}+\delta t$. Então, a colisão ocorre num intervalo de tempo infinitamente pequeno $\delta t$ entre $t^{*}$ e $t^{n+1}$,

$$
\begin{gathered}
\left(\begin{array}{c}
\mathbf{x}_{i}^{*} \\
\mathbf{v}_{i}^{*}
\end{array}\right)=\mathscr{F}\left(\begin{array}{c}
\mathbf{x}_{i}^{n} \\
\mathbf{v}_{i}^{n}
\end{array}\right) \\
\mathbf{x}_{i}^{n+1}=\mathbf{x}_{i}^{*} \\
\mathbf{v}_{i}^{n+1}=\mathbf{v}_{i}^{*}+\frac{\mathbf{l}_{i}}{m_{i}}
\end{gathered}
$$

onde $m_{i}$ é a massa do ponto e $\mathbf{I}_{i}$ é o impulso resultante de todas as colisões envolvendo o ponto $i$. A equação 4.43 vem da equação 4.40 , usando $p_{i}=m_{i} v_{i}$, o momento do ponto $i$.

O impulso só será aplicado se houver contato entre o ponto e o triângulo e se eles estiverem em aproximação. Se houver contato mas o ponto estiver se afastando do triângulo, a colisão é considerada resolvida pelo algoritmo. Quando há colisões múltiplas, em geral é necessário aplicar o algoritmo várias vezes, até que todas as colisões sejam resolvidas. Um fator de relaxação, aplicado aos impulsos, pode ser usado para melhorar a convergência.

As posições dos pontos não mudam durante a colisão. Isso é importante, pois mover um ponto geralmente leva a uma mudança de energia, e.g. energia elástica ou gravitacional. Outra vantagem desse algoritmo de colisão é que ele pode ser aplicado com qualquer esquema de evolução temporal, explícito ou implícito, visto que ele apenas introduz uma correção adicional e não muda o esquema em si.

Esse método é de certa forma similar ao método da projeção usado em dinâmica dos fluidos para resolver as equações de Navier-Stokes. O método da projeção primeiro aplica um esquema de evolução temporal para calcular as velocidades e depois faz uma correção para garantir incompressibilidade. O modelo de colisões baseado em impulso primeiro aplica um esquema de evolução temporal para calcular as velocidades e depois faz uma correção para resolver as colisões.

\subsubsection{Colisão ponto-superfície}

Como discutido na seção 4.2, quando um ponto colide com um triângulo, o impulso $I_{p}$ recebido pelo ponto gera uma reação $l_{i}$ no vértice $i$ do triângulo com sinal oposto $\mathrm{e}$ ponderado pela coordenada baricêntrica $\lambda_{i}$ do ponto de contato,

$$
l_{i}=-\lambda_{i} I_{p}
$$

Isso é suficiente para garantir conservação de momento linear e angular. As quantidades $l_{i} \mathrm{e}$ $I_{p}$ são as componentes do impulso na direção da colisão, i.e. normal ao triângulo.

A conservação de energia está relacionada com o coeficiente de restituição, seção 4.3,

$$
C_{R}=-\frac{v_{p}-v_{t}}{v_{p}^{*}-v_{t}^{*}}
$$

onde $v_{t}$ e $v_{p}$ são as velocidades do triângulo e ponto na direção da colisão. As quantidades com asterisco são tomadas antes da colisão e as sem asterisco depois da colisão. A 
velocidade $v_{t}$ do triângulo é medida no ponto de contato e pode ser interpolada usando coordenadas baricêntricas,

$$
v_{t}=\sum_{i} \lambda_{i} v_{i}
$$

onde o somatório é feito sobre os vértices do triângulo.

Para um coeficiente de restituição prescrito, é possível montar um sistema linear a partir das equações acima para determinar as velocidades após a colisão,

$$
\begin{array}{rlrl}
v_{p}-\lambda_{1} v_{1}-\lambda_{2} v_{2}-\lambda_{3} v_{3} & =-C_{R}\left(v_{p}^{*}-\lambda_{1} v_{1}^{*}-\lambda_{2} v_{2}^{*}-\lambda_{3} v_{3}^{*}\right), \\
\lambda_{1} m_{p} v_{p}+m_{1} v_{1} & & & =\lambda_{1} m_{p} v_{p}^{*}+m_{1} v_{1}^{*} \\
\lambda_{2} m_{p} v_{p} & +m_{2} v_{2} & =\lambda_{2} m_{p} v_{p}^{*}+m_{2} v_{2}^{*} \\
\lambda_{3} m_{p} v_{p} & & +m_{3} v_{3} & =\lambda_{3} m_{p} v_{p}^{*}+m_{3} v_{3}^{*}
\end{array}
$$

As equações de momento, que são as três últimas, podem ser usadas para eliminar as velocidades dos vértices do triângulo na primeira equação, o que permite que $v_{p}$ seja calculado diretamente. Com isso em mãos, o cálculo dos impulsos segue naturalmente. O impulso no ponto será

$$
I_{p}=\Delta p_{p}=m_{p} v_{p}-m_{p} v_{p}^{*}
$$

e o impulso nos vértices será dado pela equação 4.44 .

O impulso resultante em um ponto será a soma dos impulsos produzidos por todas as colisões nas quais o ponto está envolvido. Os impulsos são aplicados em todos os pontos simultaneamente. Todos os impulsos provenientes de todas as colisões são primeiro calculados e somados antes de serem aplicados aos respectivos pontos.

\subsubsection{Colisão aresta-aresta}

Sejam dois segmentos de reta parametrizados como na seção 4.1.2. O coeficiente de restituição da colisão entre eles será

$$
C_{R}=-\frac{v_{1}-v_{2}}{v_{1}^{*}-v_{2}^{*}}
$$

onde $v_{1}$ e $v_{2}$ denotam as velocidades, na direção da colisão, dos respectivos pontos de contato nos segmentos. As velocidades com asterisco são tomadas antes da colisão.

Se $s$ e $t$ são os valores dos parâmetros que indicam os pontos de contato,

$$
(1-s) v_{p_{1}}+s v_{q_{1}}-(1-t) v_{p_{2}}-t v_{q_{2}}=-C_{R}\left((1-s) v_{p_{1}}^{*}+s v_{q_{1}}^{*}-(1-t) v_{p_{2}}^{*}-t v_{q_{2}}^{*}\right) \text {, }
$$

onde $v_{p_{1}}, v_{q_{1}}, v_{p_{2}}$ e $v_{q_{2}}$ são as velocidades dos extremos dos segmentos na direção da colisão. As equações 4.32 podem ser reescritas como

$$
\begin{aligned}
& v_{p_{1}}=v_{p_{1}}^{*}+\frac{(1-s)}{m_{p_{1}}} l, \\
& v_{q_{1}}=v_{q_{1}}^{*}+\frac{s}{m_{q_{1}}} l, \\
& v_{p_{2}}=v_{p_{2}}^{*}-\frac{(1-t)}{m_{p_{2}}} l, \\
& v_{q_{2}}=v_{q_{2}}^{*}-\frac{t}{m_{q_{2}}} l,
\end{aligned}
$$


onde $m_{p_{1}}, m_{q_{1}}, m_{p_{2}}$ e $m_{q_{2}}$ são as massas dos extremos dos segmentos e $/$ é o módulo do

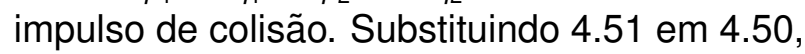

$$
I=-\left(C_{R}+1\right) \frac{(1-s) v_{p_{1}}^{*}+s v_{q_{1}}^{*}-(1-t) v_{p_{2}}^{*}-t v_{q_{2}}^{*}}{(1-s)^{2} / m_{p_{1}}+s^{2} / m_{q_{1}}+(1-t)^{2} / m_{p_{2}}+t^{2} / m_{q_{2}}}
$$

\subsection{Atrito}

Superfícies sólidas em contato deslizando uma contra a outra sofrem atrito. Atrito é a força que resiste ao movimento relativo das superfícies. É uma força dissipativa, i.e. energia cinética é convertida em outro tipo de energia, em geral calor, de uma forma irreversível.

Atrito provém da interação eletromagnética entre as moléculas dos materiais. Devido ao grande número de moléculas envolvidas, descrever o atrito em termos de conceitos fundamentais é impraticável. Ao invés disso, modelos empíricos são criados para aplicações específicas.

Dois dos mais conhecidos modelos, atrito fluido e atrito seco, serão apresentados a seguir. O papel deles no contexto de simulações numéricas também será investigado.

\subsubsection{Atrito fluido}

Atrito fluido, atrito viscoso ou arrasto acontece entre camadas de um fluido em fluxo laminar. Se uma camada fina de fluido estiver presente entre duas superfícies sólidas deslizantes, essas superfícies também sofrem atrito fluido. Esse caso especial é conhecido como atrito lubrificado.

O atrito se opõe ao movimento relativo das superfícies, portanto depende da direção e sentido da velocidade tangencial relativa. Atrito fluido, em particular, também depende do módulo dessa velocidade. Em geral, a força de atrito fluido $\mathbf{F}_{\text {fluid }}$ é

$$
\mathbf{F}_{\text {fluid }}=-\left|\mathbf{f}\left(\mathbf{v}_{t}\right)\right| \hat{\mathbf{v}}_{t}
$$

onde $\hat{\mathbf{v}}_{t}$ é o vetor unitário na direção da velocidade relativa tangencial $\mathbf{v}_{t}$. A função $\mathbf{f}$ descreve a relação entre o atrito e a velocidade. Uma aproximação de primeira ordem produz

$$
\mathbf{F}_{\text {fluid }}=-\beta \mathbf{v}_{t},
$$

onde $\beta$ é um constante de proporcionalidade não negativa, relacionada ao conceito de viscosidade.

Este modelo possui algumas complicações quando usado em simulações numéricas com evolução temporal explícita. A equação 4.54 é uma equação diferencial rígida. Isso impõe uma restrição ao passo temporal $\Delta t$. Se o produto $\beta \Delta t$ for muito grande, a força de atrito entre um ponto e um triângulo inverterá o sentido da velocidade tangencial. O ponto terá um comportamento oscilatório, que não é físico e leva à instabilidade numérica.

Em um esquema implícito, essa restrição pode ser relaxada. Mas, por outro lado, como no caso das forças de colisão, essa força de atrito é descontínua. Não há atrito quando não há contato. Por esta razão, este modelo baseado em forças para o atrito não pode ser usado com o esquema implícito desenvolvido neste trabalho. 


\subsubsection{Dissipador viscoso}

Um dissipador viscoso ou amortecedor (figure 4.6) é um dispositivo mecânico que resiste ao movimento por meio de atrito viscoso. Um exemplo bem conhecido é a suspensão de um carro, que é a combinação de uma mola elástica com um amortecedor.

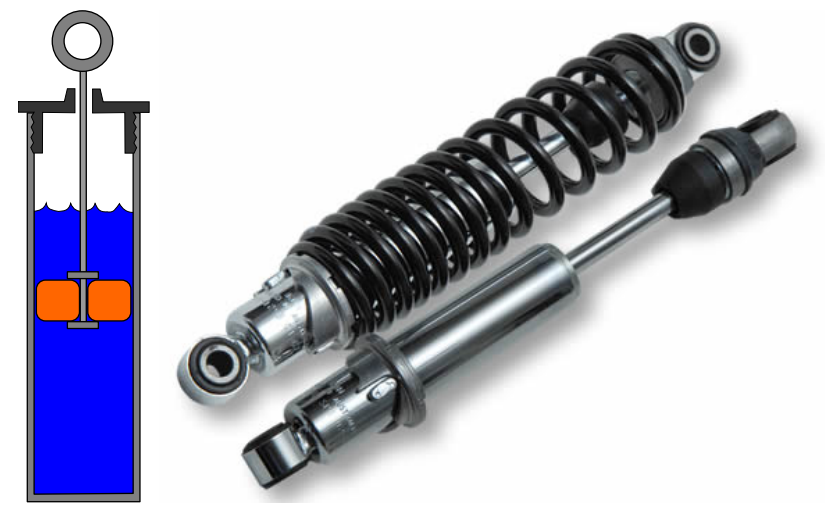

Figura 4.6: A suspensão de um carro é composta por uma mola elástica e um amortecedor. O dissipador viscoso é um dispositivo mecânico que resiste ao movimento por meio de atrito viscoso. Ele dissipa energia cinética, diminuindo a velocidade do movimento. Imagens retiradas de (Wikipedia, 2013b) e (Bike Revival, 2013).

Um amortecedor linear exerce uma força que é proporcional à velocidade, mas no sentido oposto, reduzindo a velocidade do movimento e dissipando energia. O seu comportamento pode ser descrito pela equação 4.54, mas na direção normal ao invés da tangencial.

Um amortecedor pode ser adicionado ao modelo baseado em forças para colisões, descrito na seção 4.4. A combinação da mola com amortecedor permite simular colisões inelásticas. Além disso, alguns materiais viscoelásticos também são modelados dessa forma. Por exemplo, o modelo de Maxwell pode ser representado por um amortecedor puramente viscoso e uma mola puramente elástica conectados em série. Uma conexão em paralelo leva ao material de Kelvin-Voigt.

Infelizmente, esse modelo de atrito sofre dos mesmos problemas que o modelo de colisões baseado em forças. É difícil encontrar bons valores para a constante elástica da mola e "viscosidade" $\beta$, além do fato de as forças serem descontínuas.

\subsubsection{Atrito seco}

Na ausência de lubrificantes, superfícies sólidas deslizando uma contra a outra estão sujeitas a atrito seco. O atrito seco é regido por três leis empíricas:

- A força de atrito é diretamente proporcional à força normal.

- A força de atrito é independente da área aparente de contato.

- A força de atrito é independente da velocidade de deslizamento.

A força normal é a força exercida pelas superfícies em contato. O atrito seco é subdividido em atrito estático $F_{s}$ e atrito dinâmico ou cinético $F_{k}$. Se as superfícies estão 
em contato mas não estão deslizando, há atrito estático. Atrito dinâmico acontece quando as superfícies estão em contato e deslizando. Eles são dados por

$$
\begin{aligned}
& F_{s} \leq \mu_{s} F_{n}, \\
& F_{k}=\mu_{k} F_{n},
\end{aligned}
$$

onde o valor não negativo $\mu$ é chamado coeficiente de atrito e $F_{n}$ é a força normal. A força normal é normal às superfícies no ponto de contato. $O$ atrito dinâmico tem sentido oposto à velocidade tangencial de deslizamento.

O atrito estático contrapõe a força tangencial aplicada. Se a força tangencial aplicada for menor do que 0 atrito de destaque $\mu_{s} F_{n}$, a força de atrito estática máxima, a força de atrito estática terá a mesma magnitude mas sentido oposto. Elas se cancelarão e o objeto não deslizará. Se a força aplicada for maior do que o atrito de destaque, os objetos começarão a deslizar e o atrito dinâmico passará a agir.

O atrito dinâmico age no sentido oposto ao movimento. Ele pode frear os objetos até que eles parem. Neste ponto, passa a agir o atrito estático. $O$ atrito, tanto estático quanto dinâmico, nunca produz ou aumenta o movimento. Ele sempre se opõe ao movimento.

O coeficiente de atrito $\mu$ é um escalar adimensional que expressa a razão entre as magnitudes do atrito e da força normal. É sempre maior ou igual a zero e não tem limite superior. É equivocado dizer que $\mu$ deve ser menor do que um. Por exemplo, alguns tipos de borracha possuem coeficientes entre um e dois. Um coeficiente maior do que um não é um absurdo. Apenas significa que a força tangencial aplicada deve ser maior do que a força normal para fazer com que haja deslizamento.

A maioria dos materiais secos tem coeficientes de atrito entre 0,3 e 0,6. Valores fora desse intervalo são mais raros, mas o teflon, por exemplo, pode ter um coeficiente de 0,04 . Um valor de zero significaria que não há atrito algum, uma situação que nunca acontece em situações práticas.

Experimentos simples de atrito demonstram que o coeficiente de atrito estático é em geral maior ou igual ao dinâmico. O contrário pode ocorrer, mas experimentos muito sofisticados se fazem necessários para detectar tal situação. Também se faz necessário um modelo empírico diferente do apresentado acima. Por essa razão, admite-se que o coeficiente de atrito estático é maior ou igual ao dinâmico.

\subsubsection{Modelo numérico}

Atrito seco pode facilmente ser incorporado ao modelo de colisões baseado em impulso descrito na seção 4.5. Integrar as equações 4.55 e 4.56 com respeito ao tempo produz os impulsos de atrito estático $I_{s}$ e dinâmico $I_{k}$,

$$
\begin{aligned}
& I_{s} \leq \mu_{s} I_{n}, \\
& I_{k}=\mu_{k} I_{n},
\end{aligned}
$$

onde $I_{n}$ é o impulso normal total calculado pelo algoritmo de colisão.

Para determinar quando aplicar atrito estático ou dinâmico, o seguinte critério é adotado: atrito estático é maior do que o dinâmico pois, quando as superfícies em contato estão em repouso relativo, suas moléculas têm tempo de formar ligações mais fortes. Então, para que o atrito estático comece a agir, as superfícies devem estar em repouso relativo por algum tempo. Caso contrário, atrito dinâmico se aplica. 
Outro importante ponto é que o atrito nunca pode inverter o sentido da velocidade. Em outras palavras, o impulso de atrito tem que ser menor ou igual ao momento tangencial. Esta é a razão para a desigualdade nas equações 4.55 e 4.57. Para o caso dinâmico, se o impulso de atrito dinâmico for maior do que o momento, significa que durante a colisão o objeto parou.

O algoritmo é o seguinte:

- O algoritmo de colisão calcula e aplica os impulsos normais.

- Para cada par ponto-triângulo em contato:

- Se o contato estiver marcado como "colado", calcula-se o impulso de atrito de destaque. Caso contrário, calcula-se o impulso de atrito dinâmico.

- Calcula-se o momento tangencial, que é o impulso que aplicado ao ponto e triângulo os colocará em repouso relativo.

- Se o impulso de atrito for menor ou igual ao momento tangencial, o impulso de atrito será o impulso aplicado. O contato é marcado como "descolado".

- Se o impulso de atrito for maior do que o momento tangencial, o momento tangencial será o impulso aplicado. O contato é marcado como "colado".

- Depois que todos os impulsos forem calculados, eles serão aplicados, respeitando a lei de ação e reação para garantir conservação de momento.

Todas as colisões estão inicialmente "descoladas" pelas razões discutidas anteriormente. O momento tangencial é o momento do ponto ou triângulo no referencial centro de momento do conjunto ponto e triângulo. $\mathrm{O}$ impulso de atrito é sempre aplicado no sentido oposto à velocidade tangencial.

\subsection{Resultados - modelo baseado em impulso}

\subsubsection{Colisão elástica}

A figura 4.7 mostra uma colisão elástica entre um ponto e um triângulo. O triângulo é equilátero e tem altura igual a 1 . O ponto e cada vértice do triângulo tem massa igual a 1 , portanto o triângulo tem o triplo da massa do ponto. O coeficiente de restituição é 1 para garantir uma colisão elástica. O passo temporal é $10^{-4}$. Os vértices estão conectados com molas elásticas para preservar a forma do triângulo. Essa constante elástica vale $10^{7}$. O ponto de contato é o centro de massa, o baricentro do triângulo, e as velocidades são normais ao triângulo.

Inicialmente, o ponto e o triângulo têm a mesma velocidade de 0.025 , mas em sentidos opostos como indicado pelas setas na figura 4.7. Depois da colisão, os vértices ficam em repouso e o ponto tem velocidade 0.05 . Isso está de acordo com a solução analítica para este problema.

\subsubsection{Colisão perfeitamente inelástica}

Essa simulação tem os mesmos parâmetros da anterior, exceto pelo coeficiente de restituição que agora é 0 . A figura 4.8 mostra o resultado. O ponto e o triângulo ficam grudados depois da colisão. A velocidade final é 0.0125 , a qual está de acordo com o resultado analítico. 


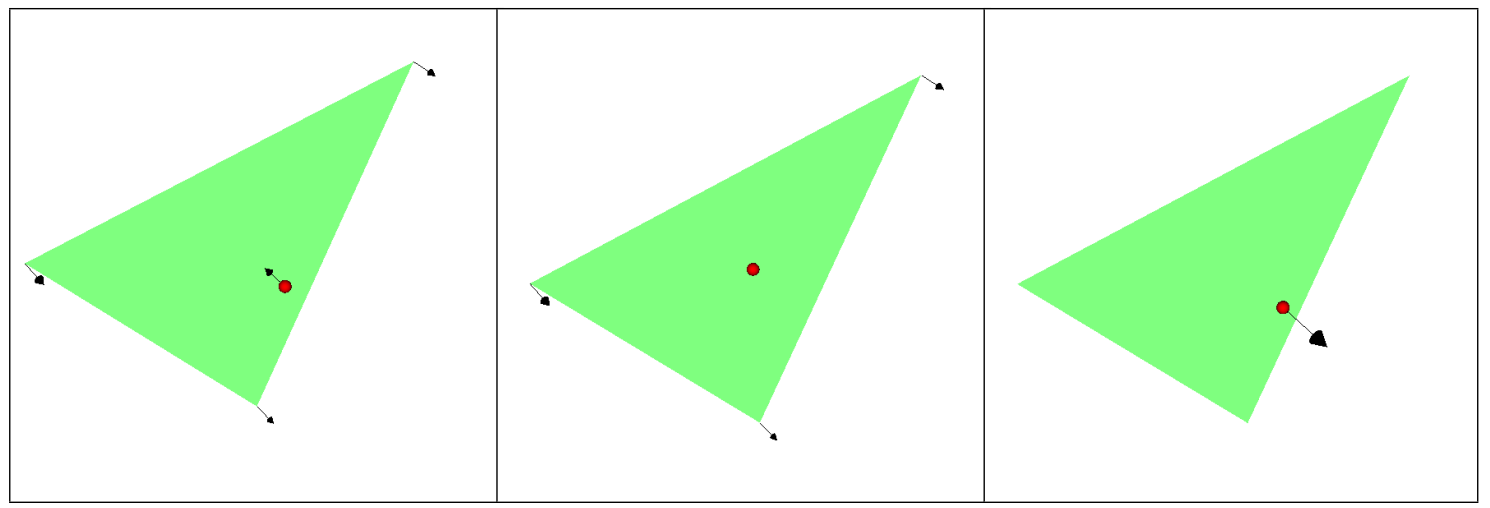

Figura 4.7: Colisão elástica entre um ponto e um triângulo, onde o triângulo tem três vezes a massa do ponto e ambos têm a mesma velocidade inicial, mas em sentidos opostos. Após a colisão, o triângulo fica em repouso e o ponto é arremessado com o dobro da velocidade inicial. As setas indicam a velocidade.

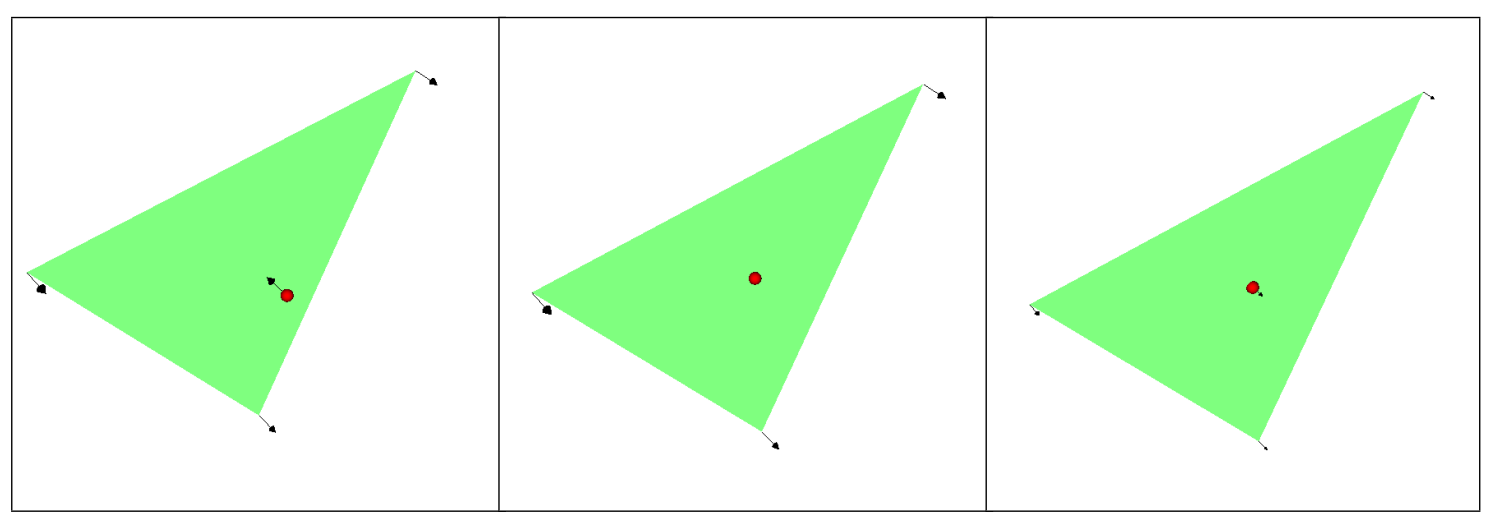

Figura 4.8: Em uma colisão perfeitamente inelástica, os objetos grudam depois da colisão. A velocidade inicial é a mesma para ambos os objetos, mas em sentidos opostos. O triângulo tem o triplo da massa do ponto. A velocidade final é metade da inicial, como esperado.

\subsubsection{Colisão ponto-superfície entre dois triângulos}

A colisão elástica entre dois triângulos de mesma forma, tamanho e massa é mostrada na figura 4.9. Os triângulos são equiláteros e tem altura igual a 1. Cada triângulo tem massa igual a 1 , dividida igualmente entre os vértices. A velocidade inicial é $10^{-1}$, representada pelas setas. O passo temporal é $10^{-4}$. Os vértices são novamente conectados com molas de constante igual a $10^{7}$.

Duas colisões acontecem. A primeira colisão faz o triângulo azul girar e atingir o lado oposto do triângulo verde. A figura 4.10 mostra que há conservação de momento linear e angular. A energia total do sistema, cinética mais elástica, também é conservada.

\subsubsection{Colisão aresta-aresta entre três triângulos}

A figura 4.11 mostra a colisão aresta-aresta entre três triângulos iguais. A configuração é a mesma do caso anterior, apenas com a adição de mais um triângulo para produzir uma segunda colisão. A figura 4.12 mostra que há conservação de momento e energia também nesse caso. 


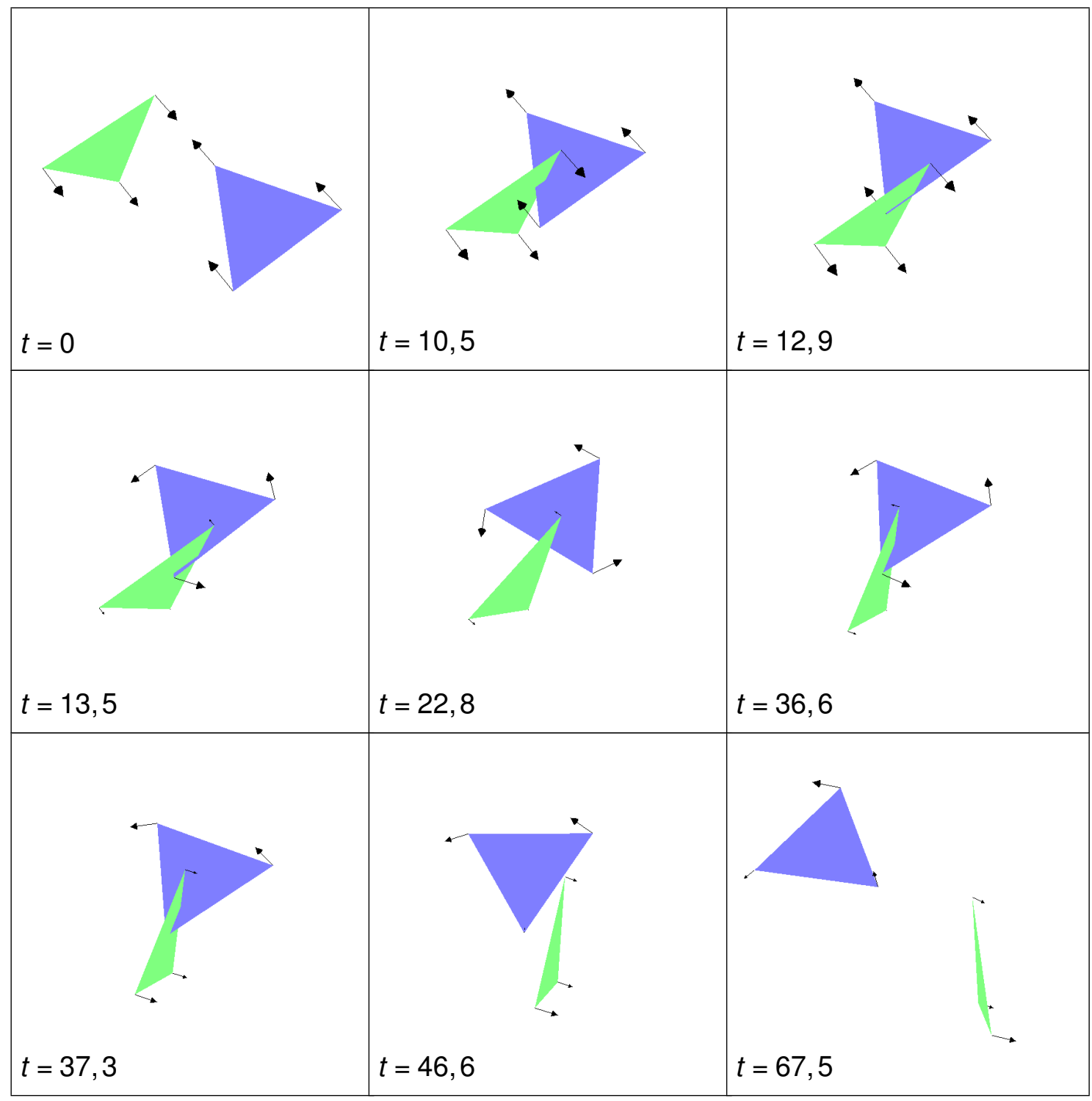

Figura 4.9: Dois triângulos de mesma forma e tamanho estão em trajetória de colisão. Primeiro há uma interseção, visto que colisões do tipo aresta-aresta não são tratadas. A primeira colisão faz o triângulo azul girar e atingir o lado oposto do triângulo verde. A colisão é elástica, logo se espera conservação de momento e energia. As setas representam a velocidade, com tamanhos proporcionais a magnitude. $\mathrm{O}$ tempo de simulação está especificado em cada quadro.

\subsubsection{Colisão entre vários triângulos}

A figura 4.13 mostra colisões simultâneas entre vários triângulos. Os triângulos são equiláteros. O maior tem altura igual a 1 e os outros $0.8,0.6,0.4$ e 0.2 . Todos tem massa igual a 1, dividida igualmente entre os vértices. Eles estão sob a ação da aceleração da gravidade, com módulo igual a 1, e há um "chão" abaixo do maior triângulo. A espessura da membrana foi aumentada do usual valor de 0.01 para 0.1 visando melhorar a visualização da acomodação dos triângulos. Os triângulos estão inicialmente paralelos e a uma distância de 0.2. Eles caem em cima uns dos outros e se empilham perfeitamente, separados por uma distância de 0.1 . 

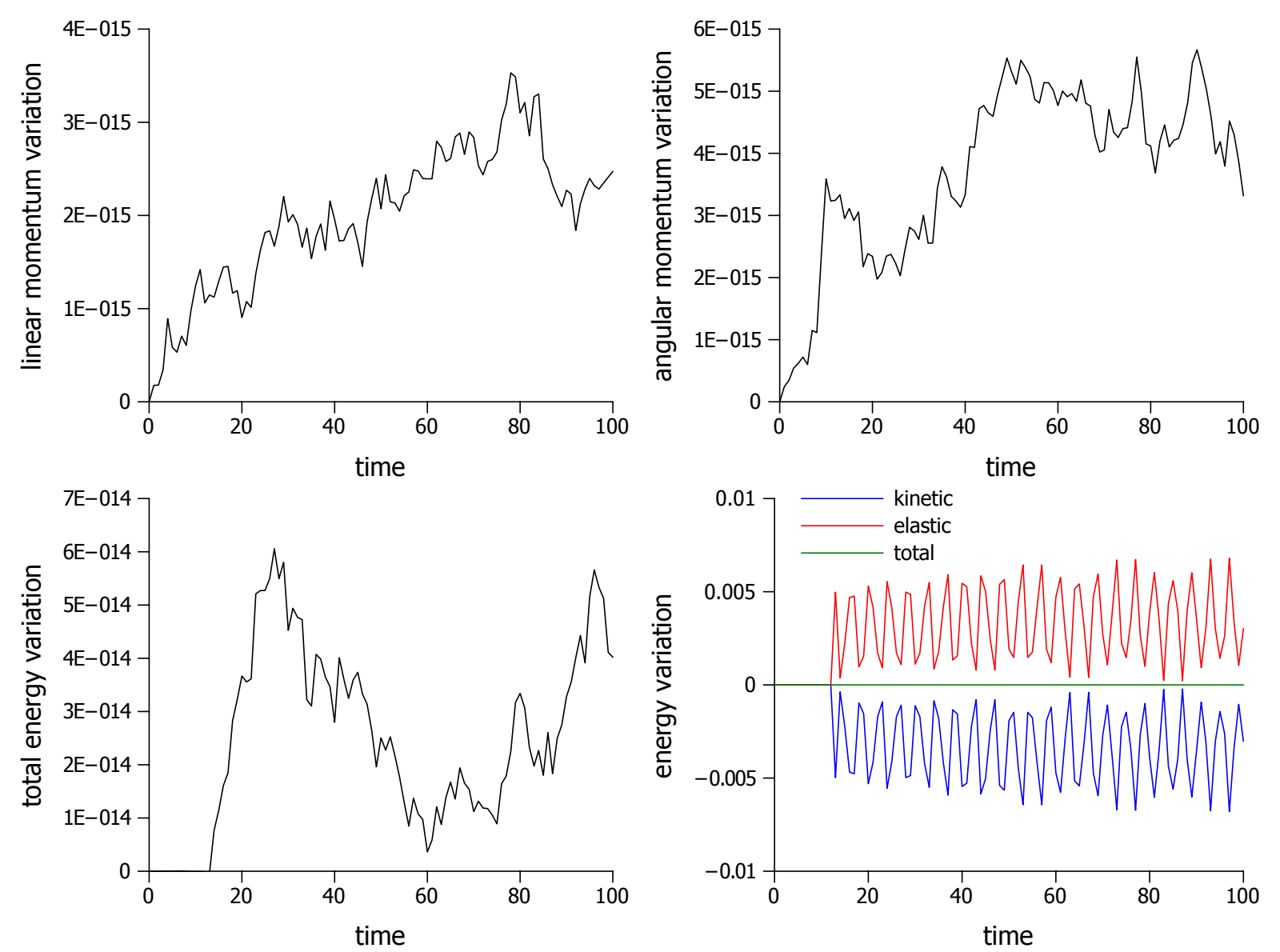

Figura 4.10: A colisão entre dois triângulos mostra boas propriedades de conservação. Os gráficos mostram a variação das grandezas em relação aos seus valores iniciais. A variação de momento linear e angular está abaixo de $10^{-14}$ e a variação de energia total, cinética mais elástica, está abaixo de $10^{-13}$. O gráfico na parte de baixo à direita mostra a variação individual da energia cinética em azul e elástica em vermelho. Quando uma aumenta, a outra diminui, levando à conservação da energia total, em verde, como esperado. As oscilações começam no tempo 12,9500, quando ocorre a primeira colisão. A segunda colisão acontece no tempo 36,6618 .

\subsubsection{Plano inclinado}

A figura 4.14 mostra o arranjo do conhecido problema de um bloco deslizando sobre um plano inclinado. Ambos o bloco e o plano inclinado são feitos de membranas elásticas. O modelo elástico de molas é usado novamente, com uma constante de $10^{7}$, o que faz com que eles se comportem como objetos sólidos rígidos.

O bloco está sob a ação da gravidade, com valor igual a 1 , na direção vertical $z$ e tem massa igual a 8 . O plano inclinado tem massa igual a $6 \times 10^{10}$ e não é afetado pela gravidade. Isso deixa o plano estacionário enquanto o bloco pode se mover. O plano se estende ao longo da direção $x$ com um comprimento igual a 1. Sua largura, direção $y$, é 0,2. Uma das extremidades é fixa enquanto a outra pode variar de altura, direção $z$.

Como primeiro experimento, a altura do plano é fixada em 0,5 . O bloco desliza sem atrito para testar o algoritmo de colisão. A velocidade do bloco é mostrada na figura 4.15, gráfico da esquerda. Há uma acomodação inicial, que produz uma pequena oscilação no gráfico. O bloco ganha velocidade com uma aceleração constante até que cai do plano, entre os tempos 2 e 3. Depois disso, o bloco está em queda livre, por isso a aceleração maior.

No próximo experimento, o mesmo arranjo é usado, mas o bloco só desliza sem 


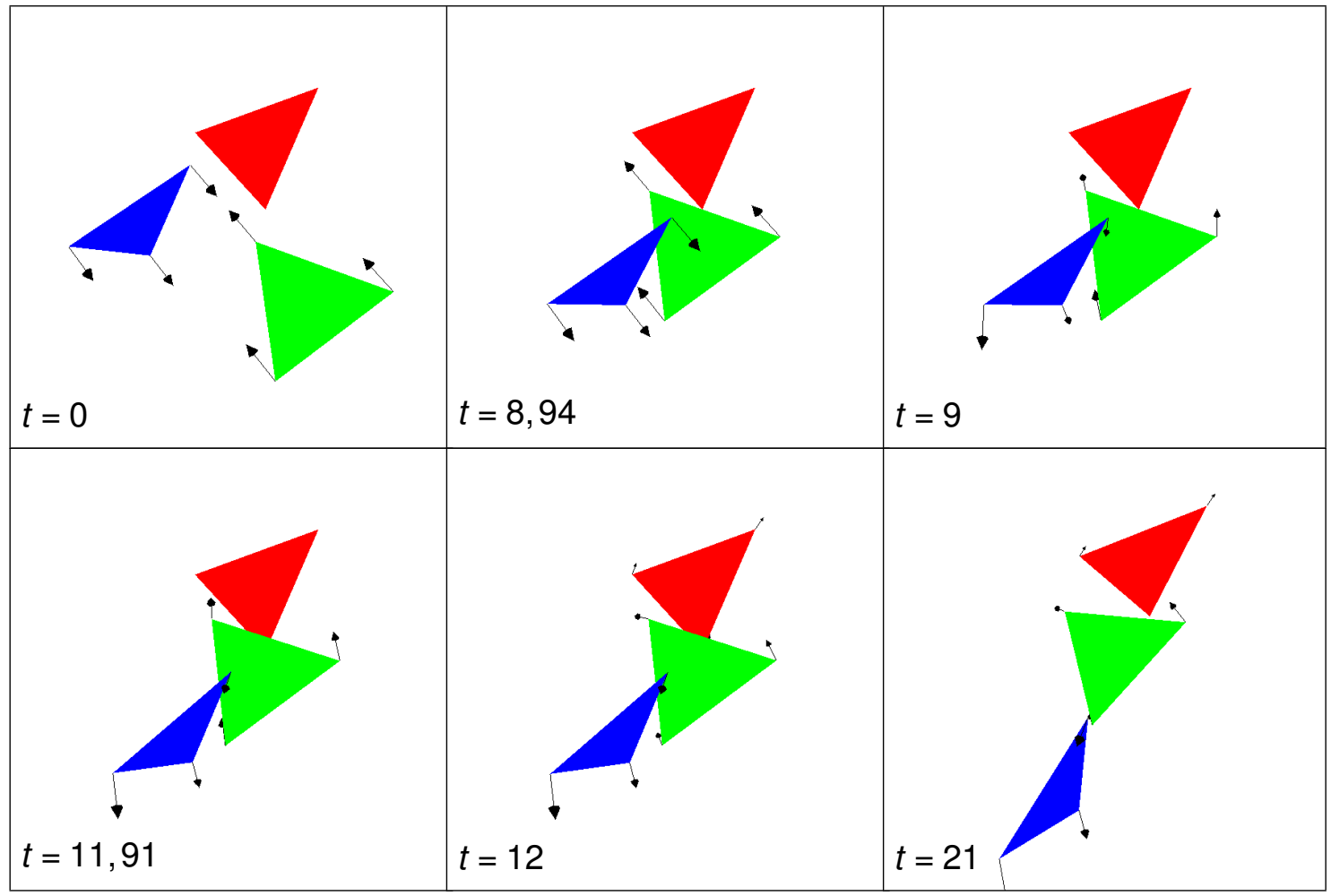

Figura 4.11: O teste de colisão aresta-aresta evita que os triângulos se intersectem, como ocorre quando somente contatos ponto-superfície são tratados.

atrito até o tempo 0,5. Neste ponto, o atrito é ligado, com coeficientes 0,57 (dinâmico) e 0,74 (estático). Esses valores correspondem ao atrito entre duas superfícies de aço. 0 bloco imediatamente para de ganhar e começa a perder velocidade, também com aceleração constante, até parar totalmente. Isso pode ser visto no gráfico da direita da figura 4.15.

Agora a situação oposta é testada. Ao invés de usar o atrito para desacelerar e parar o bloco, o bloco estará inicialmente em repouso e a gravidade irá gradualmente superar o atrito e fazer o bloco deslizar. O arranjo é o mesmo, com atrito desde o início, mas o plano está inicialmente na horizontal. Sua altura aumenta a uma taxa constante de 0,01, o que também aumenta a componente tangencial da gravidade que age sobre o bloco. Em um dado momento, a componente tangencial da gravidade supera o atrito de destaque e o bloco começa a deslizar, como visto na figura 4.16.

Até por volta do tempo 19, o bloco está em repouso. Depois disso, a componente tangencial da gravidade passa a ser grande o suficiente para superar 0 atrito de destaque. $O$ bloco começa a deslizar com uma aceleração constante. A linha vermelha na figura 4.16 representa a aceleração esperada de deslizamento, que é a componente tangencial da gravidade menos o atrito dinâmico. O salto que ocorre na aceleração perto do tempo 19 é a diferença entre o atrito de destaque e o dinâmico. O bloco chega ao fim do plano perto do tempo 25.

Finalmente, o coeficiente de atrito é aumentado para 1. O resultado pode ser visto na figura 4.17. Ao invés de deslizar, quando a inclinação se torna muito grande, o bloco começa a rolar plano abaixo. 

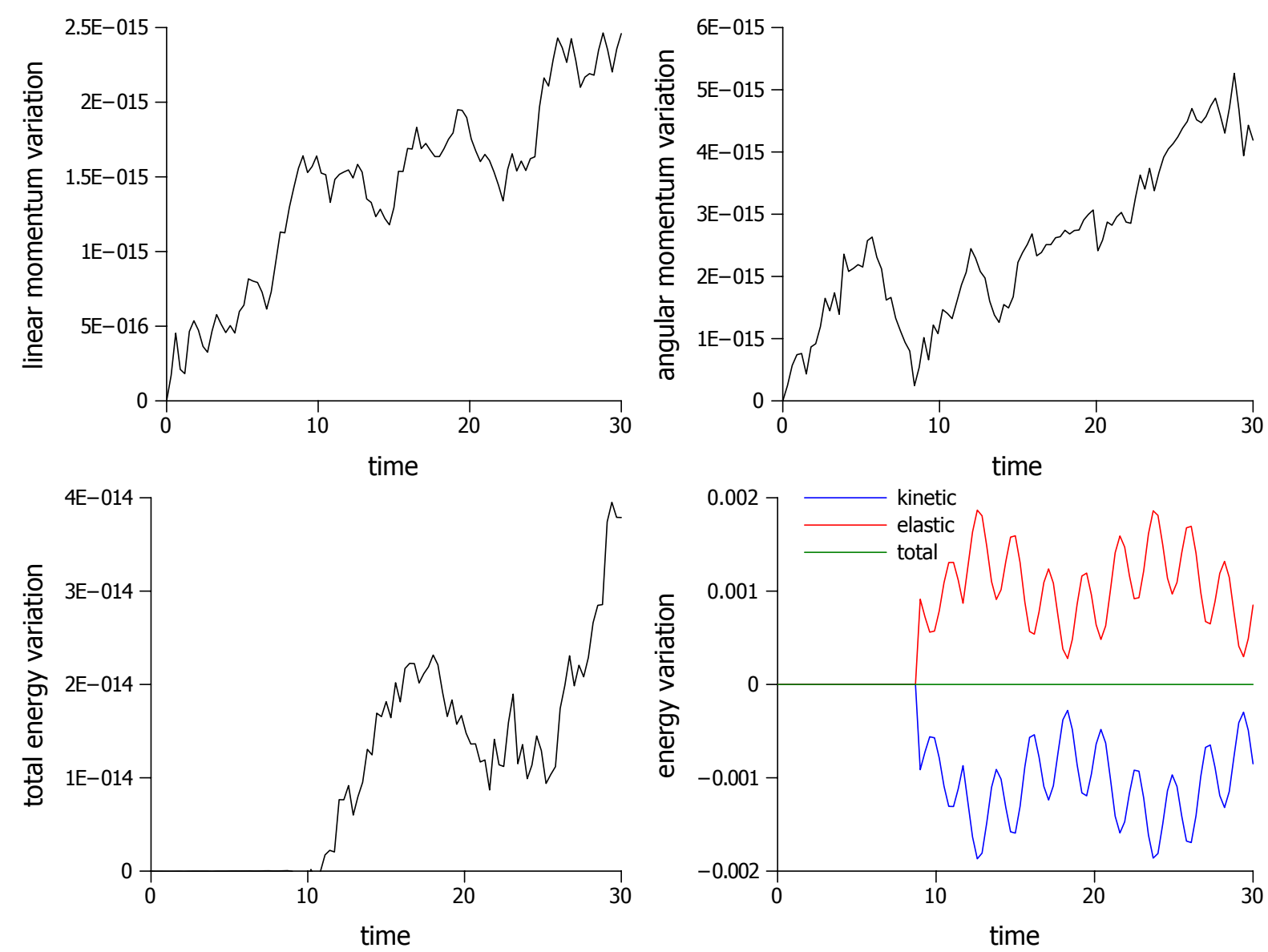

Figura 4.12: Assim como no caso de colisão ponto-superfície, a colisão aresta-aresta mostra uma boa conservação de momento e energia.

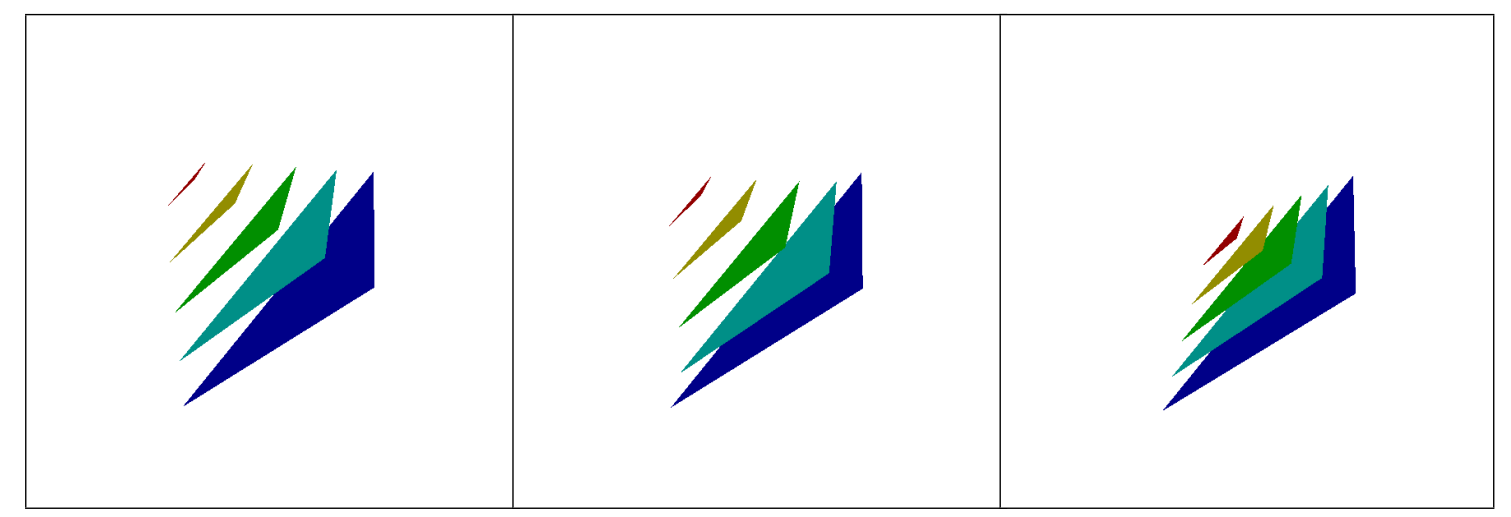

Figura 4.13: O algoritmo pode tratar colisões múltiplas como a mostrada aqui. Os triângulos caem uns em cima dos outros e se empilham perfeitamente. A espessura da membrana foi aumentada dez vezes para melhorar a visibilidade.

\subsection{Resultados - modelo baseado em força}

\subsubsection{Colisão com objetos fixos}

A figura 4.18 mostra uma membrana cheia de fluido sob a ação da gravidade interagindo com vários obstáculos cilíndricos. O raio inicial é $R=1$, a massa total da membrana é $M=1$ e a densidade do fluido interno é $\rho_{f}=1$, sob uma aceleração gravitacional 


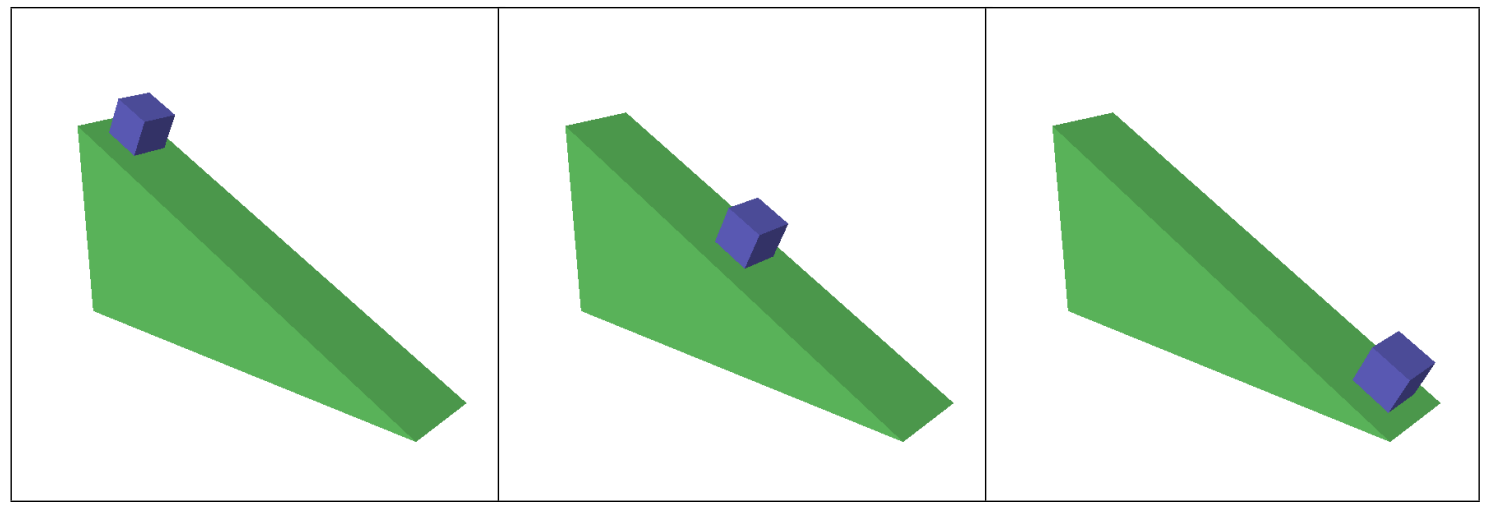

Figura 4.14: Plano inclinado. O bloco, em azul, desliza ao longo do plano, em verde. O plano é estacionário, quanto o bloco está sob a ação da gravidade. Forças de contato e atrito são trocadas.
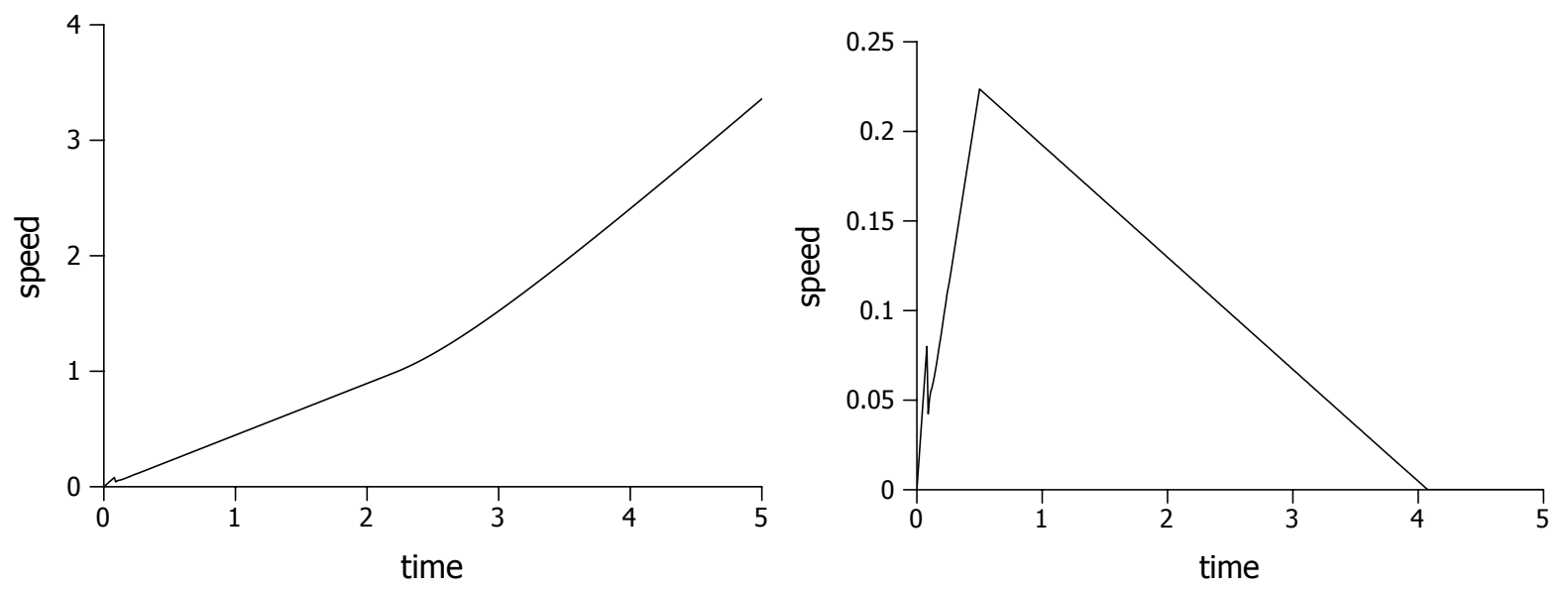

Figura 4.15: Na esquerda, a velocidade do bloco para o caso sem atrito. O bloco ganha velocidade com uma aceleração constante, deslizando ao longo do plano. Entre os tempos 2 e 3, o bloco sai do plano, o que aumenta a aceleração. Na direita, antes do tempo 0,5 não há atrito, e o bloco acelera. Depois disso, os coeficientes de atrito passam a ser 0,57 (dinâmico) e 0,74 (estático). O bloco diminui de velocidade até parar. Em ambos os casos, há uma acomodação inicial que produz uma oscilação no gráfico próximo a $t=0$.

$\mathbf{g}=(-0,1 ; 0 ;-1)$. O material segue o modelo de Hooke com módulo de cisalhamento $G=1$ e módulo de compressibilidade $K=2$. Um arrasto de Stokes com constante $b=10$ foi usado para dissipar energia e permitir que o repouso fosse atingido. O passo temporal é $\Delta t=10^{-3}$. A constante da mola de colisão é $k=10^{6}$. A constante de atrito fluido é $\beta=10^{2}$. A membrana tem uma espessura de $h=10^{-2}$.

\subsubsection{Colisão entre membranas}

A figura 4.19 mostra várias membranas sob a ação da gravidade colidindo entre si. O raio inicial de cada membrana é $R=1$, a massa total de cada membrana é $M=1 \mathrm{e}$ não há fluido interno, sob uma aceleração gravitacional $\mathbf{g}=(0 ; 0 ;-1)$. O material segue o modelo de Hooke com módulo de cisalhamento $G=1$ e módulo de compressibilidade $K=2$. Um arrasto de Stokes com constante $b=1$ foi usado para dissipar energia e permitir que 0 repouso fosse atingido. O passo temporal é $\Delta t=10^{-3}$.

A constante da mola de colisão é $k=10^{6}$. A constante de atrito fluido é $\beta=10^{3}$. A membrana tem uma espessura de $h=10^{-2}$. 

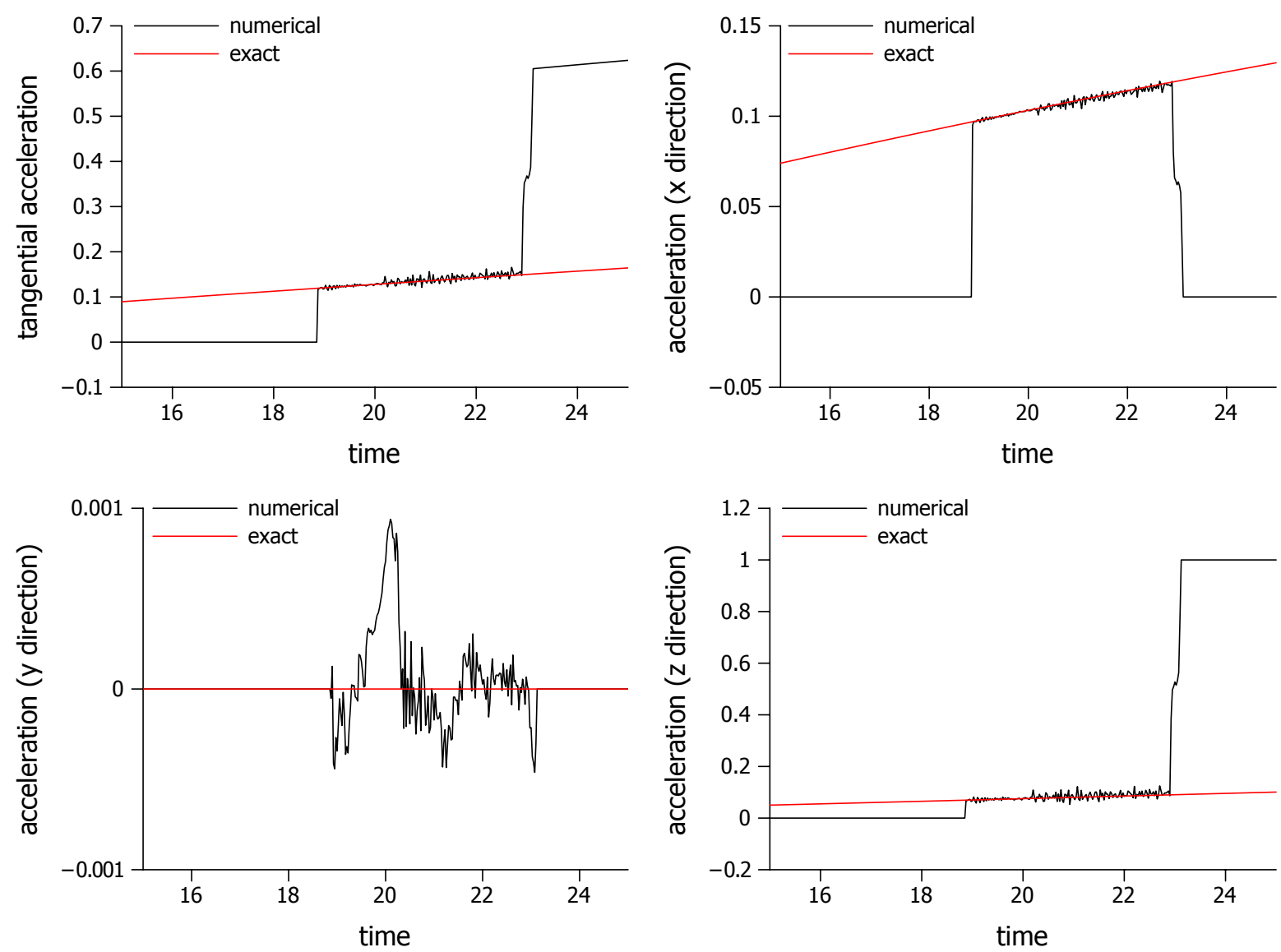

Figura 4.16: Os coeficientes de atrito são postos em 0,57 (dinâmico) e 0,74 (estático) e a gravidade é 1 na direção vertical $z$. O plano está inicialmente na horizontal e se estende ao longo da direção $x$. Um extremo do plano está fixo e o outro sobe a uma taxa constante. Por volta do tempo 19, a componente tangencial da gravidade excede o atrito de destaque. O bloco começa a acelerar até que cai do plano, por volta do tempo 21. A linha vermelha mostra a aceleração esperada, que é a componente tangencial da gravidade menos o atrito dinâmico.

\subsection{Considerações finais}

Apesar de nem sempre produzir resultados fisicamente corretos, o algoritmo baseado em forças gera resultados visualmente plausíveis. Além disso, ele é útil para situações onde a dinâmica da colisão não é fundamental, e há interesse no estado de equilíbrio estático.

O algoritmo baseado em impulso apresentado aqui mostrou correção física e robustez em todos os casos testados. A única situação que trouxe dificuldades foi o caso envolvendo múltiplas colisões onde um ponto colide simultaneamente com dois triângulos, formando um "sanduíche". Nesses casos, o algoritmo pode não convergir para um estado onde todas as colisões estão resolvidas. Esse desafio também é enfrentado por outros autores, e.g. (Bridson et al., 2002). Esse é um dos motivos que fazem o problema de colisões ainda ser considerado um problema em aberto. 


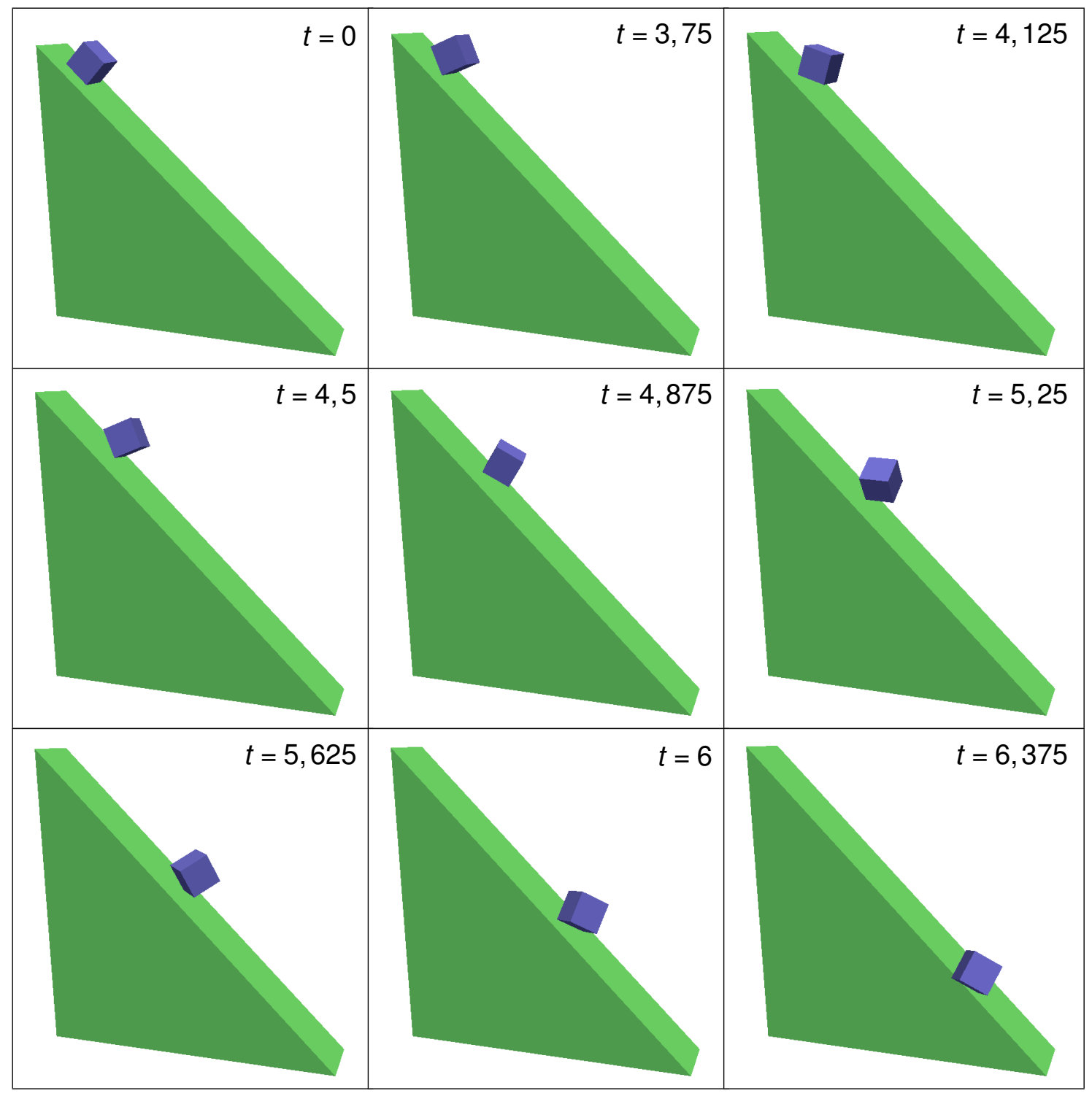

Figura 4.17: Quando o coeficiente de atrito é muito grande, neste caso 1, o bloco começa a rolar antes de deslizar, quando o plano atinge uma inclinação crítica. O tempo de simulação está indicado em cada quadro. 


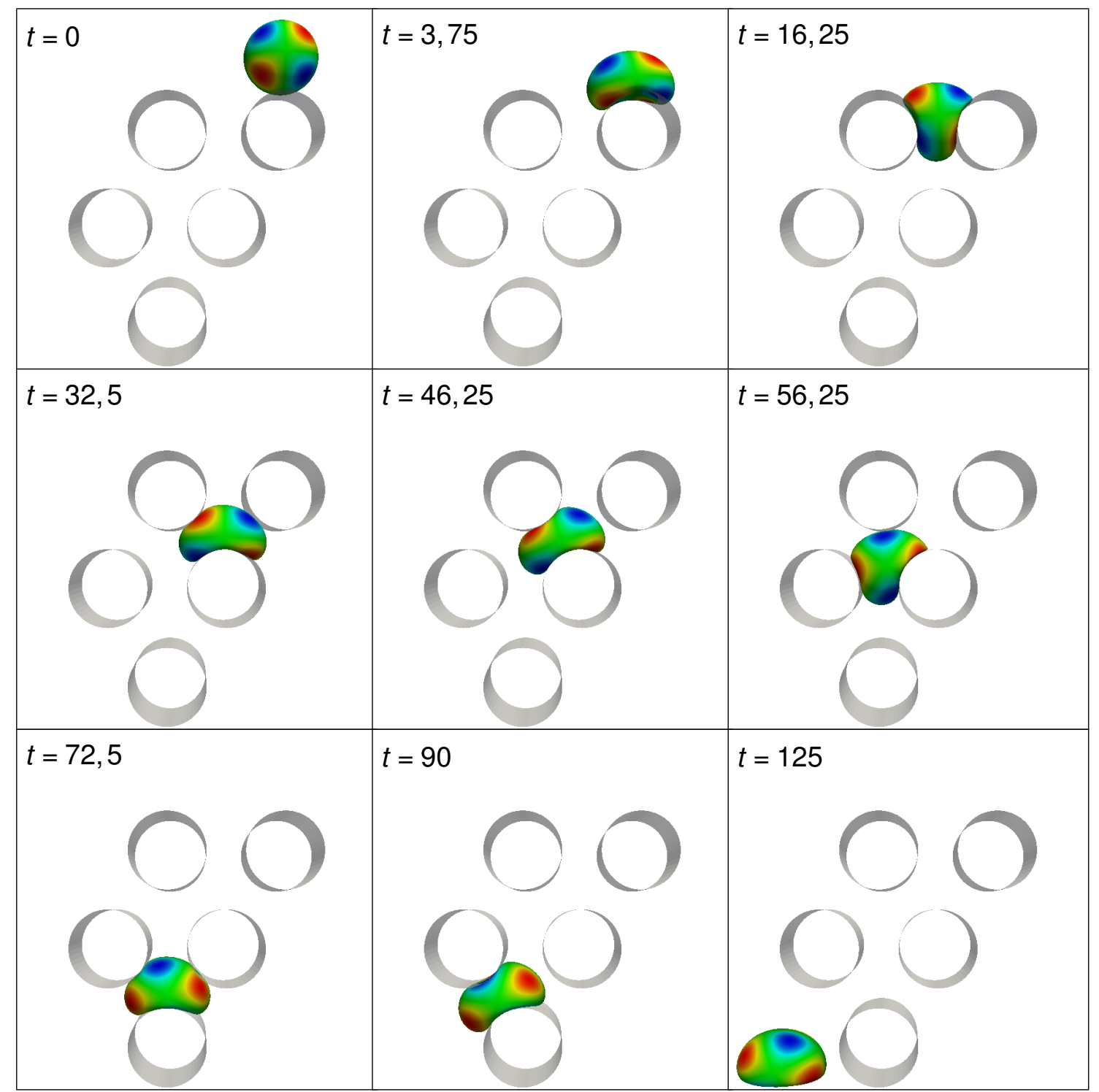

Figura 4.18: Membrana elástica sob ação da gravidade colidindo com objetos fixos. O tempo da simulação está indicado nos quadros. 


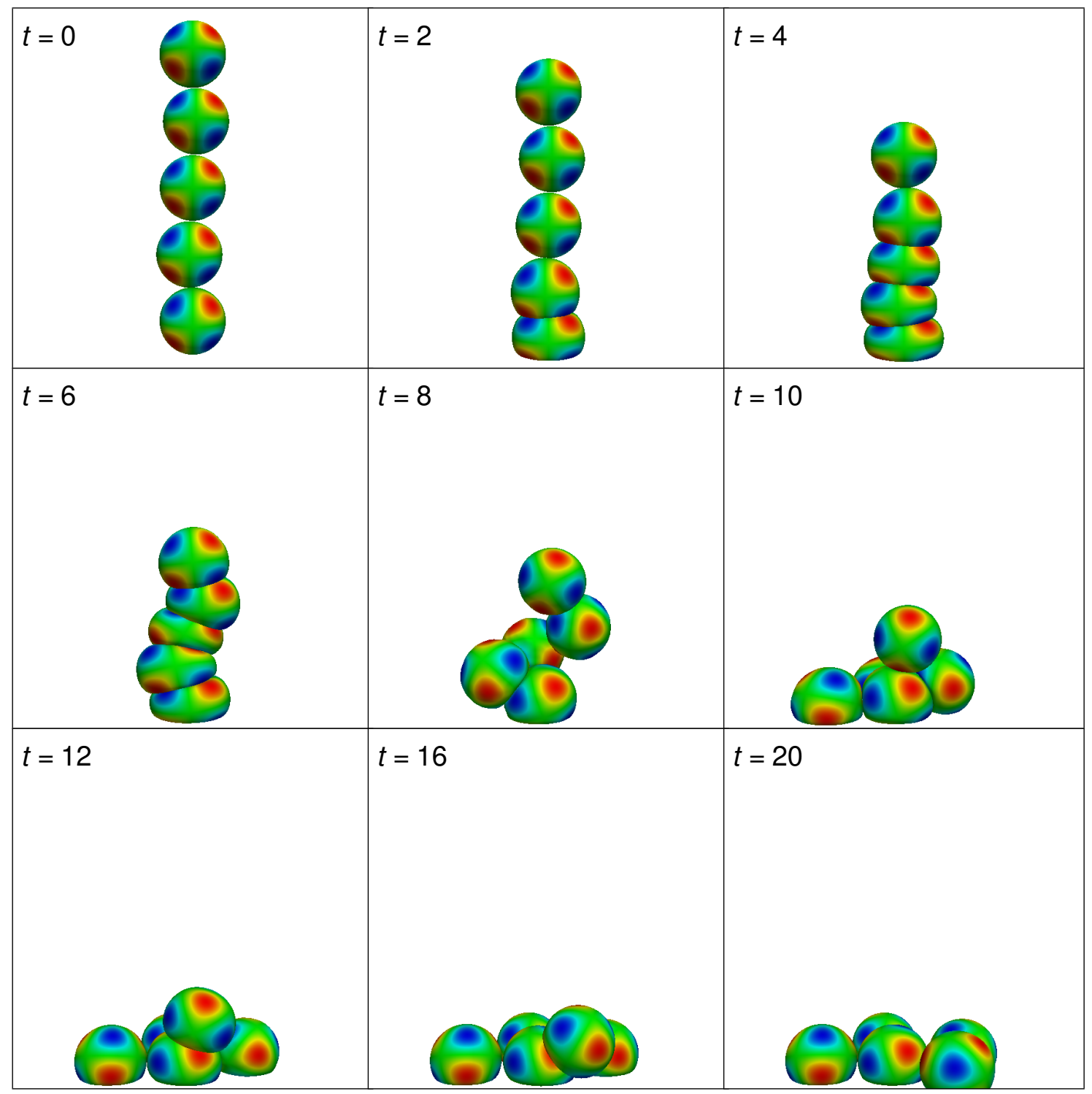

Figura 4.19: Membranas elásticas sob ação da gravidade colidindo entre si. O tempo da simulação está indicado nos quadros. 

Divide each difficulty into as many parts as is feasible and necessary to resolve it.

René Descartes

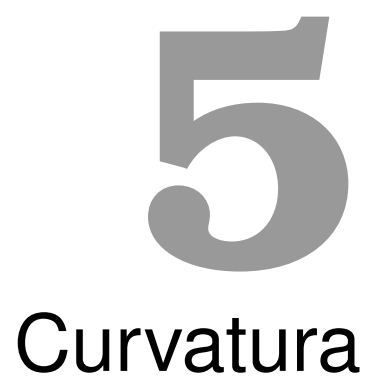

A dinâmica e forma de repouso de membranas celulares são mais bem explicadas em termos da minimização da energia de Canham-Helfrich. Essa energia é diretamente dependente da curvatura da membrana. Em simulações lagrangianas de elementos finitos, a informação sobre a curvatura deve ser inferida a partir de superfícies discretas, i.e. da malha. Neste capítulo, alguns dos mais populares métodos de estimativa de curvatura são analisados quanto à sua capacidade de descrever o comportamento dinâmico de membranas regidas pela energia de Canham-Helfrich.

\subsection{Energia de Canham-Helfrich}

Membranas celulares, figura 5.1 , são formadas por bicamadas de moléculas fosfolipídicas. Essas moléculas são hidrofílicas de um lado e hidrofóbicas de outro. Por causa disso, em solução aquosa, elas se tornam uma superfície fechada, uma vesícula chamada lipossoma, vista na figura 5.2. Essas membranas são sabidamente inextensíveis, i.e. a área superficial não muda. Por serem semipermeáveis, o volume interno depende apenas das concentrações dos fluidos interno e externo. A pressão osmótica é algumas ordens de grandeza maior do que quaisquer forças mecânicas exercidas pela membrana (Pozrikidis, 2003).

As moléculas na superfície estão livres para se rearranjarem e mudarem a forma da vesícula. A forma de repouso é atingida quando a energia elástica de dobramento sobre toda a membrana chega a um mínimo local. Essa energia foi estudada inicialmente por (Canham, 1970; Helfrich, 1973; Evans, 1974), e variações dela foram introduzidas por (Seifert, 1997). Os mínimos dessa energia reproduzem com grande realismo as formas encontradas em células vivas e vesículas lipídicas (Lipowsky, 1991; Seifert et al., 1991; Wortis \& Mukhopadhyay, 2002; Wang \& Du, 2008; Seifert, 1997).

A energia de Canham-Helfrich tem a forma

$$
E=\int\left[a_{1}+a_{2}\left(H-H_{0}\right)^{2}+a_{3} G\right] d A,
$$

onde $a_{1}$ representa a tensão superficial, que está relacionada com a interação entre a vesícula e o fluido adjacente. $H=\left(\kappa_{1}+\kappa_{2}\right) / 2$ é a curvatura média da membrana, sendo $\kappa_{1}$ e $\kappa_{2}$ as 


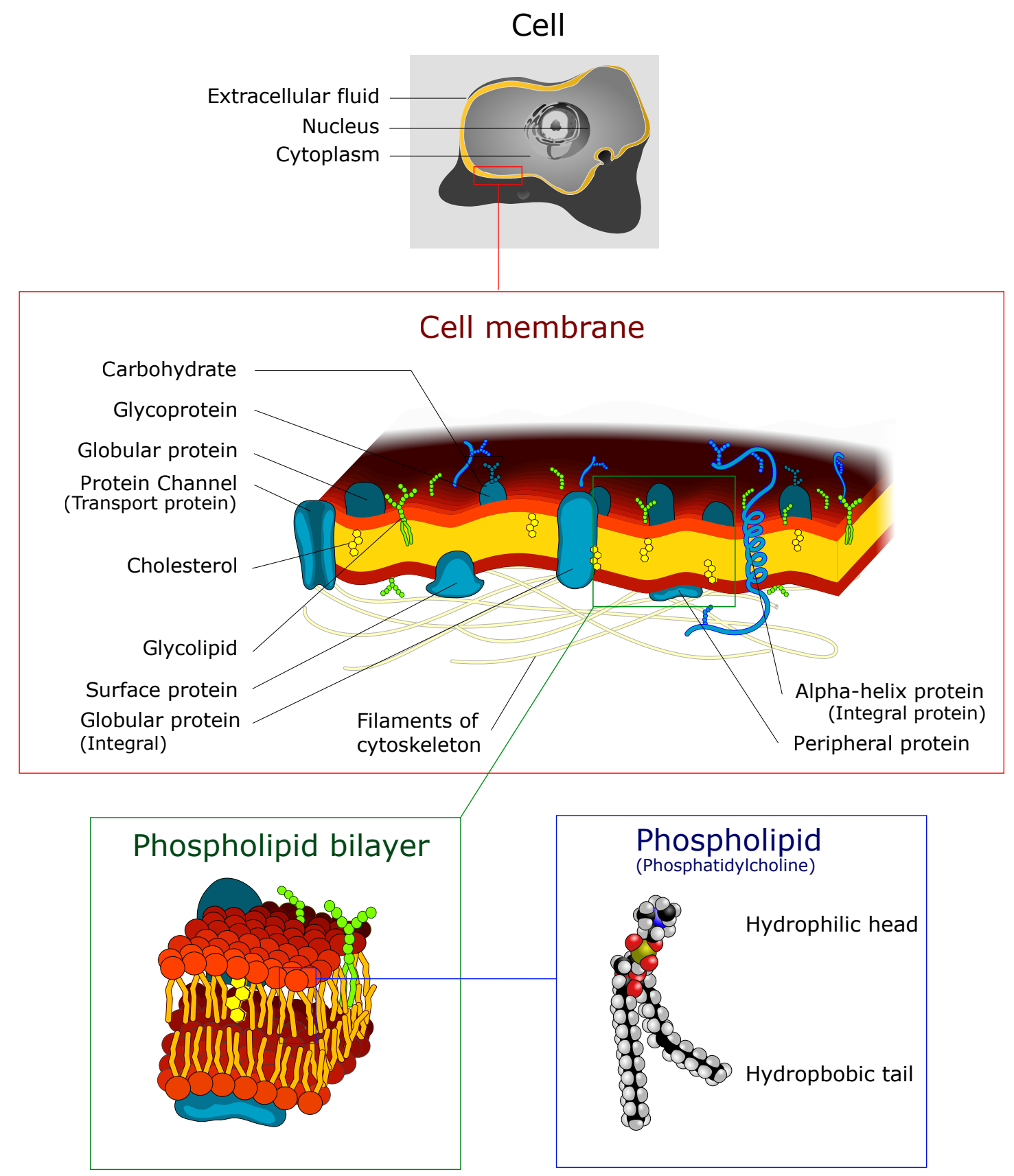

Figura 5.1: Membranas celulares são formadas por bicamadas de fosfolipídios. Fosfolipídios são moléculas que possuem uma cabeça hidrofílica e uma cauda hidrofóbica. Imagem retirada de (Wikipedia, 2013a).

curvaturas principais. $G=\kappa_{1} \kappa_{2}$ é a curvatura gaussiana. $a_{2}$ é a rigidez de dobramento e $a_{3}$ a rigidez de distensão. $H_{0}$ é a curvatura espontânea. A integral é feita sobre toda a área $A$ da membrana.

Neste trabalho, será considerada uma forma simplificada da energia de CanhamHelfrich, onde $a_{1}, a_{3}$ e $H_{0}$ são nulos. Portanto, para calcular o estado de repouso e a dinâmica da membrana, é fundamental saber a curvatura da superfície, em particular a curvatura média. 


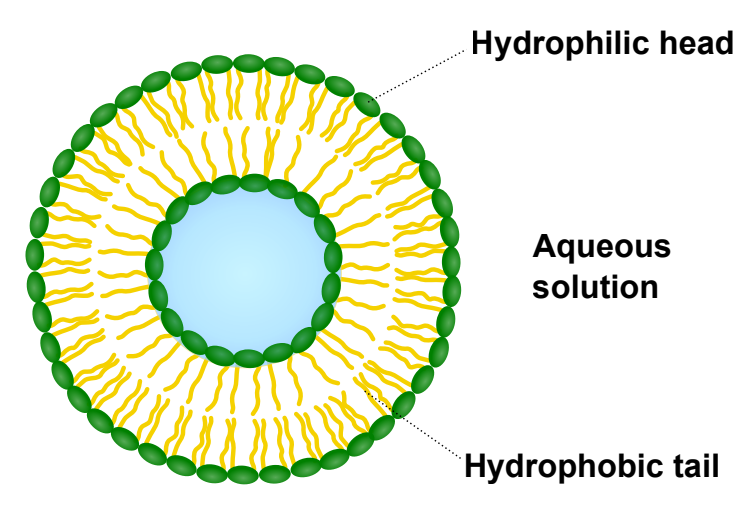

Figura 5.2: Em solução aquosa, um conjunto de fosfolipídios forma uma superfície fechada, uma vesícula chamada lipossoma. Imagem retirada de (Wikipedia, 2013c).

\subsection{Curvatura}

Em simulações de elementos finitos, a forma exata da superfície é desconhecida. A única aproximação confiável disponível é a própria malha, a qual é constituída por faces planas. Por isso, usando elementos $\mathbb{P}_{1}$, sua curvatura é zero dentro do elemento e indefinida nas arestas e vértices, visto que uma superfície duplamente diferenciável $\left(C^{2}\right)$ é necessária para calcular a curvatura média e gaussiana. O que se procura é uma maneira de estimar a curvatura da superfície que a malha está aproximando.

Uma característica importante das estimativas de grandezas associadas a superfícies, como curvatura ou vetor normal, é a convergência. Neste caso, convergência significa que, dada uma superfície analítica onde a grandeza que se quer estimar é conhecida exatamente, uma malha mais fina cujos vértices estão sobre essa superfície produz um erro na estimativa menor do que uma malha mais grossa, também com os vértices sobre a superfície analítica.

Não há consenso com relação à maneira mais apropriada de estimar a curvatura em superfícies discretas. Alguns autores ajustam localmente uma superfície, de segunda ordem pelo menos, e calculam a curvatura a partir dela. Esses métodos são ditos contínuos. Em contraste, um método discreto usa formas fechadas para operadores geométricos diferenciais que agem diretamente sobre a malha. Muitos são os trabalhos presentes na literatura que propõem técnicas "novas" e "melhores" em ambas as categorias, assim como estudos e comparações das diferentes abordagens. Esses artigos comparam as estimativas de curvatura à curvatura verdadeira de superfícies analíticas.

Nas seções seguintes, será feita uma avaliação do desempenho das aproximações de curvatura na simulação de sistemas dinâmicos regidos por energias elásticas de dobramento. Alguns dos métodos mais populares, tanto discretos quanto contínuos, serão usados em simulações de membranas até que um estado estacionário seja atingido. A forma final da membrana será então comparada aos resultados analíticos de (Veerapaneni et al., 2009) para os casos bidimensionais. Casos tridimensionais também serão simulados. 


\subsection{Vetor normal nos vértices}

Alguns algoritmos de curvatura dependem da informação sobre os vetores normais nos vértices da malha. Esses vetores estão bem definidos e são fáceis de calcular nas faces da malha, mas nos vértices eles precisam ser estimados. A maneira mais comum de estimar a normal $\mathbf{n}_{v}$ em um vértice é calcular uma média ponderada das normais das faces adjacentes,

$$
\mathbf{n}_{v}=\frac{\sum_{i} \alpha_{i} \mathbf{n}_{i}}{\left|\sum_{i} \alpha_{i} \mathbf{n}_{i}\right|}
$$

onde $\mathbf{n}_{i}$ é a normal da face $i$ adjacente ao vértice e $\alpha_{i}$ é o peso associado. O somatório é feito sobre todas as faces adjacentes ao vértice.

Um método de pesos iguais, i.e. $\alpha_{i}=1$, foi proposto por (Gouraud, 1971). Outro método conhecido é tomar $\alpha_{i}$ como sendo a área do triângulo $i$.

Pesos dependentes do ângulo incidente são usados por (Thürmer \& Wüthrich, 1998). Faz-se $\alpha_{i}$ igual ao ângulo da face $i$ no vértice onde a normal está sendo calculada. Uma vantagem desse método é que diferentes tesselações de uma superfície discreta produzem a mesma normal. O mesmo não é válido para pesos iguais ou baseados na área.

O desempenho desses algoritmos varia de acordo com a malha. (Max, 1999) comparou os métodos acima e outros com um proposto por ele. Sua conclusão foi que a ponderação pelo ângulo incidente gera os piores resultados e o método proposto por ele seria o melhor. (Max, 1999) usou superfícies polinomiais de terceira ordem geradas aleatoriamente como casos testes e a derivação do seu método parte da suposição que a malha está inscrita em uma esfera.

Por outro lado, a investigação feita por (Jin et al., 2005) concluiu que o método que pondera pelo ângulo incidente "é mais frequentemente uma boa escolha". Os métodos foram testados em 10 modelos geométricos diferentes, como esferas, toros e superfícies.

Todos esses métodos baseados na soma ponderada das normais das faces vizinhas convergem linearmente em malhas irregulares (Langer et al., 2007). Em malhas compostas por vértices regulares, a convergência é quadrática. Vértices regulares têm valência par, ou seja, possuem um número par de arestas incidentes. Além disso, arestas opostas têm comprimento igual e ângulos opostos também são iguais. Um exemplo de vértice regular pode ser visto na figura 5.4 (direita).

Neste trabalho, seguindo a recomendação de (Jin et al., 2005), será usada a ponderação pelo ângulo incidente (Thürmer \& Wüthrich, 1998) quando o método de estimativa de curvatura depender da normal nos vértices.

\subsection{Método de Meyer}

O método de Meyer (Meyer et al., 2002) é a mais amplamente utilizada aproximação discreta para a curvatura média (Langer et al., 2007). Ele usa células de Voronoi e um método misto de elementos finitos e volumes finitos para calcular o chamado "vetor normal de curvatura média discreto". Este vetor, localizado nos vértices da malha, aponta na direção normal e seu módulo está relacionado à curvatura média. Meyer também mostra como obter outras quantidades como a curvatura gaussiana e as curvaturas e direções principais.

O primeiro passo para calcular o vetor normal de curvatura média discreto é determinar a área em torno de um vértice associada com o vetor. Essa área é o polígono cujos lados conectam os pontos médios das arestas que emanam do vértice em direção a um 


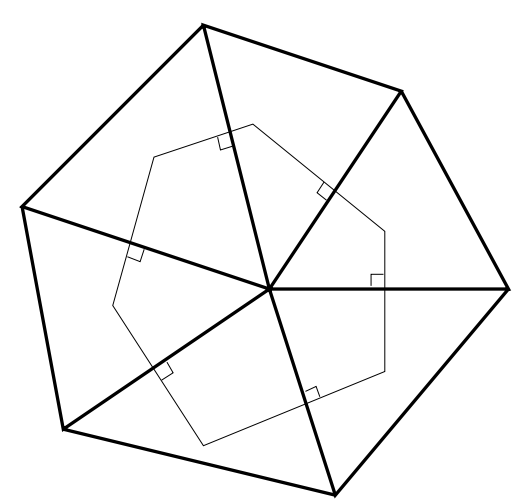

(a)

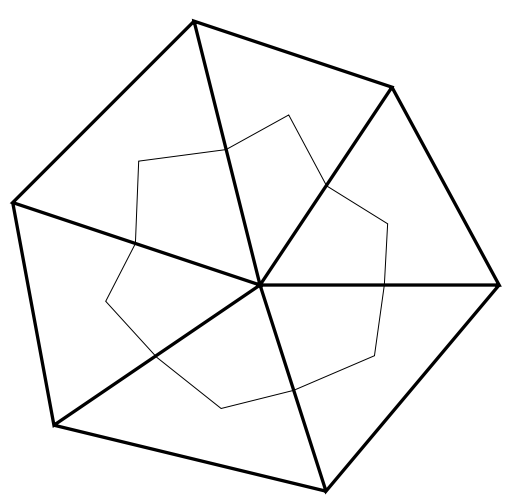

(b)

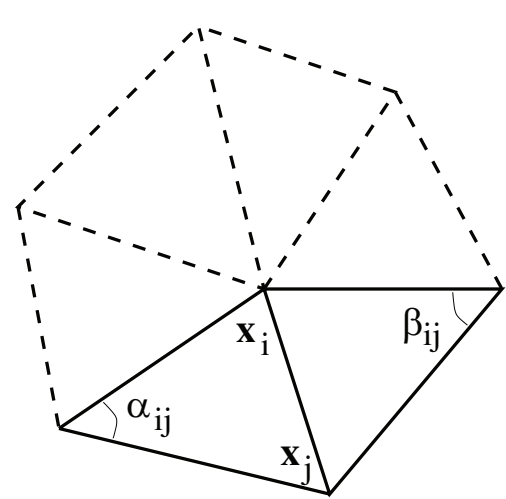

(c)

Figura 5.3: Região de volumes finitos em uma superfície triangulada usando células de Voronoi (a) e células baricêntricas (b). Vizinhança de um vértice e ângulos opostos à aresta (c). Imagem retirada de (Meyer et al., 2002).

ponto dentro de cada triângulo adjacente. O ponto dentro de cada triângulo é escolhido como sendo o circuncentro, se o triângulo for acutângulo, ou o baricentro, caso contrário. A área associada ao circuncentro, $\mathscr{A}$ Voronoi, é a célula de Voronoi local, vista na figura 5.3a e a área

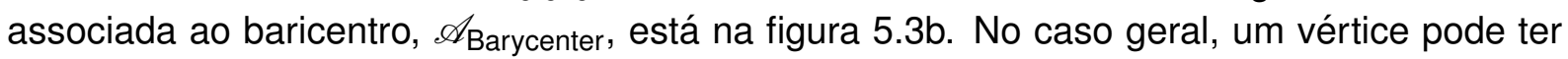
adjacente a si tanto triângulos acutângulos quanto obtusângulos. A área associada, $\mathscr{A}_{\text {Mixed }}$, é a combinação das áreas de Voronoi e baricêntricas.

Seja $\mathbf{x}_{i}$ o vértice onde se quer estimar a curvatura e $\mathbf{x}_{j}$ um de seus vizinhos, como na figura 5.3c. O conjunto dos primeiros vizinhos de $\mathbf{x}_{i}$ é denotado por $N_{1}(i)$. A área de Voronoi é

$$
\mathscr{A} \text { Voronoi }\left(\mathbf{x}_{i}\right)=\frac{1}{8} \sum_{j \in N_{1}(i)}\left(\cot \alpha_{i j}+\cot \beta_{i j}\right)\left|\mathbf{x}_{i}-\mathbf{x}_{j}\right|^{2}
$$

e a área mista é obtida pelo seguinte pseudocódigo:

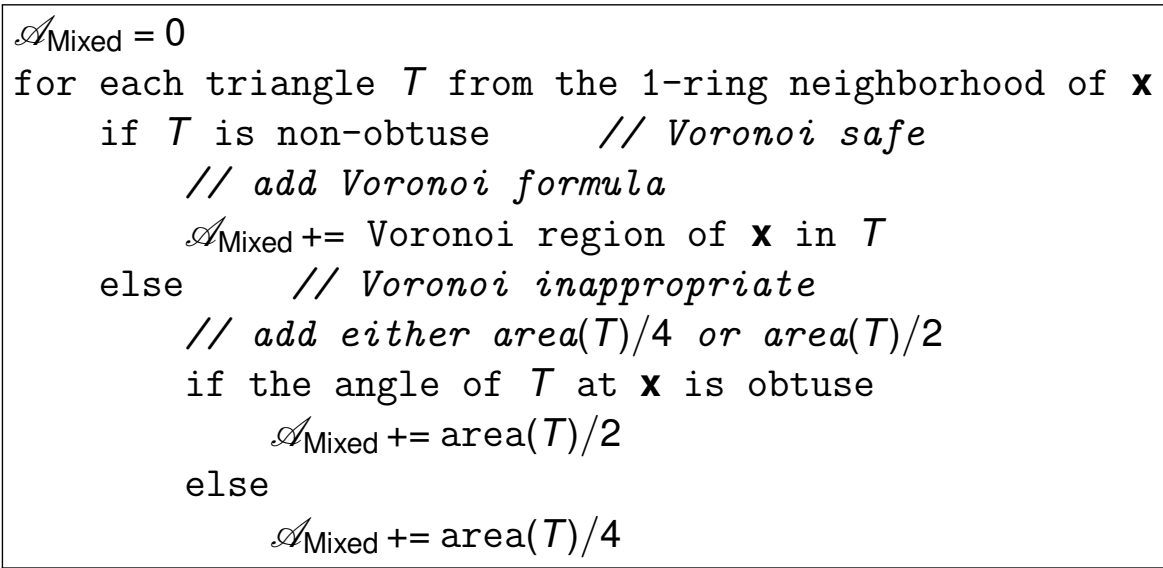

Finalmente, o vetor normal de curvatura média discreto é

$$
\mathbf{K}\left(\mathbf{x}_{i}\right)=\frac{1}{2 \mathscr{A}_{\text {Mixed }}} \sum_{j \in N_{1}(i)}\left(\cot \alpha_{i j}+\cot \beta_{i j}\right)\left(\mathbf{x}_{i}-\mathbf{x}_{j}\right)
$$

A curvatura média é

$$
H\left(\mathbf{x}_{i}\right)=\frac{1}{2}\left|\mathbf{K}\left(\mathbf{x}_{i}\right)\right|
$$


e a curvatura gaussiana é

$$
G\left(\mathbf{x}_{i}\right)=\frac{1}{\mathscr{A}_{\text {Mixed }}}\left(2 \pi-\sum_{j=1}^{\# f} \theta_{j}\right)
$$

onde $\theta_{j}$ é o ângulo em $\mathbf{x}_{i}$ no triângulo $j$. A soma é feita sobre todos os triângulos incidentes.

\subsubsection{Método de Meyer modificado}

Uma grande desvantagem do método de Meyer é que a área de Voronoi não pode ser usada para triângulos obtusângulos. Por isso Meyer define a área "mista", que consiste na área da célula de Voronoi para triângulos acutângulos e na área da célula baricêntrica para triângulos obtusângulos. Para malhas que se deformam, essa abordagem faz com que a evolução da curvatura seja descontínua. Um triângulo pode transicionar de acutângulo para obtusângulo, causando uma repentina mudança na curvatura dos vértices próximos. Esse comportamento é indesejável em simulações que usam deslocamentos virtuais para estimar derivadas.

O problema é ainda mais sério quando esquemas de evolução temporal implícita são usados. A descontinuidade da curvatura prejudica o cálculo do jacobiano e pode fazer com que o método de Newton-Raphson não convirja. Nesses casos, uma versão modificada do método de Meyer é adotada, onde a área de Voronoi passa a ser sempre usada, inclusive para triângulos obtusângulos. Isso prejudica o cálculo da curvatura se a malha tiver ângulos muito obtusos, mas há melhora significativa na convergência do método de Newton-Raphson.

Essa versão modificada do método de Meyer também é usada em (Langer et al., 2007). Os autores justificam que usar sempre a área de Voronoi garante uma tesselação perfeita sem sobreposições se forem admitidas áreas negativas. A célula de Voronoi no ângulo obtuso extrapola a área do triângulo, mas isso é compensado pelas células de Voronoi nos ângulos agudos que contam a mesma área negativamente.

O método de Meyer converge linearmente se a malha for composta de vértices regulares (Xu, 2004; Langer et al., 2007). Sem essa regularidade não há convergência.

\subsection{Método de Langer}

Uma curva possui apenas uma curvatura em um ponto. No entanto, em cada ponto de uma superfície existe uma curvatura para cada direção tangencial. A curvatura média $H$ é a média dessas curvaturas direcionais. Baseado nisso, (Langer et al., 2007) propõe aproximar a curvatura média por uma média ponderada de curvaturas direcionais,

$$
H=\sum_{i} \omega_{i} k_{i}
$$

onde $k_{i}$ é uma aproximação de uma curvatura direcional e $\omega_{i}$ o peso correspondente.

Seja $P$ um vértice da malha e $Q_{i}$ cada um dos seus vizinhos, como visto na figura 5.4 esquerda, onde as distâncias entre vértices $a_{i}$ e os ângulos incidentes $\alpha_{i}$ também estão desenhados. Nessa configuração, os pesos $\omega_{i}$ são

$$
\omega_{i}=\frac{\tan \alpha_{i-1}+\tan \alpha_{i}}{\sum_{j}\left(\tan \alpha_{j-1}+\tan \alpha_{j}\right)},
$$

e as curvaturas direcionais $k_{i}$ são

$$
k_{i}=2 \frac{\mathbf{a}_{i} \cdot \mathbf{n}}{a_{i}^{2}}
$$



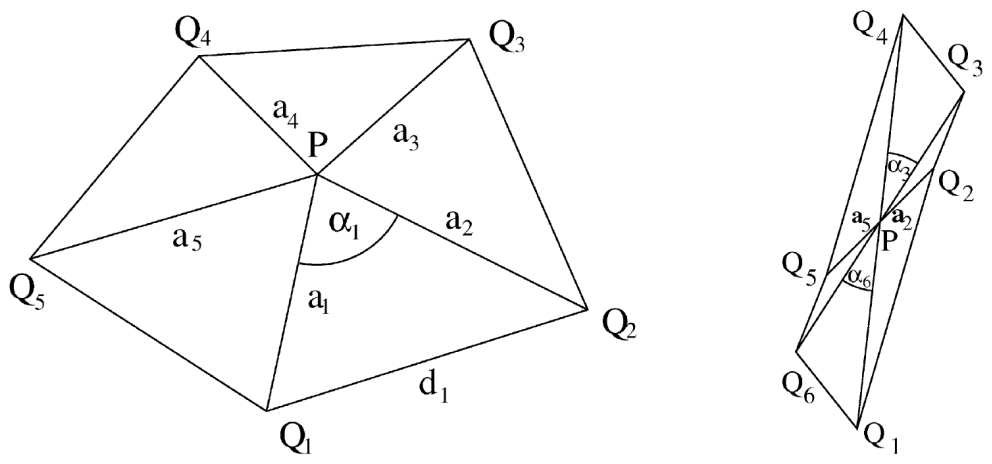

Figura 5.4: À esquerda, conjunto dos primeiros vizinhos $Q$ de um vértice P. À direita, um exemplo de um vértice regular. Imagem retirada de (Langer et al., 2007).

onde $\mathbf{n}$ é a normal no ponto $P$.

Uma limitação deste método está relacionada aos ângulos incidentes. Os autores não discutem o caso de ângulos retos, ou aproximadamente retos, ou mesmo obtusos. No caso de haver ângulos retos na malha, há uma indeterminação no cálculo dos pesos $\omega_{i}$.

Outra limitação é que o método depende do conhecimento das normais nos vértices. Os autores sugerem a aproximação baseada na média ponderada das normais dos vizinhos, que tem convergência quadrática em malhas regulares e linear nas irregulares. Mas para haver convergência da curvatura, é necessário que a estimativa das normais convirja, pelo menos, quadraticamente. Portanto, o método só converge para malhas regulares, assim como o método de Meyer.

\subsection{Método de Taubin}

Um dos métodos diretos mais conhecidos é o proposto por (Taubin, 1995). autor define o tensor de curvatura, a partir do qual várias informações, dentre elas a curvatura média, podem ser extraídas.

A matriz $\underline{\underline{M}}_{i}$, é definida em cada vértice $i$ da malha como

$$
\underline{\underline{M}}_{i}=\sum_{j \in V_{i}} \omega_{i j} \kappa_{i j} \mathbf{T}_{i j} \otimes \mathbf{T}_{i j}
$$

onde $V_{i}$ é o conjunto dos vértices vizinhos a $i$. O vetor $\mathbf{T}_{i j}$ é definido como

$$
\mathbf{T}_{i j}=\frac{\left(\underline{\underline{I}}-\mathbf{N}_{i} \otimes \mathbf{N}_{i}\right)\left(\mathbf{x}_{i}-\mathbf{x}_{j}\right)}{\left.\mid \underline{\underline{I}}-\mathbf{N}_{i} \otimes \mathbf{N}_{i}\right)\left(\mathbf{x}_{i}-\mathbf{x}_{j}\right) \mid}
$$

onde $\underline{\underline{C}}$ é a matriz identidade, $\mathbf{x}_{i}$ é a posição e $\mathbf{N}_{i}$ o vetor normal do vértice $i$. O autor sugere estimar a normal no vértice como sendo a média ponderada das normais das faces incidentes, usando a área da face como peso.

A curvatura direcional $\kappa_{i j}$ é estimada como

$$
\kappa_{i j}=2 \mathbf{N}_{i} \cdot \frac{\mathbf{x}_{j}-\mathbf{x}_{i}}{\left|\mathbf{x}_{j}-\mathbf{x}_{i}\right|^{2}}
$$

e os pesos $\omega_{i j}$ são proporcionais à área das faces incidentes à aresta $i j$, ou seja, duas faces no caso de uma aresta interna e uma face se a aresta estiver na borda da malha. Os pesos são normalizados de forma que 


$$
\sum_{j \in V_{i}} \omega_{i j}=1
$$

Finalmente, a curvatura média pode ser calculada como sendo o traço da matriz $\underline{\underline{M}}$

$$
H=\operatorname{tr}\left(\underline{\underline{M}}_{i}\right) .
$$

O método de Taubin, apesar de sua popularidade, está longe de ser ideal. Uma desvantagem é que não há convergência quando a malha é refinada (Xu, 2004). Além disso, o método precisa da informação das normais nos vértices. Como, em geral, essa informação precisa ser estimada, o erro nessa estimativa aumenta o erro na estimativa da curvatura. No entanto, o maior obstáculo está no fato de que o método falha para malhas que possuam triângulos obtusângulos, como pode ser visto na figura 5.6.

\subsection{Método de Belkin}

Em (Belkin et al., 2008), é proposta uma maneira de calcular o operador de Laplace-Beltrami $\Delta_{S}$ para malhas discretas. A curvatura média $H$ pode ser obtida a partir da aplicação desse operador ao vetor posição $\mathbf{x}$,

$$
\Delta_{S} \mathbf{x}=-2 H \mathbf{n}
$$

onde $\mathbf{n}$ é o vetor normal.

Seja $K$ uma malha em $\mathbb{R}^{3}$ e $V$ o conjunto de seus vértices. Sendo $t \in K$ uma face da malha, \#t será o número de vértices dessa face e $V(t)$ o conjunto desses vértices. $f: V \rightarrow \mathbb{R}$ é uma função escalar definida em cada vértice da malha. No cálculo da curvatura, $f$ seria cada uma das coordenadas da posição do vértice. O operador de Laplace-Beltrami discreto $L_{K}^{h}$ em um vértice $w \in K$ é

$$
L_{K}^{h} f(w)=\frac{1}{4 \pi h^{2}} \sum_{t \in K} \frac{\operatorname{area}(t)}{\# t} \sum_{p \in V(t)} e^{-\frac{\|p-w\|^{2}}{4 h}}(f(p)-f(w)),
$$

onde $h$ é um parâmetro positivo. Apesar de não explicitado no artigo, $\|p-w\|$ é provavelmente a distância entre os vértices $p$ e $w$.

Os autores afirmam que o método proposto possui convergência em cada ponto, ou seja, usando a norma $\mathbf{L}^{\infty}$, para malhas arbitrárias. No entanto, o método tem algumas desvantagens.

Não é apresentada uma forma de calcular o parâmetro $h$. É dito que ele "intuitivamente corresponde ao tamanho da vizinhança considerada em cada ponto". Ao final do artigo, é sugerido que $h$ seja "um múltiplo, por exemplo 3, do comprimento médio das arestas no vértice". O valor de $h$ influi fortemente no valor calculado da curvatura.

O cálculo da curvatura não depende apenas dos primeiros vizinhos do vértice, como no método de Meyer. Uma vizinhança relativamente grande é necessária para obter bons resultados. Isso tem um grande impacto no desempenho.

\subsection{Métodos contínuos}

Os métodos contínuos de estimativa de curvatura, por exemplo (Gois et al., 2006), ajustam uma superfície contínua e, pelo menos, duplamente diferenciável na vizinhança de 
um vértice e calculam a curvatura a partir dela. Em geral, essa superfície é definida pela equação

$$
z=F(x, y)
$$

onde $F(x, y)$ é um polinômio.

Sendo $\mathbf{x}_{i}=\left(x_{i}, y_{i}, z_{i}\right)$ um dos $N$ pontos que serão usados para fazer o ajuste, é possível construir o sistema de equações

$$
\begin{aligned}
z_{1} & =F\left(x_{1}, y_{1}\right), \\
z_{2} & =F\left(x_{2}, y_{2}\right), \\
\vdots & \\
z_{N} & =F\left(x_{N}, y_{N}\right) .
\end{aligned}
$$

Visto que $F(x, y)$ é um polinômio, tem-se um sistema linear cujas incógnitas são os coeficientes do polinômio. O ideal é que haja mais pontos (equações) do que coeficientes (incógnitas). Isso torna o sistema sobredeterminado. A sua solução, no sentido de mínimos quadrados, pode ser encontrada de forma eficiente pelas equações normais ou por decomposição QR. Se o sistema for determinado, a solução de mínimos quadrados coincide com a solução exata do sistema.

\subsubsection{Método dos mínimos quadrados}

Seja o sistema sobredeterminado

$$
\sum_{j=1}^{n} X_{i j} \beta_{j}=y_{i},(i=1,2, \ldots, m),
$$

de $m$ equações lineares e $n$ coeficientes desconhecidos $\beta_{1}, \beta_{2}, \ldots, \beta_{n}$ com $m>n$. Isso pode ser escrito em forma matricial como

$$
\underline{\underline{X}} \beta=\mathbf{y}
$$

onde

$$
\underline{\underline{X}}=\left(\begin{array}{cccc}
X_{11} & x_{12} & \cdots & X_{1 n} \\
X_{21} & x_{22} & \cdots & X_{2 n} \\
\vdots & \vdots & \ddots & \vdots \\
X_{m 1} & x_{m 2} & \cdots & x_{m n}
\end{array}\right), \quad \beta=\left(\begin{array}{c}
\beta_{1} \\
\beta_{2} \\
\vdots \\
\beta_{n}
\end{array}\right), \quad \mathbf{y}=\left(\begin{array}{c}
y_{1} \\
y_{2} \\
\vdots \\
y_{m}
\end{array}\right)
$$

Tal sistema não tem solução exata se as equações forem linearmente independentes. $O$ objetivo então é achar o valor de $\beta$ que "melhor" se ajusta ao sistema. No sentido de mínimos quadrados, o melhor $\beta$ é aquele que minimiza a quantidade

$$
S(\beta)=\sum_{i=1}^{m}\left|y_{i}-\sum_{j=1}^{n} X_{i j} \beta_{j}\right|^{2}=\|\mathbf{y}-\underline{\underline{X}} \beta\|^{2},
$$

que é a norma $L^{2}$ do resíduo

$$
\mathbf{r}=\left(\begin{array}{c}
r_{1} \\
r_{2} \\
\vdots \\
r_{m}
\end{array}\right), \quad r_{i}=y_{i}-\sum_{j=1}^{n} X_{i j} \beta_{j}, \quad \mathbf{r}=\mathbf{y}-\underline{\underline{X}} \beta
$$




\subsubsection{Equações normais}

As chamadas equações normais são obtidas a partir da equação 5.20

$$
\underline{\underline{X}}^{T} \underline{\underline{X}} \beta=\underline{\underline{X}}^{T} \mathbf{y}
$$

onde $\underline{\underline{X}}^{T}$ é a transposta de $\underline{\underline{X}}$. A matriz $\underline{\underline{X}}^{T} \underline{\underline{X}}$ é quadrada e o sistema linear é determinado. A sua solução é a solução do problema de mínimos quadrados e pode ser obtida por métodos convencionais. Visto que a matriz é simétrica, o sistema pode ser resolvido de forma eficiente por decomposição de Cholesky.

\subsubsection{Decomposição $Q R$}

Outra maneira de resolver o problema de mínimos quadrados é por meio de decomposição QR. A matriz $\underline{\underline{X}}$ é decomposta em fatores

$$
\underline{\underline{X}}=\underline{\underline{Q}} \underline{\underline{R}}
$$

onde $\underline{\underline{Q}}$ é uma matriz $m \times m$ ortogonal e $\underline{\underline{R}}$ é particionada em um bloco $n \times n$ triangular superior $\underline{\underline{R}}_{n}$ e $\overline{\overline{\text { os }}}$ demais $(m-n) \times n$ elementos são nulos

$$
\underline{\underline{R}}=\left[\begin{array}{c}
\underline{R}_{n} \\
\underline{\underline{0}} \\
m-n
\end{array}\right] \text {. }
$$

Multiplica-se à esquerda o resíduo por $\underline{\underline{Q}}^{T}$

$$
\underline{\underline{Q}}^{\top} \mathbf{r}=\underline{\underline{Q}}^{\top} \mathbf{y}-\left(\underline{\underline{Q}}^{\top} \underline{\underline{Q}}\right) \underline{\underline{R}} \beta=\left[\begin{array}{c}
\left(\underline{\underline{Q}}^{\top} \mathbf{y}\right)_{\eta}-\underline{\underline{R}}_{n} \hat{\beta} \\
\left(\underline{\underline{Q}}^{\top} \mathbf{y}\right)_{m-n}
\end{array}\right]=\left[\begin{array}{l}
\mathbf{u} \\
\mathbf{v}
\end{array}\right] .
$$

Como $\underline{\underline{Q}}$ é ortogonal, a norma do resíduo pode ser escrita como

$$
S(\beta)=\|\mathbf{r}\|^{2}=\mathbf{r}^{\top} \mathbf{r}=\mathbf{r}^{\top} \underline{\underline{Q}} \underline{\underline{Q}}^{\top} \mathbf{r}=\mathbf{u}^{\top} \mathbf{u}+\mathbf{v}^{\top} \mathbf{v} .
$$

Visto que $\mathbf{v}$ não depende de $\beta$, o valor mínimo de $S(\beta)$ é atingido quando o bloco superior $\mathbf{u}$ é zero. Portanto, basta resolver

$$
\underline{\underline{R}}_{n} \beta=\left(\underline{\underline{Q}}^{\top} \mathbf{y}\right)_{n}
$$

que é fácil pois $\underline{\underline{R}}_{n}$ é triangular.

Em geral, resolver por decomposição QR é mais lento do que pelas equações normais, mas é mais estável numericamente.

\subsubsection{Cálculo da normal e da curvatura média}

A partir da equação 5.17 é possível calcular exatamente a normal e a curvatura da superfície ajustada. A normal está na direção do gradiente de $z-F(x, y)$, ou seja,

$$
\mathbf{N}=\frac{1}{\sqrt{1+F_{x}^{2}+F_{y}^{2}}}\left(\begin{array}{c}
-F_{x} \\
-F_{y} \\
1
\end{array}\right)
$$

onde $F_{x}$ e $F_{y}$ são as derivadas de $F$ com relação a $x$ e $y$. 
A curvatura média é

$$
\begin{aligned}
2 H & =-\nabla \cdot \mathbf{N} \\
& =\frac{F_{x x}+F_{y y}+F_{y}^{2} F_{x x}+F_{x}^{2} F_{y y}-2 F_{x} F_{y} F_{x y}}{\left(1+F_{x}^{2}+F_{y}^{2}\right)^{\frac{3}{2}}} .
\end{aligned}
$$

\subsection{Ajuste de paraboloide}

Um dos mais simples métodos contínuos é o ajuste de paraboloide, também conhecido como método de aproximação de superfície quadrática. Esse algoritmo ajusta um paraboloide usando pontos na vizinhança do vértice onde se quer calcular a curvatura. $O$ paraboloide é construído de forma que passe pelo vértice e sua normal nesse ponto seja a normal do vértice.

Depois de analisar vários métodos, tanto discretos quanto contínuos, os autores de (Surazhsky et al., 2003) concluíram que esse método é "o melhor método para estimar a curvatura média" e "o mais estável que sempre tem uma boa convergência".

O primeiro passo para se fazer o ajuste é a escolha da base, composta pelos versores tangentes $\mathbf{T}_{1}$ e $\mathbf{T}_{2}$ e normal $\mathbf{N}$ no vértice onde se quer calcular a curvatura. Todos os cálculos são feitos nessa base, tomando a posição do vértice como origem.

A forma mais geral de um polinômio quadrático de duas variáveis é

$$
z=A x^{2}+B x y+C y^{2}+D x+E y+F .
$$

Para que a função passe pela origem, é necessário que $F$ seja zero. A normal está na direção

$$
\mathbf{N} \propto\left(\begin{array}{c}
-(2 A x+B y+D) \\
-(2 C y+B x+E) \\
1
\end{array}\right)
$$

e na origem ela é proporcional a

$$
\mathbf{N} \propto\left(\begin{array}{c}
-D \\
-E \\
1
\end{array}\right)
$$

Como a normal é prescrita e está na direção $z, D$ e $E$ também são nulos. A expressão do paraboloide passa a ser

$$
z=A x^{2}+B x y+C y^{2} .
$$

Três coeficientes requerem, pelo menos, três pontos vizinhos. Isso sempre é satisfeito em malhas triangulares de superfícies fechadas. A curvatura na origem será

$$
H=A+C
$$

\subsubsection{Estimativa da normal}

O paraboloide ajustado com a equação 5.35 tem o seu vetor normal na origem prescrito. Isso simplifica o método, mas pode causar erros grandes se a estimativa da normal não for boa. 
Uma alternativa é usar uma versão iterativa do método, que além de estimar a curvatura também estima a normal. Para isso, os coeficientes $D$ e $E$ não são eliminados, e a função a ser ajustada é

$$
z=A x^{2}+B x y+C y^{2}+D x+E y .
$$

Uma estimativa inicial da normal é usada para fazer o ajuste. Depois de feito esse primeiro ajuste, uma nova normal é calculada usando a equação 5.34. O ajuste é refeito com essa nova normal. O processo é repetido até a convergência, ou seja, até que a normal calculada seja próxima o suficiente da normal usada no ajuste. Na prática, há convergência quando $D$ e $E$ estão suficientemente próximos a zero.

Uma desvantagem dessa abordagem é que são necessários pelo menos cinco vizinhos para fazer o ajuste, mas nem todas as malhas possuem essa característica. Além disso, o custo computacional é maior.

\subsection{Método de ordem cúbica}

Outro método contínuo é o método de aproximação cúbica da normal adjacente por (Goldfeather \& Interrante, 2004), ou simplesmente método de ordem cúbica. Neste método, um polinômio de terceira ordem é ajustado

$$
z=\frac{A}{2} x^{2}+B x y+\frac{C}{2} y^{2}+D x^{3}+E x^{2} y+F x y^{2}+G y^{3}
$$

Aqui, assim como no ajuste de paraboloide, impõe-se que a superfície ajustada passe pelo vértice alvo e que a sua normal no vértice esteja na direção $z$. A base utilizada também é composta pelos versores tangentes e a normal do vértice alvo, que é a origem. Isso permite eliminar o termo constante e os termos lineares.

Sete incógnitas requerem pelo menos sete equações para tornar o ajuste possível. Seriam necessários pelo menos sete vizinhos para fazer o ajuste. Entretanto, o autor usa também a informação das normais nos vértices vizinhos para produzir mais equações. A normal dessa superfície está na direção

$$
\mathbf{N} \propto\left(\begin{array}{c}
A x+B y+3 D x^{2}+2 E x y+F y^{2} \\
B x+C y+E x^{2}+2 F x y+3 G y^{2} \\
-1
\end{array}\right)
$$

Desta forma, há três equações para cada vizinho, uma referente à sua posição e duas referentes à sua normal. São necessários apenas três vizinhos para realizar o ajuste.

Seja $\mathbf{x}_{i}=\left(x_{i}, y_{i}, z_{i}\right)$ a posição e $\mathbf{N}_{i}=\left(a_{i}, b_{i}, c_{i}\right)$ a normal do vértice vizinho $i$. Pode-se escrever $\mathbf{N}_{i} \propto\left(-\frac{a_{i}}{c_{i}},-\frac{b_{i}}{c_{i}},-1\right)$. O sistema de equações é

$$
\left(\begin{array}{ccccccc}
\frac{1}{2} x_{i}^{2} & x_{i} y_{i} & \frac{1}{2} y_{i}^{2} & x_{i}^{3} & x_{i}^{2} y_{i} & x_{i} y_{i}^{2} & y_{i}^{3} \\
x_{i} & y_{i} & 0 & 3 x_{i}^{2} & 2 x_{i} y_{i} & y_{i}^{2} & 0 \\
0 & x_{i} & y_{i} & 0 & x_{i}^{2} & 2 x_{i} y_{i} & 3 y_{i}^{2}
\end{array}\right)\left(\begin{array}{c}
A \\
B \\
C \\
D \\
E \\
F \\
G
\end{array}\right)=\left(\begin{array}{c}
z_{i} \\
-\frac{a_{i}}{c_{i}} \\
-\frac{b_{i}}{c_{i}}
\end{array}\right)
$$

e a curvatura média no vértice alvo é

$$
H=\frac{A+C}{2} .
$$


O artigo de (Razdan \& Bae, 2005) afirma que este método é "de longe considerado o melhor algoritmo para estimar curvaturas". No entanto, o método usa os valores exatos das normais nos vértices para conseguir ordem cúbica. Em geral, valores exatos para as normais não estão disponíveis e devem ser estimados. Erros nessas estimativas introduzem erros nos cálculos das curvaturas.

\subsection{Enrugamento}

O ajuste de paraboloide e o método de ordem cúbica produzem um efeito indesejado em simulações envolvendo a energia de Canham-Helfrich. Espera-se que a membrana evolua para uma superfície suave, com baixa curvatura. Mas, na realidade, a malha adquire uma configuração enrugada.
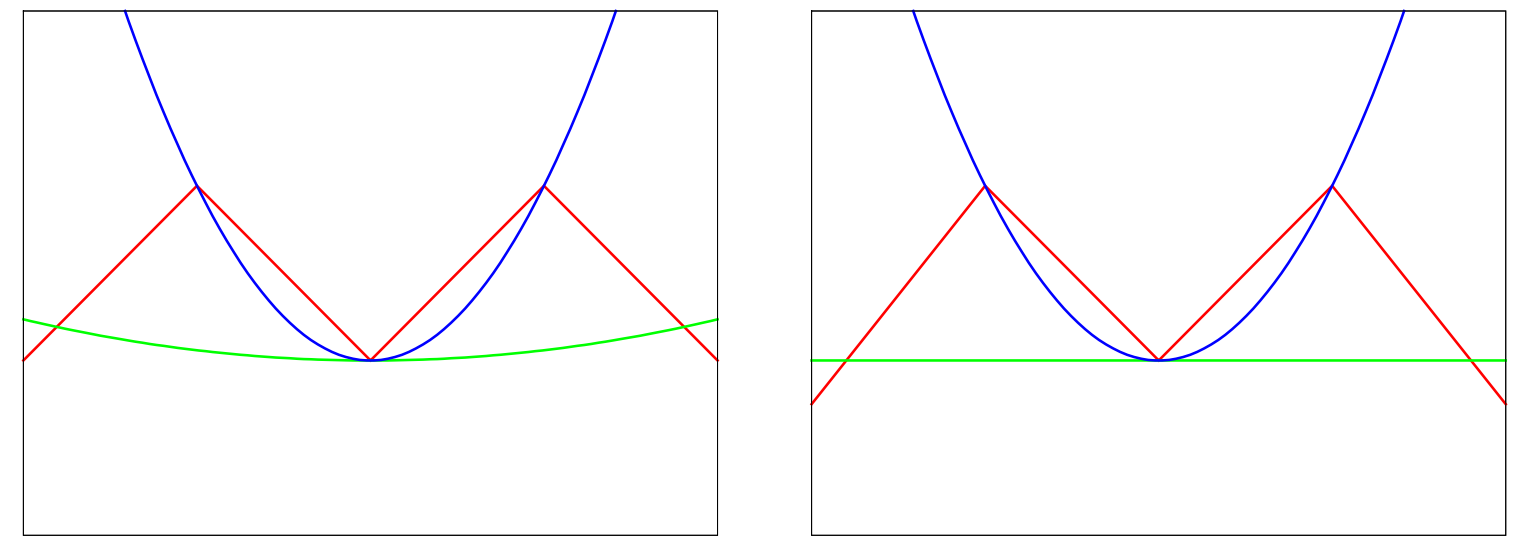

Figura 5.5: Efeito de enrugamento da malha. A linha em vermelho representa a malha enrugada. A curva em azul é ajustada em torno do nó central levando em conta apenas os primeiros vizinhos. A curva em verde considera também os segundos vizinhos. Quando são considerados os segundos vizinhos, a curvatura estimada em uma malha enrugada é bem menor. À direita, um exemplo onde a curvatura é zero se calculada considerando os segundos vizinhos, mas é alta se somente os primeiros vizinhos são considerados.

A explicação desse efeito pode ser vista na figura 5.5. A linha em vermelho representa uma malha enrugada. A curva em azul é a parábola ajustada levando-se em conta apenas os primeiros vizinhos do vértice central. A curva em verde considera também os segundos vizinhos. Nota-se que a curvatura estimada com a curva azul é bem superior àquela estimada com a curva verde. À direita, tem-se um caso extremo onde a estimativa de curvatura é zero se são considerados os segundos vizinhos. Como o sistema busca uma configuração de curvatura baixa, ele pode tender a uma configuração enrugada se forem considerados os segundos vizinhos.

Algo semelhante acontece em duas dimensões. Os métodos contínuos estudados estimam uma curvatura baixa para configurações enrugadas, e a membrana evolui para esse estado, como pode ser visto na figura 5.6.

\subsection{Método ideal}

Nenhum dos métodos analisados pode ser considerado ideal para as simulações realizadas nesse trabalho. São características de um método ideal de cálculo de curvatura: 

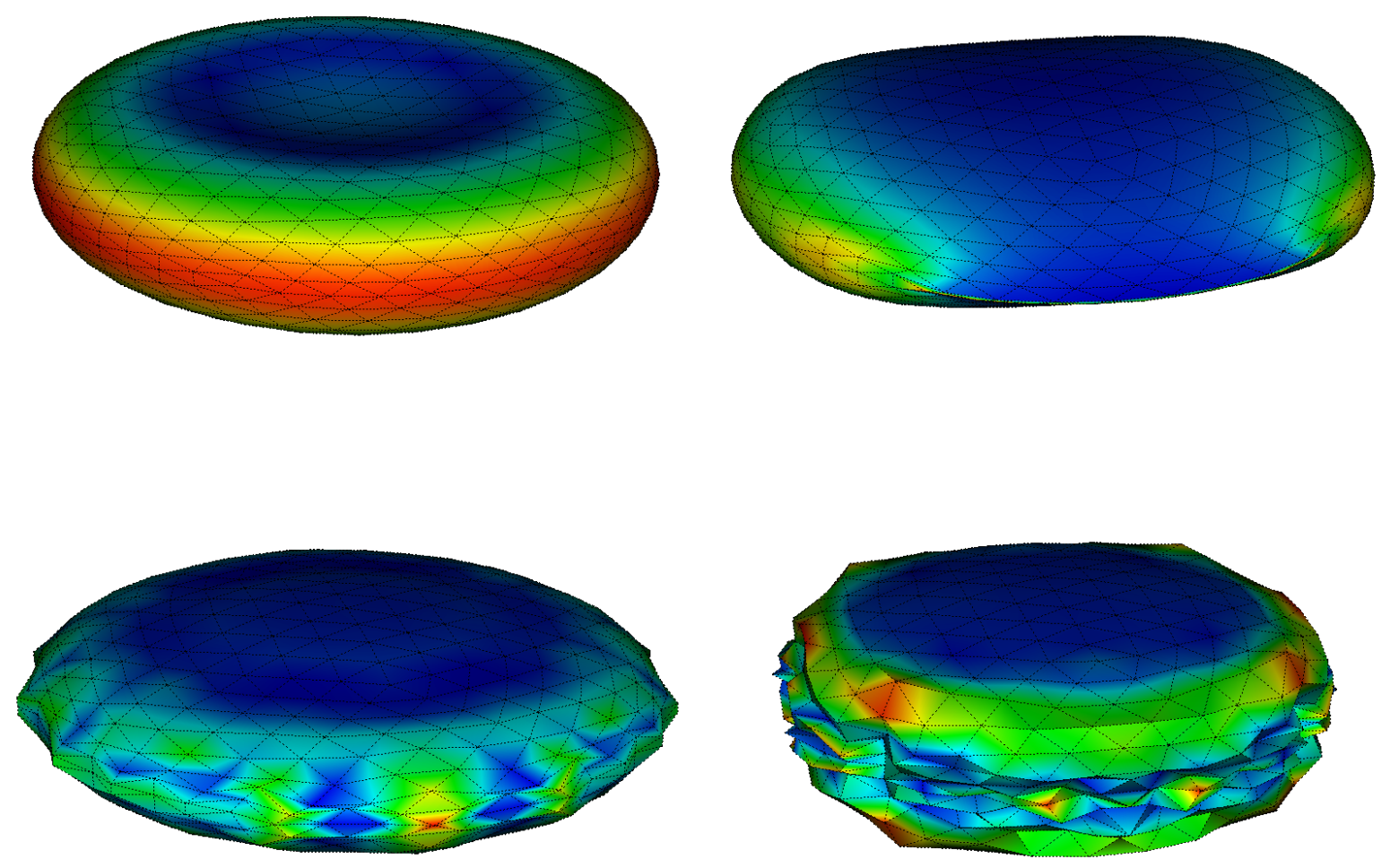

Figura 5.6: Resultados da simulação de uma membrana elástica fechada, com forma inicial de um esferoide oblato, sujeita a restrição de área e volume e sob a ação da energia de Canham-Helfrich. Acima à esquerda foi usado o método de Meyer para estimar a curvatura. A forma bicôncava final é a esperada. Acima à direita, o método de Taubin produz deformações espúrias na região onde há ângulos obtusos na malha. Abaixo à esquerda o método de ajuste de paraboloide e à direita o método de ordem cúbica. Ambos sofrem do problema de enrugamento.

- ser convergente com o refinamento da malha;

- depender de poucos vizinhos do vértice, preferencialmente apenas dos primeiros;

- robusto para malhas que possuam ângulos obtusos;

- o valor calculado da curvatura deve variar suavemente quando os pontos são deslocados;

- completo e fechado, sem parâmetros que precisem ser calibrados.

Os métodos contínuos, que envolvem ajuste de funções, não variam suavemente quando os pontos são deslocados. Ao se mover um ponto, em alguns casos, a função que é ajustada muda abruptamente. Isso prejudica a convergência do método de Newton-Raphson na formulação implícita. Além disso, os métodos contínuos estudados produzem o efeito de enrugamento.

O método de Belkin depende de muitos vizinhos e tem parâmetros que devem ser calibrados. 
O método de Meyer converge apenas para malhas regulares. E, na sua forma original, nem sempre varia suavemente quando um vértice é deslocado.

O método de Langer também só converge para malhas regulares. A presença de ângulos retos ou aproximadamente retos na malha inviabiliza a sua utilização.

O método de Taubin falha para malhas com ângulos obtusos.

Dentre os métodos analisados, o método de Meyer modificado, seção 5.4.1, mostrou-se o mais adequado para simulações regidas pela energia de Canham-Helfrich. Suas limitações produzem imprecisões no cálculo da curvatura, mas não comprometem a estabilidade e robustez da simulação e produzem resultados satisfatórios.

\subsection{Resultados}

\subsubsection{Formas de mínima energia}

A forma típica de uma hemácia é a de um disco com duas concavidades, como pode ser visto na figura 5.7. Essa forma minimiza a energia de Canham-Helfrich dependendo do volume reduzido. Outras formas também são possíveis, como no caso de equinócitos e acantócitos, vistos na figura 5.8. Essas formas irregulares são mínimos locais da energia de Canham-Helfrich.

Seja uma membrana fechada com área $A$ que envolve um volume $V$. O volume reduzido $v$ é a razão entre o volume $V$ e o volume de uma esfera de área $A$. Ou seja,

$$
v=\frac{6 \sqrt{\pi} V}{A^{3 / 2}}
$$

A figura 5.9 mostra as formas finais obtidas por meio de simulações de membranas regidas pela energia de Canham-Helfrich. A malha utilizada é uma icoesfera de 1280 elementos, como pode ser visto na figura 5.11. Uma icoesfera é construída a partir de um icosaedro. Ele é refinado por subdivisão das arestas e os novos nós são projetados radialmente na superfície da esfera que circunscreve o icosaedro.

Para obter formas com diferentes volumes reduzidos, uma das coordenadas de cada ponto da malha é multiplicada por um fator menor do que um, transformando a esfera em um esferoide oblato. Esse esferoide é a forma inicial da simulação. A área e volume da membrana são mantidos constantes e uma força de arrasto é usada para dissipar energia.

Um procedimento análogo pode ser usado para se obter esferoides prolatos a partir da malha da esfera. As formas finais são vistas na figura 5.10.

O artigo de (Seifert et al., 1991) traz os valores mínimos exatos da energia de Canham-Helfrich, integrada sobre toda a superfície, para as formas oblatas e prolatas em função dos volumes reduzidos. As figuras 5.12 e 5.13 mostram a comparação entre esses valores exatos e os obtidos por meio de simulações numéricas. Nesses gráficos, a energia normalizada $E$ é dada pela fórmula

$$
E=\frac{1}{4 \pi} \int H^{2} \mathrm{~d} A
$$

onde $H$ é a curvatura média e a integral é feita sobre toda a superfície.

Para verificar a convergência espacial, malhas mais refinadas e adaptadas às formas oblata e prolata foram geradas usando o programa Netgen (Joachim Schoeberl, 2013). As malhas podem ser vistas na figura 5.11.

Apesar de a estimativa da curvatura não melhorar com o refinamento da malha, o cálculo da área e volume converge para o valor exato. Por isso há alguma melhora nos resultados com o refinamento da malha. 


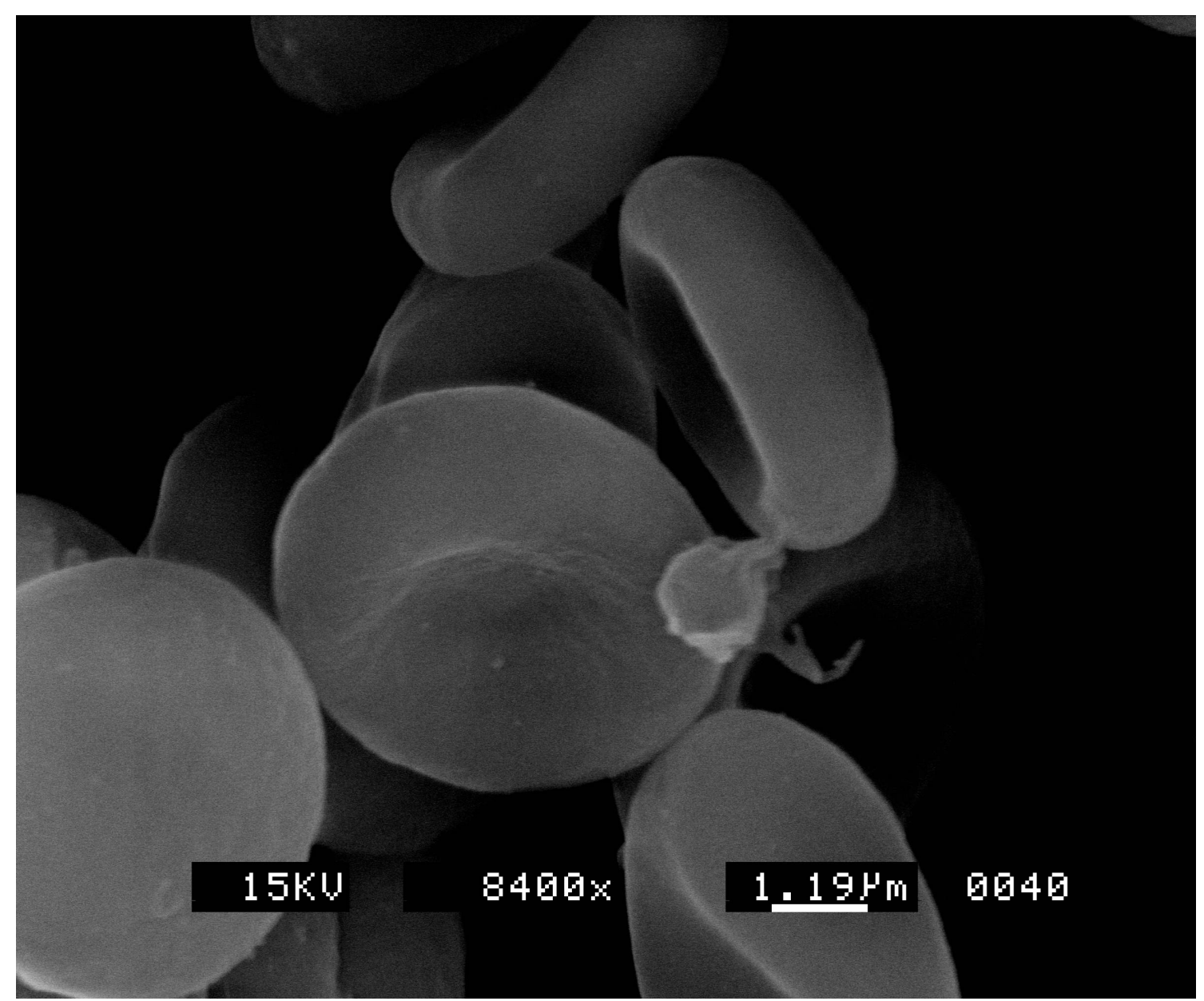

Figura 5.7: Imagem de um conjunto de hemácias obtida por meio de microscopia eletrônica. Imagem retirada de (Wikipedia, 2013e).

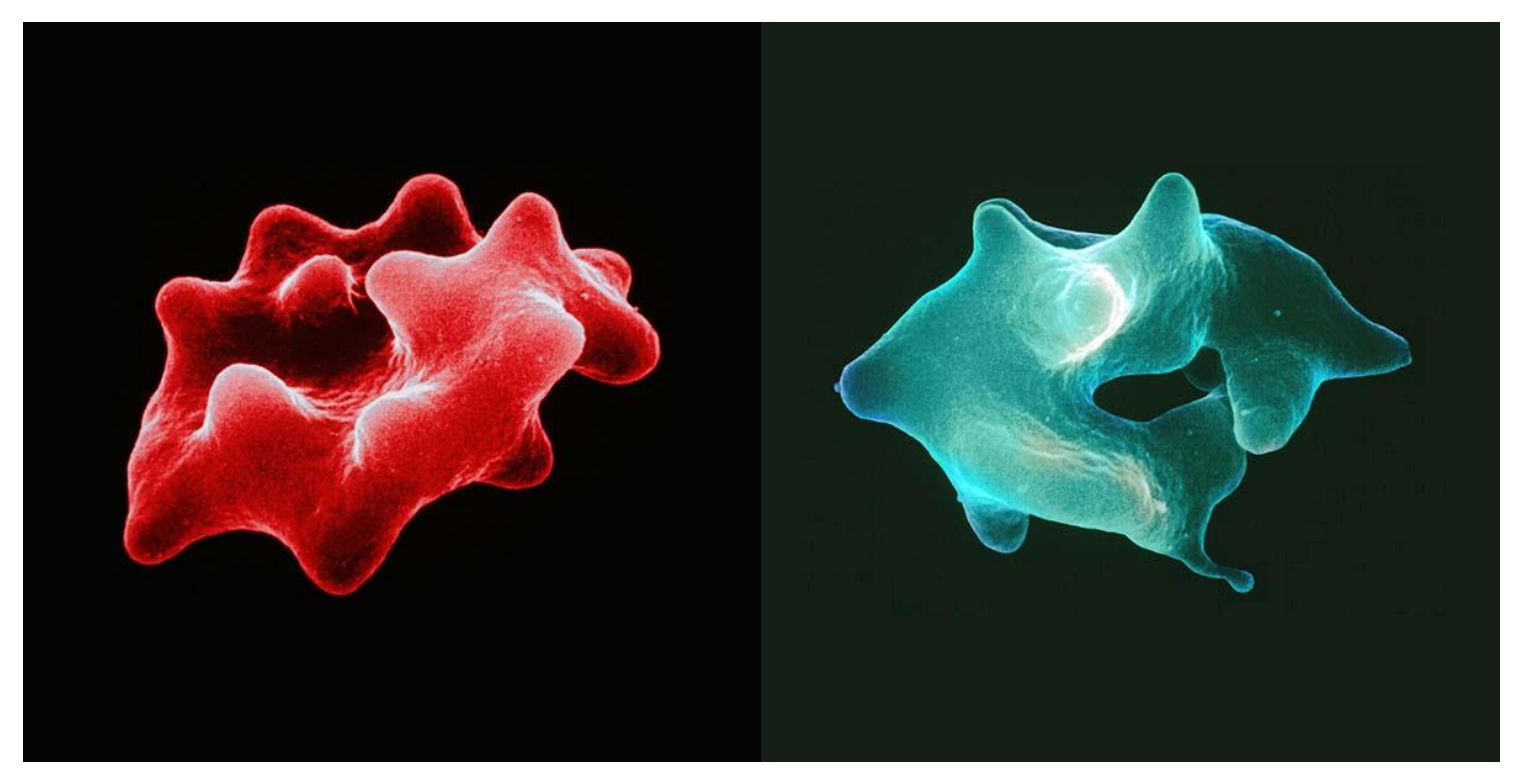

Figura 5.8: Hemácias podem tomar formas irregulares, como no caso de equinócitos (à esquerda) e acantócitos (à direita). Essas formas, em geral, estão relacionadas a patologias. Imagem retirada de (Visualphotos, 2013) 


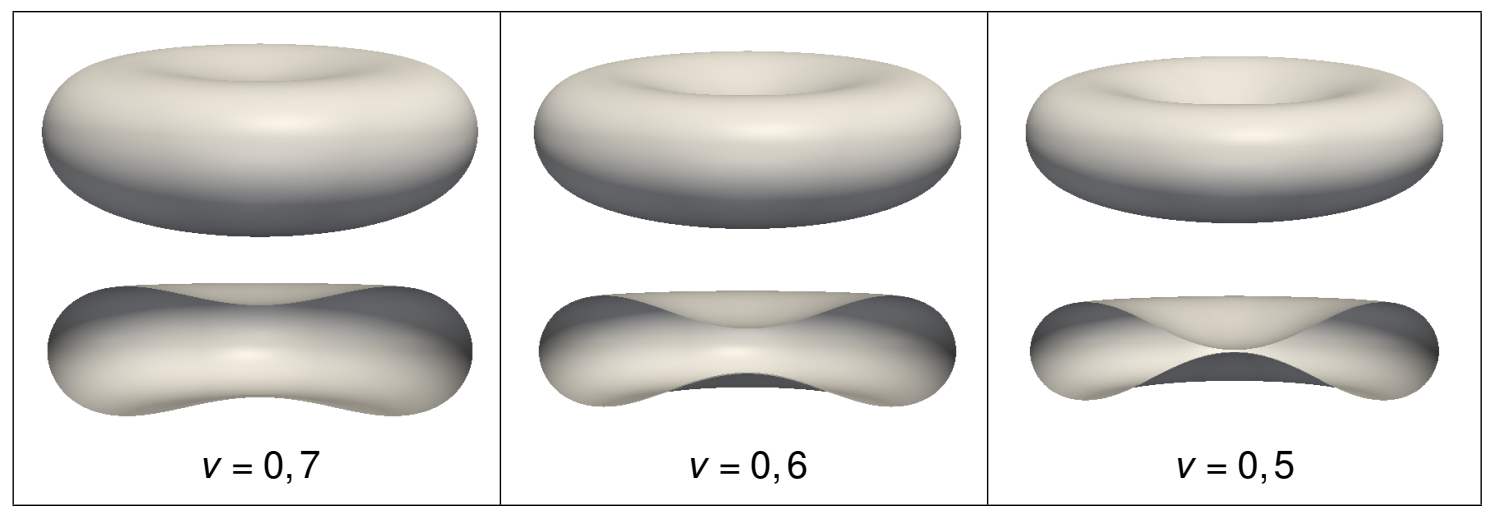

Figura 5.9: Algumas formas oblatas que são mínimos locais da energia de Canham-Helfrich. O volume reduzido está indicado em cada quadro.

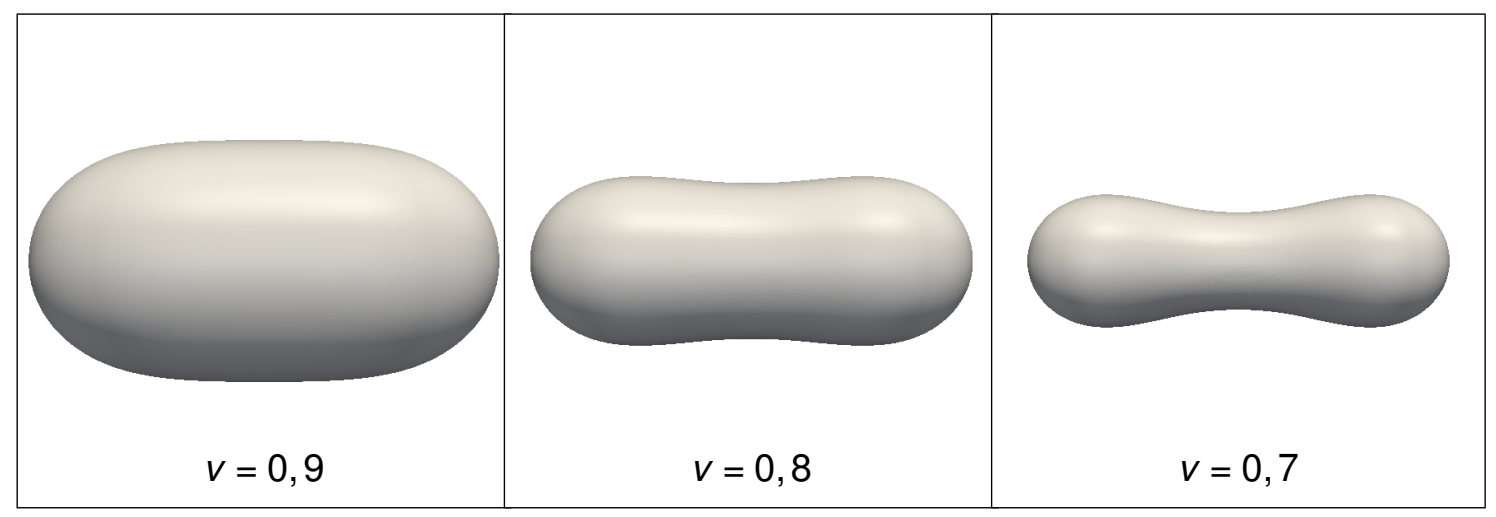

Figura 5.10: Algumas formas prolatas que são mínimos locais da energia de Canham-Helfrich. O volume reduzido está indicado em cada quadro.

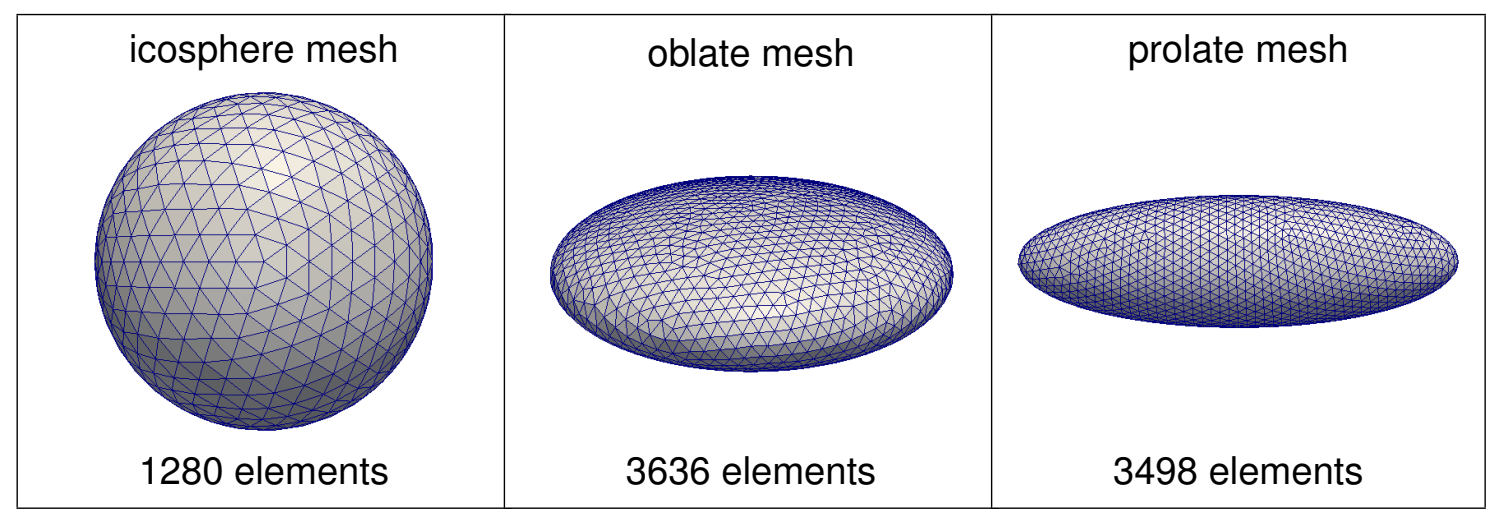

Figura 5.11: Malhas utilizadas nas simulações. Diferentes volumes reduzidos são obtidos ao se multiplicar por um fator uma das coordenadas dos pontos.

\subsubsection{Outras formas}

As formas oblata e prolata não são as únicas possíveis formas de repouso. Existem outras formas metaestáveis que são mínimos locais da energia de Canham-Helfrich, como pode ser visto na figura 5.14. A forma inicial da membrana influi fortemente na forma final de repouso que será atingida. Nessa figura, a forma final do cubo tem $25 \%$ do volume inicial, e o icosaedro $50 \%$. A forma final do icosaedro assemelha-se à forma de equinócitos e acantócitos, vistos na figura 5.8 . 


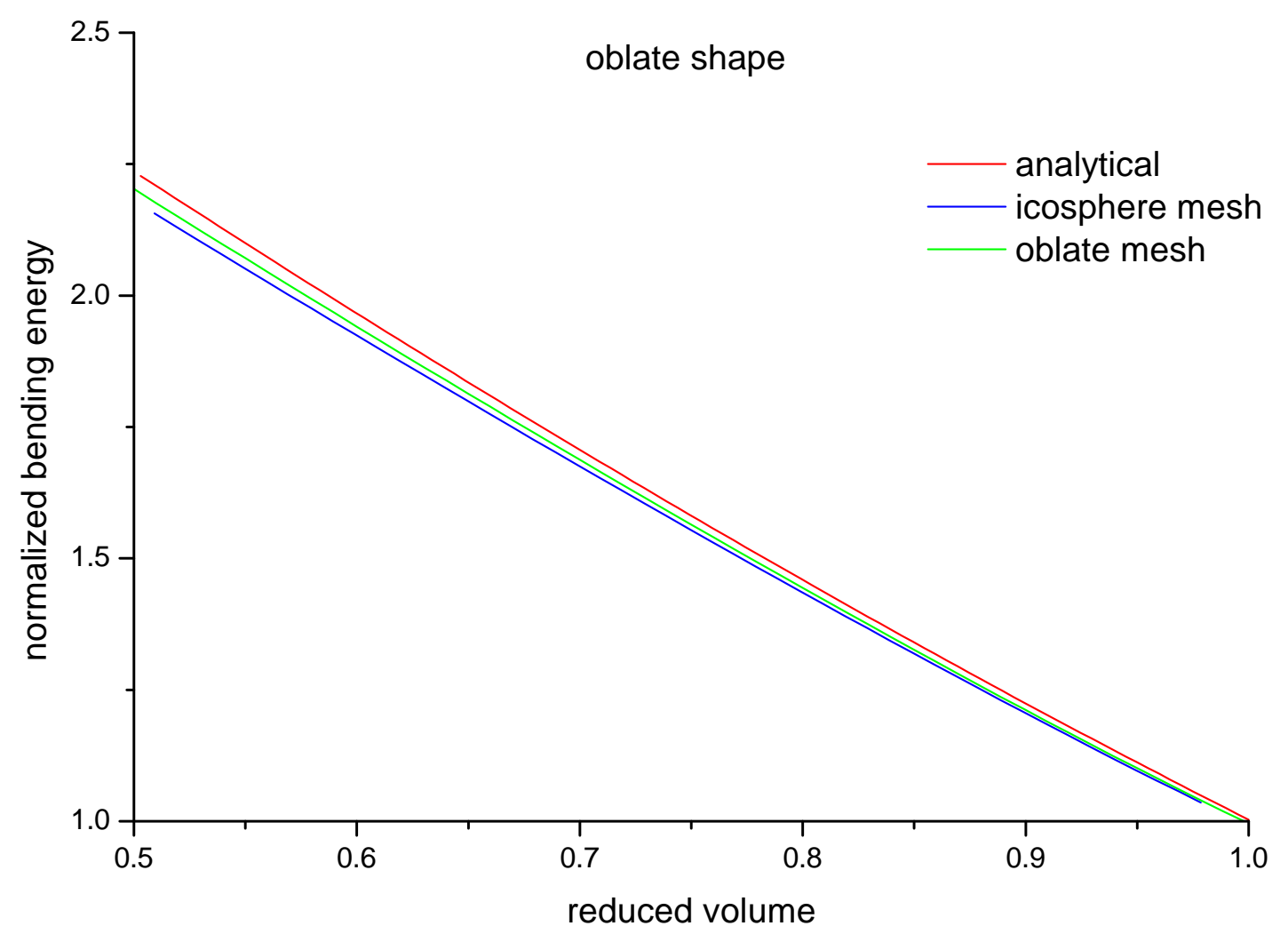

Figura 5.12: Comparação entre as energias totais de curvatura dos estados estacionários simulados e os resultados analíticos de (Seifert et al., 1991) para algumas formas oblatas.

\subsubsection{Curvatura espontânea}

Outro fator que influi fortemente na forma de repouso é a curvatura espontânea. A figura 5.15 mostra algumas formas de repouso de membranas com curvatura espontânea $H_{0}=\operatorname{sen}(k \theta)$, onde $\theta$ é o ângulo azimutal. 


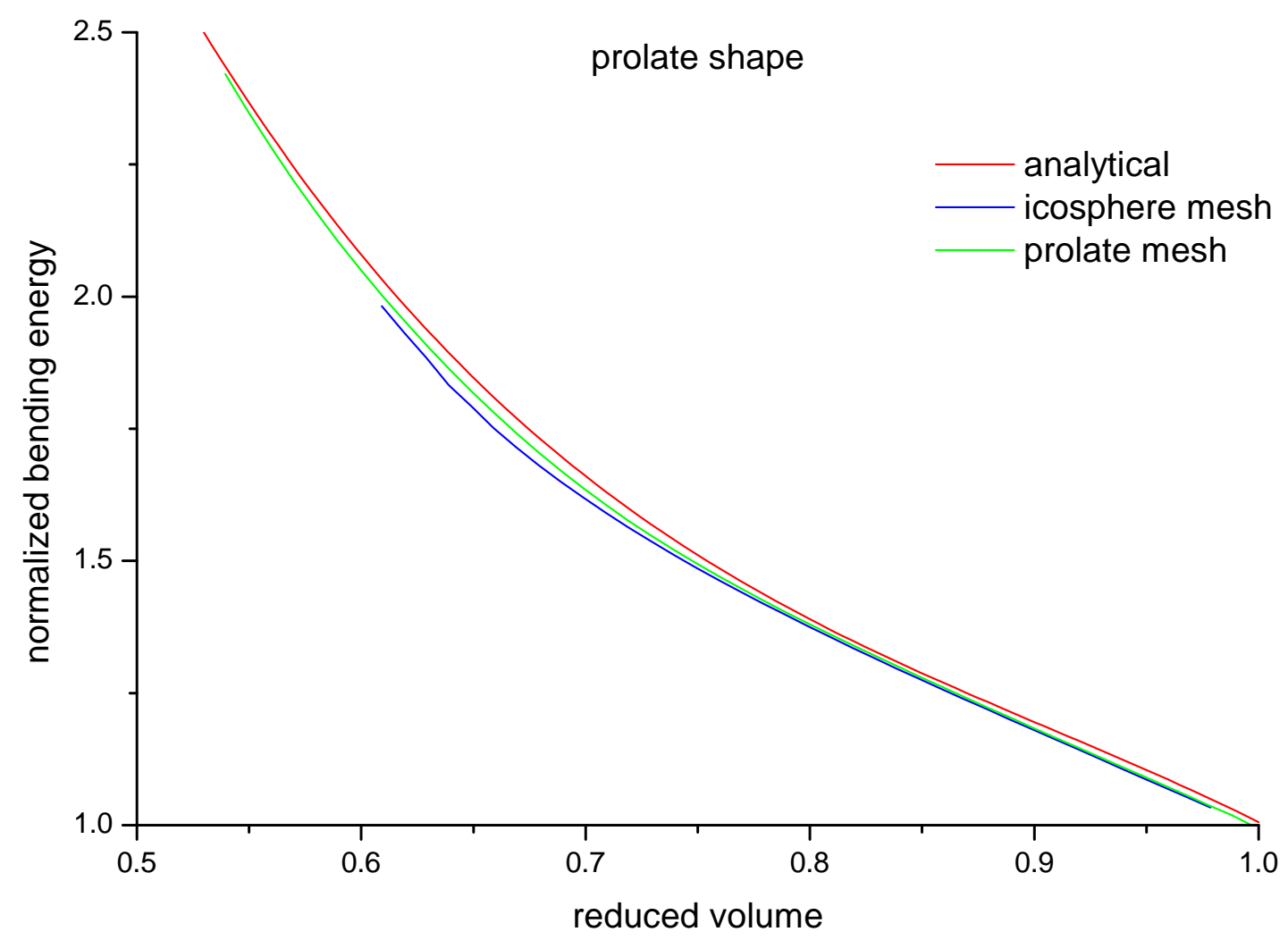

Figura 5.13: Comparação entre as energias totais de curvatura dos estados estacionários simulados e os resultados analíticos de (Seifert et al., 1991) para algumas formas prolatas. 


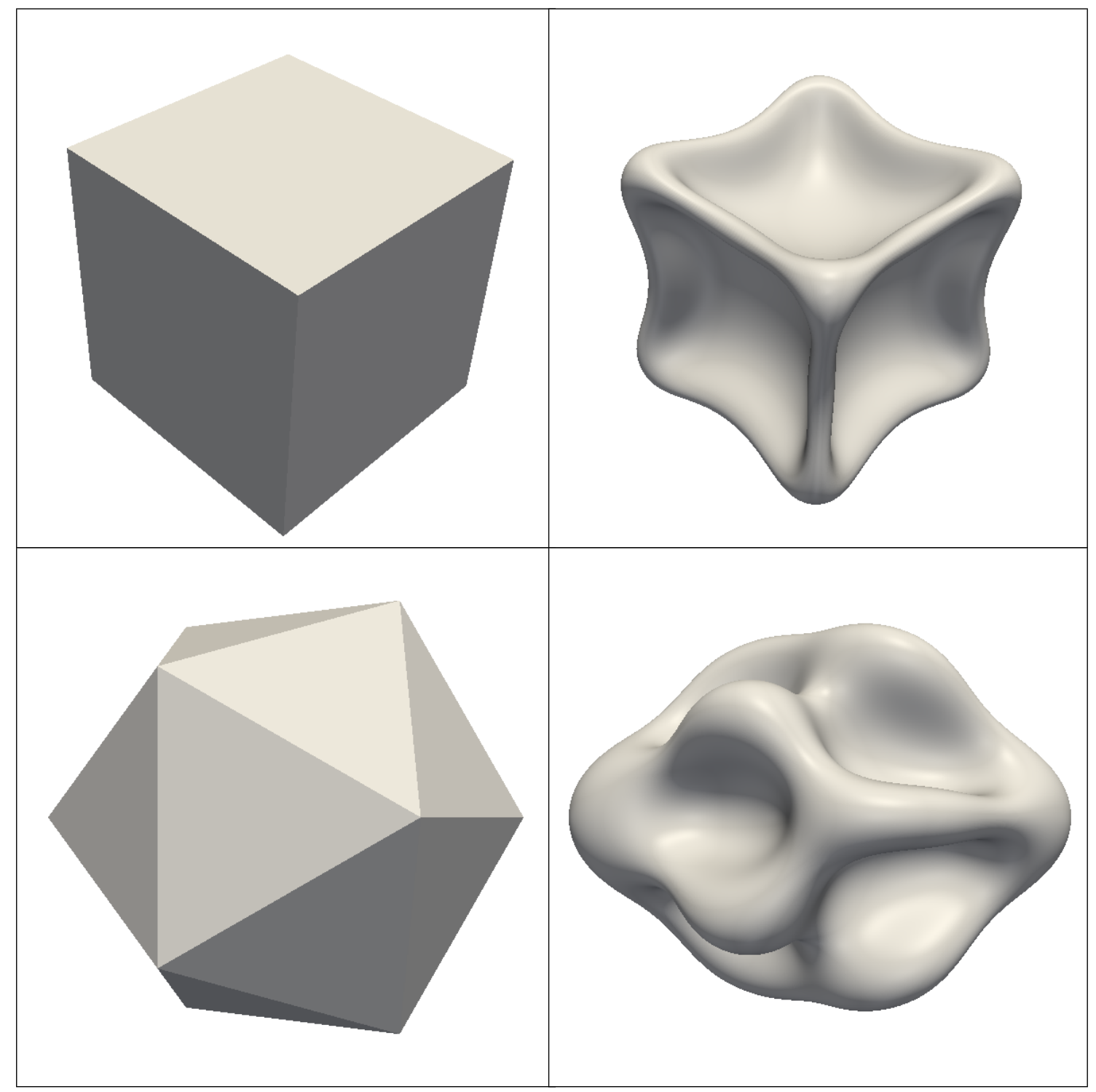

Figura 5.14: A forma inicial da membrana (à esquerda) influi fortemente na forma de repouso que será atingida (à direita). Existem inúmeras formas que são mínimos locais da energia de Canham-Helfrich. 


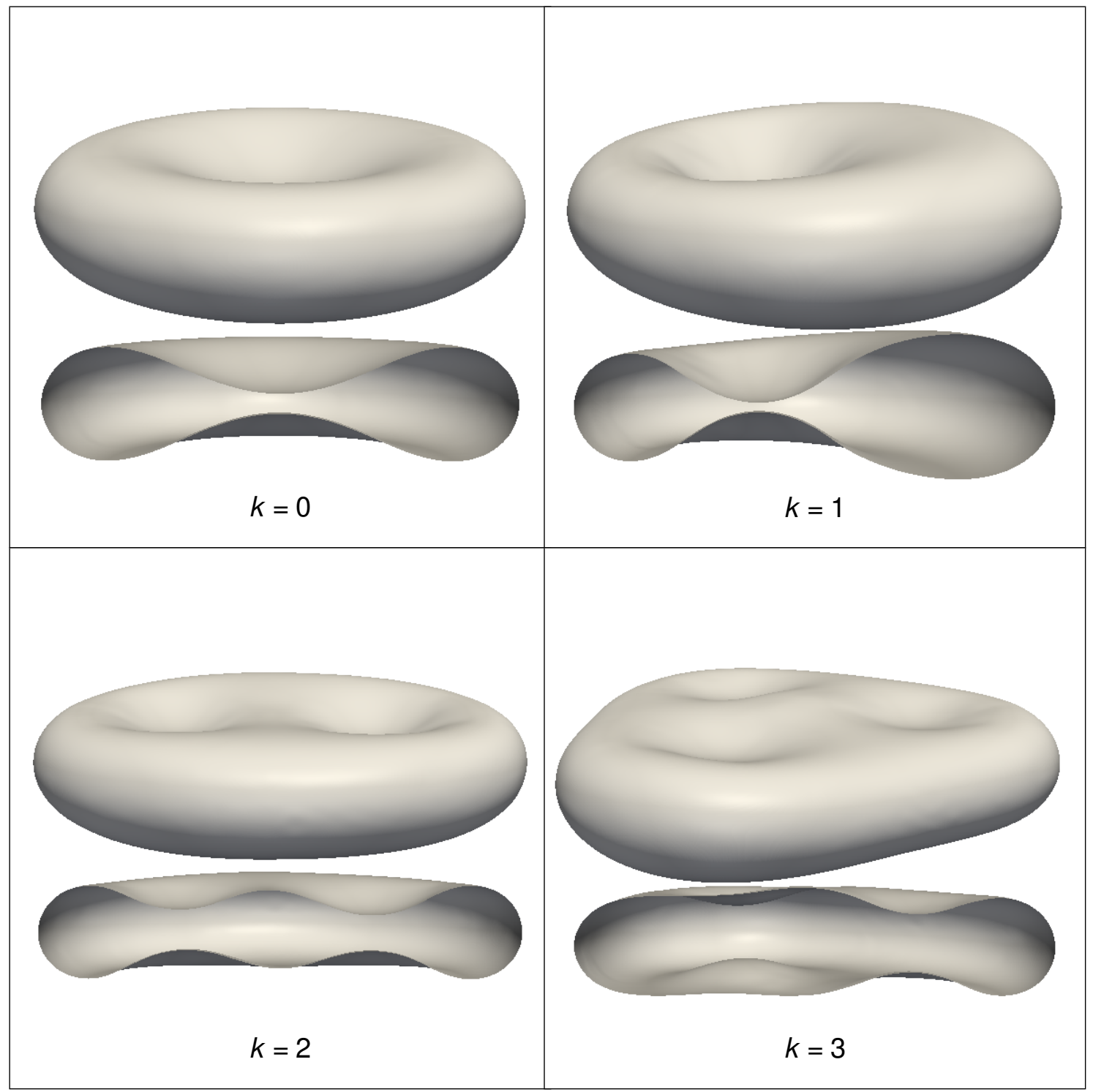

Figura 5.15: Formas de repouso de membranas com curvatura espontânea $H_{0}=\operatorname{sen}(k \theta)$, onde $\theta$ é o ângulo azimutal. 

If I could explain it to the average person, I wouldn't have been worth the Nobel Prize.

Richard Feynman

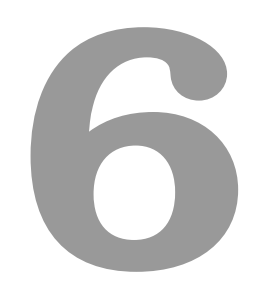

Membranas Viscosas

Sólidos submetidos a tensões externas, sejam de compressão ou cisalhamento, reagem produzindo as chamadas forças elásticas. Essas forças são, em geral, funções crescentes da deformação sofrida pelo objeto e tendem a levá-lo de volta à forma original.

Fluidos também reagem a tensões aplicadas por meio da viscosidade. No entanto, essa reação não depende da deformação, e sim da taxa de deformação com o tempo. Enquanto a força elástica depende das posições das moléculas (deformação) de um sólido, a força viscosa depende das suas velocidades (taxa de deformação com o tempo). Além disso, um sólido se deforma somente até que um equilíbrio entre a força elástica e a força externa aplicada seja atingido. Um fluido, por outro lado, continuará a se deformar indefinidamente enquanto a força externa for aplicada.

James Clerk Maxwell adotou o ponto de vista de que um fluido possui uma quantidade limitada de rigidez, que, sob a ação de forças de cisalhamento, se quebra continuamente e tenta se restabelecer. Ele usou o termo "fugitive elasticity", ou elasticidade fugaz, para viscosidade (Barber \& Loudon, 1989; Massey \& Ward-Smith, 1998).

Neste capítulo, seguindo a ideia original de Maxwell, essa relação existente entre elasticidade e viscosidade é explorada para criar um método de simulação de membranas viscosas a partir de técnicas bem conhecidas de simulações elásticas.

\subsection{Viscosidade superficial}

Uma interface fluida é regida pela lei de Boussinesq-Scriven (Boussinesq, 1913; Scriven, 1960; Gross \& Reusken, 2011)

$$
\begin{aligned}
\gamma \frac{\partial \mathbf{W}}{\partial t}= & \mathbf{F}+\nabla_{s} \sigma+(\kappa+\varepsilon) \nabla_{s}\left(\nabla_{s} \cdot \mathbf{W}\right)+ \\
& \varepsilon\left[2 K(\mathbf{W}-\mathbf{n n} \cdot \mathbf{W})+\mathbf{n} \times \nabla_{s}\left(\mathbf{n} \cdot \nabla_{s} \times \mathbf{W}\right)+2\left(\mathbf{n} \times \nabla_{s} \mathbf{n} \times \mathbf{n}\right) \cdot \nabla_{s}(\mathbf{n} \cdot \mathbf{W})\right]+ \\
& \mathbf{n}\left[2 H \sigma+2 H(\kappa+\varepsilon) \nabla_{s} \cdot \mathbf{W}-2 \varepsilon\left(\mathbf{n} \times \nabla_{s} \mathbf{n} \times \mathbf{n}\right): \nabla_{s} \mathbf{W}\right],
\end{aligned}
$$

onde $\mathbf{W}$ é a velocidade, $t$ é o tempo, $\gamma$ é a densidade superficial, $\mathbf{F}$ é a força externa aplicada, $\sigma$ é a tensão superficial, $\kappa$ é o coeficiente de viscosidade superficial dilatacional, $\varepsilon$ é o 
coeficiente de viscosidade superficial de cisalhamento, $\mathbf{n}$ é a normal,

$$
\begin{aligned}
& 2 H=-\nabla_{s} \cdot \mathbf{n}, \\
& 2 K=-\left(\mathbf{n} \times \nabla_{s} \mathbf{n} \times \mathbf{n}\right): \nabla_{s} \mathbf{n},
\end{aligned}
$$

são as curvaturas média $H$ e gaussiana $K$, e $\nabla_{s}$ é o operador gradiente superficial.

Uma forma geométrica desse operador em linguagem diferencial é derivada no artigo de (Arroyo \& DeSimone, 2009), onde exemplos bidimensionais interessantes de gemulação podem ser encontrados.

As equações resultantes são bastante intrincadas, com a complicação adicional de dependerem explicitamente do tensor de curvatura, que é difícil de discretizar. Por consequência, não existe algoritmo baseado em mecânica de meios contínuos para a simulação dinâmica tridimensional do comportamento viscoso superficial. A maioria das metodologias publicadas concentra-se na obtenção de estados de equilíbrio por meio de fluxos gradientes (Feng \& Klug, 2006; Ma \& Klug, 2008; Dziuk, 2008; Barrett et al., 2008; Elliott \& Stinner, 2010; Bonito et al., 2010), sem levar em conta a dinâmica de relaxação. Outros calculam o efeito amortecedor do fluido adjacente mas não consideram os efeitos viscosos superficiais (Bonito et al., 2011; Salac \& Miksis, 2011). Em (Reusken \& Zhang, 2012), o modelo estacionário de Stokes é usado para aproximar o comportamento da interface viscosa, modelada pela lei de Boussinesq-Scriven, na simulação bifásica de uma gota esférica imersa em um fluxo de Stokes-Poiseuille.

O efeito do fluido externo e interno é dominante para membranas macroscópicas. No entanto, a viscosidade superficial é significativa para membranas suficientemente pequenas, mais precisamente para membranas menores que o comprimento de SaffmanDelbrück (Saffman \& Delbrück, 1975)

$$
\mathscr{L}_{S D}=\frac{\mu}{\mu_{b}}
$$

onde $\mu$ é a viscosidade superficial e $\mu_{b}$ a viscosidade do fluido. A dominância da dissipação superficial em membranas menores do que $\mathscr{L}_{S D}$ foi discutida por (Arroyo \& DeSimone, 2009) e confirmada por (Arroyo et al., 2010) por meio de simulações axissimétricas.

Considerando $\mu=10^{-8} \mathrm{~Pa} s \mathrm{~m}$ (Waugh, 1982a,b) e $\mu_{b}=10^{-3} \mathrm{~Pa}$ s, obtém-se $\mathscr{L}_{S D}=10 \mu \mathrm{m}$. Hemácias são tipicamente menores do que isso, o que requer que efeitos viscosos superficiais sejam considerados em simulações.

\subsection{Molas e amortecedores}

A força elástica $F_{e}$ de uma mola linear é dada pela lei de Hooke

$$
F_{e}=-k(x-X)
$$

onde $k$ é a constante elástica da mola, $x$ é o seu comprimento atual e $X$ é o comprimento de referência da mola, quando ela não está tensionada. Um amortecedor, i.e. um dissipador viscoso, produz a força viscosa $F_{V}$

$$
F_{v}=-\eta v
$$

onde $\eta$ é a viscosidade e $v$ é a velocidade do êmbolo.

Em uma aproximação por diferenças finitas, a força viscosa é dada por

$$
F_{v} \approx-\eta \frac{x^{n}-x^{n-1}}{\Delta t}
$$


onde $n$ é o ciclo e $\Delta t$ é o passo de tempo da simulação. Ou seja, a força viscosa pode ser aproximada pela força elástica de uma mola com constante elástica $k=\frac{\eta}{\Delta t}$ e comprimento de referência $X=x^{n-1}$. Essa aproximação foi usada por (Ma \& Klug, 2008) com o intuito de controlar a deformação sofrida pela malha.

Uma alternativa é tomar a constante elástica $k=\frac{\eta}{\tau}$ e o estado de referência como sendo $X=x-v \tau$. Nesse caso, $\tau$ não precisa ser igual ao passo de tempo da simulação. Essa escolha também faz com que $F_{v} \approx F_{e}$. Portanto, um código que resolve a equação 6.4 pode também ser usado para resolver a equação 6.5 , bastando apenas uma escolha apropriada para as constantes $k$ e $X$.

Essa ideia pode ser estendida para membranas bidimensionais em um espaço tridimensional. A lei de Hooke para membranas elásticas em termos de energia, apresentada na seção 2.5.2, é

$$
E=\frac{\lambda}{8}\left(\Lambda_{1}^{2}+\Lambda_{2}^{2}-2\right)^{2}+\frac{\mu}{4}\left[\left(\Lambda_{1}^{2}-1\right)^{2}+\left(\Lambda_{2}^{2}-1\right)^{2}\right]
$$

Para simular viscosidade, tomam-se os coeficientes de Lamé $\lambda=\mu=\frac{\eta}{\tau}$. $\tau$ é escolhido como uma fração do passo no tempo, em geral $\tau=\frac{\Delta t}{100}$. Os autovalores $\Lambda^{2}$ do tensor esquerdo de Cauchy-Green são calculados usando um estado de referência virtual, dado por

$$
\mathbf{X}_{i}=\mathbf{x}_{i}-\mathbf{v}_{i} \tau,
$$

onde $\mathbf{X}_{i}$ é a posição de referência, $\mathbf{x}_{i}$ a posição atual e $\mathbf{v}_{i}$ a velocidade da partícula $i$. Essas escolhas fazem com que um código desenvolvido para simular membranas elásticas seja capaz de simular também membranas viscosas.

\subsubsection{Princípio do trabalho virtual}

É importante destacar que o estado de referência virtual $\mathbf{X}$ descrito na equação 6.8 é considerado constante ao se aplicar o método de deslocamentos virtuais. Para calcular a força a partir da energia, a posição atual $\mathbf{x}$ que faz parte do estado de referência não deve variar.

Em outras palavras, a energia elástica depende da posição atual $\mathbf{x}$ e da posição de referência $\mathbf{X}$ das partículas

$$
E=E(\mathbf{x}, \mathbf{X}),
$$

onde $\mathbf{x}$ e $\mathbf{X}$ representam o conjunto das posições de todas as partículas da membrana. $\mathrm{Na}$ aproximação proposta, a "energia viscosa" é obtida por meio de uma escolha apropriada do estado de referência

$$
E=E(\mathbf{x}, \mathbf{x}-\mathbf{v} \tau)
$$

onde $\mathbf{v}$ representa o conjunto das velocidades de todas as partículas. A forca viscosa é obtida por meio do princípio do trabalho virtual, seção 2.3,

$$
\left[\mathbf{F}_{i}(\mathbf{x}, \mathbf{v})\right]_{x} \approx-\frac{-E\left(\mathbf{x}^{++}, \mathbf{x}-\mathbf{v} \tau\right)+8 E\left(\mathbf{x}^{+}, \mathbf{x}-\mathbf{v} \tau\right)-8 E\left(\mathbf{x}^{-}, \mathbf{x}-\mathbf{v} \tau\right)+E\left(\mathbf{x}^{--}, \mathbf{x}-\mathbf{v} \tau\right)}{12 h}
$$

onde $\left[\mathbf{F}_{i}(\mathbf{x}, \mathbf{v})\right]_{x}$ é a componente na direção $x$ da força aplicada à partícula $i . \mathbf{x}^{+}$é a configuração $\mathbf{x}$, mas com a partícula $i$ deslocada de $+h$ na direção $x$. De forma análoga, $\mathbf{x}^{++}, \mathbf{x}^{-}$e $\mathbf{x}^{--}$correspondem a deslocamentos de $+2 h,-h$ e $-2 h$.

Há um abuso de linguagem quando se usa a expressão "energia viscosa", pois a força viscosa é dissipativa e não tem uma energia potencial associada. Entenda-se, então, por "energia viscosa" a energia elástica adaptada para que, quando submetida a deslocamentos virtuais, aproxima a força viscosa. 


\subsection{Método para simulação de membranas viscosas}

O método desenvolvido até agora pode ser resumido pelas equações

$$
\begin{aligned}
& \frac{\mathrm{d}}{\mathrm{d} t} \mathbf{x}_{i}=\mathbf{v}_{i} \\
& m_{i} \frac{\mathrm{d}}{\mathrm{d} t} \mathbf{v}_{i}=\mathbf{F}_{i} \\
& -\left(V-V_{0}\right)=0 \text {, } \\
& \sum_{m \in M_{i}} \frac{1}{3}\left(A_{m}-A_{m}^{0}\right)-\frac{\partial}{\partial \gamma_{i}} \sum_{m \in M_{i}} \tau_{m}\left|\nabla \gamma_{m}\right|^{2} A_{m}=0 \text {, } \\
& \left\{\begin{array}{r}
\left(\mathbf{x}_{a}-\mathbf{X}_{a}\right)_{x}=0 \\
\left(\mathbf{x}_{a}-\mathbf{X}_{a}\right)_{y}=0 \\
\left(\mathbf{x}_{a}-\mathbf{X}_{a}\right)_{z}=0 \\
\left(\mathbf{x}_{b}-\mathbf{X}_{a}\right) \cdot \mathbf{B}_{3}=0 \\
\left(\mathbf{x}_{c}-\mathbf{X}_{a}\right) \cdot \mathbf{B}_{3}=0 \\
\left(\mathbf{x}_{b}-\mathbf{X}_{a}\right) \cdot \mathbf{B}_{2}=0
\end{array}\right. \\
& \mathbf{F}_{i}=\nabla_{v w}\left(E_{\text {elastic }}+E_{\text {curvature }}+E_{\text {viscous }}+E_{\text {volume }}+E_{\text {area }}+E_{z m / m}\right)+\mathbf{F}_{\text {ext }} .
\end{aligned}
$$

A equação 6.12 é a definição da velocidade e a equação 6.13 é a segunda lei de Newton. Ambas foram apresentadas na seção 2.2.

seção 2.5 .

A energia elástica $E_{\text {elastic }}$ é dada por uma das leis constitutivas discutidas na

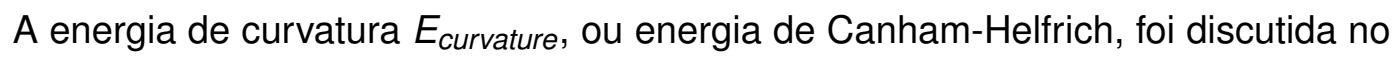
capítulo 5. Ela é dada pela equação 5.1 .

A "energia viscosa" superficial $E_{\text {viscous }}$ é calculada a partir do modelo de Hooke de elasticidade e de uma escolha apropriada do estado de referência, como discutido na seção 6.2 .

O operador $\nabla_{v w}$ presente na equação 6.17 é calculado por meio do princípio do trabalho virtual, discutido na seção 2.3 e também na seção 6.2.1 para o caso particular da "energia viscosa". Nessa equação, $\mathbf{F}_{\text {ext }}$ representa forças externas aplicadas à membrana, como por exemplo arrasto de Stokes (seção 2.7). Outras energias e forças também podem ser consideradas na simulação para simular efeitos como pressão interna e tensão superficial (seção 2.8) ou gravidade (seção 2.6).

A equação 6.14 é a restrição de volume ou incompressibilidade volumétrica, discutida na seção 2.11.1. E Evolume é a energia correspondente a essa restrição, dada pela equação 2.112.

A equação 6.15 é a restrição de área local ou incompressibilidade superficial estabilizada, discutida na seção 2.11.3. Essa restrição pode ser substituída pela restrição de área global, discutida na seção 2.11.2. Nesse caso, a equação 6.15 seria substituída pela

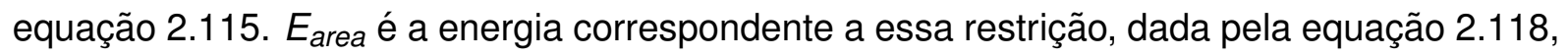
para o caso local, ou 2.116, para o caso global.

As equações 6.16 correspondem aos chamados "multiplicadores de Lagrange para massa zero", discutidos na seção 2.10.4. Eles são necessários quando se quer simular sistemas sem massa e sem arrasto de Stokes para garantir a boa postura do problema.

A solução desse sistema de equações não lineares é obtida por meio do método de Newton-Raphson, discutido na seção 2.10.5. 


\subsection{Resultados}

\subsubsection{Cilindro sob tração}

Seja uma membrana em forma de um cilindro de raio $R$ e altura $L$ ao qual uma força $F$ é aplicada, como visto na figura 6.1. O cilindro é aberto, i.e. não possui os círculos nas bases. A força é distribuída uniformemente ao longo das bordas e é aplicada em ambos os extremos. A energia de dobramento é considerada nula para permitir testar o comportamento do operador viscoso isoladamente. A membrana tem restrição de área local, para simular o efeito de incompressibilidade. Por isso, o esquema implícito é usado.
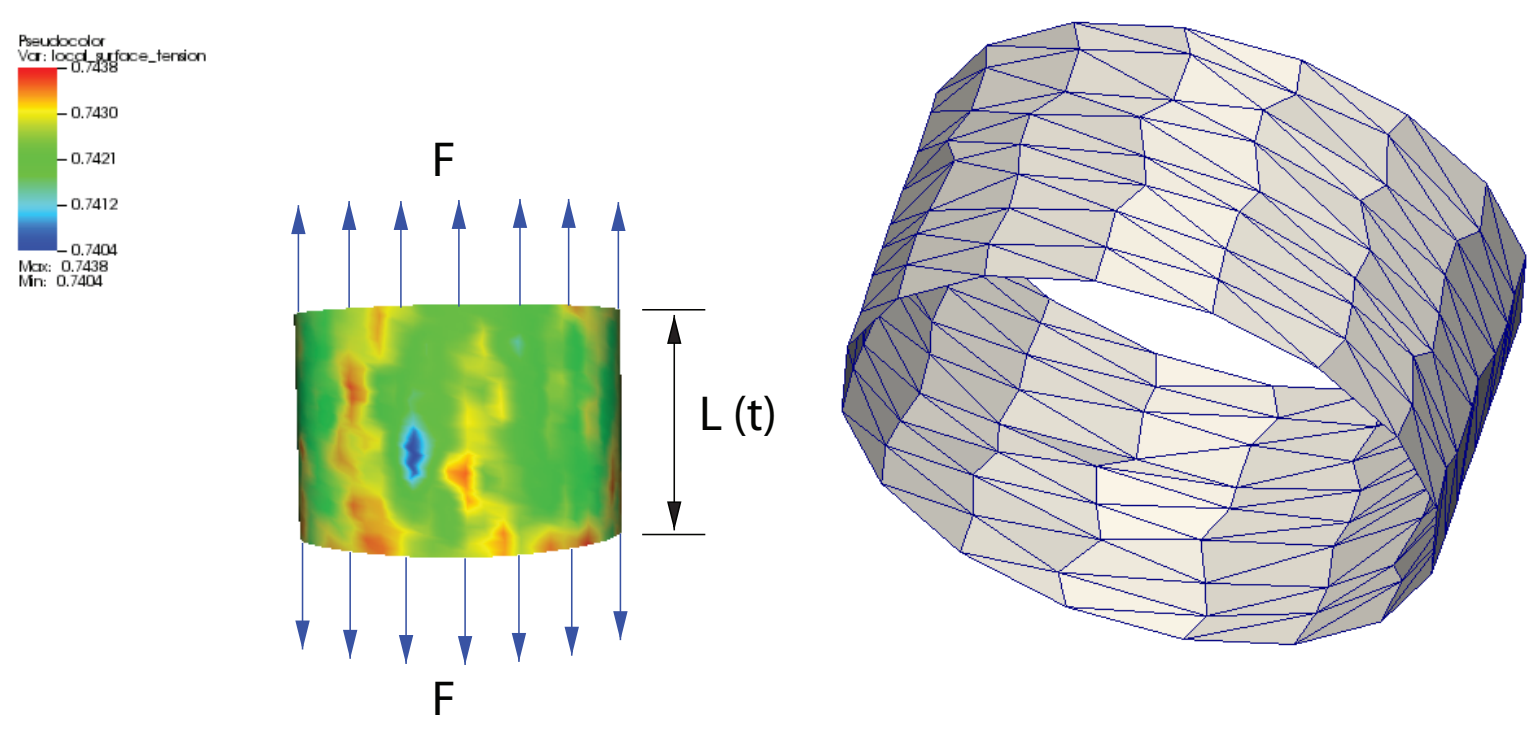

Figura 6.1: À esquerda, esquema da aplicação das forças sobre a membrana. As cores representam a pressão, ou tensão, superficial $P$. À direita, a malha computacional usada.

É possível calcular a solução exata deste problema de fluxo extensional uniforme. A tensão axial é $\frac{F}{2 \pi R}$ e a tensão circunferencial é $R \Delta p$, onde $\Delta p$ é a diferença de pressão volumétrica ao longo da membrana. A solução exata para a pressão superficial $P$, que é a tensão superficial, é um campo uniforme

$$
P=-\frac{1}{2}\left(\frac{F}{2 \pi R}+R \Delta p\right)
$$

A taxa de extensão é

$$
\frac{d L}{d t}=\frac{L}{4 \mu}\left(\frac{F}{2 \pi R}-R \Delta p\right),
$$

onde $\mu$ é a viscosidade da membrana. Tomando $\Delta p=0, F=8, \mu=1$ e os valores iniciais $R(0)=1$ e $L(0)=1$,

$$
L(t)=\frac{1}{1-\frac{t}{\pi}}, \quad R(t)=1-\frac{t}{\pi}, \quad P(t)=-\frac{2}{\pi-t} .
$$

As figuras 6.2 e 6.3 mostram que o método converge para a solução exata quando a malha é refinada. Malhas estruturadas com $16 \times 8,32 \times 16$ e $64 \times 32$ quadriláteros foram usadas. Como visto na figura 6.1, cada quadrilátero da malha é dividido em dois triângulos 
e as posições dos nós foram perturbadas para evitar que as arestas fiquem alinhadas com a direção axial ou circunferencial, o que causaria superconvergência. O passo no tempo é $\Delta t=10^{-2}$ e a massa total da membrana é 0,05 . É necessário adicionar massa para garantir a boa postura do problema. Os modos de dissipação nula do operador de Stokes em um cilindro são infinitos, além dos modos de corpo rígido.

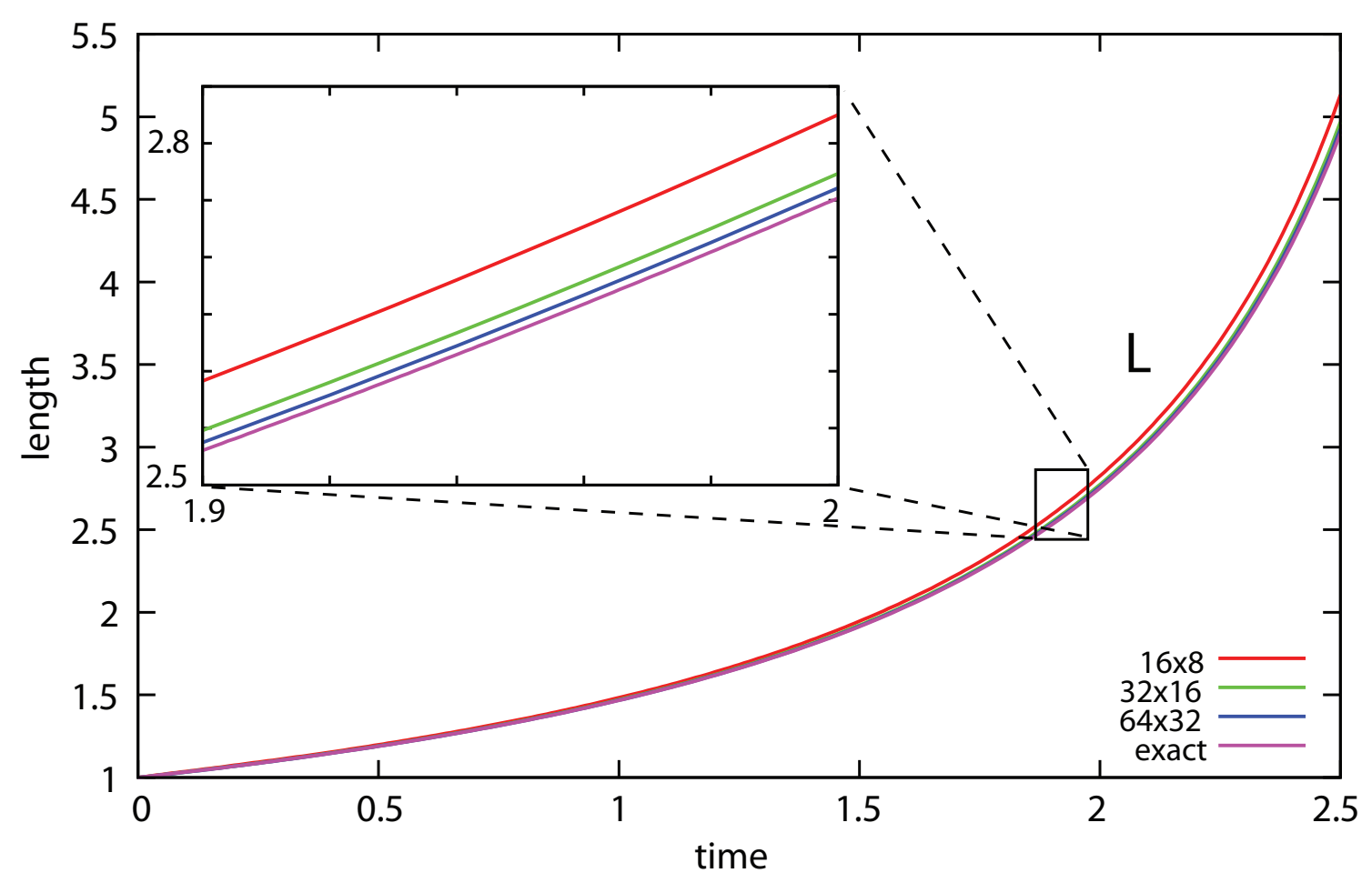

Figura 6.2: Convergência numérica da evolução temporal da altura do cilindro.

Uma boa concordância com a solução exata é observada para $L(t)$ e $\bar{P}(t)$, a média de $P$ sobre a membrana. Oscilações numéricas são observadas em $P$, como pode ser visto na figura 6.4. A amplitude das oscilações parece convergir para zero com ordem $O(h)$.

\subsubsection{Pinçamento de vesícula}

Pinçamento óptico é um método experimental pelo qual feixes de laser são usados para mover objetos microscópicos (Sheetz, 1998). Isso é possível pois a interferência entre as ondas eletromagnéticas dos feixes de laser produz um campo eletromagnético resultante nas proximidades do objeto. As propriedades mecânicas de membranas celulares podem ser estudadas com essa técnica (Kim et al., 2009). Simulações baseadas em mecânica de meios contínuos de hemácias sob pinçamento foram reportadas por (Dao et al., 2003) usando um modelo elástico no software comercial ABAQUS. Um modelo similar foi adotado nas simulações de fronteira imersa em (Le et al., 2009). A energia de Canham-Helfrich foi considerada por (Lee et al., 2008) no estudo de vesículas unilamelares gigantes DOPC. Modelos mais complexos, multiescala, foram defendidos recentemente por (Peng et al., 2010) para a simulação acurada de hemácias.

Nesta seção, é descrita a simulação de uma membrana viscosa sob a ação de pinçamento óptico. A força aplicada varia com o tempo de forma senoidal. A vesícula tem um volume reduzido $V=0,807$. O seu estado estacionário de mínima energia tem forma prolata 


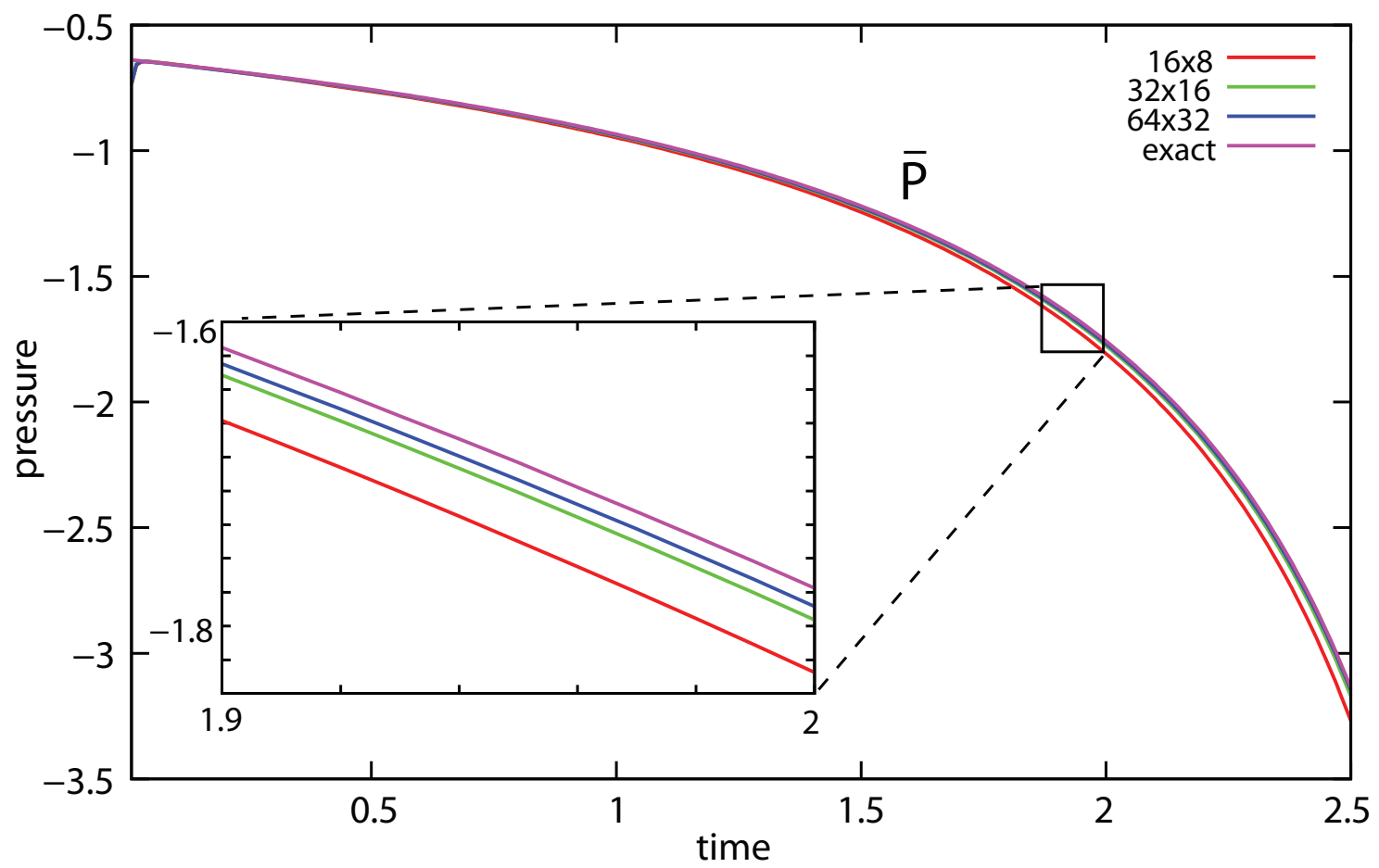

Figura 6.3: Convergência numérica da evolução temporal da pressão (tensão) superficial média do cilindro.

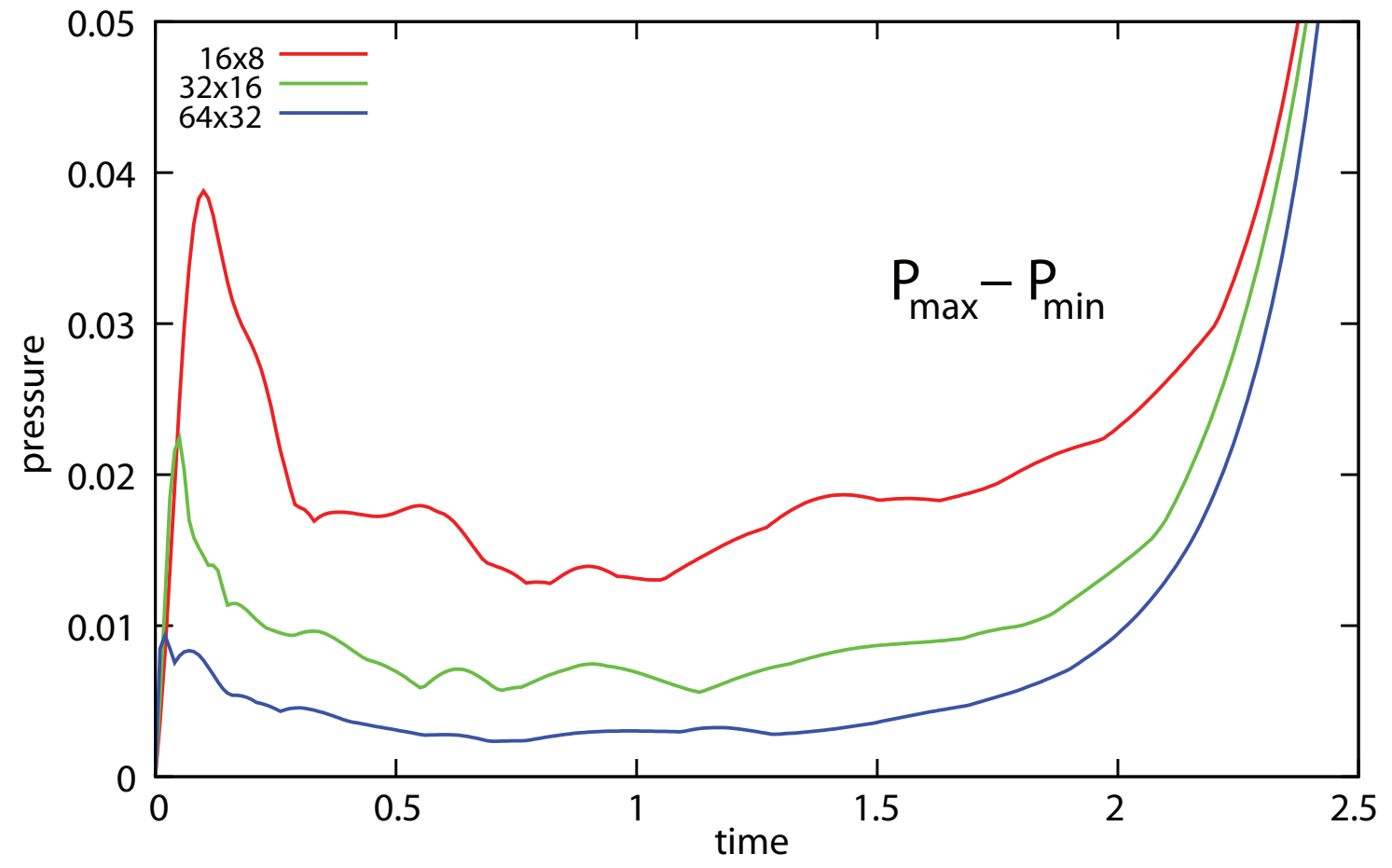

Figura 6.4: Evolução temporal da amplitude da pressão (tensão) superficial do cilindro.

(Seifert, 1997), com energia de Canham-Helfrich dada por

$$
E_{\text {prolate }}=\frac{1}{16 \pi} \int H^{2} d A \approx 1,37,
$$


onde $H$ é a curvatura média e a integral é feita sobre toda a superfície da membrana. Existem outros mínimos locais, em particular há uma forma oblata com energia ligeiramente maior

$$
E_{\text {oblate }}=1,44
$$

O objetivo é estudar o desempenho do algoritmo proposto na simulação de transições entre essas duas formas, induzidas por uma força de pinçamento da forma

$$
F=A \sin \left(2 \pi \frac{t}{T}\right)
$$

Essa força é aplicada em lados opostos da vesícula, distribuída uniformemente entre um nó da malha e seus vizinhos. $F>0$ indica tração e $F<0$ compressão.

Nas figuras 6.5 e 6.6 a energia $E$ é plotada como uma função do tempo, junto com as formas correspondentes a alguns instantes. A vesícula começa em uma configuração arbitrária, a qual corresponde a uma forma prolata oblíqua à direção da força. Ela é esticada lateralmente até $t \approx 0,2 T$, quando uma transição ocorre em direção a um estado prolato alinhado com a força. Essa forma então relaxa em direção ao equilíbrio em $t=0,5 T$, quando a força aplicada retorna a zero. $O$ valor de $E$ chega bem próximo ao valor de $E_{\text {prolate }}$. A diferença é atribuída a erros de discretização. Essa forma prolata é então comprimida pela força, e consequentemente se deforma aumentando a sua energia até que em $t \approx 0,7 T$ uma segunda transição ocorre que leva a membrana a uma forma oblata. Essa forma oblata persiste após a força de compressão chegar a zero em $t=T$, quando $E=1,416$, em boa concordância com $E_{\text {oblate }}$.

Depois de $t=T$, a força empurra os lados côncavos do disco para fora. Essa configuração deixa a forma instável e uma transição de volta à forma prolata alinhada é observada em $t \approx 1,16 T$. Essa forma novamente relaxa para o equilíbrio em $t=1,5 T \mathrm{e}$ então sofre compressão axial até $t \approx 1.7 T$, quando ela transiciona novamente para oblata. As transições em $t \approx 0,7 T$ e $t \approx 1,7 T$ são bastante similares. Em particular, elas consistem primeiro em uma evolução relativamente lenta em direção a uma forma quadrada, seguida de uma repentina transição para a forma metaestável circular (oblata metaestável).

Analisando o gráfico de $E(t)$, é possível observar a escala de tempo da força aplicada, da ordem de $T$, e as escalas de tempo das transições oblata-prolata e prolata-oblata, que são muito menores. Uma estimativa dessas escalas pode ser obtida a partir da figura 6.7, onde a energia $E(t)$ e a pressão volumétrica interna $p(t)$ estão representadas de $t=0,7$ até $t=0,8$. Por inspeção visual, pode-se concluir que o tempo obtido na simulação para a transição é aproximadamente $\tau \approx 10^{-2} T=80$. Isso é consistente com a análise dimensional. Dada a viscosidade superficial $\mu=1$ [força-tempo/comprimento], e a constante da energia de Canham-Helfrich $C_{C H}=10^{-3}$ [energia], e admitindo a partir dos gráficos que a escala de comprimento típica para as transições é $L \approx 0,3$ (o raio da forma de equilíbrio prolata), a combinação dimensional que produz um tempo característico é $\frac{\mu}{L^{2} C_{C H}} \approx 100$, não muito distante do $\tau$ previsto.

\subsubsection{Viscosidade versus arrasto}

Vários estudos recentes de membranas biológicas modeladas por meio da energia de Canham-Helfrich, e suas variantes, não consideram a viscosidade superficial da membrana (Feng \& Klug, 2006; Ma \& Klug, 2008; Dziuk, 2008; Bonito et al., 2010). Ao invés disso, uma força de arrasto, seção 2.7, é utilizada para permitir que a membrana dissipe energia e chegue a um estado de equilíbrio. 

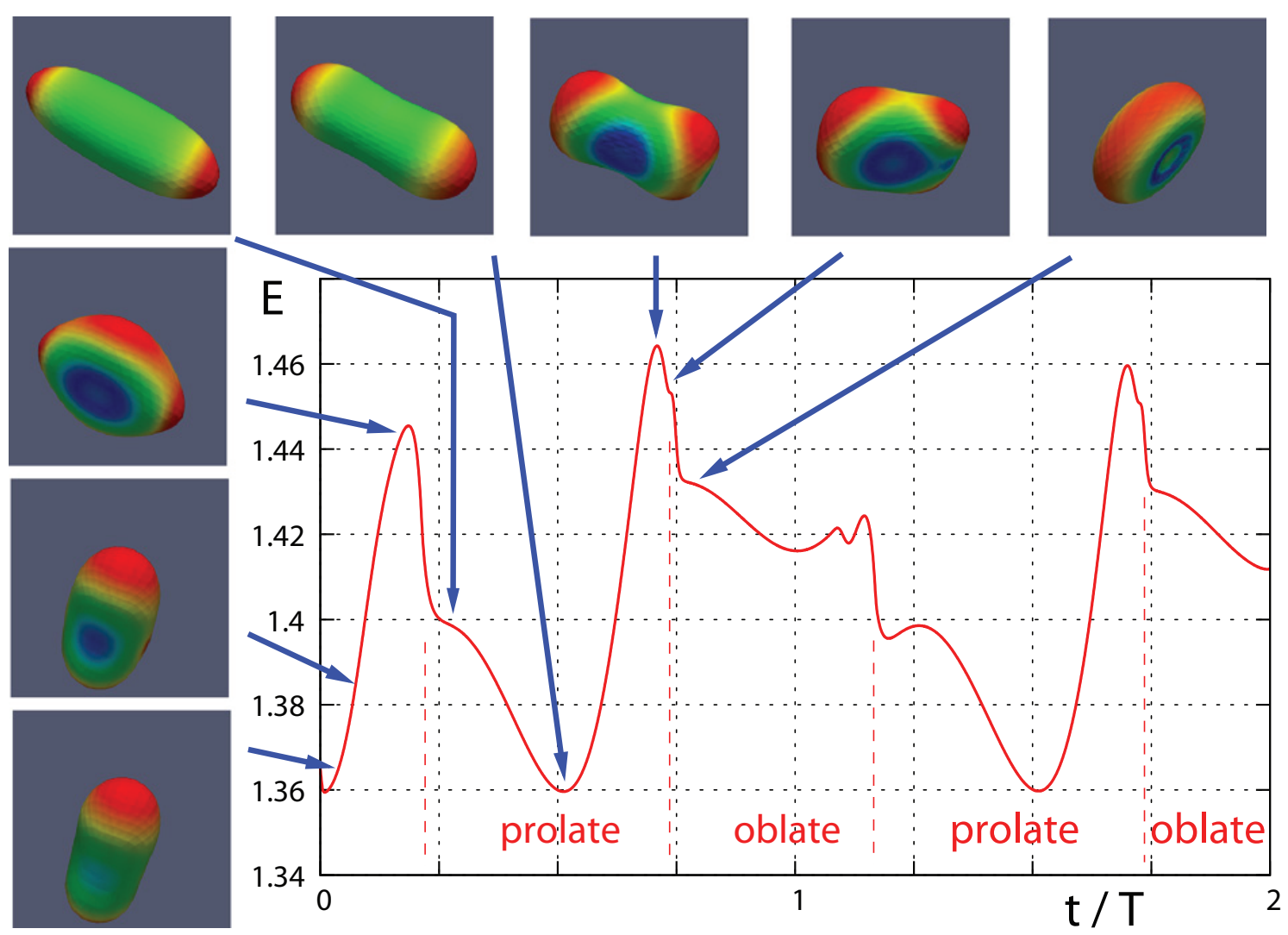

Figura 6.5: Pinçamento de vesícula com uma força $F=A \sin \left(2 \pi \frac{t}{T}\right)$. Tração corresponde à força positiva e compressão à negativa. A energia de Canham-Helfrich é vista em função do tempo. Várias formas instantâneas mostram as transições entre os estados oblato (metaestável) e prolato (estável). As cores correspondem à curvatura média com sinal, sendo azul o mínimo e vermelho o máximo.

Nesta seção, é feita uma comparação entre os resultados obtidos com a viscosidade superficial e aqueles provenientes de arrasto. Os demais parâmetros da simulação são os mesmos, incluindo a restrição de área e volume. A diferença entre conservação de área global e local, seções 2.11 .2 e 2.11.3, também é explorada.

Simulações foram feitas para vários valores de viscosidade $\mu$ e arrasto $\gamma$. $\mathrm{O}$ estado inicial é a forma deformada correspondente ao tempo $t / T=0,74$ na simulação de pinçamento, figuras $6.5,6.6$ e 6.7. Nenhuma força externa é aplicada, o que permite que a membrana relaxe em direção a um estado estacionário.

As curvas 1 e 2 nas figuras 6.8 e 6.9 correspondem ao fluxo apenas com arrasto, com $\gamma=0,1$ e $\mu=0$. A curva 1 usa inextensibilidade global e a 2 local. A curva 5 nessas mesmas figuras, por outro lado, corresponde a situação puramente viscosa, com $\gamma=0$ e $\mu=1$ e inextensibilidade local. A evolução desses dois casos é completamente diferente. A principal razão é que a malha se estraga muito rapidamente no fluxo com arrasto puro, como pode ser visto na figura 6.10. Os ângulos da malha se tornam muito obtusos e a simulação falha. A restrição de inextensibilidade local beneficia um pouco a simulação. Porém, o operador de viscosidade superficial é muito melhor para a malha e permite a evolução para o equilíbrio com ângulos menores. Esse comportamento já foi explorado por (Ma \& Klug, 2008), que usa uma regularização viscosa da malha semelhante, como discutido na seção 6.2. O uso do operador viscoso diminui a necessidade de remalhamento, mas, para simulações muito longas, ainda há degradação da malha. 


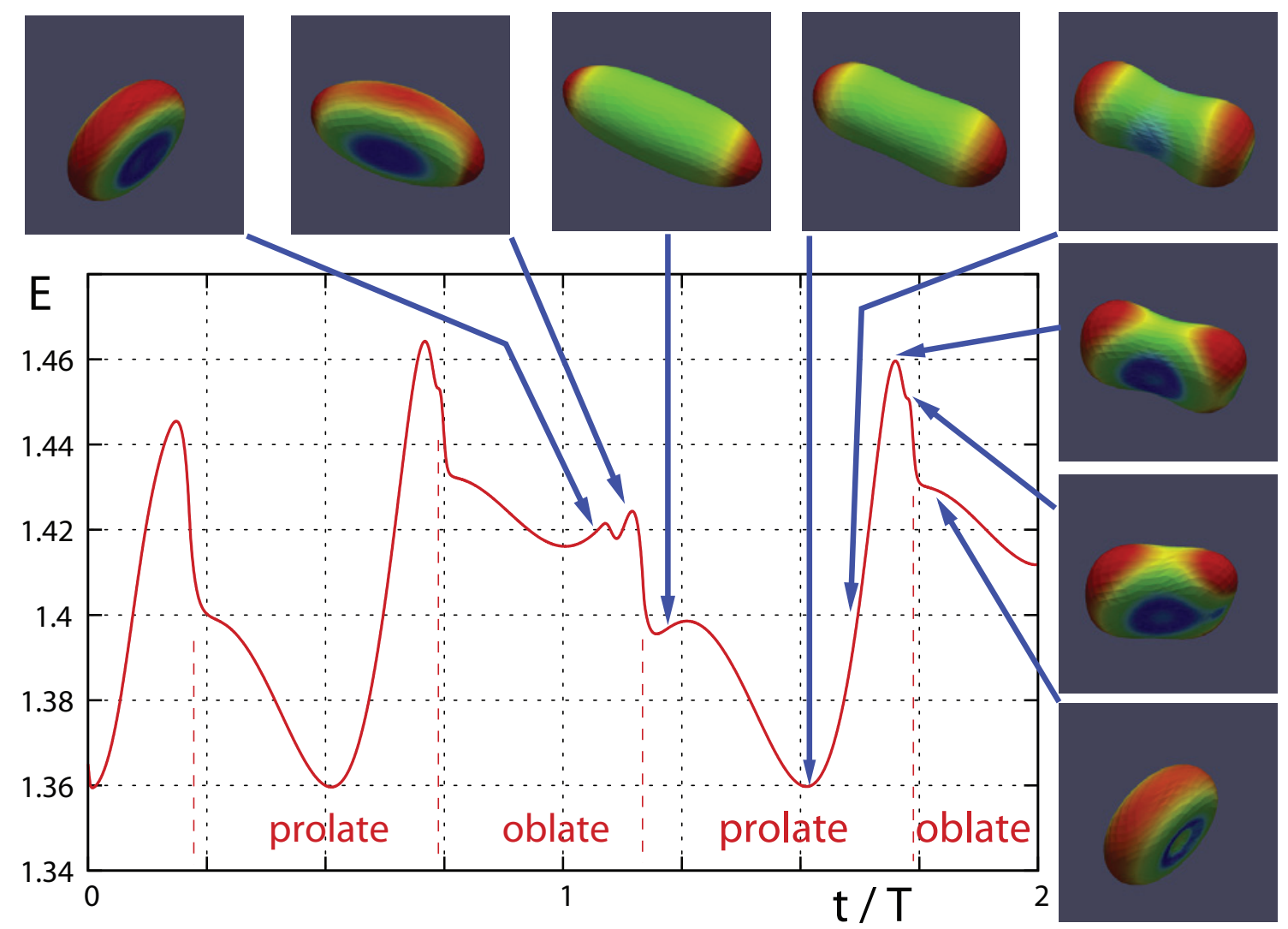

Figura 6.6: Continuação da figura 6.5.

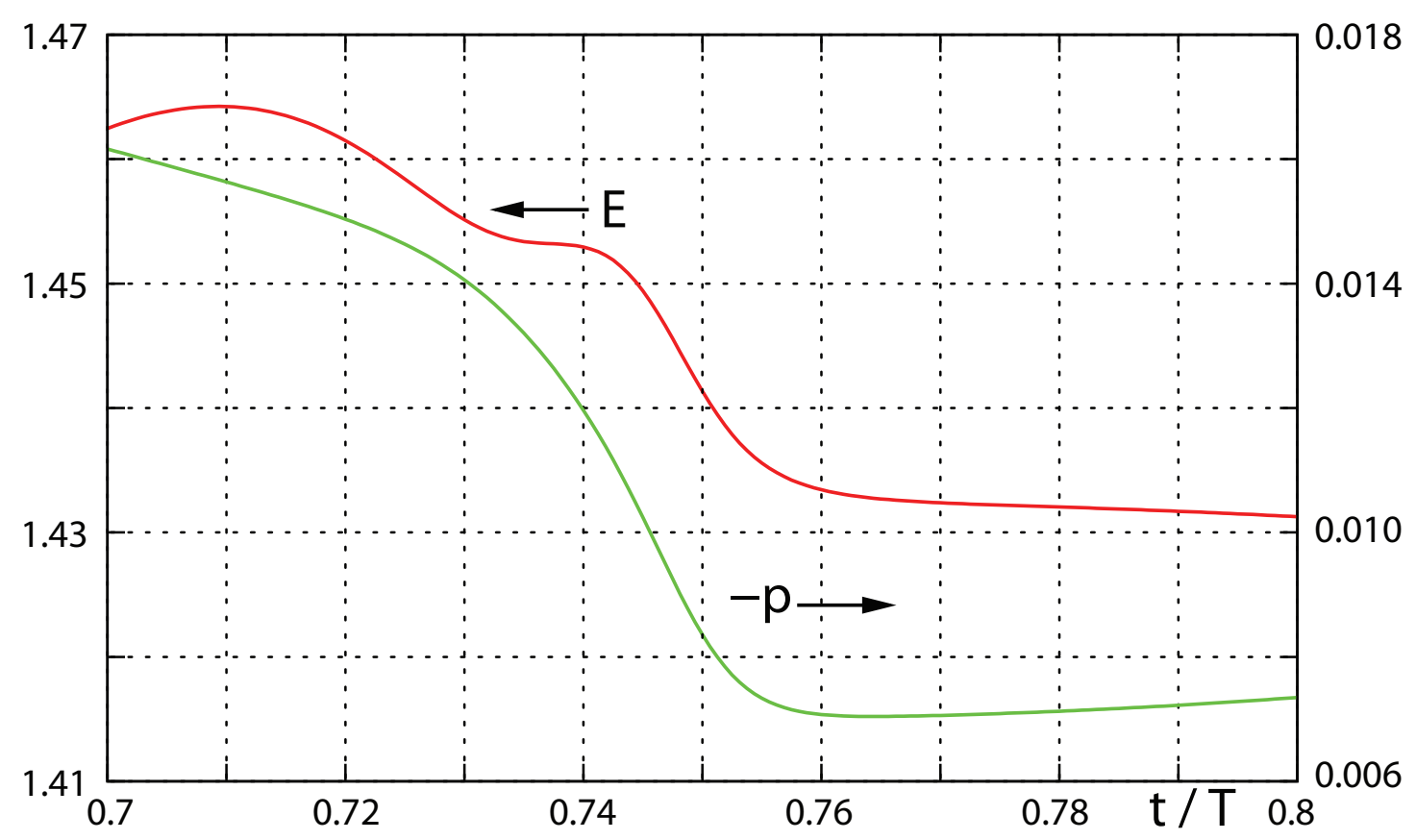

Figura 6.7: Energia de Canham-Helfrich $E$ e pressão volumétrica interna $p$ no intervalo entre $t=0,7 T$ e $t=0,8 T$.

Os casos 3 e 4 nas figuras 6.8, 6.9 e 6.10 correspondem a casos intermediários que combinam arrasto com viscosidade superficial. Inextensibilidade local foi usada nos dois 
casos. Os valores de $\mu$ e $\gamma$ estão indicados nas figuras. A viscosidade superficial penaliza deslocamentos tangenciais e leva a malhas mais bem comportadas.

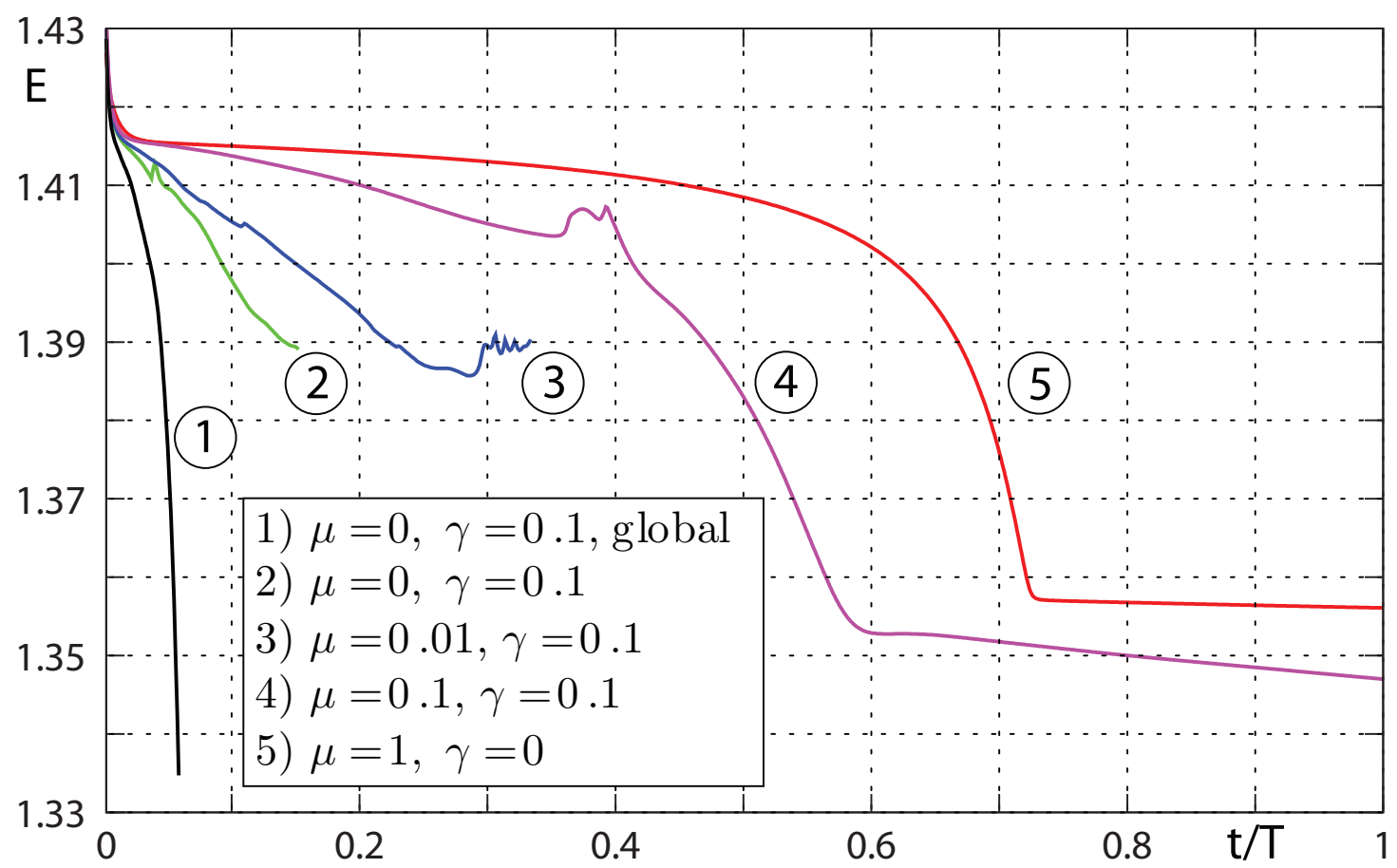

Figura 6.8: Evolução temporal da energia de Canham-Helfrich $E$. O estado inicial é uma membrana deformada. Não há força externa, e a forma evolui em direção ao equilíbrio. A simulação foi feita para contrastar o efeito de diferentes valores da viscosidade $\mu$ e arrasto $\gamma$. O primeiro caso usa restrição de inextensibilidade global, enquanto as demais o fazem localmente.

As formas correspondentes aos casos 4 e 5 são mostradas na figura 6.11 para vários tempos intermediários. À esquerda de cada quadro está o caso puramente viscoso, curva 5, e a direita o caso misto de viscosidade e arrasto, curva 4. Ambas as evoluções primeiro se aproximam da forma oblata metaestável e depois seguem para a forma prolata estável, mas por caminhos diferentes. O fluxo puramente viscoso passa mais tempo perto da forma oblata antes de transicionar, mais abruptamente, para a forma prolata. Apesar de o caso híbrido tender em geral para a mesma forma, a simulação puramente viscosa é mais realística do ponto de vista físico, o que é essencial para avaliar qualquer processo biológico associado com o caminho de relaxação de uma membrana lipídica. 


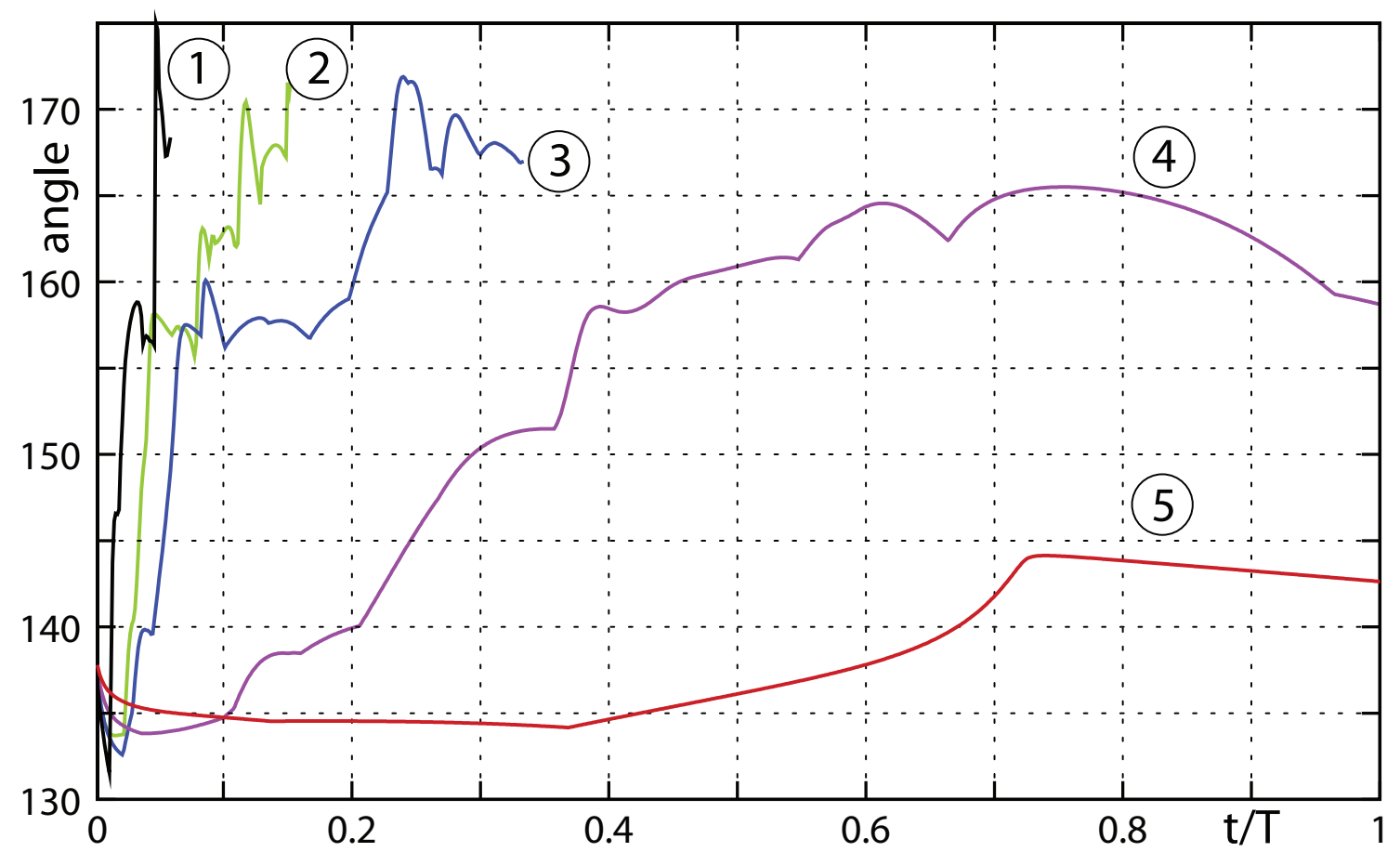

Figura 6.9: Mesma simulação da figura 6.8, agora mostrando a evolução temporal do maior ângulo presente na malha.

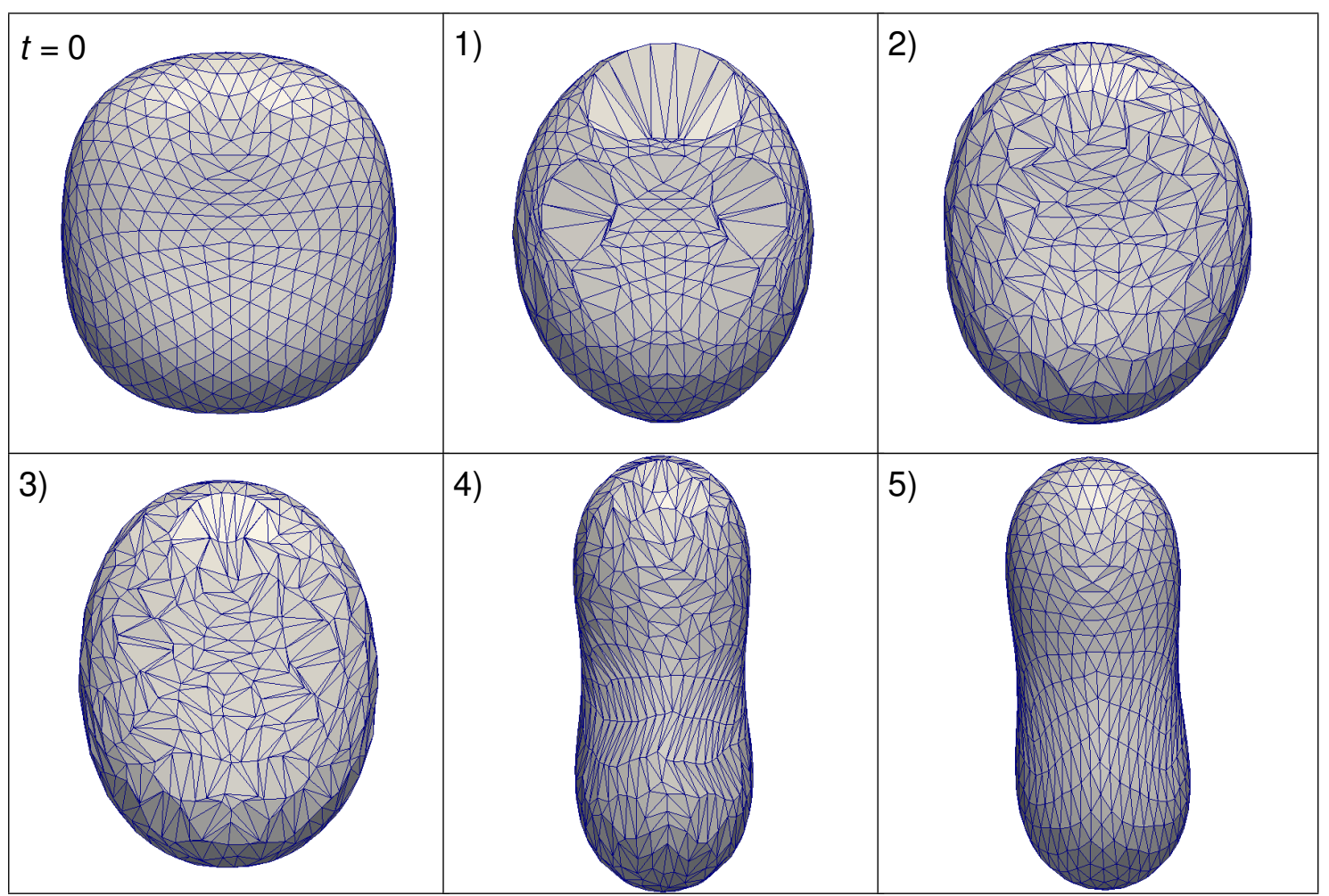

Figura 6.10: Forma inicial (acima à esquerda) e formas finais correspondentes às curvas 1-5 das figuras 6.8 e 6.9 . 


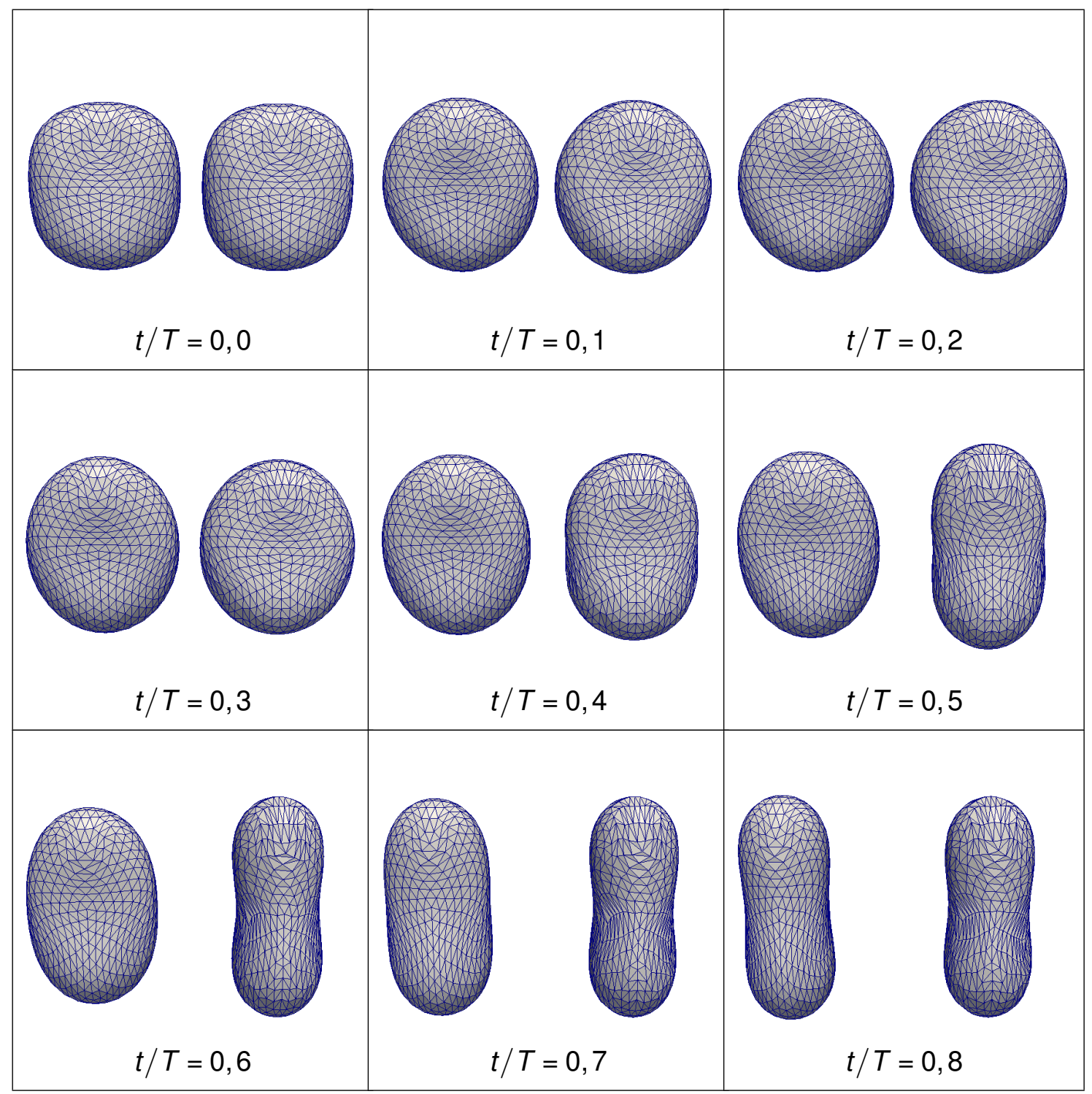

Figura 6.11: Formas e malhas correspondentes às curvas 4 e 5 das figuras 6.8 e 6.9. O lado esquerdo de cada quadro corresponde ao fluxo puramente viscoso, curva 5 , e à direita o fluxo é híbrido, com viscosidade e arrasto, curva 4 . O tempo $t / T$ está indicado em cada quadro. 

Reading diverts the mind too much from its creative pursuits. Any man who reads too much and uses his own brain too little falls into lazy habits of thinking.

Albert Einstein

\section{7 \\ Conclusão}

A possibilidade de criar e manipular bicamadas lipídicas microscópicas em laboratório serve como motivação para o desenvolvimento de técnicas de simulação. Simulações moleculares são capazes de prever o comportamento de fosfolipídios na formação de micelas e lipossomas. No entanto, bicamadas lipídicas maiores, da ordem de tamanho de uma membrana celular, requerem modelos baseados na mecânica de meios contínuos. O modelo apresentado nesse trabalho é o de um fluido bidimensional viscoso, newtoniano e incompressível, disposto sobre uma superfície de formato variável, imersa em três dimensões. A forma da superfície varia de acordo com uma densidade de energia proporcional ao quadrado da curvatura média local.

O capítulo 2 descreveu um método baseado em elementos finitos de simulação de membranas elásticas, o qual serviu de base para o resto do trabalho. Foi apresentado o princípio do trabalho virtual, que permite simulações dinâmicas a partir de leis constitutivas de elasticidade em termos de energia. Alguns exemplos dessas leis também foram apresentados. As restrições de conservação de volume e conservação de área, global e local, foram incorporadas por meio tanto de técnicas de penalização quanto de multiplicadores de Lagrange. A necessidade de um termo de estabilização para a conservação de área local foi discutida. Várias discretizações temporais, não só explícitas mas também implícitas, foram testadas quanto à sua ordem de convergência, apresentando bons resultados. No entanto, métodos de passo temporal adaptativo foram pouco explorados. É interessante melhorar o método adaptativo presente e implementar outros, em particular métodos implícitos adaptativos.

O capítulo 3 mostrou uma maneira de acoplar forças eletromagnéticas à dinâmica da membrana. Além de forças monopolares, a interação entre dipolos também foi considerada, o que permite aproximar distribuições de carga mais intrincadas. Outros acoplamentos envolvendo forças eletromagnéticas são possíveis e podem ser incorporados futuramente.

O capítulo 4 apresentou duas técnicas para tratar colisões e atrito entre membranas, uma baseada em forças elásticas e de arrasto e outra baseada em impulsos. Essa última mostrou-se mais correta do ponto de vista físico por garantir conservação de momento e energia. A possibilidade de incorporá-la a métodos com discretização temporal 
implícita também a torna mais interessante. O desempenho da detecção de contato ainda pode ser melhorado por meio de técnicas bem conhecidas na literatura. Além disso, os casos patológicos de colisão múltipla e autocolisão ainda requerem tratamento mais elaborado.

No capítulo 5 foi apresentada a energia de Canham-Helfrich, que é uma das principais forças motrizes da dinâmica de membranas fosfolipídicas e determinante para a forma de repouso. Algumas técnicas de estimativa de curvatura foram analisadas não na sua precisão, mas sim no seu comportamento em simulações dinâmicas. Viu-se que nem todas são viáveis por produzirem resultados incompatíveis com os dados experimentais. Tal análise é inédita na literatura e será submetida à publicação em breve. Todas as técnicas analisadas apresentam limitações, o que motiva a procura por métodos mais apropriados para estimativa de curvatura em malhas triangulares.

Finalmente, o cerne desse trabalho é apresentado no capítulo 6, que trata de um novo método para a simulação da viscosidade em membranas. Membranas com comportamento predominantemente viscoso são praticamente inexistentes no mundo macroscópico. O método apresentado é construído a partir de técnicas bem estabelecidas de simulação de membranas elásticas macroscópicas. O comportamento viscoso é obtido como uma resposta elástica em relação a uma configuração de referência evanescente, continuamente atualizada. Como o estado de referência é "esquecido" a cada passo da simulação, a energia elástica acumulada é perdida, o que leva a uma dissipação de energia condizente com o comportamento viscoso. Isso permite que códigos existentes para a simulação de sólidos elásticos bidimensionais sejam adaptados para simular membranas fluidas, assim como membranas que possuam simultaneamente comportamento viscoso e elástico.

Como um todo, o método apresentado parece ser o primeiro a simular realmente o comportamento viscoso e incompressível de membranas bidimensionais imersas em três dimensões com formas gerais. Isso é ilustrado pela simulação dinâmica de uma hemácia simplificada sob pinçamento oscilatório. Possíveis aplicações são numerosas, como estudos dinâmicos da adesão de membranas (Das \& Du, 2008), conformação (Lipowsky, 1991), estomatócitos, discócitos e equinócitos (Wortis \& Mukhopadhyay, 2002) e outras transformações de forma (Seifert et al., 1991; Peng et al., 2010), dentre muitas outras.

O método desenvolvido neste trabalho foi publicado em (Tasso \& Buscaglia, 2013). 
If you wish to make an apple pie from scratch, you must first invent the universe.

Carl Sagan

\section{A \\ Desempenho}

Desempenho é parte fundamental da computação científica. Visto que os recursos computacionais, como memória e processador, são limitados, deve-se procurar reduzir o seu uso. A redução do consumo de memória e do tempo de processamento permite que problemas maiores e mais complexos sejam simulados. Por outro lado, desempenho não deve ser uma obsessão. Não se pode sacrificar a correção e a legibilidade do código.

Neste apêndice, é demonstrado que a simples escolha de compiladores e bibliotecas pode trazer grandes ganhos de desempenho, sem a necessidade de maiores modificações no código. O uso do OpenMP como ferramenta de paralelização também é analisado.

\section{A.1 Metodologia}

O computador utilizado em todos os testes possui um processador Intel Core i7 930. Esse processador tem quatro núcleos (cores) de processamento, com duas linhas (threads) em cada núcleo. A memória, 12GB no total, é do tipo DDR3 de $666 \mathrm{MHz}$ (PC310700), ligada em canal triplo (triple channel). A placa mãe é uma ASUS P6TD Deluxe.

O sistema operacional usado foi o Linux versão 3.5, distribuição Ubuntu versão 12.04. Em alguns casos também foi utilizado o Windows 7. Ambos os sistemas operacionais são de 64 bits.

Nos testes de desempenho, foi medido o tempo de relógio (wall time) e não o tempo de CPU, devido à dificuldade de medir tempo de CPU em processadores e sistemas operacionais modernos. O tempo foi medido pelo próprio código sendo executado. Foram utilizadas funções de medição de tempo de alta resolução: gettimeofday no Linux e QueryPerformanceCounter / QueryPerformanceFrequency no Windows.

\section{A.2 Compiladores e OpenMP}

Para testar o desempenho do código em relação à escolha de compilador e a paralelização por OpenMP, foi executada uma simulação com o método explícito, o qual não 
envolve a resolução de sistemas lineares. O tempo de 1000 ciclos de simulação foi medido várias vezes, em várias execuções, e o melhor tempo foi tomado.

Os compiladores utilizados foram:

- GCC 4.7.2

- Intel 13.0 (2013)

- Visual Studio 17.0 (2012)

Todos geram código 64 bits. As opções de otimização para máxima velocidade foram usadas na compilação: "-Ofast" para o GCC, "-fast" para o Intel e "/Ox" para o Visual Studio. Os tempos medidos no Windows e Linux estão nas tabelas A.1 e A.2.

\begin{tabular}{c|c|c|c|c|c}
\hline \multicolumn{5}{c}{ Windows } \\
\hline GCC & Intel & VS & GCC & Intel & VS \\
\hline $115,462 \mathrm{~s}$ & $75,136 \mathrm{~s}$ & $156,859 \mathrm{~s}$ & $28,649 \mathrm{~s}$ & $18,047 \mathrm{~s}$ & $31,827 \mathrm{~s}$ \\
\hline
\end{tabular}

Tabela A.1: Desempenho dos compiladores no Windows.

\begin{tabular}{c|c|c|c}
\hline \multicolumn{3}{c}{ Linux } \\
\hline \multicolumn{2}{c|}{ Serial } & \multicolumn{2}{c}{ OpenMP } \\
\hline GCC & Intel & GCC & Intel \\
\hline $114,857 \mathrm{~s}$ & $73,018 \mathrm{~s}$ & $27,614 \mathrm{~s}$ & $17,623 \mathrm{~s}$ \\
\hline
\end{tabular}

Tabela A.2: Desempenho dos compiladores no Linux.

O compilador da Intel é claramente o que gera o código mais rápido. Ele é $57 \%$ mais rápido do que o segundo colocado, o GCC, no Linux. A paralelização por OpenMP produziu um speedup de $414 \%$ para o compilador Intel no Linux. A lei de Amdahl diz que um speedup de $414 \%$ em oito processadores indica que $87 \%$ do código está paralelizado. No entanto, é importante lembrar que a máquina não possui oito processadores físicos, e sim quatro núcleos com duas linhas cada. Segundo a Intel, a tecnologia Hyper-threading produz até $30 \%$ de ganho de desempenho em situações práticas (Binstock \& Gerber, 2003). Portanto, o mais correto seria considerar que a máquina tem 5,2 processadores, e não oito. Neste caso, um speedup de $414 \%$ em 5,2 processadores indica que $94 \%$ do código está paralelizado. A eficiência é de $80 \%$.

A pequena diferença que há entre os tempos no Windows e Linux deve-se provavelmente a outros processos do sistema operacional e não ao código gerado em si. O Linux utilizado era recém-instalado, enquanto o Windows era uma instalação antiga, com muitos outros programas instalados.

\section{A.3 Solucionadores de sistemas lineares}

Técnicas de resolução de sistemas lineares constituem um campo de pesquisa bastante amplo e complexo. Sistemas pequenos, com poucas equações, podem ser resolvidos com algoritmos de inversão de matrizes ou pela regra de Cramer. Sistemas grandes, com milhares de equações, necessitam de métodos mais sofisticados. Esses métodos podem ser divididos em três classes: 
Métodos iterativos estacionários usam uma aproximação do operador original do sistema. A cada iteração, o resíduo é calculado e o operador é corrigido, produzindo uma solução mais próxima da exata. O método termina quando uma tolerância de erro é atingida. Como exemplo há o método de Jacobi, Gauss-Seidel e "successive over relaxation" ou SOR. Métodos multigrid se encaixam nessa categoria.

Métodos de Krylov formam uma base a partir da aplicação sucessiva do operador original ao resíduo inicial. Uma aproximação da solução é obtida ao se minimizar o resíduo sobre esse subespaço formado. Métodos de Krylov, em geral, são usados de forma iterativa, ou seja, são feitas iterações até que uma tolerância seja atingida. No entanto, o método converge para a solução exata do sistema, a menos de erros de arredondamento, em um número finito de iterações. Como exemplos, há o método dos gradientes conjugados (CG), "generalized minimal residual method" (GMRES) e "biconjugate gradient method" (BiCG).

Métodos diretos são aqueles capazes de calcular a solução exata do sistema, a menos de erros de arredondamento, com um número finito de operações. O principal algoritmo é a eliminação de Gauss. A decomposição LU pode ser vista como uma versão matricial da eliminação de Gauss. Para matrizes hermitianas e positivas definidas, existe a decomposição de Cholesky, que é mais eficiente. A decomposição QR é um método direto para a solução de problemas de mínimos quadrados lineares, aplicável a sistemas lineares onde o número de equações linearmente independentes é maior do que o número de incógnitas.

Neste trabalho, foram usados métodos diretos para a solução de sistemas lineares.

\section{A.3.1 Matrizes esparsas}

Simulações de elementos finitos, em geral, produzem matrizes esparsas. Uma matriz de ordem $n$ possui $n^{2}$ elementos. Ela é dita esparsa se o número de elementos não nulos for proporcional a $n$. Isso significa que para matrizes esparsas grandes, há muito mais elementos nulos do que não nulos. Um algoritmo eficiente deve levar em conta essa esparsidade, tanto no armazenamento quanto no processamento. Dois formatos comuns de armazenamento de matrizes esparsas são a lista de coordenadas e o formato de Yale.

Lista de coordenadas são listas de tuplas (linha, coluna, valor). Para cada elemento não nulo da matriz há uma tupla na lista.

O formato de Yale, também conhecido como "compressed sparse row" (CSR) ou "compressed row storage" (CRS), é baseado em três listas. A lista de valores guarda os valores não nulos da matriz. A lista de colunas guarda a coluna correspondente a cada item da lista de valores. Essas duas listas formam uma tupla (coluna, valor) semelhante à lista de coordenadas. Essas tuplas são agrupadas e ordenadas de acordo com a linha da matriz. Uma terceira lista, a lista de linhas, indica onde cada um desses grupos começa e termina. Alguns algoritmos requerem que as colunas também sejam ordenadas dentro de cada linha.

O formato "compressed sparse column" (CSC) ou "compressed column storage" (CCS) é análogo ao formato de Yale, mas trocando-se a coluna pela linha. A representação de uma matriz em CSC ou CCS corresponde à representação da matriz transposta em CSR ou CRS.

\section{A.3.2 Preenchimento}

Em geral, implementações de métodos iterativos e de Krylov operam apenas nos elementos não nulos das matrizes esparsas, o que os tornam eficientes. Métodos diretos, 
como decomposição LU e de Cholesky, sofrem do problema conhecido como preenchimento. Quando uma matriz esparsa é decomposta em fatores, esses fatores podem não ser tão esparsos como a matriz original, o que torna o algoritmo muito caro.

Esse preenchimento pode ser reduzido se as linhas e colunas da matriz forem permutadas de maneira conveniente. Vários são os algoritmos de reordenamento que reduzem o preenchimento. Alguns dos mais populares são:

- Approximate Minimum Degree (AMD) (Amestoy et al., 1996)

- Approximate Minimum Fill (AMF) (Rothberg, 1996)

- AMD with automatic quasi-dense row detection (QAMD) (Amestoy, 1997)

- METIS e ParMETIS (Karypis \& Kumar, 1998)

- Minimum degree algorithm (MDA) (Li \& Demmel, 1999)

- Nested Dissection (ND) (George, 1973)

- One-way Dissection (1WD) (George, 1980)

- PORD (Schulze, 2001)

- Quotient Minimum Degree (QMD) (George \& Liu, 1989)

- Reverse Cuthill-McKee (RCM) (Cuthill \& McKee, 1969)

- SCOTCH e PT-SCOTCH (Pellegrini, 2007)

- Multiple Minimum Degree (MMD) (Liu, 1985)

- Column Approximate Minimum Degree (COLAMD) (Davis et al., 2004) básicos:

Portanto, um solucionador direto para matrizes esparsas segue três passos

1. Análise e ordenação

2. Fatoração

3. Substituição reversa

A análise e ordenação visam reduzir o preenchimento que ocorrerá na etapa de fatoração. A etapa de fatoração é a mais cara em matrizes grandes, correspondendo a mais de $90 \%$ do processo. Depois de fatorada a matriz, a solução é facilmente calculada a partir das matrizes triangulares obtidas. 


\begin{tabular}{c|c|c|c}
\hline malha & elementos & ordem & não nulos \\
\hline 1 & 1280 & 4495 & $188 \mathrm{k}$ \\
2 & 5120 & 17935 & $755 \mathrm{k}$ \\
3 & 20480 & 71695 & $3,0 \mathrm{M}$ \\
\hline
\end{tabular}

Tabela A.3: Malhas e matrizes utilizadas como teste de desempenho das bibliotecas de resolução de sistemas lineares.

\section{A.3.3 Desempenho}

Nas seções seguintes, algumas das bibliotecas mais populares para resolução direta de sistemas lineares serão avaliadas com relação ao seu desempenho. Como caso teste, foi feita uma simulação típica com o método implícito que envolvia viscosidade, energia de curvatura, conservação de volume e conservação local de área. A matriz gerada pela primeira iteração do método de Newton-Raphson do primeiro passo de tempo foi usada como entrada. Três malhas foram utilizadas para gerar as matrizes. Suas características estão na tabela A.3. O tempo de relógio foi medido pelo próprio código e apenas o tempo de gasto pela biblioteca foi considerado.

Todas as bibliotecas foram compiladas com o compilador Intel usando a opção de otimização para máxima velocidade "-fast”, exceto a Intel MKL que é distribuída já em formato binário.

\section{A.4 Intel MKL e PARDISO}

A Intel Math Kernel Library (MKL) (Intel, 2013) é uma biblioteca matemática desenvolvida em Fortran e C que implementa as conhecidas interfaces BLAS (Basic Linear Algebra Subprograms) e LAPACK (Linear Algebra PACKage), e também as versões paralelizadas PBLAS (Parallel BLAS), ScaLAPACK (Scalable LAPACK) e BLACS (Basic Linear Algebra Communication Subprograms). Possui várias outras funcionalidades, inclusive uma versão do solucionador direto para sistemas lineares esparsos PARDISO (Schenk \& Gärtner, 2004). Há versões para Windows, Linux e OS X. Sua licença é comercial, mas a versão Linux possui uma licença gratuita para aplicações não comerciais e acadêmicas.

A versão do PARDISO presente na MKL possui dois algoritmos para a fase de fatoração de sistemas lineares: um serial, chamado fatoração clássica, e outro paralelo, chamado fatoração de dois níveis. A fase de ordenação pode ser feita pelos algoritmos seriais MDA e METIS ou pelo ParMETIS, que é paralelo. A paralelização é feita usando memória compartilhada (OpenMP). Os tempos medidos estão nas tabelas A.4 e A.5.

\begin{tabular}{c|c|c|c}
\hline \multicolumn{4}{c}{ PARDISO } \\
\hline \multicolumn{4}{c}{ fatoração clássica } \\
\hline ordenamento & malha 1 & malha 2 & malha 3 \\
\hline MDA & $0,199 \mathrm{~s}$ & $1,015 \mathrm{~s}$ & $8,643 \mathrm{~s}$ \\
METIS & $0,219 \mathrm{~s}$ & $0,999 \mathrm{~s}$ & $5,550 \mathrm{~s}$ \\
ParMETIS & $0,189 \mathrm{~s}$ & $0,839 \mathrm{~s}$ & $4,760 \mathrm{~s}$ \\
\hline
\end{tabular}

Tabela A.4: Tempos medidos com a biblioteca PARDISO usando a fatoração clássica (serial).

A ordenação pelo ParMETIS se mostra superior. Não houve grande diferença entre a fatoração clássica e a de dois níveis. Segundo o manual da MKL, a fatoração de dois 


\begin{tabular}{c|c|c|c}
\hline \multicolumn{4}{c}{ PARDISO } \\
\hline \multicolumn{4}{c}{ fatoração de dois níveis } \\
\hline ordenamento & malha 1 & malha 2 & malha 3 \\
\hline MDA & $0,185 \mathrm{~s}$ & $1,011 \mathrm{~s}$ & $8,634 \mathrm{~s}$ \\
METIS & $0,214 \mathrm{~s}$ & $0,969 \mathrm{~s}$ & $5,442 \mathrm{~s}$ \\
ParMETIS & $0,192 \mathrm{~s}$ & $0,808 \mathrm{~s}$ & $4,647 \mathrm{~s}$ \\
\hline
\end{tabular}

Tabela A.5: Tempos medidos com a biblioteca PARDISO usando a fatoração de dois níveis (paralela).

níveis geralmente melhora o desempenho quando o número de processadores é maior do que oito.

\section{A.5 MUMPS}

A biblioteca MUMPS (MUltifrontal Massively Parallel sparse direct Solver) é desenvolvida em Fortran e C (Amestoy et al., 2001, 2006). É um software livre de domínio público e código aberto. Ao contrário da PARDISO, a versão paralela da MUMPS usa memória distribuída (MPI).

A fase de ordenação pode ser feita pelos métodos AMD, QAMD e AMF. Por meio de bibliotecas adicionais, os métodos PORD, METIS, ParMETIS, SCOTCH e PT-SCOTH também podem ser usados. A tabela A. 6 mostra os tempos medidos.

\begin{tabular}{c|c|c|c}
\hline \multicolumn{4}{c}{ MUMPS } \\
\hline ordenamento & malha 1 & malha 2 & malha 3 \\
\hline AMD & $0,405 \mathrm{~s}$ & $1,796 \mathrm{~s}$ & $15,309 \mathrm{~s}$ \\
AMF & $0,399 \mathrm{~s}$ & $1,807 \mathrm{~s}$ & $11,513 \mathrm{~s}$ \\
SCOTCH & $0,632 \mathrm{~s}$ & $2,869 \mathrm{~s}$ & $14,209 \mathrm{~s}$ \\
PORD & $1,600 \mathrm{~s}$ & $2,015 \mathrm{~s}$ & $12,401 \mathrm{~s}$ \\
METIS & $0,393 \mathrm{~s}$ & $1,754 \mathrm{~s}$ & $10,990 \mathrm{~s}$ \\
QAMD & $0,400 \mathrm{~s}$ & $1,807 \mathrm{~s}$ & $15,185 \mathrm{~s}$ \\
PT-SCOTCH & $0,637 \mathrm{~s}$ & $2,883 \mathrm{~s}$ & $14,163 \mathrm{~s}$ \\
ParMETIS & $0,395 \mathrm{~s}$ & $1,774 \mathrm{~s}$ & $10,918 \mathrm{~s}$ \\
\hline
\end{tabular}

Tabela A.6: Tempos medidos com a biblioteca MUMPS.

Os métodos METIS e ParMETIS se mostraram superiores, sendo que os métodos AMD e AMF possuem desempenho semelhante.

\section{A.6 PETSc}

A biblioteca PETSc (Balay et al., 2012b,a, 1997) possui um conjunto de estruturas de dados e rotinas para a solução de problemas modelados por equações diferenciais parciais. Em particular, ela possui um solucionador de sistemas lineares esparsos por decomposição LU. A tabela A.7 mostra os tempos obtidos usando esse solucionador.

Não foi encontrada na documentação a definição do que seriam os ordenamentos "natural" e "rowlength". Os tempos marcados como $\infty$ indicam que o caso não foi testado pois iria demorar demais. A ordenação "rowlength" produziu o erro "zero pivot row", o que impossibilitou o seu uso. 


\begin{tabular}{c|c|c|c}
\hline \multicolumn{4}{|c}{ PETSc } \\
\hline ordenamento & malha 1 & malha 2 & malha 3 \\
\hline natural & $12,830 \mathrm{~s}$ & $809,225 \mathrm{~s}$ & $\infty$ \\
ND & $3,647 \mathrm{~s}$ & $151,226 \mathrm{~s}$ & $\infty$ \\
1WD & $14,545 \mathrm{~s}$ & $856,569 \mathrm{~s}$ & $\infty$ \\
RCM & $15,171 \mathrm{~s}$ & $1040,796 \mathrm{~s}$ & $\infty$ \\
QMD & $6,192 \mathrm{~s}$ & $355,200 \mathrm{~s}$ & $\infty$ \\
rowlength & - & - & - \\
AMD & $0,831 \mathrm{~s}$ & $8,245 \mathrm{~s}$ & $97,619 \mathrm{~s}$ \\
\hline
\end{tabular}

Tabela A.7: Tempos medidos com a biblioteca PETSc.

É importante ressaltar que o solucionador utilizado é aquele provido pela biblioteca PETSc, que não é paralelizado. É possível, no entanto, utilizar bibliotecas externas, como a MUMPS, usando a PETSc como interface.

\section{A.7 HSL}

A biblioteca de sub-rotinas Harwell (Harwell Subroutine Library, HSL) é uma coleção de pacotes para computação em grande escala desenvolvida pelo grupo de análise numérica do STFC Rutherford Appleton Laboratory. O pacote testado foi o HSL_MA48, que resolve sistemas esparsos assimétricos por meio de métodos diretos. Os resultados obtidos podem ser vistos na tabela A.8.

\begin{tabular}{c|c|c}
\hline \multicolumn{3}{c}{ HSL } \\
\hline malha 1 & malha 2 & malha 3 \\
\hline $0,853 \mathrm{~s}$ & $11,953 \mathrm{~s}$ & $324,969 \mathrm{~s}$ \\
\hline
\end{tabular}

Tabela A.8: Tempos medidos com a biblioteca HSL.

O pacote não possui versão paralela e não há opções de escolha de ordenamento.

\section{A.8 SuperLU}

A biblioteca SuperLU (Li, 2005) possui três versões: sequencial, paralela com memória distribuída e paralela com memória compartilhada. A tabela A.9 mostra os tempos medidos para a versão paralela com memória compartilhada.

\begin{tabular}{c|r|r|c}
\hline \multicolumn{4}{c}{ SuperLU } \\
\hline ordenamento & malha 1 & \multicolumn{1}{c}{ malha 2 } & malha 3 \\
\hline natural & $5,359 \mathrm{~s}$ & $480,300 \mathrm{~s}$ & $\infty$ \\
$\operatorname{MMD}\left(A^{T} A\right)$ & $1,636 \mathrm{~s}$ & $93,480 \mathrm{~s}$ & $\infty$ \\
MMD $\left(A^{T}+A\right)$ & $8,118 \mathrm{~s}$ & $1332,780 \mathrm{~s}$ & $\infty$ \\
COLAMD & $0,975 \mathrm{~s}$ & $23,281 \mathrm{~s}$ & $1165,205507 \mathrm{~s}$ \\
\hline
\end{tabular}

Tabela A.9: Tempos medidos com a biblioteca SuperLU.

demais.

Os tempos marcados como $\infty$ indicam que o caso não foi testado pois iria demorar 


\section{A.9 Comparação}

tabela A.10.

O resumo dos melhores tempos medidos com as diversas bibliotecas está na

\begin{tabular}{c|r|r|r}
\hline biblioteca & malha 1 & \multicolumn{1}{c|}{ malha 2} & \multicolumn{1}{c}{ malha 3 } \\
\hline PARDISO & $0,185 \mathrm{~s}$ & $0,808 \mathrm{~s}$ & $4,647 \mathrm{~s}$ \\
MUMPS & $0,393 \mathrm{~s}$ & $1,754 \mathrm{~s}$ & $10,918 \mathrm{~s}$ \\
PETSc & $0,831 \mathrm{~s}$ & $8,245 \mathrm{~s}$ & $97,619 \mathrm{~s}$ \\
HSL & $0,853 \mathrm{~s}$ & $11,953 \mathrm{~s}$ & $324,969 \mathrm{~s}$ \\
SuperLU & $0,975 \mathrm{~s}$ & $23,281 \mathrm{~s}$ & $1165,205 \mathrm{~s}$ \\
\hline
\end{tabular}

Tabela A.10: Comparação entre os tempos medidos com as diversas bibliotecas.

Para os casos testados, a biblioteca PARDISO mostrou-se superior com relação ao desempenho. 
Wit is educated insolence.

Aristotle

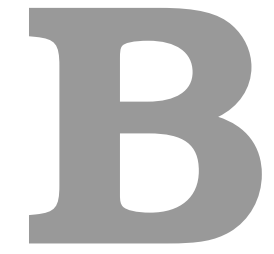

Remalhamento

A introdução do operador viscoso (seção 6.1) reduz significativamente a degradação da malha. No entanto, para grandes deformações, a malha se estraga ao ponto de inviabilizar a simulação. Para contornar esse problema, um código gerador de malhas foi acoplado ao código simulador, com a colaboração de Fernando Mut da George Mason University.

O processo de remalhamento é ilustrado na figura B.1. O programa simulador executa um ou mais passos de simulação a partir de uma malha inicial. O resultado da simulação é passado ao código remalhador, que faz o processamento e retorna para o código simulador, fechando o ciclo.

Um desafio introduzido pelo remalhamento é a determinação do campo de velocidades da nova malha. Não é trivial interpolar o campo de velocidades da malha anterior para a nova malha. No entanto, os exemplos apresentados neste capítulo possuem massa nula, ou seja, não há inércia, e por isso o campo de velocidades da malha anterior pode ser ignorado. Mas situações onde a inércia da malha é importante requerem um tratamento mais elaborado.

A nova malha, em geral, possui área e volume ligeiramente diferentes da malha antiga. Por isso, o código simulador impõe a área e volume da malha original. No caso de conservação de área local, a área prescrita para cada triângulo é multiplicada por um fator, que faz a área total da malha nova ser igual à da malha original.

Uma alternativa, ainda em estudo, ao programa remalhador é o uso das chamadas malhas universais (Rangarajan \& Lew, 2012). Uma malha universal é construída a partir de uma malha volumétrica que se adapta na vizinhança da superfície que se quer representar, fazendo com que os nós da malha fiquem sobre a superfície. Há apenas movimentação de nós, sem criação de nós ou mudança na conectividade, o que é bastante interessante. Além disso, a malha volumétrica permite a simulação de fluidos adjacentes à membrana.

\section{B.1 Pinçamento de vesícula}

A figura B.2 mostra uma comparação dos casos com e sem remalhamento para o problema de pinçamento de vesícula. Em cada quadro, na parte de cima está o caso com 


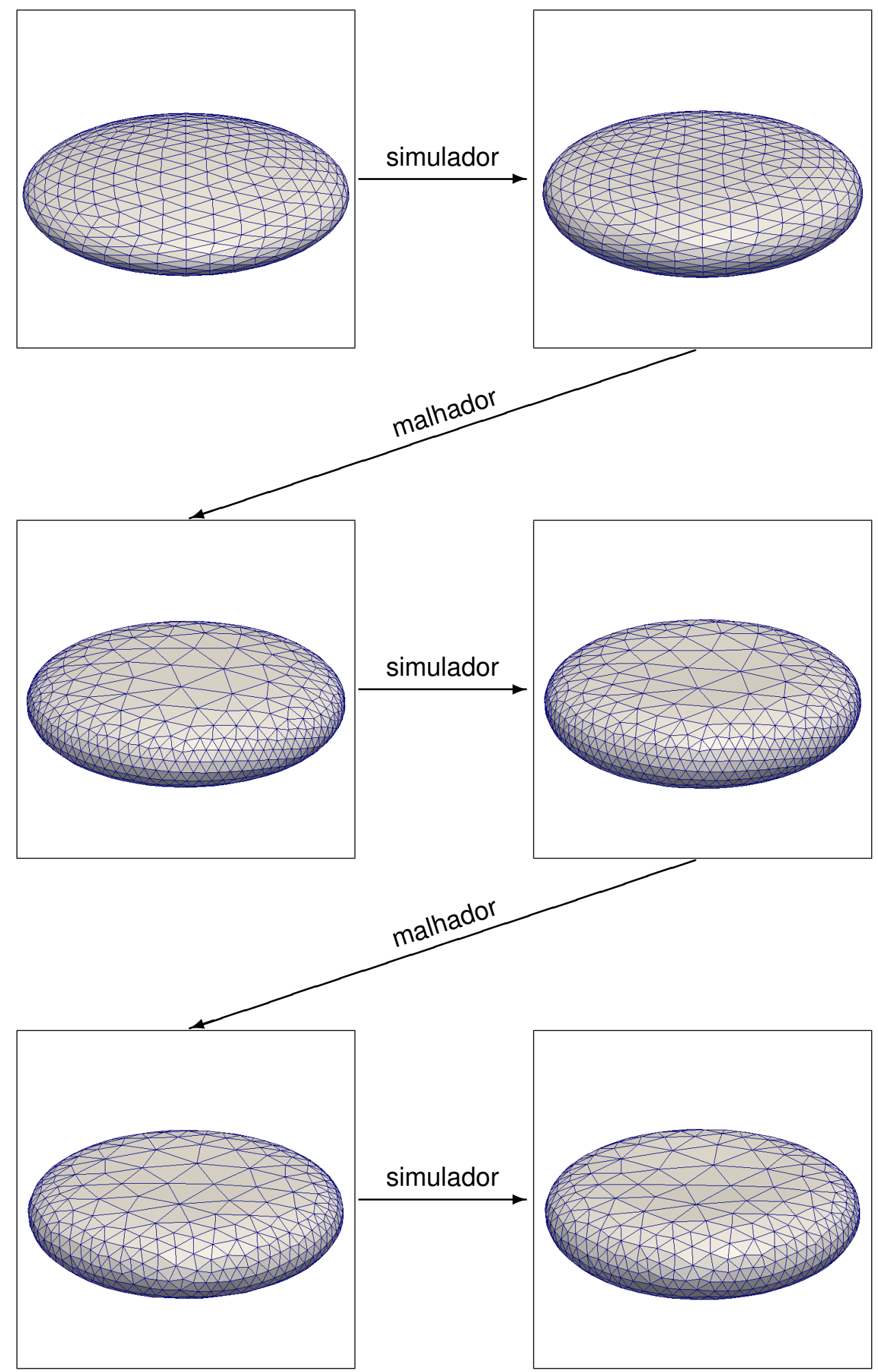

Figura B.1: Ciclo de simulação e remalhamento. O programa simulador executa um ou mais passos de simulação a partir de uma malha inicial. O resultado da simulação é passado para o código remalhador, que faz o processamento e retorna para o código simulador. 


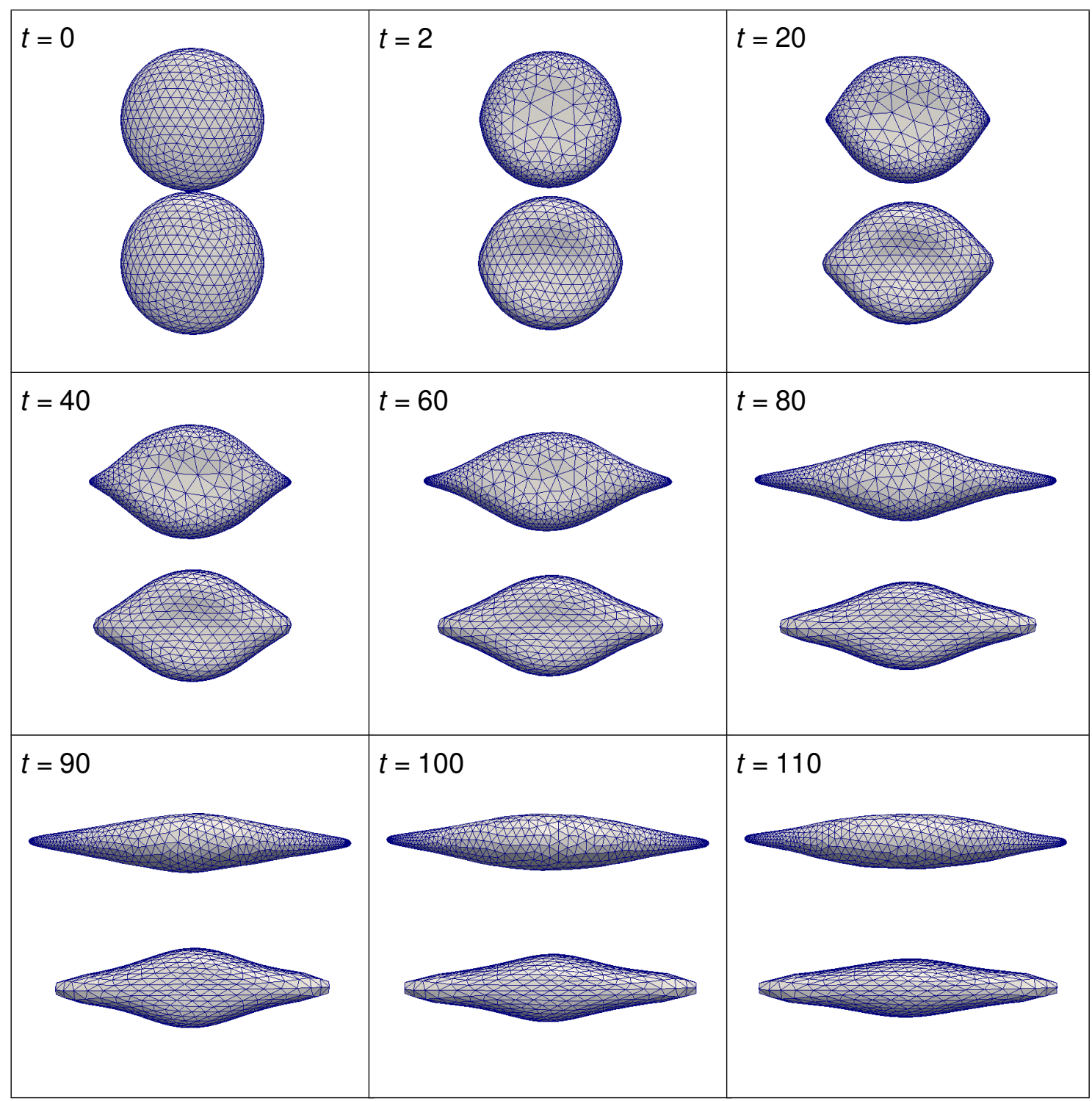

Figura B.2: Pinçamento de vesícula. Em cada quadro, na parte de cima está o caso com remalhamento e na parte de baixo a mesma simulação, mas sem remalhamento.

\section{B.2 Atrelamento}

Quando uma membrana é pinçada e esticada por uma longa distância, ocorre o chamado atrelamento, onde há um afilamento da membrana, como se ela estivesse presa por uma trela ou guia, como pode ser visto na figura B.3. 


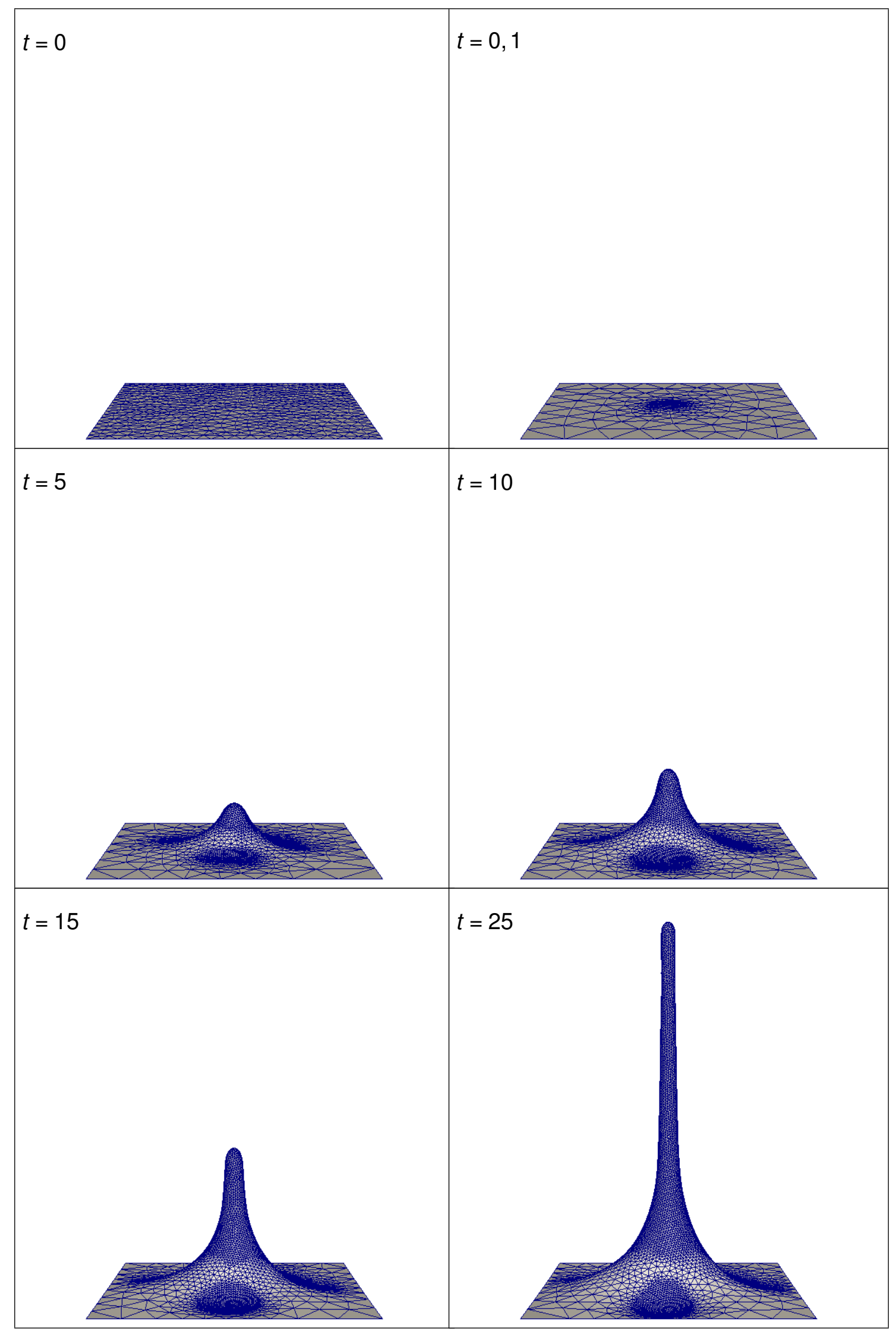

Figura B.3: Atrelamento. Ao ser pinçada, a membrana adquire uma forma afilada, como se estivesse presa por uma trela ou guia. 


\section{Referências Bibliográficas}

Amestoy, P., 1997. Recent progress in parallel multifrontal solvers for unsymmetric sparse matrices. In Proceedings of the 15th World Congress on Scientific Computation, Modelling and Applied Mathematics, IMACS, volume 97.

Amestoy, P., Davis, T., \& Duff, I., 1996. An approximate minimum degree ordering algorithm. SIAM Journal on Matrix Analysis and Applications, vol. 17, n. 4, pp. 886-905.

Amestoy, P. R., Duff, I. S., Koster, J., \& L'Excellent, J.-Y., 2001. A fully asynchronous multifrontal solver using distributed dynamic scheduling. SIAM Journal on Matrix Analysis and Applications, vol. 23, n. 1, pp. 15-41.

Amestoy, P. R., Guermouche, A., L'Excellent, J.-Y., \& Pralet, S., 2006. Hybrid scheduling for the parallel solution of linear systems. Parallel Computing, vol. 32, n. 2, pp. 136-156.

Arroyo, M. \& DeSimone, A., 2009. Relaxation dynamics of fluid membranes. Physical review. E, Statistical, nonlinear, and soft matter physics, vol. 79, n. 3, pp. 031915.

Arroyo, M., DeSimone, A., \& Heltai, L., 2010. The role of membrane viscosity in the dynamics of fluid membranes. arXiv preprint arXiv:1007.4934.

Balay, S., Brown, J., , Buschelman, K., Eijkhout, V., Gropp, W. D., Kaushik, D., Knepley, M. G., Mclnnes, L. C., Smith, B. F., \& Zhang, H., 2012a. PETSc users manual. Technical Report ANL-95/11 - Revision 3.3, Argonne National Laboratory.

Balay, S., Brown, J., Buschelman, K., Gropp, W. D., Kaushik, D., Knepley, M. G., Mclnnes, L. C., Smith, B. F., \& Zhang, H., 2012b. PETSc Web page. http://www.mcs.anl.gov/petsc.

Balay, S., Gropp, W. D., Mclnnes, L. C., \& Smith, B. F., 1997. Efficient management of parallelism in object oriented numerical software libraries. In Arge, E., Bruaset, A. M., \& Langtangen, H. P., eds, Modern Software Tools in Scientific Computing, pp. 163-202. Birkhäuser Press.

Barber, D. \& Loudon, R., 1989. An introduction to the properties of condensed matter. Cambridge University Press.

Barrett, J., Garcke, H., \& Nürnberg, R., 2008. On the parametric finite element approximation of evolving hypersurfaces in r3. Journal of Computational Physics, vol. 227, n. 9, pp. 42814307.

Belkin, M., Sun, J., \& Wang, Y., 2008. Discrete laplace operator on meshed surfaces. In Proceedings of the twenty-fourth annual symposium on Computational geometry, pp. 278287. ACM.

Bike Revival, 2013. Ikons. Disponível em: http://www. bike-revival.co.uk/exp.html. 
Binstock, A. \& Gerber, R., 2003. Programming with Hyper-Threading Technology. Intel Press.

Boedec, G., Leonetti, M., \& Jaeger, M., 2011. 3d vesicle dynamics simulations with a linearly triangulated surface. Journal of Computational Physics, vol. 230, n. 4, pp. 1020-1034.

Bonet, J., Wood, R., Mahaney, J., \& Heywood, P., 2000. Finite element analysis of air supported membrane structures. Computer methods in applied mechanics and engineering, vol. 190, n. 5, pp. 579-595.

Bonito, A., Nochetto, R., \& Pauletti, M., 2010. Parametric FEM for geometric biomembranes. Journal of Computational Physics, vol. 229, n. 9, pp. 3171-3188.

Bonito, A., Nochetto, R., \& Pauletti, M., 2011. Dynamics of biomembranes: Effect of the bulk fluid. Mathematical Modelling of Natural Phenomena, vol. 6, n. 5, pp. 25-43.

Boussinesq, M. J., 1913. Sur l'existence d'une viscosité superficielle, dans la mince couche de transition séparant un liquide d'un autre fluide contigu. Annales de chimie et de physique, vol. 29, pp. 349-357.

Bridson, R., Fedkiw, R., \& Anderson, J., 2002. Robust treatment of collisions, contact and friction for cloth animation. In ACM Transactions on Graphics (TOG), volume 21, pp. 594603. ACM.

Bridson, R., Marino, S., \& Fedkiw, R., 2003. Simulation of clothing with folds and wrinkles. In Proceedings of the 2003 ACM SIGGRAPH/Eurographics symposium on Computer animation, pp. 28-36. Eurographics Association.

Buscaglia, G. C. \& Ausas, R. F., 2011. Variational formulations for surface tension, capillarity and wetting. Computer Methods in Applied Mechanics and Engineering, vol. 200, n. 45, pp. 3011-3025.

Buscaglia, G. C., Basombrio, F. G., \& Codina, R., 2000. Fourier analysis of an equal-order incompressible flow solver stabilized by pressure gradient projection. International journal for numerical methods in fluids, vol. 34, n. 1, pp. 65-92.

Canham, P., 1970. The minimum energy of bending as a possible explanation of the biconcave shape of the human red blood cell. Journal of Theoretical Biology, vol. 26, n. 1, pp. 61-81.

CMSoft, 2013. Collision cases. Disponível em: http://www.cmsoft.com.br/index.php? option=com_content\&view=category\&layout=blog\&id=81\&Itemid=132.

Codina, R., 2001. A stabilized finite element method for generalized stationary incompressible flows. Computer Methods in Applied Mechanics and Engineering, vol. 190, n. 20, pp. 26812706.

Codina, R., Blasco, J., Buscaglia, G., \& Huerta, A., 2001. Implementation of a stabilized finite element formulation for the incompressible navier-stokes equations based on a pressure gradient projection. International journal for numerical methods in fluids, vol. 37, n. 4, pp. 419-444.

Cuthill, E. \& McKee, J., 1969. Reducing the bandwidth of sparse symmetric matrices. In Proceedings of the 1969 24th national conference, pp. 157-172. ACM. 
Dao, M., Lim, C., \& Suresh, S., 2003. Mechanics of the human red blood cell deformed by optical tweezers. Journal of the Mechanics and Physics of Solids, vol. 51, n. 11, pp. 22592280.

Das, S. \& Du, Q., 2008. Adhesion of vesicles to curved substrates. Physical Review E, vol. 77, n. 1, pp. 011907.

Davis, T. A., Gilbert, J. R., Larimore, S. I., \& Ng, E. G., 2004. A column approximate minimum degree ordering algorithm. ACM Transactions on Mathematical Software (TOMS), vol. 30, n. 3, pp. 353-376.

Den Otter, W. \& Shkulipa, S., 2007. Intermonolayer friction and surface shear viscosity of lipid bilayer membranes. Biophysical journal, vol. 93, n. 2, pp. 423-433.

Dziuk, G., 2008. Computational parametric Willmore flow. Numerische Mathematik, vol. 111, n. 1 , pp. 55-80.

Elliott, C. \& Stinner, B., 2010. Modeling and computation of two phase geometric biomembranes using surface finite elements. Journal of Computational Physics, vol. 229, n. 18 , pp. 6585-6612.

Ericson, C., 2005. Real-Time Collision Detection. Elsevier.

Evans, E., 1974. Bending resistance and chemically induced moments in membrane bilayers. Biophysical Journal, vol. 14, n. 12, pp. 923-931.

Feng, F. \& Klug, W., 2006. Finite element modeling of lipid bilayer membranes. Journal of Computational Physics, vol. 220, n. 1, pp. 394-408.

Floater, M. S., 1997. Parametrization and smooth approximation of surface triangulations. Computer Aided Geometric Design, vol. 14, n. 3, pp. 231-250.

George, A., 1973. Nested dissection of a regular finite element mesh. SIAM Journal on Numerical Analysis, vol. 10, n. 2, pp. 345-363.

George, A., 1980. An automatic one-way dissection algorithm for irregular finite element problems. SIAM Journal on Numerical Analysis, vol. 17, n. 6, pp. 740-751.

George, A. \& Liu, J. W., 1989. The evolution of the minimum degree ordering algorithm. Siam review, vol. 31, n. 1, pp. 1-19.

Gois, J. P., Tejada, E., Etiene, T., Nonato, L. G., Castelo, A., \& Ertl, T., 2006. Curvaturedriven modeling and rendering of point-based surfaces. In Computer Graphics and Image Processing, 2006. SIBGRAPI'06. 19th Brazilian Symposium on, pp. 27-36. IEEE.

Goldfeather, J. \& Interrante, V., 2004. A novel cubic-order algorithm for approximating principal direction vectors. ACM Transactions on Graphics (TOG), vol. 23, n. 1, pp. 45-63.

Gouraud, H., 1971. Continuous shading of curved surfaces. IEEE Transactions on Computers, vol. 20, n. 6, pp. 623-629.

Gross, S. \& Reusken, A., 2011. Numerical methods for two-phase incompressible flows. Springer. 
Halliday, D., Resnick, R., \& Walker, J., 2011. Fundamentals of Physics. Wiley, 9th edition.

Harland, C., Bradley, M., \& Parthasarathy, R., 2010. Phospholipid bilayers are viscoelastic. Proceedings of the National Academy of Sciences of the United States of America, vol. 107, n. 45, pp. 19146-19150.

Harland, C., Bradley, M., \& Parthasarathy, R., 2011. Retraction for harland et al., phospholipid bilayers are viscoelastics. Proceedings of the National Academy of Sciences.

Helfrich, W., 1973. Elastic properties of lipid bilayers: theory and possible experiments. Zeitschrift fur Naturforschung. Teil C: Biochemie, Biophysik, Biologie, Virologie, vol. 28, n. 11, pp. 693.

Holzapfel, G., Eberlein, R., Wriggers, P., \& Weizsacker, H., 1996. Large strain analysis of soft biological membranes: Formulation and finite element analysis. Computer methods in applied mechanics and engineering, vol. 132, n. 1-2, pp. 45-61.

Hughes, T. J., Franca, L. P., \& Balestra, M., 1986. A new finite element formulation for computational fluid dynamics: $V$. circumventing the babuška-brezzi condition: a stable petrov-galerkin formulation of the stokes problem accommodating equal-order interpolations. Computer Methods in Applied Mechanics and Engineering, vol. 59, n. 1, pp. 85-99.

Intel, 2013. Intel Math Kernel Library (MKL). Disponível em: http://software.intel .com/ en-us/intel-mkl.

Jin, S., Lewis, R., \& West, D., 2005. A comparison of algorithms for vertex normal computation. The Visual Computer, vol. 21, n. 1, pp. 71-82.

Joachim Schoeberl, 2013. Netgen mesh generator. Disponível em: http://sourceforge . net/projects/netgen-mesher/.

Karypis, G. \& Kumar, V., 1998. A fast and high quality multilevel scheme for partitioning irregular graphs. SIAM Journal on Scientific Computing, vol. 20, n. 1, pp. 359-392.

Kim, D.-H., Wong, P. K., Park, J., Levchenko, A., \& Sun, Y., 2009. Microengineered platforms for cell mechanobiology. Annual review of biomedical engineering, vol. 11, pp. 203-233.

Lac, E. \& Barthès-Biesel, D., 2005. Deformation of a capsule in simple shear flow: Effect of membrane prestress. Physics of Fluids, vol. 17, n. 7, pp. 072105.

Landau, L. \& Lifshitz, E., 1976. Mechanics, vol. 1. Course of theoretical physics.

Langer, T., Belyaev, A., \& Seidel, H., 2007. Exact and interpolatory quadratures for curvature tensor estimation. Computer Aided Geometric Design, vol. 24, n. 8, pp. 443-463.

Le, D., White, J., Peraire, J., Lim, K., \& Khoo, B., 2009. An implicit immersed boundary method for three-dimensional fluid-membrane interactions. Journal of Computational Physics, vol. 228, n. 22, pp. 8427-8445.

Lee, H. J., Peterson, E. L., Phillips, R., Klug, W. S., \& Wiggins, P. A., 2008. Membrane shape as a reporter for applied forces. Proceedings of the National Academy of Sciences, vol. 105, n. 49, pp. 19253-19257. 
Li, X. \& Demmel, J., 1999. A scalable sparse direct solver using static pivoting. In Proceedings of the Ninth SIAM Conference on Parallel Processing for Scientific Computing, pp. 22-24.

Li, X. \& Sarkar, K., 2008. Front tracking simulation of deformation and buckling instability of a liquid capsule enclosed by an elastic membrane. Journal of Computational Physics, vol. 227, n. 10, pp. 4998-5018.

Li, X. S., 2005. An overview of SuperLU: Algorithms, implementation, and user interface. ACM Transactions on Mathematical Software, vol. 31, n. 3, pp. 302-325.

Lipowsky, R., 1991. The conformation of membranes. Nature, vol. 349, n. 6309, pp. 475-481.

Liu, J. W., 1985. Modification of the minimum-degree algorithm by multiple elimination. ACM Transactions on Mathematical Software (TOMS), vol. 11, n. 2, pp. 141-153.

Ma, L. \& Klug, W., 2008. Viscous regularization and $r$-adaptive remeshing for finite element analysis of lipid membrane mechanics. Journal of Computational Physics, vol. 227, n. 11, pp. 5816-5835.

Mader, M., Vitkova, V., Abkarian, M., Viallat, A., \& Podgorski, T., 2006. Dynamics of viscous vesicles in shear flow. The European Physical Journal E: Soft Matter and Biological Physics, vol. 19, n. 4, pp. 389-397.

Massey, B. \& Ward-Smith, J., 1998. Mechanics of fluids, volume 1. Spon Press.

Max, N., 1999. Weights for computing vertex normals from facet normals. Journal of Graphics Tools, vol. 4, n. 2, pp. 1-6.

Meyer, M., Desbrun, M., Schröder, P., \& Barr, A., 2002. Discrete differential-geometry operators for triangulated 2-manifolds. Visualization and mathematics, vol. 3, n. 7, pp. 3457.

Moore, M. \& Wilhelms, J., 1988. Collision detection and response for computer animation. In ACM Siggraph Computer Graphics, volume 22, pp. 289-298. ACM.

Noguchi, H., 2009. Membrane simulation models from nanometer to micrometer scale. Journal of the Physical Society of Japan, vol. 78, n. 4, pp. 1007.

Pellegrini, F., 2007. Scotch 5.0 user's guide. Technical report, LaBRI, Université Bordeaux I.

Peng, Z., Asaro, R., \& Zhu, Q., 2010. Multiscale simulation of erythrocyte membranes. Physical Review E, vol. 81, n. 3, pp. 031904.

Plateau, J. A. F., 1873. Statique expérimentale et théorique des liquides soumis aux seules forces moléculaires. Gauthier-Villars.

Pozrikidis, C., 2003. Modeling and simulation of capsules and biological cells. Chapman \& Hall/CRC Mathematical Biology and Medicine Series.

Provot, X., 1997. Collision and self-collision handling in cloth model dedicated to design garments. In Graphics interface, volume 97, pp. 177-189.

Ramanujan, S. \& Pozrikidis, C., 1998. Deformation of liquid capsules enclosed by elastic membranes in simple shear flow: large deformations and the effect of fluid viscosities. Journal of Fluid Mechanics, vol. 361, n. 1, pp. 117-143. 
Rangarajan, R. \& Lew, A. J., 2012. Universal meshes: A new paradigm for computing with nonconforming triangulations. arXiv preprint arXiv:1201.4903.

Rayleigh, L., 1878. On the instability of jets. Proceedings of the London Mathematical Society, vol. 10, pp. 4-13.

Razdan, A. \& Bae, M., 2005. Curvature estimation scheme for triangle meshes using biquadratic Bézier patches. Computer-Aided Design, vol. 37, n. 14, pp. 1481-1491.

Real World Physics Problems, 2013. Elastic collision. Disponível em: http://www. real-world-physics-problems.com/elastic-collision.html.

Reusken, A. \& Zhang, Y., 2012. Numerical simulation of incompressible two-phase flows with a boussinesq-scriven interface stress tensor. Technical report, RWTH Aachen University.

Rothberg, E., 1996. Ordering sparse matrices using approximate minimum local fill. In Second SIAM Conference on Sparse Matrices.

Saffman, P. \& Delbrück, M., 1975. Brownian motion in biological membranes. Proceedings of the National Academy of Sciences, vol. 72, n. 8, pp. 3111-3113.

Saiz, L., Bandyopadhyay, S., \& Klein, M., 2002. Towards an understanding of complex biological membranes from atomistic molecular dynamics simulations. Bioscience reports, vol. 22, n. 2, pp. 151-173.

Salac, D. \& Miksis, M., 2011. A level set projection model of lipid vesicles in general flows. Journal of Computational Physics, vol. 230, n. 22, pp. 8192-8215.

Savart, F., 1833. Mémoire sur la constitution des veines liquides lancées par des orifices circulaires en mince paroi. Annales de Chimie et de Physique, vol. 53, pp. 337-386.

Schenk, O. \& Gärtner, K., 2004. Solving unsymmetric sparse systems of linear equations with PARDISO. Future Generation Computer Systems, vol. 20, n. 3, pp. 475-487.

Schulze, J., 2001. Towards a tighter coupling of bottom-up and top-down sparse matrix ordering methods. BIT Numerical Mathematics, vol. 41, n. 4, pp. 800-841.

Scriven, L., 1960. Dynamics of a fluid interface: equation of motion for newtonian surface fluids. Chemical Engineering Science, vol. 12, n. 2, pp. 98-108.

Seifert, U., 1997. Configurations of fluid membranes and vesicles. Advances in physics, vol. 46 , n. 1, pp. 13-137.

Seifert, U., Berndl, K., \& Lipowsky, R., 1991. Shape transformations of vesicles: Phase diagram for spontaneous-curvature and bilayer-coupling models. Physical Review A, vol. 44, n. 2, pp. 1182.

Selle, A., Su, J., Irving, G., \& Fedkiw, R., 2009. Robust high-resolution cloth using parallelism, history-based collisions, and accurate friction. IEEE Transactions on Visualization and Computer Graphics, vol. 15, n. 2, pp. 339-350.

Sheetz, M. P., 1998. Laser tweezers in cell biology, volume 55. Academic Press. 
Shkulipa, S., Den Otter, W., \& Briels, W., 2005. Surface viscosity, diffusion, and intermonolayer friction: simulating sheared amphiphilic bilayers. Biophysical journal, vol. 89, n. 2, pp. 823829.

Skalak, R., Tozeren, A., Zarda, R., \& Chien, S., 1973. Strain energy function of red blood cell membranes. Biophysical Journal, vol. 13, n. 3, pp. 245-264.

Sui, Y., Chen, X., Chew, Y., Roy, P., \& Low, H., 2010. Numerical simulation of capsule deformation in simple shear flow. Computers \& Fluids, vol. 39, n. 2, pp. 242-250.

Surazhsky, T., Magid, E., Soldea, O., Elber, G., \& Rivlin, E., 2003. A comparison of Gaussian and mean curvatures estimation methods on triangular meshes. In Robotics and Automation, 2003. Proceedings. ICRA'03. IEEE International Conference on, volume 1, pp. 1021-1026. IEEE.

Tasso, I. V. \& Buscaglia, G. C., 2013. A finite element method for viscous membranes. Computer Methods in Applied Mechanics and Engineering, vol. 255, pp. 226-237.

Taubin, G., 1995. Estimating the tensor of curvature of a surface from a polyhedral approximation. In Proceedings of the Fifth International Conference on Computer Vision, pp. 902-907. IEEE Computer Society.

Thürmer, G. \& Wüthrich, C., 1998. Computing vertex normals from polygonal facets. Journal of Graphics Tools, vol. 3, n. 1, pp. 43-46.

Tumblr, 2013. Clay court image. Disponível em: http://www.tumblr.com/tagged/ clay-court.

Veerapaneni, S., Raj, R., Biros, G., \& Purohit, P., 2009. Analytical and numerical solutions for shapes of quiescent two-dimensional vesicles. International Journal of Non-Linear Mechanics, vol. 44, n. 3, pp. 257-262.

Veerapaneni, S. K., Rahimian, A., Biros, G., \& Zorin, D., 2011. A fast algorithm for simulating vesicle flows in three dimensions. Journal of Computational Physics, vol. 230, n. 14, pp. 5610-5634.

Visualphotos, 2013. Echinocyte and acanthocyte. Disponível em: http://www. visualphotos.com.

Wang, X. \& Du, Q., 2008. Modelling and simulations of multi-component lipid membranes and open membranes via diffuse interface approaches. Journal of mathematical biology, vol. 56 , n. 3, pp. 347-371.

Waugh, R., 1982a. Surface viscosity measurements from large bilayer vesicle tether formation. i. analysis. Biophysical Journal, vol. 38, n. 1, pp. 19-27.

Waugh, R., 1982b. Surface viscosity measurements from large bilayer vesicle tether formation. ii. experiments. Biophysical Journal, vol. 38, n. 1, pp. 29-37.

Wikipedia, 2013a. Cell membrane. Disponível em: http://en.wikipedia.org/wiki/Cell_ membrane.

Wikipedia, 2013b. Dashpot. Disponível em: http://en.wikipedia.org/wiki/Dashpot. 
Wikipedia, 2013c. Liposome. Disponível em: http://en.wikipedia.org/wiki/Liposome.

Wikipedia, 2013d. Micelle. Disponível em: http://en.wikipedia.org/wiki/Micelle.

Wikipedia, 2013e. Red blood cell. Disponível em: http://en.wikipedia.org/wiki/File: Red_Blood_Cells.jpg.

Wortis, M. \& Mukhopadhyay, R., 2002. Stomatocyte-discocyte-echinocyte sequence of the human red blood cell: Evidence for the bilayer-couple hypothesis from membrane mechanics. Proceedings of the National Academy of Sciences, vol. 99, n. 26, pp. 1676616769.

$\mathrm{Xu}, \mathrm{G} ., 2$ 2004. Convergence of discrete laplace-beltrami operators over surfaces. Computers \& Mathematics with Applications, vol. 48, n. 3, pp. 347-360. 